
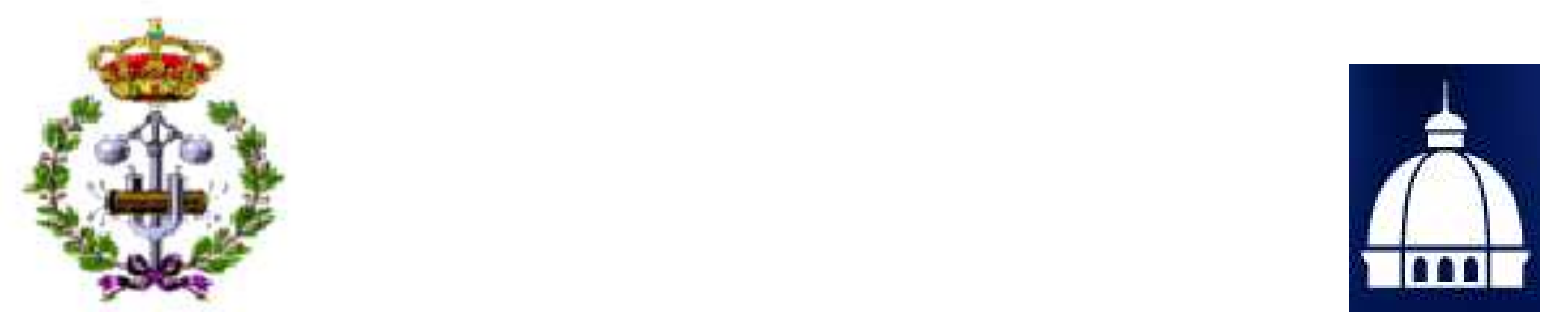

DEPARTAMENTO DE FÍSICA APLICADA E INGENIERÍA DE MATERIALES

ESCUELA TÉCNICA SUPERIOR DE INGENIEROS INDUSTRIALES

\title{
ANÁLISIS DEL COMPORTAMIENTO A FATIGA DE UNIONES ADHESIVAS \\ DE ACERO RECUBIERTO
}

\author{
RAQUEL BERMEJO LÓPEZ \\ Ingeniera Industrial \\ Universidad Politécnica de Madrid
}

\author{
Dirigida por: \\ JAVIER OÑORO LÓPEZ \\ Doctor Ingeniero Industrial por la \\ U.P.M. (E.S.T.I.I.)
}

ENERO 2016 


\section{PRESIDENTE:}

D. CARLOS RANNINGER RODRIGUEZ.

Catedrático de Universidad.

ETSI Industriales.

Universidad Politécnica de Madrid (UPM).

\section{SECRETARIO:}

\section{ANTONIO PORTOLES GARCIA.}

Profesor Titular de Universidad.

ETSI Industriales.

Universidad Politécnica de Madrid (UPM).

VOCALES:

Dña. MARIA NATIVIDAD ANTON IGLESIAS.

Profesora Titular de Universidad.

Escuela Politécnica Superior de Zamora.

Universidad de Salamanca.

Dña. ANA CRISTINA GARCIA CABEZON.

Profesora Titular de Universidad.

Escuela de Ingenierías Industriales.

Universidad de Valladolid (UVA).

D. FRANCISCO J. JUANES GARCIA.

Profesor Titular de Universidad.

EUIT Industrial de Bilbao.

Universidad del País Vasco (UPV/EHU). 


\section{AGRADECIMIENTOS}

Quisiera dar las gracias al Dr. Javier Oñoro López, director de esta tesis, por todas las sugerencias y orientaciones que me ha proporcionado para realizar con éxito este proyecto de investigación.

También agradecer a todo el personal del Departamento de Ingeniería y Ciencia de los Materiales, en especial al Dr. Ricardo García, Dña. Basilia Larena, Dña. Sandra Chacón y D. Benito casero, por los conocimientos transmitidos y la colaboración prestada durante la realización de esta tesis.

A la empresa Henkel, por la aportación de los adhesivos de estudio y por la información técnica de los mismos.

Por último, un agradecimiento de todo corazón a mi familia, muy especialmente a mi madre, por su paciencia, ánimo y ayuda incondicional. 
TESIS DOCTORAL

\section{ANÁLISIS DEL COMPORTAMIENTO A FATIGA DE UNIONES ADHESIVAS DE ACERO RECUBIERTO}

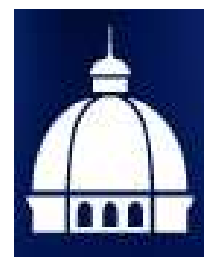




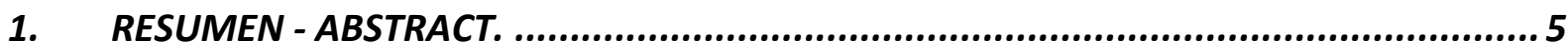

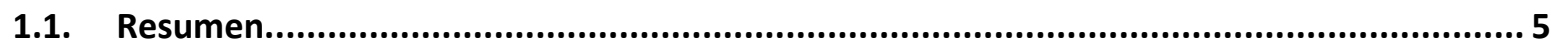

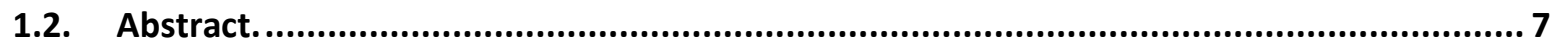

2. OBJETIVOS PRINCIPALES DE LA TESIS....................................................... 9

3. CONCEPTOS GENERALES SOBRE UNIONES ADHESIVAS..................................... 11

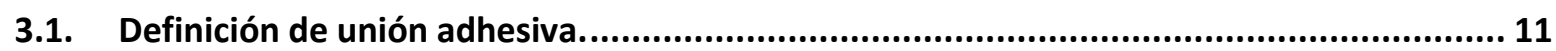

3.2. Ventajas e inconvenientes de las uniones adhesivas. ................................................. 11

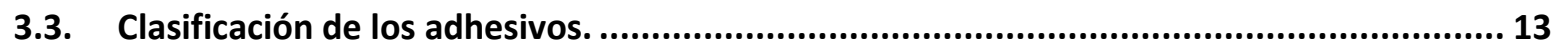

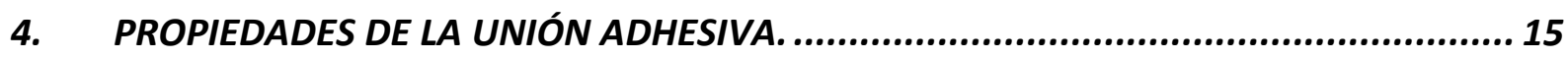

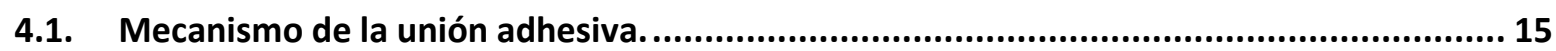

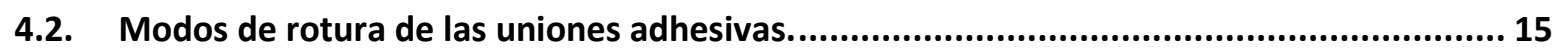

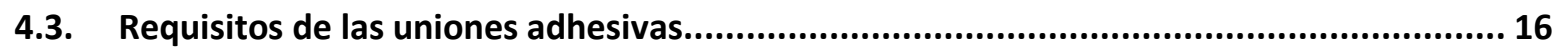

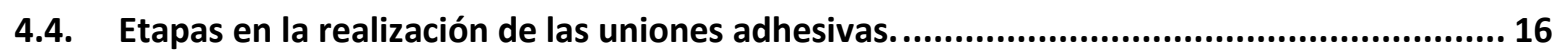

4.5. Causas y remedios para fallos de la unión adhesiva........................................................ 21

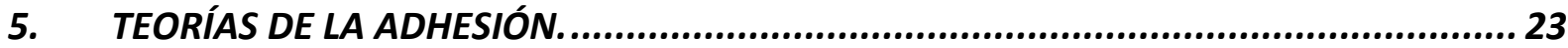

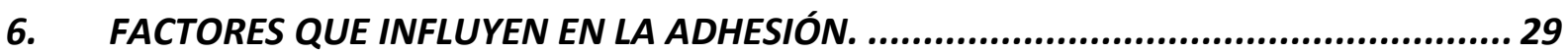

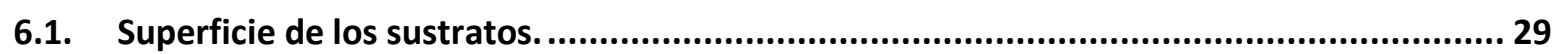

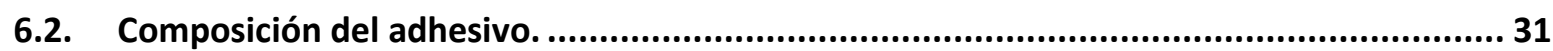

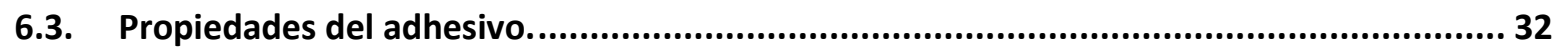

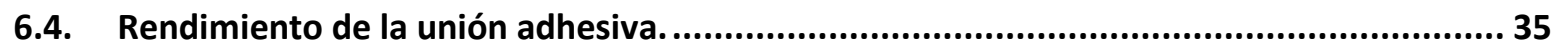

7. TRATAMIENTOS SUPERFICALES DE LOS SUSTRATOS.......................................... 41

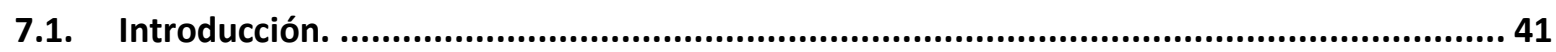

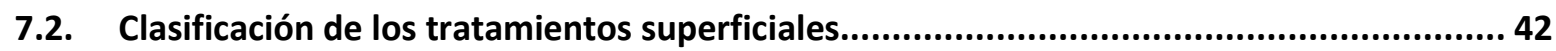

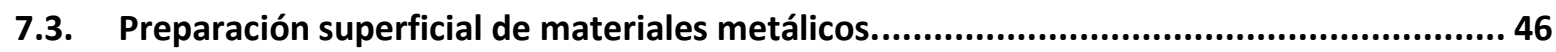

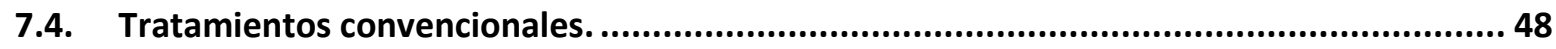

8. ENSAYOS PARA LA EVALUACIÓN DE LAS UNIONES ADHESIVAS. ........................ 49

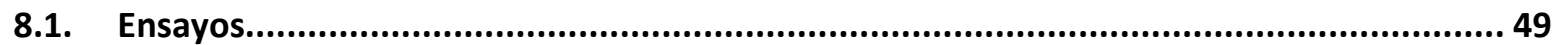

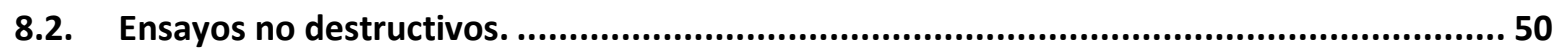

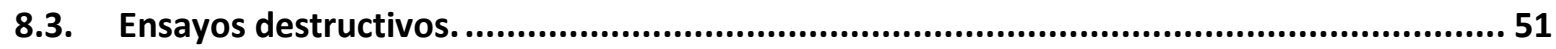

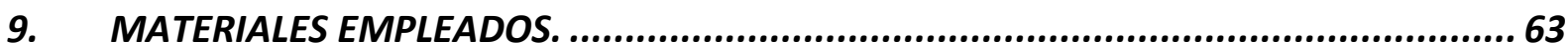

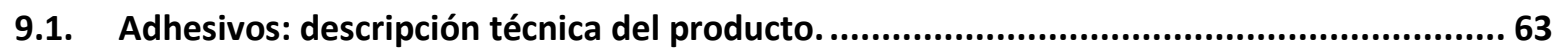

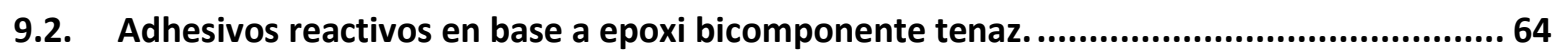

9.3. Adhesivos elásticos en base a polímero de silano modificado..........................................67

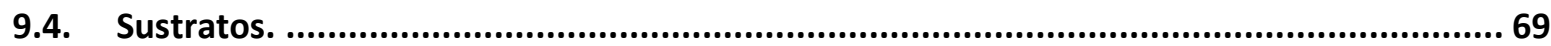




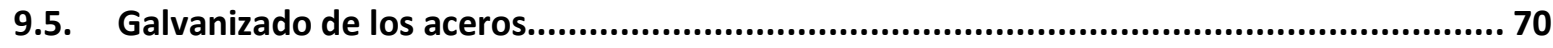

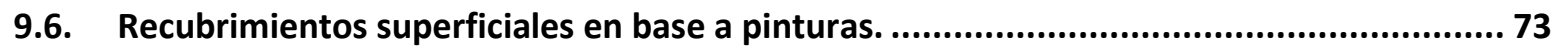

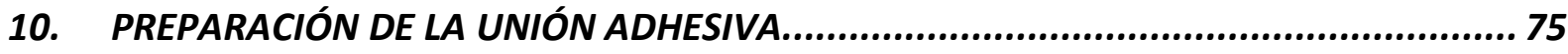

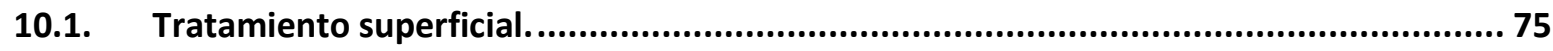

10.2. Descripción del proceso de ensamblaje. ...................................................................... 75

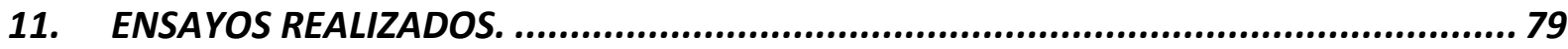

11.1. Ensayo de cizalladura por tracción a solape simple................................................. 79

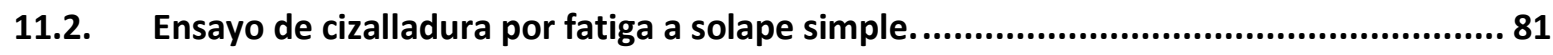

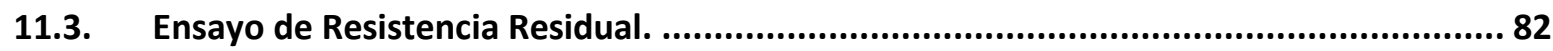

12. ANÁLISIS DE LOS RESULTADOS DEL ENSAYO DE TRACCIÓN A CIZALLADURA SIMPLE CON EPOXI BICOMPONENTE LOCTITE HYSOL 9464. ............................................ 83

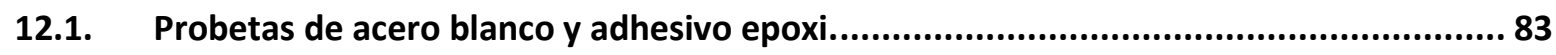

12.2. Probetas de acero recubierto de poliéster $y$ adhesivo epoxi.......................................86 86

12.3. Probetas de acero recubierto de poliéster epoxi y adhesivo epoxi...............................88

12.4. Probetas de acero galvanizado y adhesivo epoxi.................................................. 91

12.5. Comparación de resultados para probetas unidas con adhesivo epoxi bicomponente

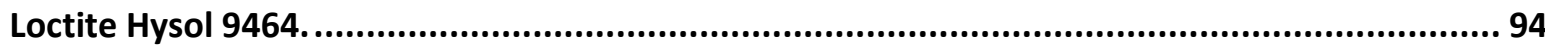

13. ANÁLISIS DE LOS RESULTADOS DEL ENSAYO DE TRACCIÓN A CIZALLADURA SIMPLE CON SILANO MODIFICADO TEROSTAT MS 939. .................................................... 97

13.1. Probetas de acero blanco y adhesivo silano modificado. ......................................... 97

13.2. Probetas de acero recubierto de poliéster $y$ adhesivo silano modificado. .................. 107

13.3. Probetas de acero recubierto de poliéster epoxi y adhesivo silano modificado.......... 117

13.4. Probetas de acero galvanizado y adhesivo silano modificado. ................................. 127

13.5. Comparación de resultados para probetas unidas con adhesivo silano modificado

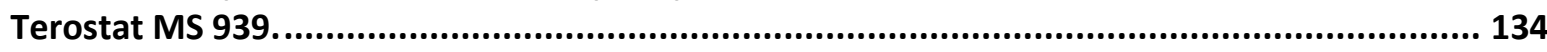

14. COMPARACIÓN DE RESULTADOS PARA PROBETAS UNIDAS CON ADHESIVO EPOXI BICOMPONENTE LOCTITE HYSOL 9464 Y SILANO MODIFICADO TEROSTAT MS 939......... 137

15. ANÁLISIS DE LOS RESULTADOS DEL ENSAYO DE FATIGA CON EPOXI BICOMPONENTE

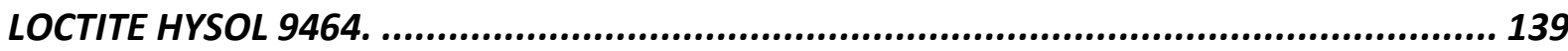

15.1. Probetas de acero blanco y adhesivo epoxi............................................................. 139

15.2. Probetas de acero recubierto de poliéster epoxi y adhesivo epoxi........................... 141

15.3. Resultados comparativos de los ensayos de fatiga. .................................................. 144

16. ANÁLISIS DE LOS RESULTADOS DEL ENSAYO DE FATIGA CON SILANO MODIFICADO

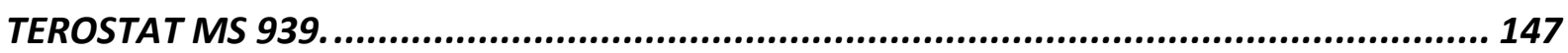

16.1. Probetas de acero blanco y adhesivo silano modificado. ........................................ 147

16.2. Probetas de acero recubierto de poliéster epoxi y adhesivo silano modificado.......... 149

16.3. Probetas de acero galvanizado y adhesivo silano modificado. ................................. 151 


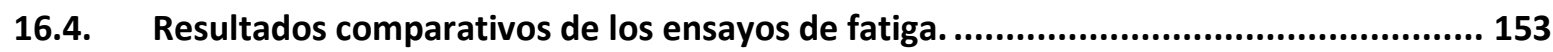

17. ANÁLISIS DE LOS RESULTADOS DEL ENSAYO DE RESISTENCIA RESIDUAL............... 155

17.1. Uniones adhesivas con epoxi bicomponente Loctite Hysol 9464 ............................... 155

17.2. Uniones adhesivas con silano modificado Terostat MS 939..................................... 156

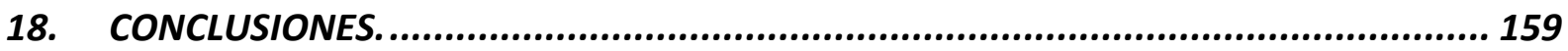

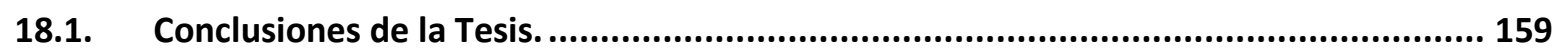

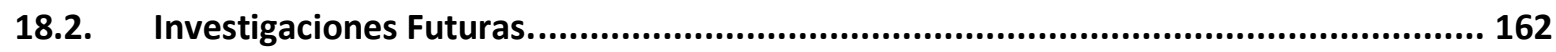

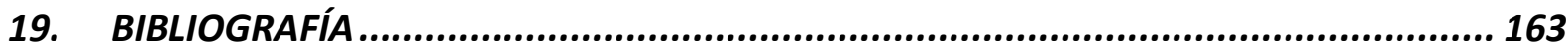




\section{RESUMEN - ABSTRACT.}

\subsection{Resumen.}

Los adhesivos se conocen y han sido utilizados en multitud de aplicaciones a lo lago de la historia. En la actualidad, la tecnología de la adhesión como método de unión de materiales estructurales está en pleno crecimiento. Los avances científicos han permitido comprender mejor los fenómenos de adhesión, así como, mejorar y desarrollar nuevas formulaciones poliméricas que incrementan el rango de aplicaciones de los adhesivos. Por otro lado, el desarrollo de nuevos materiales y la necesidad de aligerar peso, especialmente en el sector transporte, hace que las uniones adhesivas se introduzcan en aplicaciones hasta ahora reservadas a otros sistemas de unión como la soldadura o las uniones mecánicas, ofreciendo rendimientos similares y, en ocasiones, superiores a los aportados por estas.

Las uniones adhesivas ofrecen numerosas ventajas frente a otros sistemas de unión. En la industria aeronáutica y en automoción, las uniones adhesivas logran una reducción en el número de componentes (tales como los tornillos, remaches, abrazaderas) consiguiendo como consecuencia diseños más ligeros y una disminución de los costes de manipulación y almacenamiento, así como una aceleración de los procesos de ensamblaje, y como consecuencia, un aumento de los procesos de producción. En el sector de la construcción y en la fabricación de equipos industriales, se busca la capacidad para soportar la expansión y contracción térmica. Por lo tanto, se usan las uniones adhesivas para evitar producir la distorsión del sustrato al no ser necesario el calentamiento ni la deformación de las piezas cuando se someten a un calentamiento elevado y muy localizado, como en el caso de la soldadura, o cuando se someten a esfuerzos mecánicos localizados, en el caso de montajes remachados. En la industria naval, se están desarrollando técnicas de reparación basadas en la unión adhesiva para distribuir de forma más uniforme y homogénea las tensiones con el objetivo de mejorar el comportamiento frente a fatiga y evitar los problemas asociados a las técnicas de reparación habituales de corte y soldadura. Las uniones adhesivas al no requerir importantes aportes de calor como la soldadura, no producen modificaciones microestructurales indeseables como sucede en la zona fundida o en la zona afectada térmicamente de las uniones soldadas, ni deteriora los recubrimientos protectores de metales de bajo punto de fusión o de naturaleza orgánica.

Sin embargo, las uniones adhesivas presentan una desventaja que dificulta su aplicación, se trata de su durabilidad a largo plazo. La primera causa de rotura de los materiales es la rotura por fatiga. Este proceso de fallo es la causa del $85 \%$ de las roturas de los materiales estructurales en servicio. La rotura por fatiga se produce cuando se somete al material a la acción de cargas que varían cíclicamente o a vibraciones durante un tiempo prolongado. Las uniones y estructuras sometidas a fatiga pueden fallar a niveles de carga por debajo del límite de resistencia estática del material. La rotura por fatiga en las uniones adhesivas no se produce por un proceso de iniciación y propagación de grieta de forma estable, el proceso de fatiga va debilitando poco a poco la unión hasta que llega un momento que provoca una rotura de forma rápida. Underhill explica este mecanismo como un proceso de daño irreversible de los enlaces más débiles en determinados puntos de la unión. Cuando se ha producido el deterioro de estas zonas más débiles, su área se va incrementando hasta que llega un momento en que la zona dañada es tan amplia que se produce el fallo completo de la unión. En ensayos de crecimiento de grieta realizados sobre probetas preagrietadas en viga con doble voladizo (DCB), Dessureault identifica los procesos de iniciación y crecimiento de grietas en muestras unidas con adhesivo epoxi como una acumulación de microfisuras en la zona próxima al fondo de grieta que, luego, van coalesciendo para configurar la grieta principal. Lo que supone, igualmente, un proceso de daño del adhesivo en la zona de mayor concentración de tensiones que, posteriormente, conduce al fallo de la unión. 
La presente tesis surge con el propósito de aumentar los conocimientos existentes sobre el comportamiento a fatiga de las uniones adhesivas y especialmente las realizadas con dos tipos de adhesivos estructurales aplicados en aceros con diferentes acabados superficiales. El estudio incluye la obtención de las curvas de tensión frente al número de ciclos hasta el fallo del componente, curvas SN o curvas de Wöhler, que permitirán realizar una estimación de la resistencia a la fatiga de un determinado material o estructura. Los ensayos de fatiga realizados mediante ciclos predeterminados de carga sinusoidales, de amplitud y frecuencia constantes, han permitido caracterizar el comportamiento a la fatiga por el número de ciclos hasta la rotura, siendo el límite de fatiga el valor al que tiende la tensión cuando el número de ciclos es muy grande. En algunos materiales, la fatiga no tiende a un valor límite sino que decrece de forma constante a medida que aumenta el número de ciclos. Para estas situaciones, se ha definido la resistencia a la fatiga (o límite de resistencia) por la tensión en que se produce la rotura para un número de ciclos predeterminado. Todos estos aspectos permitirán un mejor diseño de las uniones y las condiciones de trabajo de los adhesivos con el fin de lograr que la resistencia a fatiga de la unión sea mucho más duradera y el comportamiento total de la unión sea mucho mejor, contribuyendo al crecimiento de la utilización de las uniones adhesivas respecto a otras técnicas. 


\subsection{Abstract.}

Adhesives are well-known and have been used in many applications throughout history. At present, adhesion bonding technology of structural materials is experiencing an important growth. Scientific advances have enabled a better understanding of the phenomena of adhesion, as well as to improve and develop new polymeric formulations that increase the range of applications. On the other hand, the development of new materials and the need to save weight, especially in the transport sector, have promote the use of adhesive bonding in many applications previously reserved for other joining technologies such as welded or mechanical joints, presenting similar or even higher performances.

Adhesive bonding offers many advantages over other joining methods. For example, in the aeronautic industry and in the automation sector, adhesive bonding allows a reduction in the number of components (such as bolts, rivets, clamps) and as consequence, resulting in lighter designs and a decrease in handling and storage costs, as well as faster assembly processes and an improvement in the production processes. In the construction sector and in the industrial equipment manufacturing, the ability to withstand thermal expansion and contraction is required. Therefore, adhesion bonding technology is used to avoid any distortion of the substrate since this technology does not require heating nor the deformation of the pieces when these are exposed to very high and localized heating, as in welding, or when are subjected to localized mechanical stresses in the case of riveted joints. In the naval industry, repair techniques based in the adhesive bonding are being developed in order to distribute stresses more uniform and homogeneously in order to improve the performance against fatigue and to avoid the problems associated with standard repair techniques as cutting and welding. Adhesive bonding does not require the use of high temperatures and as consequence they do not produce undesirable microstructural changes, as it can be observed in molten zones or in heat-affected zones in the case of welding, neither is there damage of the protective coating of metals with low melting points or polymeric films.

However, adhesive bonding presents a disadvantage that limits its application, the low longterm durability. The most common cause of fractures of materials is fatigue fracture. This failure process is the cause of $85 \%$ of the fracture of structural materials in service. Fatigue failure occurs when the materials are subjected to the action of cyclic loads or vibrations for a long period of time. The joints and structures subjected to fatigue can fail at stress values below the static strength of the material. Fatigue failure do not occurs by a static and homogeneous process of initiation and propagation of crack. The fatigue process gradually weakens the bond until the moment in which the fracture occurs very rapidly. Underhill explains this mechanism as a process of irreversible damage of the weakest links at certain points of the bonding. When the deterioration in these weaker zones occurs, their area increase until the damage zone is so extensive that the full failure of the joint occurs. During the crack growth tests performed on precracked double-cantilever beam specimen, (DCB), Dessureault identified the processes of crack initiation and growth in samples bonded with epoxy adhesive as a process of accumulation of microcracks on the zone near the crack bottom, then, they coalesced to configure the main crack. This is a damage process of the adhesive in the zone of high stress concentration that leads to failure of the bond. 
This thesis aims to further the understanding of the fatigue behavior of the adhesive bonding, primarily those based on two different types of structural adhesives used on carbon-steel with different surface treatments. This memory includes the analysis of the SN or Wöhler curves (stress vs. number of cycles curves up to the failure), allowing to carry out an estimation of the fatigue strength of a specific material or structure. The fatigue tests carried out by means of predetermined cycles of sinusoidal loads, with a constant amplitude and frequency, allow the characterisation of the fatigue behaviour. For some materials, there is a maximum stress amplitude below which the material never fails for any number of cycles, known as fatigue limit. In the other hand, for other materials, the fatigue does not tend toward a limit value but decreases constantly as the number of cycles increases. For these situations, the fatigue strength is defined by the stress at which the fracture occurs for a predetermined number of cycles. All these aspects will enable a better joint design and service conditions of adhesives in order to get more durable joints from the fatigue failure point of view and in this way contribute to increase the use of adhesive bonding over other joint techniques. 


\section{OBJETIVOS PRINCIPALES DE LA TESIS.}

Los elementos estructurales fabricados en acero están sometidos a la acción de cargas que varían cíclicamente o a la acción de vibraciones durante un tiempo prolongado. Estos efectos causan el deterioro de los materiales estructurales en servicio, provocando una rotura por fatiga. Este proceso de fallo es la primera causa en la mayoría de las roturas de los metales.

Por este motivo, el objetivo de este trabajo es analizar la influencia del recubrimiento en el comportamiento a fatiga de uniones adhesivas a solape simple.

Se han estudiado dos tipos de adhesivos y cuatro acabados superficiales diferentes.

Los adhesivos que se han utilizado han sido:

- Un adhesivo epoxi bicomponente en forma de resina más activador. de la marca comercial Loctite Hysol 9464.

- Un adhesivo/sellador elástico en base a polímero de silano modificado, cuya marca comercial es Terostat MS 939. Se trata de un adhesivo monocomponente que cura por reacción con la humedad ambiental.

Las uniones adhesivas se han realizado con los siguientes sustratos:

- Acero al carbono (acabado en blanco).

- Acero con recubrimiento orgánico: poliéster epoxi y poliéster.

- Acero galvanizado.

El estudio incluye el comportamiento mecánico mediante ensayos de cizalladura por tracción de uniones a solape simple y de cizalladura por fatiga de uniones a solape simple.

La resistencia mecánica de las uniones adhesivas está relacionada con el proceso de rotura, directamente dependiente del mecanismo cohesivo-adhesivo. Por lo tanto, en este proyecto se analiza que muestra obtiene los mejores resultados de resistencia de unión, es decir, que probeta alcanza la mayor tensión de rotura y el mayor porcentaje de rotura cohesiva.

Las propiedades mecánicas de las uniones adhesivas dependen no sólo de la naturaleza y propiedades de los adhesivos, sino también de diferentes parámetros que influyen directamente en el comportamiento de las uniones. Los más significativos son: acabado superficial de los sustratos, área y espesor de la capa adhesiva, propiedades químicas de la superficie y preparación de los sustratos antes de aplicar el adhesivo. 


\section{CONCEPTOS GENERALES SOBRE UNIONES ADHESIVAS.}

\subsection{Definición de unión adhesiva.}

Una unión adhesiva es aquella que permite unir dos sustratos por medio de un adhesivo.

En las uniones adhesivas intervienen los siguientes elementos:

- Adhesivo: sustancia que se aplica en la superficie de dos materiales para permitir entre ellos una unión resistente a la separación.

- Sustratos o adherentes: materiales que queremos unir por medio de la utilización del adhesivo.

- Adhesión: conjunto de interacciones físicas y químicas que se producen en la interfase adhesivo-adherente. Es un fenómeno superficial, por lo tanto es importante conocer las propiedades superficiales del sustrato y las propiedades del adhesivo.

- Interfase: fase con características diferentes a las del adhesivo y sustratos. Sus propiedades influyen en el comportamiento de la unión.

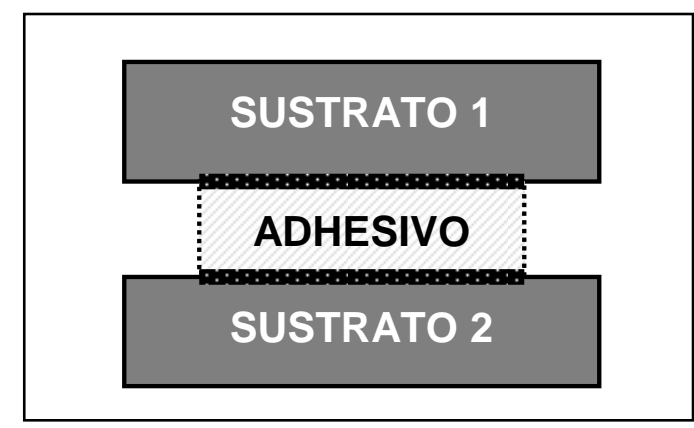

Figura 1. Esquema básico de una unión adhesiva.

\subsection{Ventajas e inconvenientes de las uniones adhesivas.}

unión:

Las uniones adhesivas presentan las siguientes ventajas con respecto a otros sistemas de

a) Distribución uniforme y homogénea de tensiones: de esta forma se evitan los cambios estructurales producidos por una unión soldada y las puntas de tensión que aparecen en los taladros necesarios para montajes remachados (ver Figura 2).

b) Rigidez de las uniones: a diferencia de las uniones realizadas por remaches o puntos de soldadura, las cuales unen dos superficies por medio de puntos localizados, los adhesivos forman uniones continuas entre las superficies de la junta. Esta cualidad permite que las uniones adhesivas sean más rígidas, como consecuencia pueden soportar cargas superiores (ver Figura 3). 


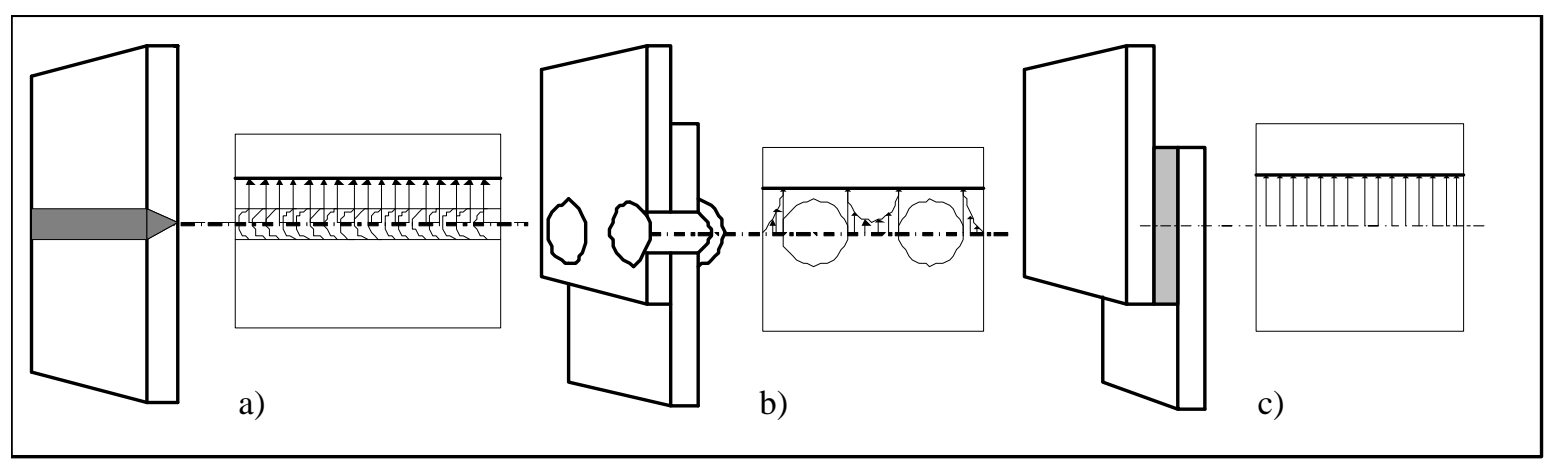

Figura 2. Distribución de la tensión en uniones: a) soldadas, b) remachadas y c) adhesivas.

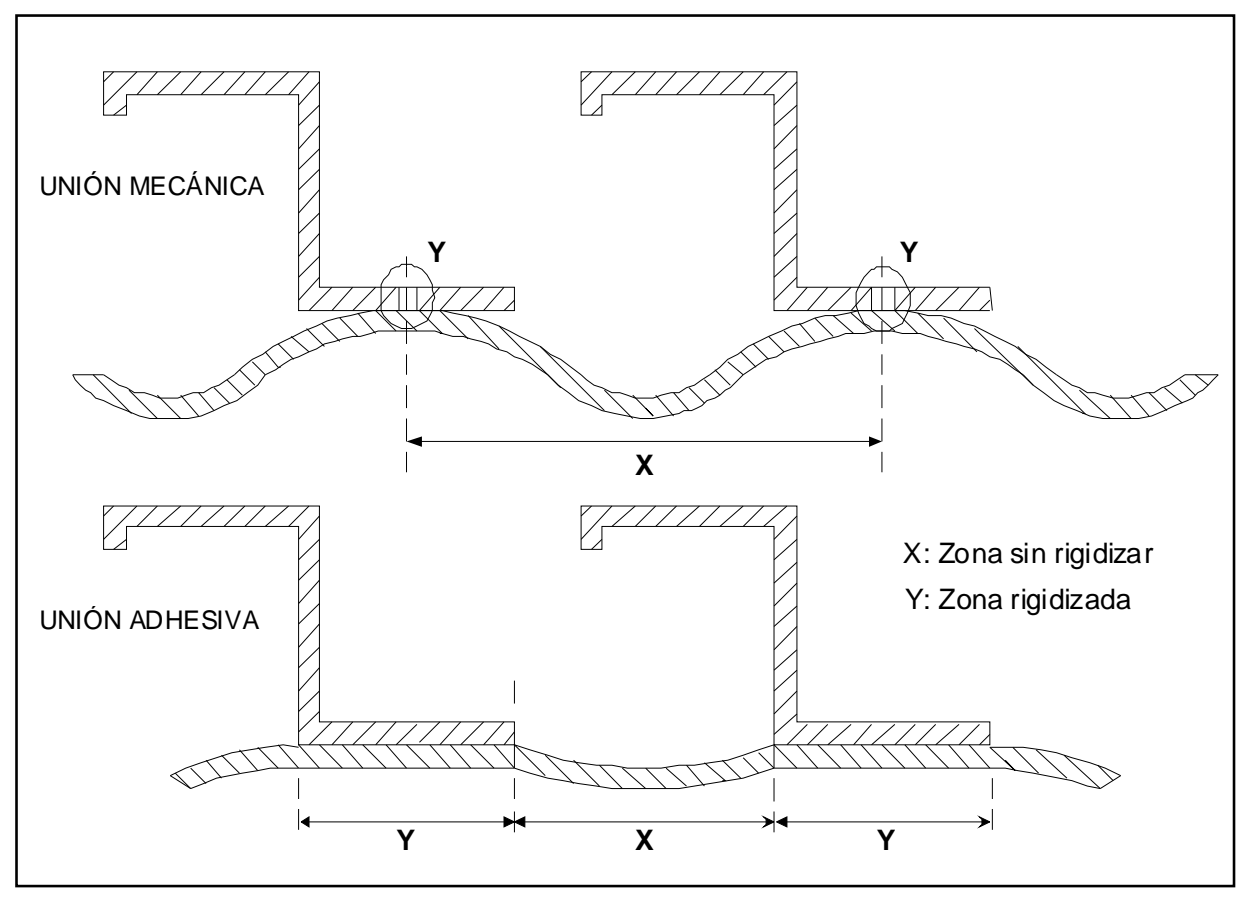

Figura 3. Zona rigidizada en uniones mecánicas y adhesivas.

c) No se produce distorsión del sustrato: se evita el calentamiento o deformación de las piezas cuando se someten a calor o a esfuerzos mecánicos.

d) Permiten la unión de distintos materiales de forma económica.

e) Uniones selladas: otra cualidad de los adhesivos es que pueden actuar como selladores, lo que permite hacer estancas uniones mecánicas.

f) Aislamiento: permite la unión de metales con diferentes propiedades electroquímicas, evitando de esta manera fenómenos tales como la corrosión galvánica, la erosión por fricción, la corrosión por frotamiento. También se evita la entrada de agentes corrosivos (humedad, aire, etc.). 
g) Reducción del número de componentes: tales como tornillos, remaches, abrazaderas, etc., lo que implica una disminución de los costes de manipulación y almacenamiento.

h) Mejora el aspecto del producto: las uniones adhesivas son más lisas y con ellas se esconden las juntas a la vista.

i) Compatibilidad del producto: se logra acelerar los procesos de ensamblaje, aumentando de este modo los procesos de producción.

j) Uniones híbridas: usando en conjunto las uniones adhesivas y las uniones mecánicas se obtiene un mejor rendimiento de la junta.

Los inconvenientes de las uniones adhesivas son:

a) Necesidad de preparación superficial: en ocasiones es necesaria para lograr resultados más fiables.

b) Espera de los tiempos de curado: cuando se emplean adhesivos que requieren elevados tiempos de curado para alcanzar la resistencia deseada, puede retrasarse la producción.

c) Dificultad de desmontaje.

d) Resistencias mecánica y a la temperatura limitadas: debido a que los adhesivos son polímeros.

\subsection{Clasificación de los adhesivos.} adhesiva:

La clasificación más empleada se realiza en función del mecanismo de formación de la junta

I. ADHESIVOS PREPOLIMERIZADOS: el polímero ya existía antes de ser aplicado el adhesivo sobre la unión.

a.) En fase líquida:

a.1.- Soluciones acuosas de origen natural:

- Origen mineral: cementos.

- Origen animal: caseína, colas.

- Origen vegetal: celulosa, almidón, colofonia.

a.2.- Soluciones acuosas de origen sintético:

- PVP (polivinilpirrolidona).

- PEG (polietilenglicol).

- PAV (polialcohol vinílico). 
a.3.- Soluciones orgánicas:

- Caucho natural.

- Polienos.

- Polidienos.

- Elastómeros termoplásticos (SBR).

a.4.- Emulsiones o líquidas:

- PVC.

- Polietileno.

- Poliacetato de vinilo.

- Poliacrílicos (acrílicos y metacrílicos).

b.) En fase sólida:

b.1.- Adhesivos sensibles a la presión o piezosensibles (PSA):

- Adhesivos de contacto.

- Películas y cintas autoadhesivas.

- Adhesivos reposicionables.

- Adhesivos reactivables por calor.

b.2.- Adhesivos termoflusibles o hot melts:

- Polietileno.

- EVA.

- Poliamidas.

- Poliésteres.

II. ADHESIVOS REACTIVOS: el adhesivo contiene el monómero u oligómero que polimerizará para generar el polímero curado final.

a.) Mediante poliadición:

- Anaeróbicos.

- Acrílicos.

- Cianoacrilatos.

- Siliconas de poliadición.

- Poliésteres.

- Polisulfuros.

b.) Mediante policondensación:

- Poliuretanos.

- Epoxis.

- Siliconas de policondensación.

- Fenólicos. 


\section{PROPIEDADES DE LA UNIÓN ADHESIVA.}

\subsection{Mecanismo de la unión adhesiva.}

El mecanismo de unión depende de:

Adhesión: fuerza de unión del adhesivo al sustrato, es decir, fuerza de unión en la interfase de contacto entre ambos materiales. Las fuerzas que mayor importancia tienen en la unión son las fuerzas de Van der Waals. La resistencia de la fuerza de adhesión depende del contacto intermolecular (grado de mojado) y de la capacidad adhesiva de la superficie.

Cohesión: fuerza interna del adhesivo, es decir, fuerza que prevalece entre las moléculas dentro del adhesivo. Dentro de estas fuerzas se incluyen las fuerzas intermoleculares de atracción (fuerzas de Van der Waals) y los enlaces entre las propias moléculas de polímero.

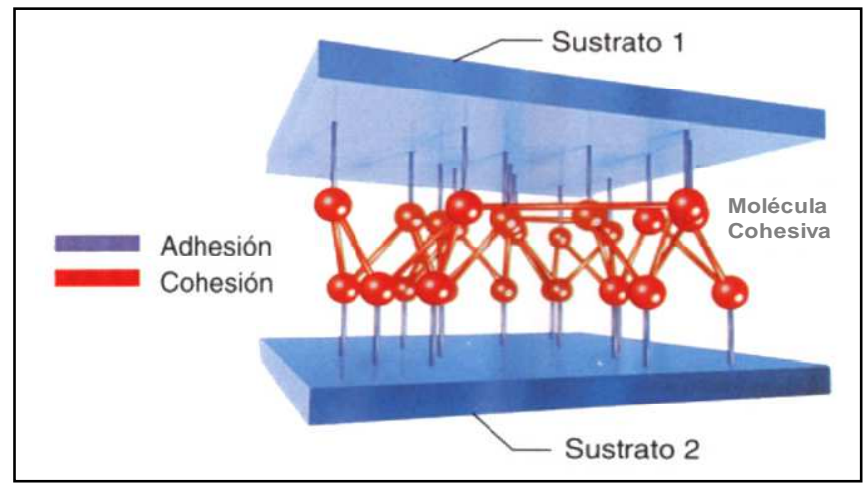

Figura 4. Diferenciación entre adhesión y cohesión.

\subsection{Modos de rotura de las uniones adhesivas.}

Para evaluar si una unión adhesiva es adecuada se debe considerar no solo la resistencia a la separación sino también la forma de ruptura de la unión adhesiva. la Figura 5:

Existen tres modos de ruptura que se describen a continuación y cuyo aspecto se muestra en

Separación por adhesión (fallo de adhesivo o rotura adhesiva): la separación se produce en la interfase sustrato-adherente, dejando limpia la superficie de uno de los sustratos. Esto denotaría algún problema de preparación superficial o de curado del adhesivo.

Separación por cohesión: la ruptura se produce en el adhesivo, produciéndose una superficie rugosa, arañada o especular sobre la superficie de ambos sustratos.

Ruptura del sustrato: se produce la ruptura del sustrato antes que la ruptura de la unión adhesiva o la interfase sustrato-adhesivo. 


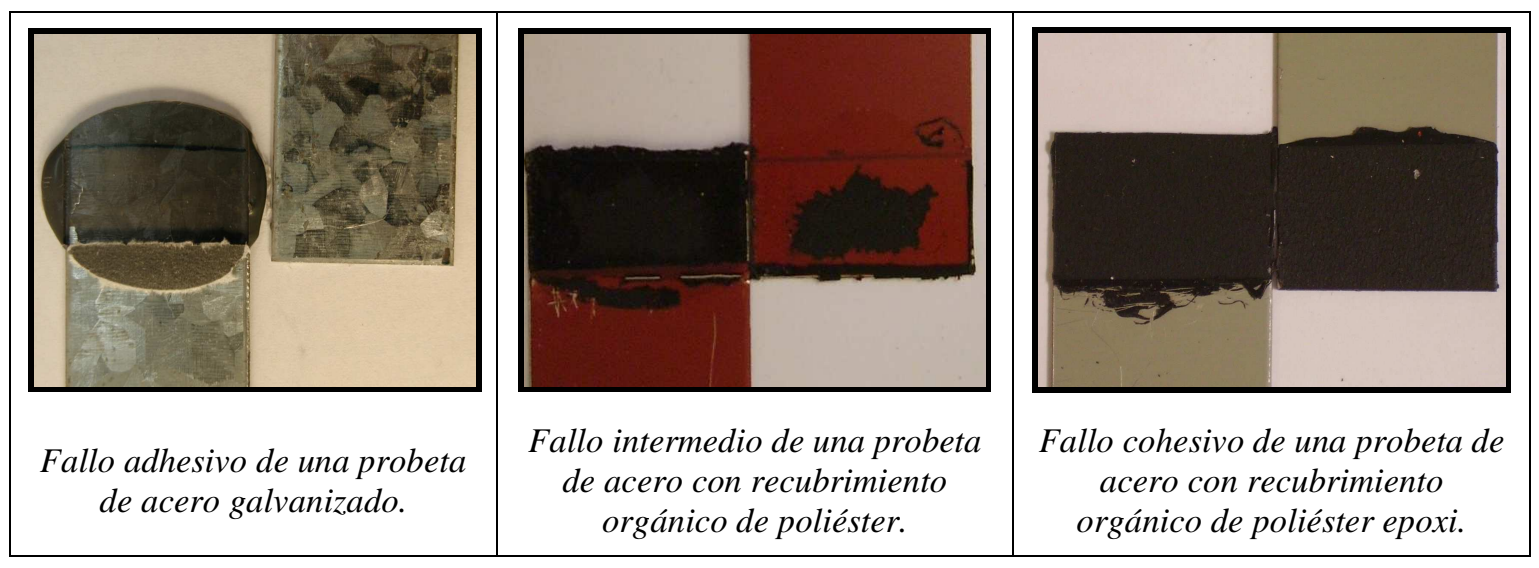

Figura 5. Modos de fallo de las uniones adhesivas.

En el diseño de una unión adhesiva se tiene que evitar la ruptura por adhesión. Es preferible una ruptura por cohesión, ya que es posible conocer las propiedades mecánicas del adhesivo, y de esta forma predecir las cargas a la rotura en modo cohesivo para diferentes tipos de esfuerzos.

\subsection{Requisitos de las uniones adhesivas.}

Los requisitos más importantes que hay que tener presentes cuando se realiza una unión adhesiva son los siguientes:

- Usar materias primas de primera calidad.

- Control de calidad cuidadoso tanto de los sustratos como de los adhesivos.

- Control exhaustivo de todas las etapas necesarias para realizar la unión adhesiva.

- Respetar los tiempos necesarios para realizar la unión.

- Trabajar en condiciones adecuadas (ventilación, atmósfera).

- Seguir la normativa vigente a niveles técnico y medioambiental.

\subsection{Etapas en la realización de las uniones adhesivas.} continuación:

Las etapas que deben seguirse en la realización de una unión adhesiva se detallan a

1. Limpieza adecuada de los sustratos.

2. Selección del adhesivo más adecuado.

3. Diseño adecuado de la unión adhesiva.

4. Lograr un buen contacto interfacial (mojado) adhesivo-sustrato.

5. Creación de fuerzas de adhesión intrínsecas en la unión.

6. Control de la reticulación, curado o cristalización del adhesivo.

7. Evaluar la adhesión usando un ensayo adecuado a la aplicación final de la unión y a las solicitaciones mecánicas que va a soportar durante su uso.

8. Determinar la durabilidad (realización de ensayos de fatiga y envejecimiento). 


\section{Limpieza adecuada de los sustratos:}

Las funciones que tiene la limpieza de los adhesivos son:

- Asegurar el control de calidad de los adherentes (adecuado proceso, regularidad de la producción).

- Conocer la existencia de agentes desmoldeantes, ya que disminuyen la adhesión.

- Realizar una limpieza superficial previa de los adherentes.

\section{Selección del adhesivo:}

Los factores necesarios para una adecuada selección del adhesivo son:

- Capacidad de adhesión inherente al sustrato.

- Condiciones de empleo de la unión adhesiva:

- Esfuerzos: tracción, cizalladura, fatiga, impacto.

- Atmósfera de trabajo: disolventes, ácidos, álcalis.

- Factores químicos internos: migraciones, reacciones interfaciales.

- Requisitos especiales: conductividad, aislamiento térmico, color, proceso de fabricación de la unión.

- Restricciones de producción: estabilidad de los materiales, método de aplicación.

- Precio.

- Factores de salud y seguridad: normativa vigente.

\section{Diseño adecuado de la unión adhesiva:}

En el diseño de una unión adhesiva se deben tener presentes los siguientes aspectos:

- La forma, tamaño y grosor de los sustratos determinan el tipo de adhesivo que es más conveniente utilizar.

- Un diseño adecuado debe conseguir minimizar la propagación de fracturas que se puedan iniciar en la unión adhesiva.

- Lograr que las fuerzas adhesivas sean siempre superiores a las cohesivas. De este modo, es conveniente conocer la naturaleza y la magnitud de las tensiones que se esperan durante el ensamblaje antes de elegir el adhesivo. Las uniones adhesivas pueden sufrir los siguientes tipos de esfuerzos (ver Figura 6):

- Esfuerzos de cortadura o cizalla.

- Esfuerzos normales: de tracción y de compresión.

- Esfuerzos de desgarro.

- Esfuerzos de pelado. 


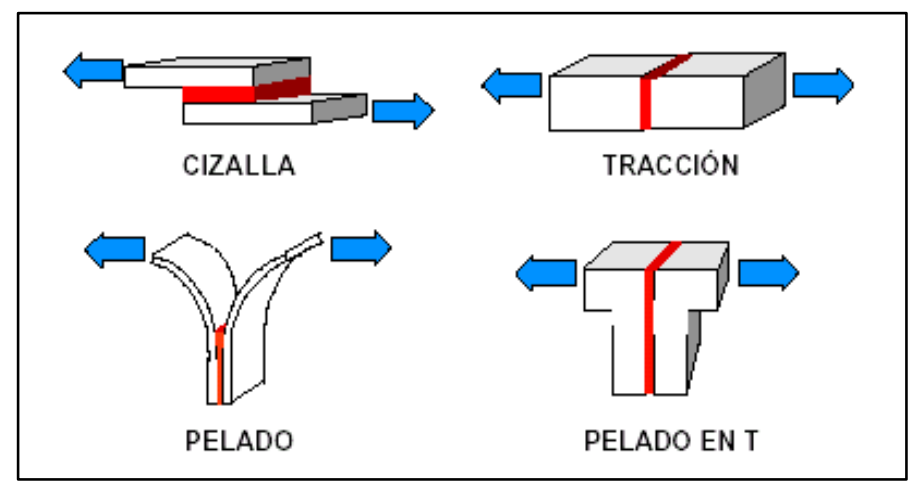

Figura 6. Solicitaciones de las uniones adhesivas.

- Durante el diseño se deben evitar los esfuerzos de desgarro y pelado.

- Utilizar la mayor área posible.

- Alinear correctamente las uniones de forma que las tensiones sean absorbidas en la dirección de mayor resistencia de la unión.

- Diseñar subensamblajes de modo que se minimicen las operaciones de ensamblado con el adhesivo.

- Es importante anticiparse a todos los esfuerzos que puedan aparecer durante el ensamblaje, las operaciones de manipulación y el funcionamiento de la pieza. adheridos.

En la Figura 7 se muestra un cuadro con posibles soluciones de diseño para ensamblajes

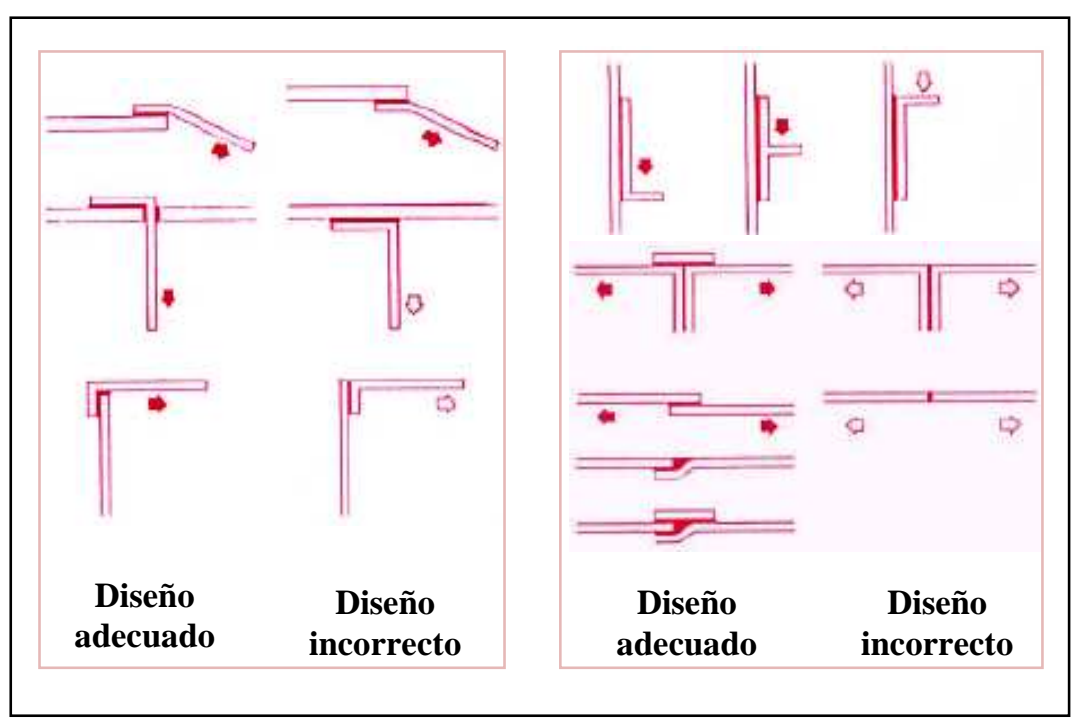

Figura 7. Soluciones de diseño. 


\section{Lograr un buen contacto interfacial (mojado):}

La capacidad de un sustrato para unirse a un adhesivo se cuantifica mediante la energía superficial $\left(\gamma_{\mathrm{Sv}}\right)$, la cual se obtiene a partir del ángulo de contacto $\theta$.

Cuando se pone en contacto un sustrato libre de contaminantes y un adhesivo de baja viscosidad, las orillas de la gota de adhesivo forman un ángulo de equilibrio $\theta$ con la superficie del sustrato. Este ángulo estará en equilibrio cuando las fuerzas de la superficie en las orillas de la gota estén en balance. Estas fuerzas de la superficie son idénticas a las energías libres de dichas superficies. Si la gota se extiende en una película delgada, el ángulo de contacto es cero, lo que significa que el adhesivo ha mojado bien el sólido y se consigue una unión íntima. Si por el contrario, la gota no se extiende sobre superficie, el ángulo de contacto será muy alto, lo que indica que el adhesivo tiene muy poca afinidad con el sustrato.

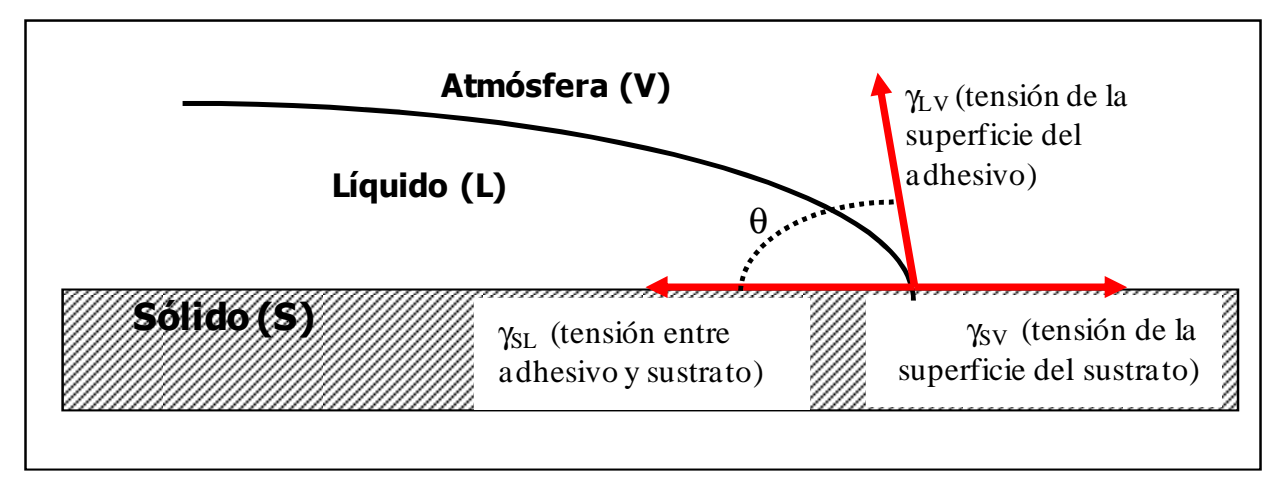

Figura 8. Esquema de la relación entre energía superficial de sólido, líquido y vapor en equilibrio.

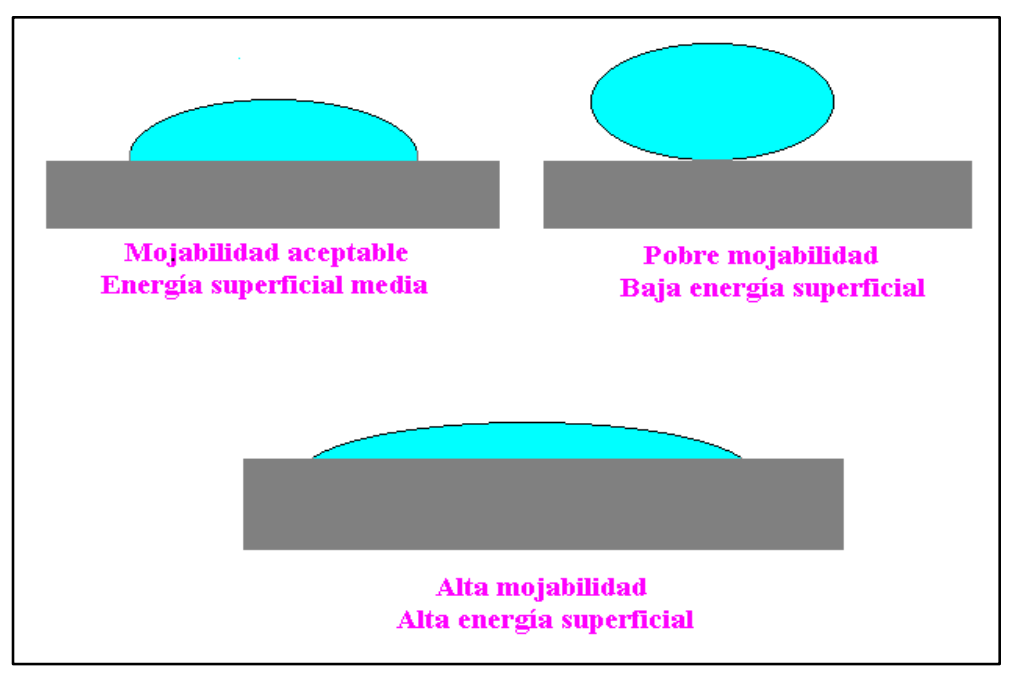

Figura 9. Diferentes grados de mojado. 
Las consideraciones necesarias para favorecer el extendido del adhesivo (mojado del sustrato) y un ángulo de contacto bajo son las siguientes:

- El sustrato debe estar limpio de contaminantes y poseer una energía superficial alta.

- El adhesivo debe tener afinidad por el sustrato (baja tensión interfacial entre adhesivo y sustrato).

- La energía superficial del adhesivo debe ser inferior a la del sustrato.

\section{Creación de fuerzas de adhesión intrínsecas en la unión:}

Para que se produzca adhesión es necesario que se desarrollen interacciones en la interfase. Como consecuencia, se deben crear uniones de naturaleza física o química.

Las fuerzas de Van der Waals y los enlaces de hidrógeno son suficientes para conseguir una alta adhesión, ya que generan múltiples puntos de contacto entre las cadenas del polímero y la superficie del sustrato. mediante:

Cuando las fuerzas de adhesión no son suficientemente elevadas, se pueden incrementar

- Tratamientos superficiales del sustrato.

- Adición de promotores de la adhesión al adhesivo.

\section{Control de la reticulación, curado o cristalización del adhesivo:}

El proceso de curado del adhesivo proporciona un aumento de la cohesión del adhesivo.

Los adhesivos se pueden clasificar según el mecanismo de curado en:

- Adhesivos de reacción química.

- Adhesivos termoflusibles (hot melts).

- Adhesivos en disolución.

- Cintas adhesivas y adhesivos sensibles a la presión (pressure sensitive adhesives, PSA).

\section{Evaluación de la adhesión:}

La resistencia a la separación de las uniones adhesivas se obtiene realizando ensayos. El ensayo elegido dependerá de la aplicación de la unión.

En la evaluación de una unión adhesiva se deben considerar la resistencia a la separación y el modo de fallo de la unión.

Los ensayos más habituales son:

- Ensayos de pelado (peel tests): para materiales flexibles.

- Ensayos de cizalla (lap shear tests): para materiales rígidos.

- Ensayos de torsión. 


\section{Determinación de la durabilidad:}

Debido a que la durabilidad de las uniones adhesivas depende de la degradación producida por el ambiente de trabajo de la unión, los ensayos que se deben realizar para determinar esta propiedad son ensayos de fatiga y de envejecimiento.

\subsection{Causas y remedios para fallos de la unión adhesiva.}

A continuación se muestra un cuadro resumen con las posibles causas de rotura de la unión adhesiva y sus soluciones:

Tabla 1. Causas de una rotura adhesiva y sus soluciones.

\begin{tabular}{|c|l|}
\hline POSIBLES CAUSAS & \multicolumn{1}{|c|}{ SOLUCIONES } \\
\hline \hline Sustratos defectuosos & $\begin{array}{l}\text { Comprobar tolerancias, holguras y materiales, y supervisar } \\
\text { más atentamente. }\end{array}$ \\
\hline Sustratos contaminados & $\begin{array}{l}\text { Comprobar el tratamiento superficial y modificar en } \\
\text { consecuencia. }\end{array}$ \\
\hline $\begin{array}{c}\text { Ejecución de la unión defectuosa o } \\
\text { incorrecta }\end{array}$ & $\begin{array}{l}\text { Comprobar parámetros del proceso, ejecución de la unión, } \\
\text { si se han cumplido todas las condiciones de curado, y } \\
\text { optimizar el tipo y duración de la fijación. }\end{array}$ \\
\hline $\begin{array}{c}\text { Curado insuficiente del adhesivo } \\
\text { Exceso de tensión mecánica o tensión } \\
\text { desfavorable (pelado) }\end{array}$ & $\begin{array}{l}\text { Comprobar condiciones previas de curado (holgura, } \\
\text { estanqueidad al aire, temperatura, humedad, etc.). } \\
\text { Observar tiempos de curado de acuerdo con la hoja de datos } \\
\text { técnicos del fabricante del adhesivo. } \\
\text { Comprobar si se ha sobrepasado la vida útil del adhesivo. }\end{array}$ \\
\hline $\begin{array}{c}\text { Exceso de tensión térmica } \\
\text { de aplicación de fuerzas de la junta. } \\
\text { Comprobar la idoneidad del adhesivo para el tipo de } \\
\text { esfuerzo. }\end{array}$ \\
\hline $\begin{array}{c}\text { Corrosión o infiltración y destrucción } \\
\text { del revestimiento adhesivo por } \\
\text { medios líquidos y gaseosos }\end{array}$ & $\begin{array}{l}\text { Seleccionar el adhesivo de mayor resistencia a la } \\
\text { temperatura. }\end{array}$ \\
\hline $\begin{array}{c}\text { Proteger la holgura de la junta en las superficies de contacto } \\
\text { con el medio utilizando un revestimiento adecuado o } \\
\text { diseñar las piezas a unir de manera que no exista contacto } \\
\text { con el medio. }\end{array}$ \\
\hline
\end{tabular}




\section{TEORÍAS DE LA ADHESIÓN.}

Los mecanismos o modelos de adhesión explican las causas por las que se produce la adhesión entre dos materiales. Pero no existe un modelo genérico de adhesión, cada unión adhesiva puede ser explicada por varios modelos de adhesión. Los modelos de adhesión más aceptados son el modelo mecánico, el modelo de la difusión y el modelo de las capas débiles de ruptura preferente.

Las diferentes teorías de adhesión (o modelos) son los siguientes:

1. Modelo mecánico.

2. Modelo eléctrico.

3. Modelo de difusión.

4. Modelo de la adsorción termodinámica (mojado superficial).

5. Modelo de enlace químico.

6. Modelo ácido-base.

7. Modelo reológico.

8. Modelo de las capas débiles de rotura preferente.

\section{Modelo mecánico:}

Este modelo postula como mecanismo de adhesión el anclaje del adhesivo en los poros y cavidades de la superficie del sustrato. La adhesión se ve favorecida por los siguientes factores:

- El aumento de la superficie del sustrato, debido a la creación de rugosidades.

- La penetración del adhesivo en las cavidades del sustrato.

Este modelo explica la adhesión de materiales porosos como la madera, los tejidos, las fibras textiles, el papel. Sin embargo, en algunas uniones adhesivas hay que considerar conjuntamente otros modelos de adhesión:

- Eliminación de capas débiles de ruptura preferente, producidas cuando se eliminan las capas más externas.

- Incremento de la mojabilidad, es decir, aumento de la energía superficial. Es necesario asegurar una buena humectabilidad del sustrato por el adhesivo, ya que aquellos poros con déficit de adhesivo constituyen potenciales puntos de iniciación de rotura de la unión adhesiva.

Con este modelo mecánico se explican las siguientes uniones adhesivas:

Metalizado de plásticos: los plásticos no tienen afinidad por los metales. Por lo tanto, para favorecer la interacción entre plástico y recubrimiento metálico se deben crear heterogeneidades en la superficie del plástico, así se consigue el anclaje del recubrimiento metálico.

Tratamiento de metales por abrasión mecánica (uniones estructurales de metales y aleaciones metálicas): se realiza antes de aplicar tratamientos químicos. Produce los siguientes efectos sobre los metales: 
- Creación de una topografía superficial adecuada.

- Eliminación de sustancias antiadherentes de la superficie como contaminantes o grasas.

- Incremento de la superficie de unión del adhesivo con el metal.

Se pueden crear dos topografías diferentes en la superficie del sustrato: hendiduras o poros. Los poros se crean en metales principalmente mediante tratamiento con chorro de arena. El efecto que se consigue es un incremento de la superficie de contacto con el adhesivo. Sin embargo, las hendiduras generan un nivel de adhesión menor que los poros, pero mejoran en mayor medida el mojado de la superficie.

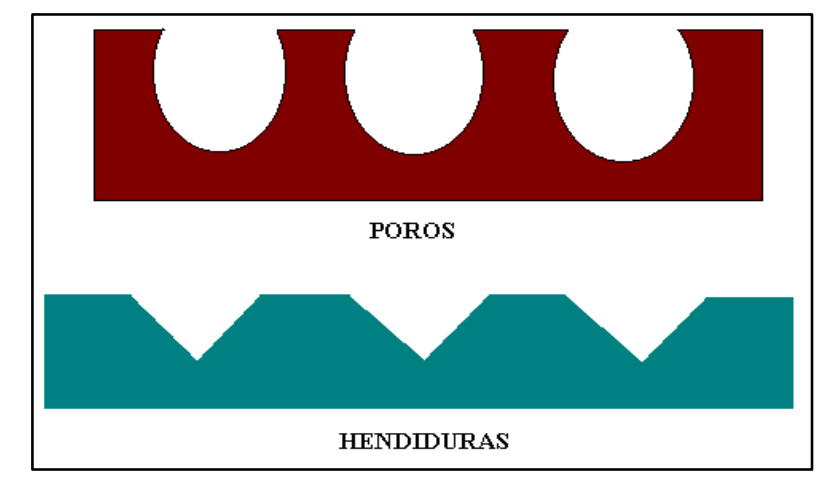

Figura 10. Diferentes topografías creadas en las superficies de los sustratos mediante abrasión mecánica.

\section{Modelo eléctrico:}

En las uniones metal-adhesivo, la diferencia entre la naturaleza de ambos materiales facilita la transferencia de electrones del metal al adhesivo. Esto produce una doble capa eléctrica en la interfase.

Cuando se separan estas uniones a altas velocidades, aparecen destellos eléctricos, además se observa un aumento en la adhesión. Todo esto ha llevado ha postular el modelo eléctrico. Sin embargo, las fuerzas electrostáticas implicadas en la separación de la unión pueden ser el resultado más que la causa del incremento de la adhesión.

Las limitaciones que presenta el modelo eléctrico son las siguientes:

- La presencia de impurezas y contaminantes en la superficie de los sustratos disminuyen tanto la adhesión como la posibilidad de formar una doble capa eléctrica. Las fuerzas eléctricas deberían mantenerse en niveles superiores.

- La unión de dos sustratos previamente separados no supera el $10 \%$ de la fuerza inicial de la adhesión. Las fuerzas eléctricas deberían mantener un nivel superior de adhesión.

- La contribución a la interfase debida a las fuerzas de Van der Waals es en algunos casos superior a la de las fuerzas electrostáticas. 


\section{Modelo de la difusión:}

Este modelo permite explicar la autoadhesión entre polímeros idénticos. Considera que la adhesión se debe a la migración de cadenas poliméricas entre las dos superficies de los polímeros en contacto.

Para que se produzca una difusión óptima, los polímeros deben ser miscibles, es decir, solubles entre sí. La miscibilidad de los polímeros se cuantifica a partir de los parámetros de solubilidad.

Los valores de estos parámetros de solubilidad dependen del grado de interacciones intermoleculares en el disolvente o polímero. Las sustancias apolares presentan fuerzas de Van der Waals, por lo tanto, poseen parámetros de solubilidad pequeños. Mientras que las sustancias que forman enlaces de hidrógeno y/o contienen grupos polares, poseen parámetros de solubilidad superiores.

Se considera que dos polímeros, dos disolventes o un polímero y un disolvente son miscibles si poseen parámetros de solubilidad parecidos.

El modelo de difusión demuestra:

- La pobre adhesión de las poliolefinas (polietileno, polipropileno).

- La pobre miscibilidad de la mayoría de los polímeros en agua.

- Los polímeros que presentan una gran diferencia en sus parámetros de solubilidad, no poseen adhesión.

- La autoadhesión de plásticos mediante soldadura por aplicación de calor o con disolventes.

Sin embargo, presenta las siguientes limitaciones:

- No considera la disipación de energía viscoelástica producida cuando se realiza un ensayo mecánico de adhesión.

- Los efectos debidos al tiempo de contacto y peso molecular de los polímeros pueden explicarse considerando variaciones en la cinética del proceso de mojabilidad de los sustratos.

\section{Modelo de adsorción termodinámica (mojado superficial):}

El modelo termodinámico es válido para cualquier proceso de adhesión. Establece que la adhesión se debe a la existencia de múltiples zonas de contacto entre el adhesivo y la superficie del sustrato. Cuanto mejor sea la mojabilidad, es decir, el contacto interfacial, mejor será la adhesión termodinámica.

Con la adhesión termodinámica se crean fuerzas intermoleculares en la interfase adhesivosustrato. Estas fuerzas son enlaces secundarios, fuerzas de Van der Waals y enlaces de hidrógeno. Aunque estos tipos de fuerzas son muy débiles, si el número de enlaces es elevado se puede conseguir una fuerte adhesión.

Junto a los enlaces secundarios pueden generarse enlaces primarios (enlaces covalentes y enlaces iónicos), pero su contribución a la adhesión formaría parte del modelo del enlace químico. 
Como ya se ha comentado, la adhesión por medio del modelo termodinámico se produce cuando el adhesivo moja al sustrato. Recordemos que la mojabilidad se mide a través del ángulo de contacto $\theta$, por lo tanto, la óptima mojabilidad se logra cuando el ángulo de contacto es bajo. Además, se produce una adecuada adhesión si la energía superficial del sustrato es mayor que la energía superficial del adhesivo. Es aconsejable que ambas energías superficiales sean del mismo orden de magnitud.

\section{Modelo de enlace químico:}

El modelo del enlace químico considera que la adhesión se debe a la creación de enlaces primarios, enlaces covalentes y enlaces iónicos, entre el sustrato y el adhesivo. Esto se consigue mediante:

- Tratamientos superficiales de los sustratos.

- Empleo de adhesivos reactivos: epoxi, cianoacrilatos.

Hay dos tipos de uniones adhesivas que se realizan mediante este modelo:

Incorporación de complejos organometálicos: contienen un átomo metálico central rodeado de ligandos orgánicos. Forman una monocapa en la superficie del sustrato, e incrementan la durabilidad de las uniones adhesivas.

Incorporación de imprimaciones: una imprimación es un compuesto que se coloca sobre la superficie del sustrato para aumentar la fuerza de unión adhesiva y/o aumentar la durabilidad de la unión. Los silanos son las imprimaciones más empleadas. Su estructura está constituida por una cadena química corta que contiene un grupo polar en un extremo y un grupo apolar en el otro. Estas imprimaciones forman uniones mediante enlaces covalentes, creando de esta manera un retículo que permite el anclaje del adhesivo. Los silanos incrementan la adhesión de los siguientes sistemas:

- Materiales y fibras de vidrio.

- Materiales metálicos como el aluminio.

- Aditivo para incrementar la mojabilidad de adhesivos epoxis y poliuretanos.

\section{Modelo ácido-base:}

El modelo ácido-base justifica la adhesión en base a interacciones químicas de esta naturaleza. Las sustancias se clasifican de acuerdo a sus propiedades ácido-base:

- Ácido: aceptor de electrones y donador de protones. Por ejemplo, moléculas con un halógeno (PVC, PE, y PP clorados o fluoruro de polivinilo).

- Base: aceptor de protones y donador de electrones. Por ejemplo, ésteres, cetonas, éteres, poliestireno, policarbonatos, poliimidas, sustancias inorgánicas $\left(\mathrm{CaCO}_{3} \mathrm{o}\right.$ $\mathrm{Al}_{2} \mathrm{O}_{3}$ ).

- Anfótero: puede actuar como donador de electrones o protones, o como aceptor de electrones o protones. Por ejemplo, amidas, aminas, alcoholes, poliamidas, sustancias inorgánicas $\left(\alpha-\mathrm{Al}_{2} \mathrm{O}_{3}\right)$. 
Los conceptos ácido-base son solamente útiles en las uniones de materiales de vidrio, en la aplicación de silanos, en los polímeros y adhesivos acrílicos, en las uniones entre aleaciones de aluminio y adhesivo epoxi. Pero su aplicación en uniones de elastómeros es muy cuestionada.

\section{Modelo reológico:}

El modelo reológico establece que al realizar un ensayo de adhesión, los sustratos y las uniones están sometidos a solicitaciones mecánicas que dirigen la ruptura de la unión a un lugar diferente dependiendo de la naturaleza y magnitud de las solicitaciones.

La energía de separación en una unión adhesiva depende de la adhesión intrínseca y de las propiedades reológicas de los materiales que intervienen en la unión.

El modelo reológico considera que la energía de separación de la unión en un ensayo destructivo depende de las propiedades de la superficie del sustrato y de las propiedades másicas de los sustratos y adhesivo.

\section{Modelo de las capas débiles de rotura preferente:}

Es el modelo de unión más común. Explica la carencia de adhesivo en muchas uniones.

Con este modelo se justifican los dos sistemas siguientes:

- El empleo de un tratamiento superficial demasiado agresivo produce una capa superficial deteriorada. Esta zona será muy débil, como consecuencia, al realizar un ensayo de adhesión la factura de la unión se dirigirá hacia esa zona. El fallo de la unión no será interfacial sino cohesivo en la capa superficial tratada.

- Una limpieza inadecuada de la superficie del sustrato puede reducir el número de puntos de anclaje en la interfase, y por tanto, producir un deterioro de la unión.

El principio de este modelo es el siguiente:

La propagación de la fractura de una unión adhesiva no tiende a producirse en la zona interfacial, sino que tiende a dirigirse hacia las zonas débiles de la superficie del sustrato o del adhesivo.

Las capas de cohesión débiles se producen por los siguientes motivos:

- Contaminación que no se ha eliminado de la superficie del sustrato antes de realizar la unión adhesiva. Es común en los metales.

- Sustancias de bajo peso molecular o aditivos que migran a la interfase una vez formada la unión.

- Reacciones entre el sustrato y el adhesivo una vez producida la unión adhesiva. Esto puede provocar la creación de nuevas estructuras con propiedades diferentes a las de la interfase. A continuación se citan algunos ejemplos:

- Unión de polietileno con aluminio: una vez formada la unión adhesiva, se crea una capa transcristalina en la superficie del sustrato, de naturaleza diferente a la del polietileno. Esta capa proporciona rigidez a la interfase y produce el deterioro de la adhesión. 
- Unión entre fibra de carbono y matriz epoxi: una vez realizada la unión, se crea una estructura cristalina en la interfase en la zona de contacto con la fibra, la cual deteriora el anclaje de la matriz epoxi.

- Unión entre caucho SBR y aluminio (a este último se la ha realizado un fosfatado como tratamiento superficial): durante el ensayo de pelado se produce una ruptura cohesiva en el caucho debida a la sobrereticulación que sufre el caucho en la superficie de aluminio fosfatado.

- Excesivo o inadecuado tratamiento superficial:

- Una abrasión excesiva provoca un debilitamiento mecánico del material que puede favorecer un fallo prematuro o inesperado en la unión adhesiva.

- Halogenación excesiva de cauchos produce un deterioro de la superficie tratada que causa el endurecimiento de la superficie en contacto con la interfase. 


\section{FACTORES QUE INFLUYEN EN LA ADHESIÓN.}

\subsection{Superficie de los sustratos.}

Debido a que la adhesión es un fenómeno superficial, la microgeometría de la superficie de los sustratos influirá en la resistencia de la adhesión. Como consecuencia, se deben estudiar los siguientes aspectos de la estructura superficial:

a.) Rugosidad superficial.

b.) Humedad.

c.) Estado de la superficie.

\section{a.) Rugosidad:}

Se define rugosidad como aquellas irregularidades microgeométricas de las superficies de las piezas mecanizadas, formadas por crestas y valles, y debidas a la acción de las herramientas utilizadas.

La rugosidad o suavidad de la superficie de un sustrato influye en el área de contacto del adhesivo. Las superficies rugosas proporcionan un anclaje mecánico favorable para el adhesivo. Pero no es conveniente que el sustrato sea demasiado rugoso, porque de lo contrario el contacto únicamente se realizará en las crestas, lo que proporcionaría un área de contacto total pequeña y como consecuencia una pobre adhesión.

Otro inconveniente de las superficies demasiado rugosas es que pueden quedar atrapados volúmenes de aire causando un mojado insuficiente. Cuando se agrega adhesivo a la superficie rugosa o áspera del sustrato, este no puede extenderse con tanta facilidad como en una superficie lisa, existiendo el riesgo de que no pueda expulsar todo el aire que hay entre las asperidades. De ocurrir esto, el adhesivo descansaría parcialmente en aire.

La cantidad de aire atrapado depende de numerosos factores. Por ejemplo, si el adhesivo posee una viscosidad baja (tiene una gran afinidad por el sustrato) y los valles y capilaridades que presenta la superficie del sustrato se van estrechando conforme se hacen más profundos, no habrá una cantidad significativa de aire atrapado. Si por el contrario, el adhesivo no es fluido (presenta una alta viscosidad) y fragua rápidamente, existirá una cantidad apreciable de aire, independientemente de la forma de la superficie del sustrato.

Como se acaba de ver la cantidad de aire atrapado dependerá del tamaño y forma del poro o capilaridad, de la viscosidad del adhesivo, del tiempo de fraguado y de la tensión de adhesión.

La forma y tamaño de los poros o capilaridades es un importante parámetro desde el punto de vista de la adhesión. Se puede tener un adhesivo con la adecuada viscosidad y afinidad por el sustrato capaz de expulsar el aire de la interfase e impedir que quede atrapado, pero sin embargo, se puede encontrar un adhesivo fluye en exceso a través de los poros de la superficie del sustrato provocando una escasez en la zona de unión. En este caso el peligro no es el aire entrampado, sino la escasez de adhesivo en la junta.

A pesar de los inconvenientes que puede presentar una superficie rugosa, también ofrece las siguientes ventajas: 
- Creación de una superficie limpia.

- Formación de una superficie reactiva.

- Formación de una superficie mayor.

- Retardo mecánico de la fractura por fragilidad en los ensayos de corte o cizalladura.

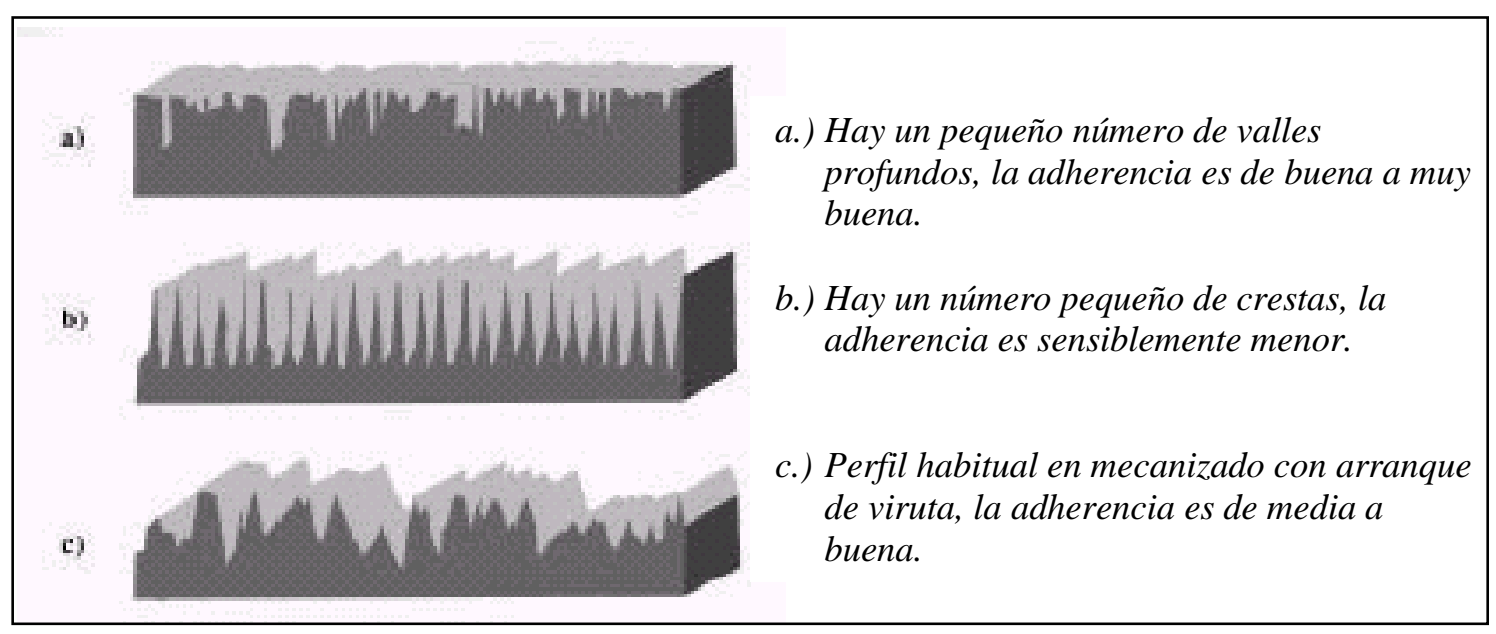

Figura 11. Perfiles de superficies con idéntica profundidad de rugosidad.

\section{b.) Humedad:}

Los gases y vapores condensados en los poros o capilaridades del sustrato ejercen una presión sobre las paredes de dichos capilares que provoca la expansión del sólido. Estos cambios en las dimensiones producen esfuerzos de tracción desfavorables para las uniones adhesivas. Las películas de adhesivo pueden ser, en principio, impermeables a los gases, pero sometidas a la acción de esfuerzos pueden crearse fisuras.

Muchos sólidos pueden ser lo suficientemente porosos como para permitir el paso de la humedad y otros agentes oxidantes. Esta adsorción causa la separación gradual del adhesivo de la superficie del sustrato, lo que conlleva la reducción de la intensidad de la unión.

\section{c) Estado de la superficie:}

En la tecnología de la adherencia es más importante reproducir las propiedades superficiales que la composición química.

Los efectos beneficiosos o perjudiciales de las impurezas dependen de la afinidad entre el adhesivo y sustrato, de todas formas siempre será preferible una superficie limpia de impurezas. Para obtener superficies limpias es preciso partir de superficies recién preparadas, ya que estas, por lo general, son más reactivas que las superficies envejecidas.

Otra característica que deben poseer las superficies de los sustratos es que su tensión superficial debe ser superior a la tensión superficial del adhesivo, de esta forma se logra un buen contacto interfacial (mojado) adhesivo-sustrato. Es decir, logramos que el adhesivo fluya sin dificultad sobre la superficie del sustrato y así pueda unirse con mayor facilidad al sustrato. 


\subsection{Composición del adhesivo.}

Las propiedades del adhesivo son debidas tanto a las propiedades del componente base como a las de los aditivos empleados.

Debido a que los constituyentes varían en función de la clase de adhesivo que se esté utilizando, es imposible realizar una clasificación general de los constituyentes de los adhesivos. A continuación se cita una serie de constituyentes presentes en los adhesivos más importantes:

a) Producto base: Puede tratarse de un único producto, de una mezcla de varios productos o de modificaciones químicas de ciertos productos base. En la mayoría de los casos, el producto base es una mezcla de monómeros, oligómeros y/o polímeros.

b) Aditivos: Sustancias que varían las características físico-químicas del producto base del adhesivo, tanto antes como después del proceso de curado.

Tenemos varias clases de aditivos:

- Indicadores: activan e inician la reacción de polimerización de los adhesivos monocomponentes reactivos.

- Agentes de reticulación: logran termoestabilizar ciertos adhesivos reactivos.

- Diluyentes: mejoran la mojabilidad del adhesivo reduciendo su concentración de sólidos. También modifican la viscosidad y la procesabilidad.

- Colorantes: para proporcionar color al adhesivo.

- Antioxidantes: evitan fenómenos de oxidación.

- Plastificantes: modifican la temperatura de transición vítrea, y como consecuencia las propiedades físicas del adhesivo ya curado.

- Agentes de "tack" (pegajosidad): sustancias que confieren untuosidad al adhesivo. Pueden ser sustancias naturales (derivadas de resinas de pino) o sustancias sintéticas (derivados de residuos del petróleo).

- Surfactantes o tensoactivos: agentes que mejoran la estabilidad de los adhesivos emulsionados.

- Sustancias fluorescentes: permiten localizar por medio de detectores al adhesivo en la pieza.

- Carriers: soportes sólidos empleados en adhesivos piezoeléctricos.

- Agentes de acoplamiento o promotores de la adhesión: mejoran la durabilidad del adhesivo por medio de la generación de enlaces primarios con el sustrato.

- Estabilizadores: mejoran la vida útil del adhesivo.

c) Cargas/espesantes: Sustancias que modifican la reología del adhesivo antes del proceso de curado, así como las características mecánicas del adhesivo curado.

d) Disolventes: Estas sustancias solo se emplean en los adhesivos en disolución y los adhesivos en contacto. Favorecen la procesabilidad y la untuosidad (tack) del adhesivo.

e) Endurecedores: $\mathrm{Se}$ emplean como segundo componente en los adhesivos bicomponentes. Provocan la reacción química del proceso de curado. 


\subsection{Propiedades del adhesivo.}

\section{a) Deformación y flujo (reología):}

Es imprescindible que un adhesivo, en el momento de la unión:

- Fluya o se deforme con el objetivo de penetrar en los valles y capilaridades de los sustratos, sin causar un empobrecimiento de la zona de unión.

- Desplace el aire.

- Llegue a un íntimo contacto con la superficie del sustrato.

Existen tres formas por las que un adhesivo puede oponerse a fluir o deformarse, puede ser viscoso, plástico o elástico.

* Viscosidad: Un líquido viscoso es aquel que fluye a velocidad infinitamente pequeña sobre una tensión infinitamente pequeña todo el tiempo que dura la aplicación de la carga. Cuando se quita la carga, el material no recuperará su forma original.

$\mathrm{Si}$, además, se cumple que la velocidad de desplazamiento aumenta proporcional al deslizamiento del esfuerzo, el fluido recibe el nombre de fluido ideal o Newtoniano.

* Plasticidad: Un sólido plástico es aquel que no fluye o no sufre una deformación apreciable a menos que la carga aplicada exceda de un determinado valor crítico de tensión. Cuando se quita la carga, el material está intacto.

La tensión critica que el material debe exceder para sufrir deformación o fluir se denomina tensión o valor de rendimiento. Cuando las tensiones de deslizamiento en un material exceden a la tensión de rendimiento, será cuando el material fluya.

Si el grado de deslizamiento es proporcional al exceso de tensión de deslizamiento sobre el valor de tensión de rendimiento, el material se denomina sólido plástico o cuerpo de Bingham.

* Elasticidad: Un material elástico es aquel que al ser cargado sufre una deformación proporcional al esfuerza aplicado. Cuando se quita la carga, el material recuperará su forma original.

Si el sólido tiene una deformación y recuperación instantánea cuando se aplica la carga o se quita, el sólido recibe el nombre de sólido de Hookean o elástico simple.

En la Figura 12 se pueden ver las diferencias entre un material elástico (I), uno viscoso (III) y otro visco-elástico (II). 


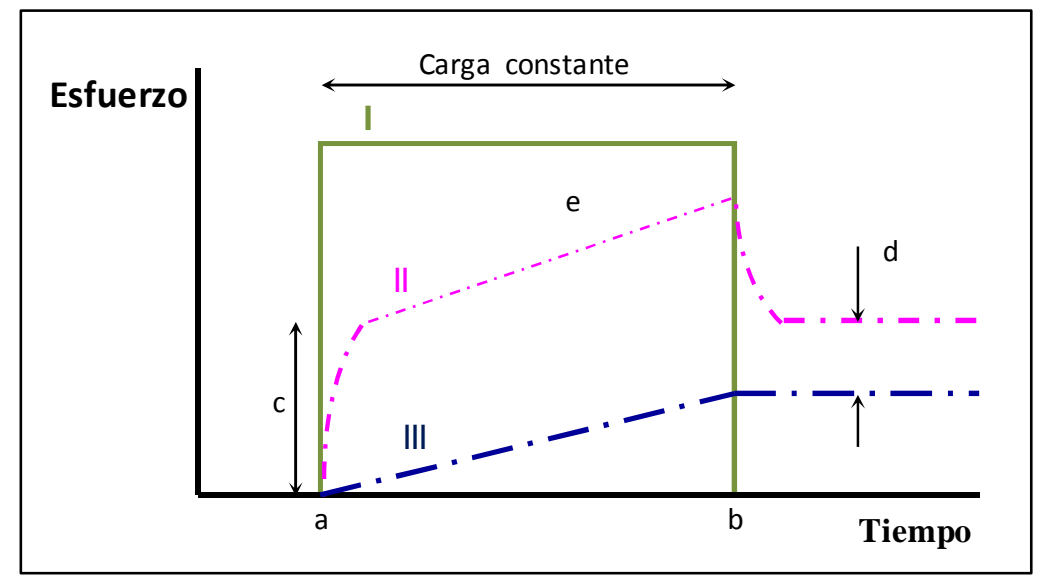

Figura 12. Comportamiento elástico, viscoso y visco-elástico de un material.

Cuando una carga es aplicada de repente en un tiempo $a$, el material elástico I se deforma inmediatamente y no hace otra cosa mientras que la carga permanece constante; cuando se quita la carga en un tiempo $b$, recupera su forma original.

El líquido viscoso III se deforma a una velocidad constante hasta que se quita la carga, momento en el cual se para.

El material visco-elástico II muestra inicialmente una deformación elástica $c$ no instantánea, a continuación enseña un comportamiento viscoso $e$ hasta que se elimina la carga, punto en el que empieza a recuperar el esfuerzo $d$ igual a $c$.

\section{b) Espesor de la película de adhesivo:}

La capa o película adhesiva debe ser tan delgada como sea posible, sin llegar a una unión insuficiente, para conseguir la máxima fuerza y rigidez de la capa de adhesivo en una unión. Para prevenir una escasez de adhesivo en la zona de unión, no solo se debe tener en cuenta la cantidad de adhesivo necesario para llenar todos los valles y capilaridades de la superficie de los sustratos, sino que también se debe tener presente el volumen de encogimiento del adhesivo por difusión o por fluir dentro de los poros del sustrato.

Las ventajas de una capa de adhesivo delgada son las siguientes:

- Se requiere una fuerza mayor para deformar una película delgada que una gruesa.

- La probabilidad de fluir o cristalizar es mayor conforme aumenta el espesor.

- Las tensiones internas en las interfases del adhesivo y las tensiones térmicas debidas a las diferencias de expansión son proporcionales al espesor de la película de adhesivo.

- Si el adhesivo es rígido o duro, una capa delgada es más resistente al agrietamiento cuando se flexiona la junta.

- Cuanto mayor sea el volumen de adhesivo, mayor es la probabilidad de que contenga burbujas de aire o alguna otra fuente de debilitamiento. 


\section{c) Tiempo de almacenamiento:}

Cuando un adhesivo es guardado durante un tiempo considerablemente grande en condiciones extremas de temperatura, pueden producirse cambios químicos y físicos en el adhesivo.

El tiempo de almacenamiento de un adhesivo es el tiempo que puede estar almacenado sin sufrir variaciones y permaneciendo adecuado para su uso.

Las condicione externas a las que está sometido el adhesivo durante el tiempo de almacenamiento, deben estar perfectamente controladas. Es aconsejable que la temperatura de almacenamiento del adhesivo esté cercana a las condiciones reales de uso.

Algunos adhesivos aparentemente pueden ser dañados cuando se exponen a bajas temperaturas, sin embargo con un ligero calentamiento y agitación pueden ser restaurados para proporcionar un óptimo servicio. A pesar de que aparentemente el adhesivo no se ve afectado en este proceso de congelación y calentamiento, si se repite el ciclo más de una vez si puede verse dañado.

\section{d) Tiempo de trabajo:}

El tiempo de trabajo o tiempo de empleo útil de un adhesivo es el tiempo que transcurre entre el momento en que el adhesivo está listo para su uso, y aquel en donde el adhesivo ya no se puede usar.

\section{e) Cobertura:}

Esta propiedad determina la extensión en la que puede ser expandido uniformemente el adhesivo sobre el aérea de unión, es decir, la cantidad de adhesivo que se debe aplicar en una operación de expansión o recubrimiento.

\section{f) Penetración:}

El control de la penetración del adhesivo dentro de materiales porosos es muy importante. El requerimiento indispensable para un adhesivo es el de mojar o lograr un íntimo contacto con las superficies de los sustratos que se van a unir. Un adhesivo que penetra en exceso en la superficie del sustrato puede original una capa de adhesivo insuficiente en la zona de la unión. Además este desperdicio de adhesivo supone un aumento de costes.

\section{g) Velocidad de curado:}

Muchos adhesivos necesitan un curado ya sea por una aplicación de calor o por agregación de un catalizador, o ambas cosas, con o sin presión en periodos de tiempo especificados.

\section{h) Pegajosidad (tack):}

La pegajosidad es la propiedad de un adhesivo que permite que la superficie recubierta con un adhesivo se adhiera a otra al ser unidas, y se requiera además aplicar una fuerza para separar ambas superficies. Por lo tanto, la falta de pegajosidad puede tener dos causas diferentes: 
- El material puede no pegarse fácilmente.

- El material no puede ser capaz de soportar un esfuerzo ligero.

Un adhesivo que tiene esta característica en alto grado se dice que posee una pegajosidad alta o pegajosidad agresiva.

La medida del valor de la pegajosidad puede variar con el tiempo, temperatura y espesor de la capa de adhesivo.

\subsection{Rendimiento de la unión adhesiva.}

Una vez que el adhesivo ha curado y ha adquirido sus propiedades o características definitivas, no se puede garantizar que estas permanezcan inalterables a lo largo de toda la vida en servicio de la unión adhesiva. Las ventajas que ofrecen las uniones adhesivas pueden disminuir si se trata de un comportamiento a largo plazo, debido a la acción de una serie de agentes externos que pueden modificar las propiedades del adhesivo. El medio puede debilitar la junta adhesiva y degradar su resistencia inicial, provocando el fallo a esfuerzos mecánicos menores que los previstos.

Por lo tanto, es necesario caracterizar las propiedades de cada adhesivo y su variación frente a la acción de agentes externos. Esto se conoce como durabilidad del adhesivo.

Existe un gran número de factores que pueden causar la degradación del adhesivo, del sustrato o de la intercara entre ambos. Además, no es suficiente investigar la influencia de cada uno de estos factores de forma independiente, es necesario estudiar el efecto combinado de dos o más factores, porque la interacción entre ellos tiene un efecto más perjudicial para la unión adhesiva.

Algunos de los factores que influyen sobre la durabilidad de la unión adhesiva son:
a) Temperatura.
b) Humedad.
c) Tensión mecánica.
d) Oxidación.
e) Resistencia química.
f) Radiación.
g) Envejecimiento y degradación.
h) Fluidos (aceites, combustibles, disolventes orgánicos y clorados, gases refrigerantes).

A continuación se expone con más detalle el efecto de la temperatura, humedad y tensión mecánica sobre la unión adhesiva.

\section{a) Efecto de la temperatura:}

Las zonas más críticas en la unión adhesiva cuando es sometida a los efectos de la temperatura son el adhesivo y la intercara de unión adhesivo-sustrato. El efecto de la temperatura produce la variación de la tensión superficial del polímero y la variación de la tensión interfacial adhesivo-sustrato. Esta última variación es más significativa, debido a la dependencia de la tensión interfacial con la temperatura. De esta manera, cuando incrementamos la temperatura, la tensión interfacial decrece y, como consecuencia, la resistencia de la junta disminuye. 
Los efectos de la temperatura sobre la junta adhesiva son muy variados, se puede diferenciar entre:

- Efecto de las bajas temperaturas: El comportamiento de la unión adhesiva a bajas temperaturas depende de las características mecánicas que presenta el adhesivo a tales temperaturas.

Por ejemplo, los adhesivos termoplásticos y los termoestables se vuelven rígidos y frágiles a bajas temperaturas debido al aumento de rigidez que sufre las cadenas poliméricas que los constituyen. Como consecuencia, la unión adhesiva no resistirá elevados esfuerzos.

Los materiales elastómeros pierden sus características viscoelásticas por debajo de su temperatura de transición vítrea (varias decenas de grados bajo cero). A estas temperaturas se vuelven rígidos y pasan a tener un comportamiento vítreo, módulos estáticos elevados y elongaciones de rotura bajas. Todo esto produce la rotura de las juntas elásticas cuando son sometidas a esfuerzos.

* Resistencia al calor: Es la resistencia que presenta el adhesivo a altas temperaturas puntuales. El efecto de estas temperaturas provoca la disminución de la viscosidad del adhesivo durante un cierto tiempo.

Los materiales termoplásticos a temperaturas superiores a la de transición vítrea sufren un reblandecimiento, llegando a un estado fluido si se supera la temperatura de reblandecimiento. Aunque el efecto del calor en estos materiales es muy perjudicial, disminuye el poder de adherencia inicial, este efecto puede ser reversible si no se sobrepasa la temperatura de descomposición.

- Envejecimiento a temperatura: Es el efecto que se produce cuando la unión adhesiva se expone a una elevada temperatura de forma constante. El comportamiento que presentan los adhesivos a alta temperatura durante largos períodos de tiempo es muy diferente del comportamiento que tienen a altas temperaturas puntuales.

Los compuestos orgánicos expuestos a altas temperaturas, pero sin superar la temperatura de degradación, sufren fenómenos de oxidación. Este proceso de oxidación puede acelerarse por la influencia de factores tales como esfuerzos mecánicos, luz ultravioleta y la presencia de agentes oxidantes, llegando a poder degradar por completo la unión adhesiva, incluso si se mantiene la temperatura por debajo de la temperatura de descomposición del material.

Los efectos de la temperatura pueden producir en los adhesivos los siguientes tipos de degradación:

* Despolimerización: Para que se produzca la despolimerización de un adhesivo deben verificarse las siguientes condiciones:

- Que la temperatura exceda un valor máximo, por encima del cual el polímero sea termodinámicamente inestable.

- Que exista un mecanismo por el cual se produzca la rotura de enlaces químicos y se generen centros activos que permitan que prosiga la despolimerización. 
Esta degradación por efecto térmico puede ocurrir de forma accidental durante la fabricación de la unión adhesiva. Si la polimerización es fuertemente exotérmica y el curado no se realiza con rapidez, el calor desprendido no puede ser transferido y provoca el daño del adhesivo. Es el caso de las uniones híbridas soldadura-adhesivo, cuando se aplica un punto de soldadura se pueden alcanzar temperaturas muy elevadas en zonas adyacentes, lo que produce una degradación local que introduce un defecto en la unión.

* Degradación oxidativa: El oxígeno atmosférico ataca a los polímeros, acelerando la degradación térmica que sufren cuando alcanzan una cierta temperatura.

La difusividad del oxígeno en los adhesivos es tan grande cuando la temperatura es elevada, que ni los adhesivos impermeables al oxígeno proporcionan la protección suficiente frente a la degradación oxidativa.

La degradación oxidativa consiste en una serie de reacciones en cadena específicas para cada tipo de adhesivo. La resistencia a la degradación oxidativa depende de la permeabilidad al oxígeno del polímero, así como de la reactividad y de la cinética de las reacciones en cadena que conducen a la degradación de cada tipo de adhesivo.

* Escisión de cadena: Antes de explicar este mecanismo de degradación del adhesivo, debemos definir el concepto de volumen libre: es el espacio libre existente entre las cadenas orgánicas que constituyen el polímero.

El mecanismo de escisión de cadena consiste en cortar en dos la molécula de polímero. Con este mecanismo aumenta el tamaño de los volúmenes libre y con ello decrece el número total de lugares de volumen libre. A medida que continúa este mecanismo, el polímero se va haciendo más esponjoso, lo que produce lleva al debilitamiento de la resistencia mecánica.

Los polímeros sufren grandes cambios en sus propiedades mecánicas cuando la temperatura está cercana a la temperatura de transición vítrea. Debido a este motivo, se usa en la práctica el criterio de fijar la temperatura máxima de servicio o utilización del adhesivo por debajo de la temperatura de transición vítrea del polímero.

Los límites de temperatura para las familias de adhesivos más importantes son los siguientes:

- Acrílicos y cianoacrilatos: la temperatura límite está en torno a $80^{\circ} \mathrm{C}$.

- Epoxi curado con poliamidas: el límite superior es de $65^{\circ} \mathrm{C}$.

- Epoxi curado con aminas alifáticas: presentan un límite de $100^{\circ} \mathrm{C}$.

- Epoxi curado con aminas aromáticas: el límite es de $150^{\circ} \mathrm{C}$.

- Epoxi curado con ácidos orgánicos: la temperatura límite es de $175^{\circ} \mathrm{C}$.

- Siliconas: presentan un límite superior de $200^{\circ} \mathrm{C}$.

- Poliimidas: el límite superior es de $260^{\circ} \mathrm{C}$. 


\section{b) Efecto de la humedad:}

El agua es uno de los agentes externos que mayor influencia negativa tiene sobre la durabilidad de las uniones adhesivas.

La unión adhesiva puede estar en contacto directo con agua líquida o en contacto con una atmósfera que presenta cierta humedad relativa. Cuando se tiene una elevada humedad relativa, el potencial químico del vapor es igual a la del agua líquida, por lo tanto, la absorción, difusión y humedad de equilibrio serán idénticas y, como consecuencia, es imposible evitar que el vapor entre en el interior del adhesivo. Existe una concentración crítica de humedad, específica para cada tipo de adhesivo, por debajo de la cual no se produce ningún daño irreversible en el adhesivo. Si se supera este valor crítico es imposible la reversibilidad.

El agua puede afectar al adhesivo, a los sustratos y a la intercara adhesivo-sustrato. Pero es el efecto de la humedad sobre la intercara o zona de adhesión la que tiene mayor influencia sobre la resistencia de la unión adhesiva.

Todos los adhesivos poliméricos absorben, en mayor o menor medida, agua. Los adhesivos que contienen grupos funcionales polares (poliamidas y poliuretanos) o aditivos polares (caucho de nitrilo carboxilado como agente reforzante) absorben más cantidad de agua que los adhesivos con grupos no polares (adhesivos fundidos en caliente basados en polietileno). Otros adhesivos (poliuretanos y cianoacrilatos) contienen grupos funcionales que reaccionan directamente con el agua, causando una degradación por hidrólisis y un descenso en la durabilidad de la unión adhesiva cuando se tiene un ambiente húmedo.

El efecto de la humedad sobre la unión adhesiva puede producir cambios reversibles, donde la resistencia de la junta se restablece tras un secado. Este es el caso de la plastificación del adhesivo. En otros casos, los cambios producidos son irreversibles, provocando daños permanentes y pérdida de propiedades en la unión. Es el caso de la hidrólisis y microagrietamiento del adhesivo.

En capítulos anteriores se ha comentado que el fallo de las uniones adhesivas debe ser cohesivo, rotura dentro de la capa de adhesivo. Si la rotura fuese adhesiva, se tendría un problema de preparación superficial o de curado del adhesivo. Sin embargo, si se expone la unión adhesiva a un ambiente húmedo durante un largo tiempo, puede cambiar el modo de fallo en la intercara adhesivosustrato, es decir, el fallo cohesivo podría convertirse en adhesivo.

La entrada de agua en la unión adhesiva se realiza por uno de los siguientes mecanismos:

- Difusión a través del adhesivo desde los bordes exteriores que están en contacto con la humedad.

- Transporte a lo largo de la intercara adhesivo-sustrato.

- Difusión a través de sustratos permeables (por ejemplo, materiales compuestos de matriz polimérica).

- Migración por las zonas microagrietadas del adhesivo.

Una vez que penetra el agua en la unión adhesiva puede causar cambios en las propiedades del adhesivo debido a los siguientes procesos:

- Plastificación del adhesivo causando la disminución de la resistencia de la unión: a bajas concentraciones, la humedad actúa como un plastificante, ablandando el adhesivo. 
- Cambio de las propiedades del adhesivo debido al efecto del microagrietamiento y la hidrólisis.

- Hinchamiento y generación de tensiones residuales en la unión: cuando una molécula de agua entra en el adhesivo, ocupa parte del volumen libre que existe entre las cadenas orgánicas del polímero que constituye el adhesivo. Para que continúe la entrada de agua en el adhesivo, las moléculas de agua tienen que empujar a las moléculas del polímero, hasta que en un instante dado el volumen del adhesivo empieza a aumentar. Este fenómeno se conoce como hinchamiento. Este hinchamiento del adhesivo genera tensiones internas que pueden desgarrar el interior de la red polimérica del adhesivo.

- Ataque de la intercara adhesivo-sustrato por el desplazamiento del adhesivo: cuando el agua accede a la interfase adhesiva tiende a desplazar el adhesivo curado produciendo tensiones en los enlaces químicos y dando lugar a fenómenos de adsorción. Este desplazamiento es característico en adhesivos donde existen enlaces secundarios de Van der Waals. El desplazamiento del adhesivo es un fenómeno reversible debido a que la superficie del sustrato no cambia irreversiblemente por efecto de la adsorción del agua.

La resistencia de las uniones adhesivas sometidas al efecto de la humedad puede mejorarse previniendo que al agua entre en la unión en cantidad suficiente o mejorando el comportamiento de la propia unión. Existen tres formas de mejorar la durabilidad de las uniones adhesivas:

* Interposición de barreras a la difusión del agua: Para retardar o reducir la difusión de agua en el interior de la unión es conveniente usar un adhesivo con valores de permeabilidad y difusividad bajos. Sin embargo, estas propiedades deben estar en equilibrio con otras propiedades: mojabilidad, fabricabilidad, resistencia mecánica, tenacidad, costes, etc. Por ejemplo, el uso de sellantes (poseen valores muy bajos de permeabilidad) en los bordes exteriores de la unión sirve para reducir la entrada de agua en la unión; pero como el cordón de sellante debe ser bastante grueso para ser efectivo, esto no resulta práctico desde el punto de vista de la fabricabilidad.

Otra forma de reducir la difusión de agua dentro de la unión es modificando la fórmula del adhesivo. Por ejemplo, si un adhesivo epoxi es fuertemente fluorado, el contenido de humedad en equilibrio disminuye y se logra así retardar la degradación de la unión adhesiva.

* Inhibición o retardo de la hidratación: Para retardar la hidratación de la capa de óxido metálica se aplicará sobre las superficies del sustrato una monocapa de inhibidores orgánicos.

- Aplicación de imprimaciones o promotores de adhesión: La imprimación es un agente acoplante, capaz de crear enlaces primarios entre el adhesivo y el sustrato, mejorando así la durabilidad en húmedo. Las imprimaciones se aplican sobre la superficie del sustrato antes de realizar la unión adhesiva.

Las imprimaciones más usadas en las uniones metal-polímero son los organosilanos. Con este tipo de imprimación se logra mejorar la durabilidad en húmedo, a pesar de que el silano posee una naturaleza higroscópica que acelera la entrada de agua en la unión adhesiva. Por este motivo se piensa que el secreto de esta mejora de la durabilidad radica en la estructura y espesor de la capa de polisilano que constituye la imprimación. 
Otros tipos de imprimaciones utilizadas son:

- Organotitanos.

- Organozirconatos.

- Organozircoaluminatos.

- Complejos de cromo.

- Mercaptoésteres multifuncionales.

\section{c) Tensión mecánica:}

La tensión mecánica por si solo no limita la vida en servicio de las uniones adhesivas. Los adhesivos pueden soportar una resistencia y deformación máximas antes de que se produzca la rotura. Si durante la vida en servicio no se superan estos valores máximos, el adhesivo no tiene ningún motivo para sufrir degradación.

Las tensiones cíclicas producen daños en las uniones adhesivas, dando lugar a fallos por fatiga. Esto tipo de fallo produce una degradación térmica del adhesivo, no una degradación por efecto mecánico directo, ya que los polímeros son capaces de transformar la energía mecánica en calorífica aumentado la temperatura.

La generación de tensiones internas es debida a la acción de cargas externas, al efecto de la concentración del adhesivo (durante el curado) o debido a la diferencia entre los coeficientes de dilatación del adhesivo y sustratos.

El efecto de la tensión mecánica sobre la durabilidad de las uniones adhesivas es acelerar la degradación provocada por algún otro agente externo, por ejemplo favorecer el ingreso de humedad en la unión. La temperatura, la humedad y las tensiones mecánicas interactúan para producir el microagrietamiento de la matriz polimérica del adhesivo. Estas microgrietas, aunque pueden parecer pequeñas, actúan como canales que facilitan la penetración de agua, causando el debilitamiento del adhesivo. El microagrietamiento sucede a temperaturas por debajo de la temperatura de transición vítrea y a elevadas actividades del agua. Esta zona puede desplazarse a actividades más bajas si se aumenta la presión. 


\section{TRATAMIENTOS SUPERFICALES DE LOS SUSTRATOS.}

\subsection{Introducción.}

Debido a que la adhesión es un fenómeno superficial y el espesor de la interfase adhesiva tiene que ser del orden de las distancias intermoleculares, cualquier sustancia o capa exterior diferente al sustrato va afectar a la adhesión. Por este motivo, es aconsejable realizar un tratamiento superficial a los sustratos, consiguiendo con ello optimizar la adhesión.

Los objetivos de un tratamiento superficial son los siguientes:

- Eliminación de contaminantes y sustancias capaces de formar capas interfaciales de débil cohesión.

- Desarrollar la fuerza y la durabilidad de las adhesiones aumentando el grado de contacto intermolecular entre el adhesivo y el sustrato.

- Mejorar las propiedades de adhesión de materiales de baja energía superficial.

- Asegurar una adecuada adhesión inmediata y una larga durabilidad de las uniones, logrando que la adhesión sea debida a fuerzas de adhesión intrínsecas y no ha un anclaje únicamente mecánico.

- Proporcionar a los adhesivos una topografía superficial adecuada: creando rugosidad y poros en la superficie que favorezcan el anclaje del adhesivo, e incrementando la superficie de unión.

- Creación de grupos específicos en la superficie del sustrato que favorezcan la adhesión química.

- Facilitar la reproducción de los resultados.

- Sellar la superficie de los sustratos para taponar los grandes poros y evitar de esta forma la perdida de adhesivo en la interfase. También se consigue dar cuerpo a la superficie para que el adhesivo no penetre demasiado rápido.

- Para secar la superficie, removiendo las capas gruesas de agua y cualquier película de líquidos adsorbidos.

Estos objetivos se logran mediante técnicas basadas en:

La eliminación de los contaminantes superficiales, por medio de métodos mecánicos o químicos.

La modificación física o química de la superficie, para lograr rugosidades adecuadas o para modificar la estructura de enlaces de la superficie. 


\subsection{Clasificación de los tratamientos superficiales.}

Los tratamientos superficiales se clasifican en los siguientes métodos:

1. Limpieza con disolventes.

2. Tratamientos abrasivos.

3. Tratamientos químicos.

4. Imprimaciones o promotores de adhesión.

5. Tratamientos de llama.

6. Plasma de baja presión.

7. Descarga en corona.

\section{Limpieza con disolventes:}

Con este tratamiento se elimina la suciedad o contaminación superficial del sustrato sin provocar alteraciones químicas o físicas.

Los disolventes usados deben cumplir los siguientes requisitos:

- Elevado poder disolvente de aceites, grasas, parafinas, etc.

- No ser inflamables ni explosivos.

- No reaccionar con la superficie de los sustratos.

- No atacar el baño o recipiente que los contiene.

- Cumplir con la normativa en vigor y con la seguridad de operación.

Existen tres tipos de tratamientos de limpiezas con disolventes:

$>$ Desengrase en fase de vapor: se pone en contacto la superficie del sustrato con el vapor caliente de un disolvente capaz de solubilizar aceites, grasas, etc. Se obtiene una limpieza superficial de alta calidad, y se conserva el disolvente siempre limpio (ver Figura 13).

Tratamiento en baño de ultrasonidos: consiste en la irradiación de ondas ultrasónicas a través de un disolvente o mezcla de disolventes. Con este tratamiento se logran eliminar partículas inaccesibles, obteniéndose una limpieza superficial de alta calidad (ver Figura 14).

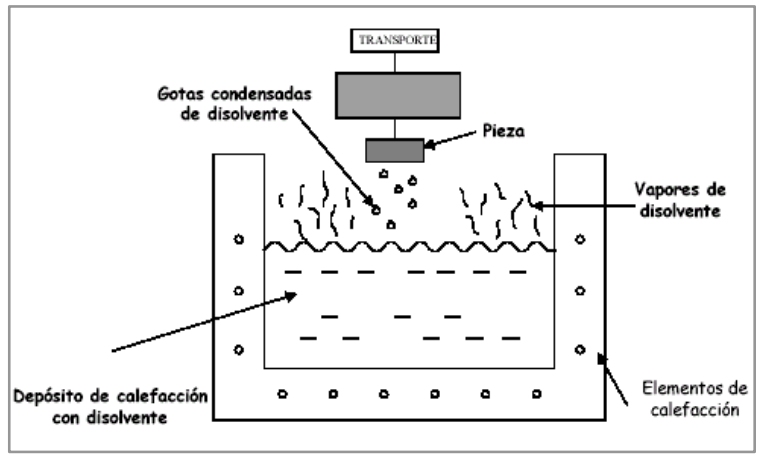

Figura 13. Desengrasado en fase de vapor. 


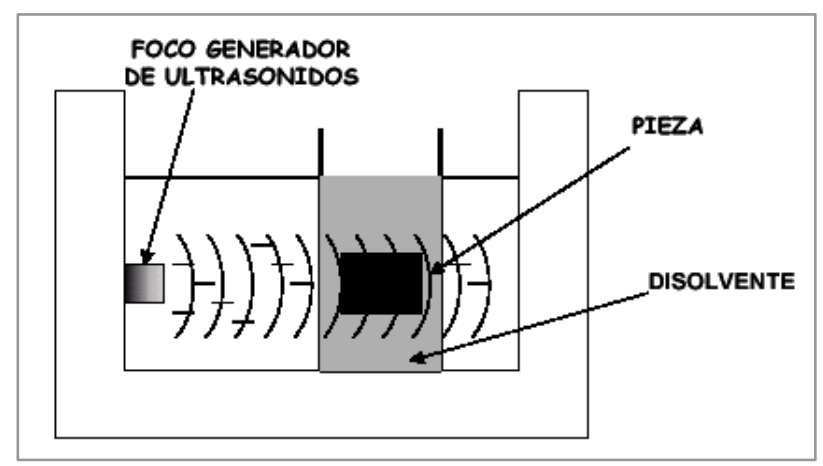

Figura 14. Tratamiento en baño de ultrasonidos.

Frotado, inmersión y spray: aunque son los métodos más sencillos y empleados, son los más difíciles de controlar. El frotado consiste en el paso de un paño, brocha o papel de celulosa empapado con disolvente. La operación se debe repetir varias veces. La inmersión se realiza en baños de disolvente. Con el spray se asegura una aplicación limpia del disolvente.

\section{Tratamientos abrasivos:}

Incluyen procesos como lijados, cardados, chorro de arena, chorro de granalla, etc.

Los tratamientos abrasivos producen los siguientes efectos sobre los sustratos:

- Eliminación de los contaminantes superficiales.

- Creación de una superficie activa.

- Aumento del área de contacto con el adhesivo.

- Retardan la factura mecánica de la unión adhesiva.

Una vez finalizado el tratamiento abrasivo, es necesario realizar una limpieza de los sustratos para eliminar los restos de polvo, contaminantes, etc., y llevar a cabo, lo antes posible, la adhesión para evitar la aparición de corrosión o contaminación.

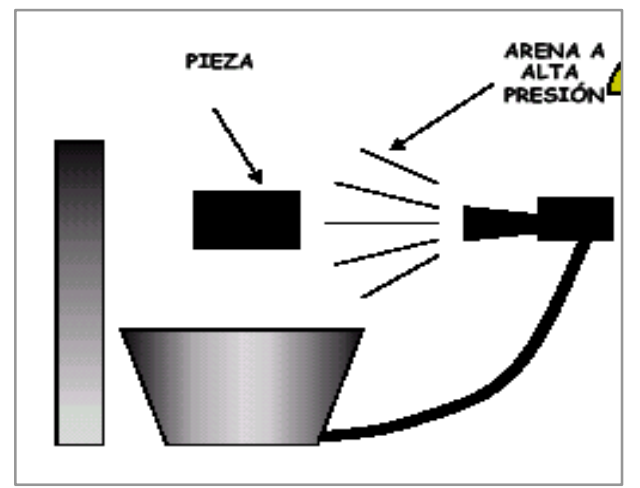

Figura 15. Tratamiento abrasivo mediante chorro de arena. 


\section{Tratamientos químicos:}

Estos tratamientos crean en la superficie del sustrato grupos polares, es decir aumentan la polaridad, y con este aumento se logra una mayor durabilidad de la unión.

Los tratamientos químicos más usados son:

- Ácido crómico: poliolefinas.

- Disoluciones de sodio: plásticos y poliolefinas fluoradas.

- Ciclación (con ácido sulfúrico): cauchos.

- Halogenación: cauchos.

\section{Imprimaciones o promotores de adhesión:}

Las imprimaciones son sustancias intermedias entre el adhesivo y el sustrato, y producen los siguientes efectos:

- Protección de la superficie del sustrato.

- Incrementan la mojabilidad de los adhesivos muy viscosos.

- Permiten la adhesión de sustratos difíciles de unir.

- Crean una capa de mayor energía superficial.

- Aumentan la vida en servicio de la unión adhesiva.

- Mejoran la adhesión de los adhesivos.

- Mejoran las propiedades cohesivas de los sustratos.

- Reducen la penetración de la humedad.

- Eliminan la rugosidad superficial.

- Protegen la interfase adhesiva de la radiación UV.

\section{Tratamientos de llama:}

Con este tipo de tratamiento se logra una oxidación superficial por medio de una reacción que se inicia por radicales libres creados a alta temperatura, $2000^{\circ} \mathrm{C}$. Los mejores resultados se obtienen con un exceso de oxígeno en la mezcla de combustión.

Este proceso se emplea fundamentalmente en la adhesión de poliolefinas.

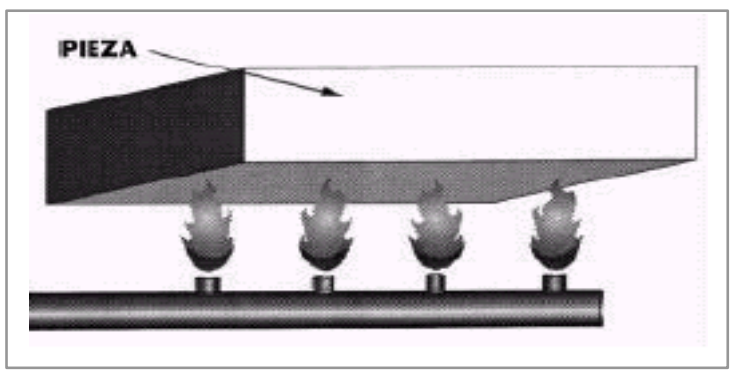

Figura 16. Tratamiento con llama. 


\section{Plasma de baja presión:}

El plasma puede ser generado en el aire (descarga corona) o a presión reducida (glow discharge). Se puede emplear un gas (aire, argón, nitrógeno, oxígeno, etc.) o un polímero, en este último caso el proceso se denomina grafting. Si se emplea como plasma un gas, este estará excitado y constituido por iones, átomos, moléculas, radicales libres, electrones y especies metaestables. En la Figura 17 se muestra un esquema del tratamiento con plasma de baja presión:

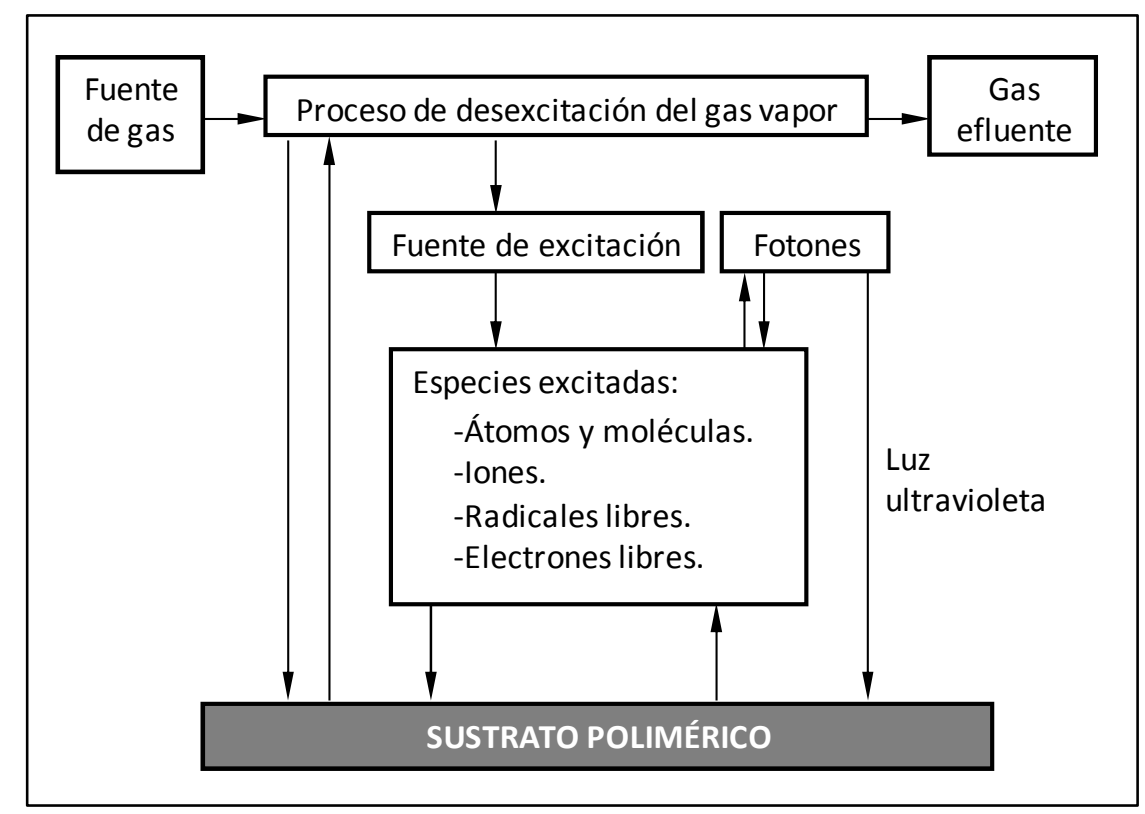

Figura 17. Esquema del tratamiento con plasma de baja presión.

El tratamiento basado en plasma de baja presión produce los siguientes efectos sobre los sustratos:

- Limpieza superficial.

- Degradación de las zonas superficiales.

- Reticulación o entrecruzamineto de los polímeros en la superficie.

- Oxidación superficial.

- Polimerización en la superficie del sustrato.

- Implantación iónica. 


\section{Descarga corona:}

Este tratamiento consiste en hacer pasar una película de polímero sobre un electrodo metálico recubierto de un material dieléctrico al que se le hace llegar un alto voltaje procedente de un generador de alta frecuencia. El voltaje se incrementa en ciclos hasta que se ioniza el gas, generándose de esta forma un plasma a presión atmosférica, lo que se conoce como descarga corona.

Es un tratamiento muy efectivo para las poliolefinas.

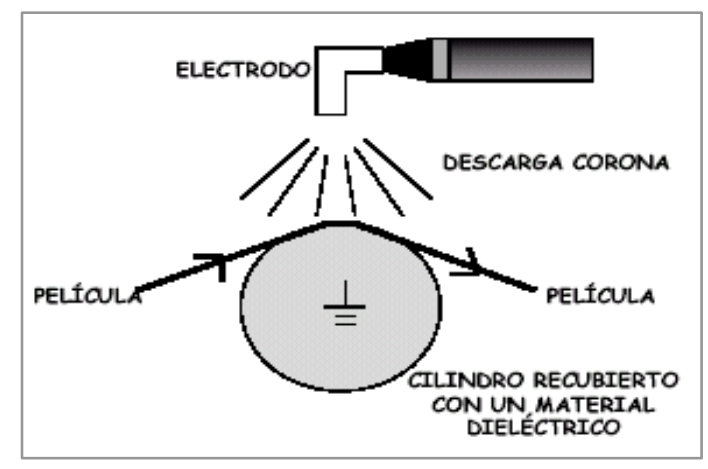

Figura 18. Tratamiento con descarga corona.

\subsection{Preparación superficial de materiales metálicos.}

En la realización de uniones adhesivas con materiales metálicos se deben tener en cuenta las siguientes características particulares de los metales:

- Alta energía superficial.

- Presentan capas de débil cohesión: recubrimientos superficiales, adsorción de humedad y contaminantes atmosféricos, capas superficiales de óxido.

- La adhesión, aunque inicialmente es adecuada, disminuye con el tiempo debido a formación de capas superficiales de óxido. Como consecuencia, serán necesarios tratamientos superficiales que mejoren la durabilidad frente agentes externos.

La preparación superficial en los metales significa:

- La eliminación de las capas superficiales débiles que son químicamente incompatibles con los adhesivos.

- La formación artificial de capas estables que sean mecánica y químicamente compatibles con los adhesivos.

Los tratamientos superficiales más empleados en los metales son los siguientes: 


\section{Limpieza superficial:}

Como se ha mencionado anteriormente, la limpieza superficial (limpieza con disolventes) consiste en la eliminación de la suciedad o contaminación superficial del sustrato o adherente.

La mayoría de los metales sufren un proceso de mecanizado en el cual se emplean grasas o lubricantes como protección ante la corrosión. Debido a esto, las superficies metálicas presentaran una capa de grasa. La forma de realizar el desengrase dependerá del tamaño de la pieza, de esta forma se podrá realizar limpieza en spray, en inmersión, en ultrasonidos, en fase de vapor, etc.

\section{Tratamientos abrasivos:}

Dentro de los tratamientos con abrasivos se recogen todos aquellos procesos que consisten en pasar un medio abrasivo sobre la superficie a limpiar. Los más utilizados son el chorreado abrasivo por impacto de arena, alúmina o granalla a presión.

La geometría, tamaño y naturaleza del medio abrasivo influyen en el perfil de la superficie del sustrato, consiguiendo un aumento en el área superficial, y como consecuencia un mayor contacto interfacial.

Se cree que la abrasión mecánica mejora el mojado del sustrato, es decir, favorece que el adhesivo se extienda y cubra con facilidad la superficie del sustrato.

Un aspecto importante en estos tipos de tratamientos es la limpieza del medio abrasivo. Por ejemplo, si se utiliza un cepillo para limpiar la grasa superficial del sustrato, y posteriormente se usa para aplicar el tratamiento abrasivo, se deberá limpiar el cepillo antes de comenzar para evitar transferir de nuevo la grasa a la superficie.

\section{Tratamientos químicos:}

Con ellos se logra alargar la vida en servicio de las uniones adhesivas, pero tiene limitaciones: requieren un cuidadoso control debido a la generación de residuos y la posibilidad de modificar las propiedades intrínsecas del metal.

\section{Tratamiento con plasma:}

Este tratamiento produce un cambio en la textura superficial de los sustratos. Los efectos de este proceso en los materiales metálicos son los que se enumeran a continuación:

- Se eliminan de la superficie las sustancias de pequeño peso molecular.

- Se mejora la durabilidad de la unión adhesiva, debido a la polimerización que se consigue en la superficie.

- Se implantan átomos en el sustrato para facilitar la creación de enlaces primarios. 


\section{Imprimaciones o promotores de adhesión:}

El primer o la imprimación es un agente acoplante que establece enlaces químicos primarios entre el adhesivo y el sustrato. Se aplica en la superficie del sustrato antes de realizar la unión adhesiva.

Los efectos principales que se logran son mejorar la durabilidad frente a la humedad, aumentar la mojabilidad de los adhesivos que poseen una alta viscosidad, proteger al sustrato de los procesos corrosivos y producir una unión de elevada resistencia.

\subsection{Tratamientos convencionales.}

A continuación se enumeran los tratamientos más empleados dependiendo del sustrato elegido para realizar la unión adhesiva:

* MATERIALES DE BAJA ENERGÍA SUPERFICIAL:

- Polímeros fluorados (PTFE): tratamiento electroquímico.

- Poliolefinas (PE, PP): limpieza con disolventes, tratamiento con llama o tratamiento químico.

- PET, PVC, nylon: limpieza con disolventes, abrasión mecánica, tratamiento químico o plasma de baja presión.

\section{* CAUCHOS:}

- SBR, SBS: abrasión mecánica más tratamiento químico.

* MATERIALES DE ALTA ENERGÍA SUPERFICIAL:

- Metales, óxidos metálicos, materiales cerámicos: limpieza con disolventes, abrasión mecánica (chorro de arena), tratamientos químicos, primers o tratamiento con plasma. 


\section{ENSAYOS PARA LA EVALUACIÓN DE LAS UNIONES ADHESIVAS.}

\subsection{Ensayos.}

La evaluación de las propiedades de los adhesivos ayuda a predecir el comportamiento de la unión adhesiva.

La evaluación de los adhesivos requiere especializados métodos de pruebas. Cuando se prueba un adhesivo se evalúa tanto el material adhesivo como la técnica de adhesión, es decir, la preparación de la superficie del sustrato sobre el que se va aplicar el adhesivo, la aplicación del adhesivo y el curado del adhesivo.

La exactitud y reproductibilidad de los resultados de las pruebas dependerá de las condiciones sobre las cuales se lleva a cabo el proceso de adhesión. Antes de iniciar la evaluación, se debe disponer de la siguiente información:

- Procedimiento para preparar la superficie de los sustratos antes de aplicar el adhesivo, incluyendo el contenido de humedad, el limpiado y secado de las superficies, y los tratamientos especiales.

- Indicaciones del mezclado del adhesivo.

- Condiciones para la aplicación del adhesivo, incluyendo la velocidad del extendido, espesor de la película de adhesivo, número de recubrimientos que se deben aplicar y si es necesario aplicarlos en una o en las dos superficies de los sustratos, y condiciones del secado donde se necesitan más de un recubrimiento.

- Condiciones de ensamblado antes de la aplicación de la presión, temperatura ambiental y porcentaje de humedad relativa.

- Condiciones de curado, cantidad de presión aplicado durante dicho proceso, tiempo que debe estar con la presión, y temperatura a la que está durante la aplicación de presión. Se debe saber si esta temperatura es en la línea de unión o en la atmósfera donde se debe realizar el ensamble.

- Procedimiento de acondicionamiento antes de la prueba, a menos que se especifique un procedimiento estándar, incluyendo el periodo de tiempo, temperatura y humedad relativa.

Una vez realizada la unión adhesiva, su inspección consiste en comprobar las dimensiones del producto y si las piezas están unidas. A partir de este punto se requieren otras técnicas de evaluación o inspección:

- Técnicas de evaluación no destructivas.

- Técnicas de evaluación destructivas. 


\subsection{Ensayos no destructivos.}

Las técnicas de evaluación no destructivas consisten en detectar los defectos de la unión, determinar las propiedades del adhesivo y asegurar el rendimiento de unión adhesiva.

Estos métodos de evaluación no destructiva se emplean únicamente para detectar defectos debido a las limitaciones que presentan:

- No determinan resistencias reales.

- No detectan fallos adhesivos, es decir, en la intercara adhesivo-sustrato.

En las estructuras adhesivas pueden aparecer una gran variedad de grietas o discontinuidades. En uniones metal-metal, los defectos típicos son huecos o despegues.

Los defectos en la intercara son debidos a errores cometidos durante la preparación superficial de los sustratos, y estos tipos de defectos no se pueden detectar con ensayos no destructivos.

Los defectos del adhesivo curado pueden ser los siguientes:

- Adhesivo escasamente curado o adhesivo excesivamente curado.

- Un espesor de adhesivo en exceso por falta de presión durante el ensamblado o por falta de coincidencia entre los sustratos. Como resultado aparecen poros o huecos.

- Adhesivo poroso producido por un curado excesivamente rápido.

- Pérdida de la ductilidad a largo plazo por la presencia de una elevada humedad en el adhesivo antes del proceso de curado.

Los métodos de ensayos no destructivos que se aplican en la inspección de uniones adhesivas son los siguientes:

* Inspección visual: Con la inspección visual se pueden evaluar los materiales, los recubrimientos o el proceso de curado (presión, temperatura, tiempo, etc.). Esta técnica permite revelar defectos como fracturas en los sustratos o en el adhesivo, despegues, delaminaciones, impactos, inclusiones de elementos extraños, aparición de burbujas, o cualquier otro defecto mecánico.

* Inspección mediante ultrasonidos: Es el método más sencillo, fiable y empleado para uniones adhesivas. Se usan ultrasonidos entre 2.25 y $10 \mathrm{MH}$. Existen diferentes técnicas:

- Eco de un pulso de contacto: se emplea el mismo transductor para emitir y detectar la reflexión del pulso de ultrasonidos.

- Transmisión por contacto: el detector del pulso se coloca en el lado opuesto del emisor del pulso.

- Método de inmersión: el ensamblaje se sumerge en un tanque de agua. El pulso se detecta por reflexión, por transmisión o usando una placa reflectora. 
La mayor limitación de esta inspección es la aparición de interferencias debidas al espesor del adhesivo o de los sustratos. Estas interferencias pueden inducir a la errónea interpretación creyendo que existen defectos donde no los hay.

* Radiografía de rayos-X: Permiten realizar inspecciones en un solo barrido, pero resulta un método muy caro. Puede detectar discontinuidades, variaciones de densidad y variaciones de absorción de rayos-X en los materiales. Este método se emplea en la inspección de adhesivos opacos a los rayos-X, porque permiten una rápida detección de los huecos y porosidades.

- Radiografía de neutrones: Posee ciertas similitudes con el método anterior, pero presenta la ventaja de no ser tan sensible a las variaciones de densidad o de espesor de los materiales. Con este método se detectan los huecos o porosidades que pueda presentar el adhesivo, ya que los hidrógenos que posee el polímero que constituye el adhesivo absorben los neutrotes y lo hacen opaco.

* Test de la moneda: Es el método más simple. Consiste en golpear la estructura de la unión adhesiva con una moneda y comprobar los cambios en el tono del sonido producido, normalmente relacionados con despegues grandes. No se puede detectar con este tipo de inspección los defectos internos, es decir, aquellos que aparecen en las uniones adhesivas internas (caso de multicapas).

* Emisión acústica: Este método resulta más ventajoso que las inspecciones con ultrasonidos o rayos-X cuando se quiere detectar corrosión interna en los metales y adhesivo degradado por la humedad. El principio de este método es la detección de ondas acústicas o mecánicas en los materiales. Cuando se emplea esta inspección en la detección de corrosión en a línea de unión, se debe comprobar que no existe agua en esa zona.

\subsection{Ensayos destructivos.}

Existen los siguientes tipos de ensayos destructivos:

* Ensayos de pelado:

Con estos ensayos se mide la resistencia al pelado de un adhesivo, es decir, se obtiene una medida de la resistencia a la propagación de la rotura a lo largo de la capa de adhesivo.

Cuando dos materiales unidos se apalancan desde uno de los extremos de la capa de adhesivo o se aplica una fuerza normal a dicha capa en un extremo, se produce una concentración de esfuerzos en la capa de adhesivo en dicho extremo (ver Figura 19).

Si la unión se realiza por puntos (mediante remaches, por ejemplo), existe una gran carga de tracción en el primer remache. Mientras que en una unión adhesiva, como la unión es continua, existe una severa concentración de esfuerzos en el extremo de la línea de unión. En el extremo contrario de la unión adhesiva, el esfuerzo de tracción no aumenta a pesar de la deformación que sufren los materiales unidos.

El ensayo de pelado más simple es el ensayo de pelado en T (MIL-A-005090E y ASTM D1876-61T). Este ensayo consiste en estirar a una velocidad específica los dos extremos de la unión adhesiva. La carga de pelado se registra automáticamente en función del recorrido del cabezal de la máquina, siendo este recorrido dos veces la longitud de pelado. 
La resistencia al pelado es el valor medio registrado, despreciando los dos máximos de cargas que aparecen en la gráfica, uno correspondiente al inicio del ensayo y otro al final (ver Figura 20). Las dimensiones de las chapas a ensayar especificadas en las normas se detallan en la Figura 21.

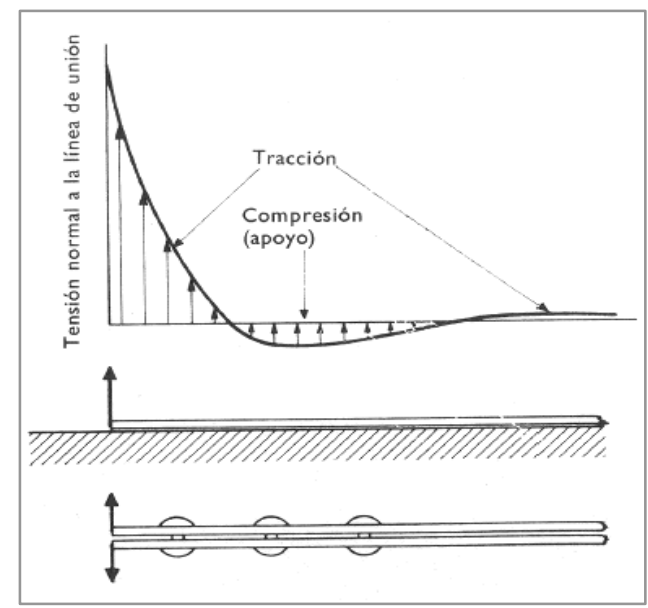

Figura 19. Representación de las tensiones de pelado.

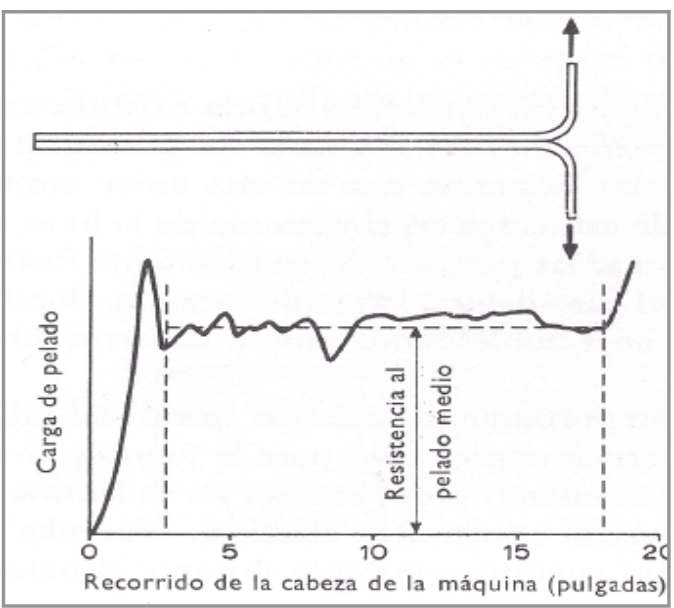

Figura 20. Registro de un ensayo de pelado en $T$.

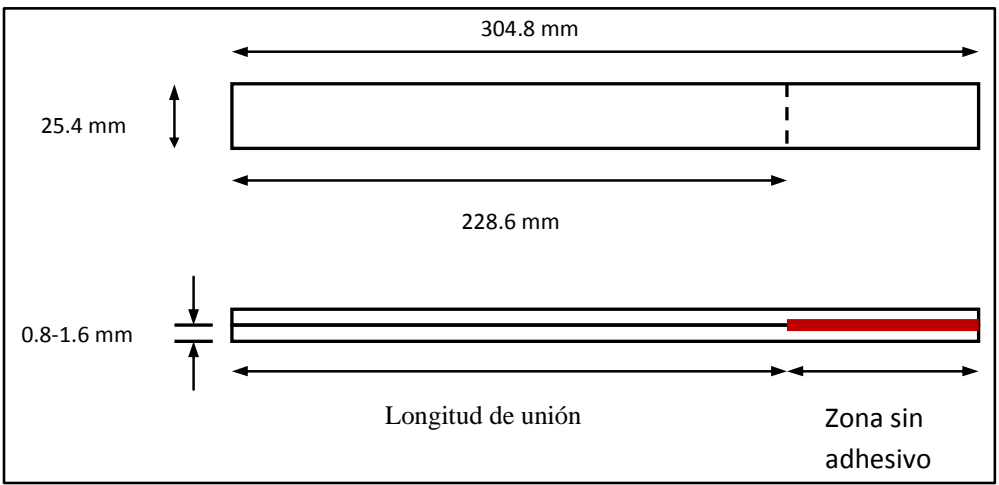

Figura 21. Dimensiones chapas de ensayo. 
Otro tipo de ensayo de pelado es el llamado ensayo el pelado con tambor ascendente. En este ensayo el esfuerzo necesario para producir el pelado se debe al momento resultante de la fuerza tangencial aplicada por la diferencia de los radios del tambor y sus llantas. Cuando se determina la resistencia al pelado, se debe reducir el peso del tambor y no considerar el valor máximo que se obtiene al inicio del ensayo.

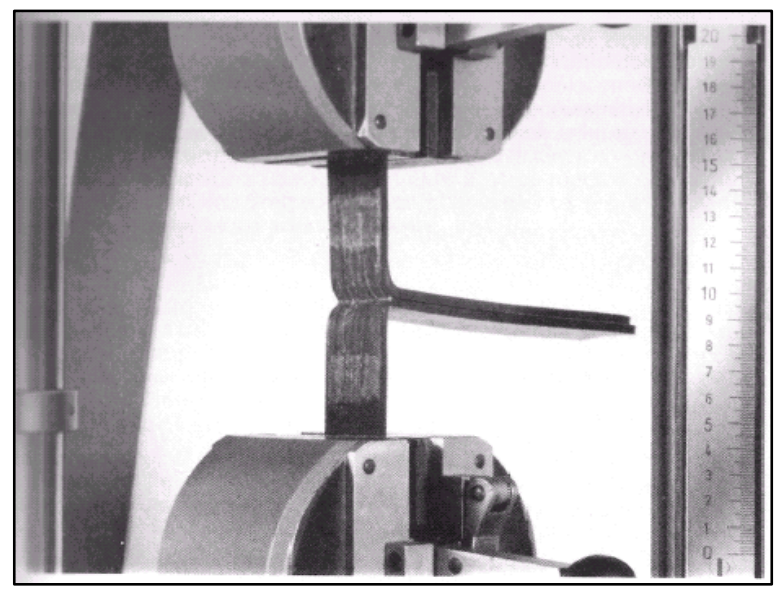

Figura 22. Ensayo de pelado con tambor ascendente.

\section{* Ensayo de pelado por flexión:}

En esto tipo de ensayo la carga se aplica sobre tres puntos de la junta adhesiva. El valor de la carga aplicada debe ser mayor de $59 \mathrm{kp}$.

Aunque la rotura que se produce en este tipo de ensayo implica una tendencia al pelado, este ensayo no distingue entre los adhesivos quebradizos y aquellos que tienen una resistencia moderada de pelado.

Un parámetro que influye de manera significativa sobre la resistencia a la flexión es la presión a la que se somete la unión adhesiva durante el proceso de curado del adhesivo. Por lo tanto, es necesario controlar el grado en que el adhesivo es exprimido cuando se presionan los extremos del solape en este tipo de ensayos.

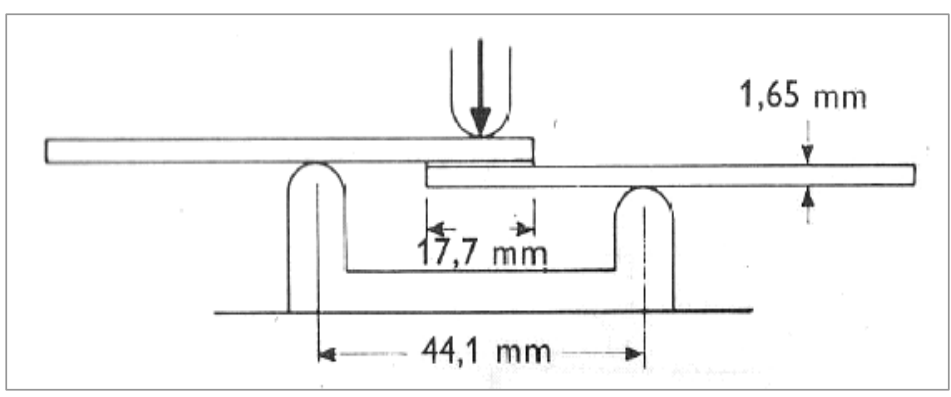

Figura 23. Ensayo de pelado MIL-A-50 90B. 


\section{* Ensayo de escisión o desgarro:}

En el ensayo de escisión se somete una probeta pegada a una flexión pura mediante una carga de cuatro puntos. La probeta puede ser de redondo o de barra cuadrangular. La resistencia a la escisión es la fuerza máxima que soporta la probeta.

Para conseguir una flexión pura y evitar esfuerzos cortantes, se debe alinear con exactitud el soporte de la carga. Si se hace esto, ya no es imprescindible la localización exacta de la probeta.

$\mathrm{Al}$ realizar este ensayo es conveniente retirar el adhesivo que rebosa de la unión.

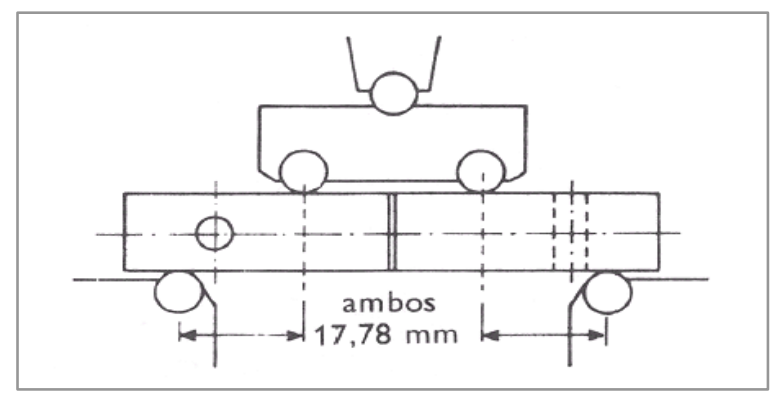

Figura 24. Ensayo de escisión.

Otro ensayo de escisión alternativo es el ensayo para ASTM D 1062-51. Este ensayo emplea bloques especiales que permiten la aplicación de una carga de tracción perpendicular a la línea de unión en uno de sus bordes. Como consecuencia, la unión está sometida a tracción y a flexión en el extremo donde aplicamos la carga, y en el extremo donde no ha actuado el esfuerzo de desgarro existe una concentración de esfuerzos por compresión.

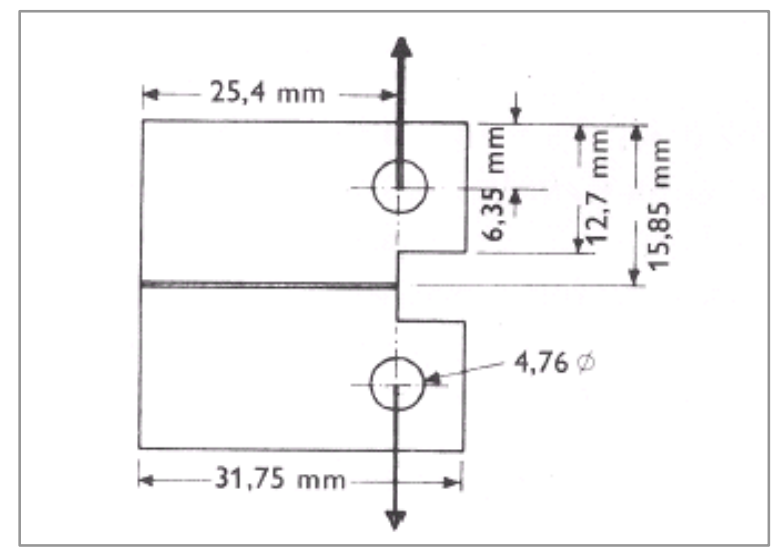

Figura 25. Probeta de ensayo: área encolada 6,45 $\mathrm{cm} 2$, anchura de la probeta 25,4 $\mathrm{mm}$. 
* Ensayo de choque o impacto:

Este ensayo de choque es poco aceptado debido a que las medidas de absorción de energía son bastante pequeñas. Por esta razón, es considerado como un método cuantitativo para distinguir entre adhesivos tenaces y frágiles.

El ensayo ASTM D 950-54, emplea una máquina y probeta normalizadas, pero la energía absorbida es con frecuencia pequeña comparada con la capacidad de la máquina.

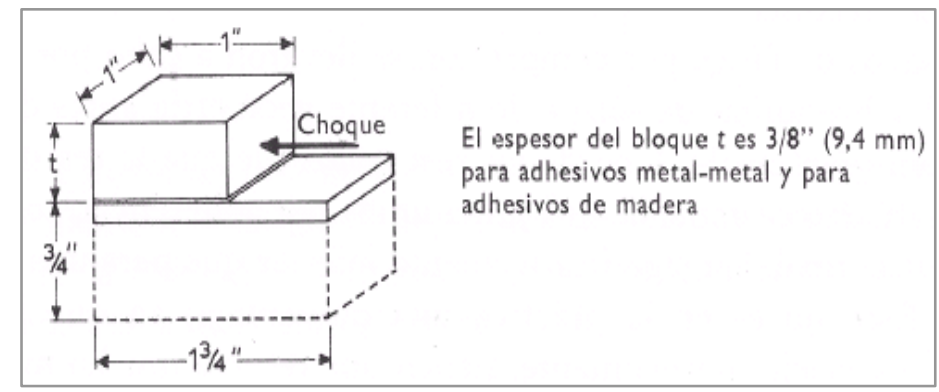

Figura 26. Ensayo de choque según ASTM D 950-54, introducida en la mordaza base.

También se podría utilizar una máquina de choque de péndulo, empleando una oscilación reducida. El inconveniente que presenta es la posibilidad de aplicar un impacto insuficiente para provocar la ruptura de la unión, como consecuencia la muestra se deterioraría y no podría utilizarse de nuevo.

\section{* Ensayo de fatiga:}

El ensayo de fatiga que más se emplea en las uniones adhesivas consiste en someter la junta por solape a una tensión oscilante. Se aplicará una carga de compresión repetida sobre la junta por solape provocando el fallo por fatiga en el metal. Los resultados que se obtiene en los ensayos de fatiga únicamente son comparativos.

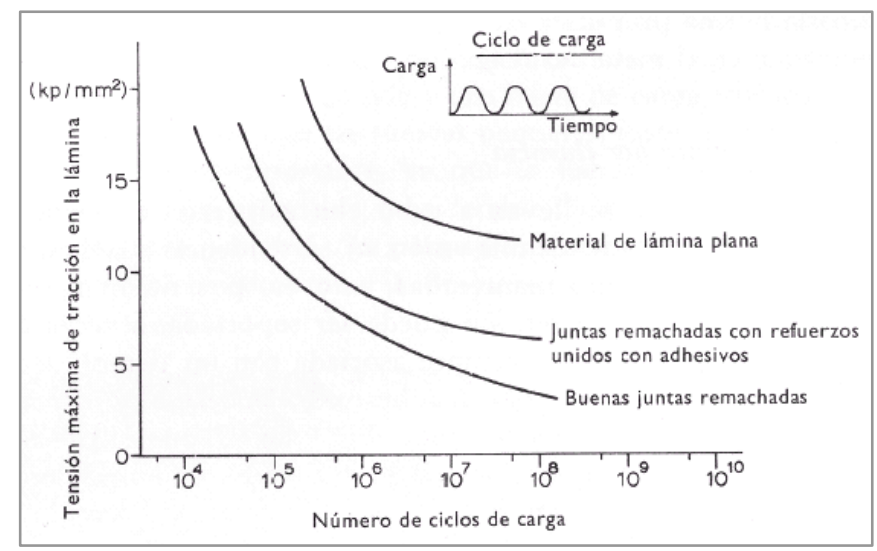

Figura 27. Resultados de ensayos de fatiga entre juntas remachadas planas y juntas remachadas con refuerzos unidos con adhesiva. 
La probeta que se utiliza en estos ensayos tiene $1,6 \mathrm{~mm}$ de espesor y $25 \mathrm{~mm}$ de ancho, con una longitud de solapa de $9,4 \mathrm{~mm}$. La longitud de solape es menor que en otros ensayos porque en los ensayos de fatiga la tensión del adhesivo debe ser menor que la del metal. De lo contrario se provocaría la ruptura del metal (fallo del sustrato) no del adhesivo.

En los ensayos de fatiga para materiales no metálicos se observa una dependencia de la resistencia de fatiga con la velocidad de carga. En las uniones metálicas con adhesivo no se observa esta dependencia de la resistencia con la velocidad de carga.

\section{* Ensayo de rotura por fluencia:}

Los ensayos de rotura por fluencia se realizan con esfuerzos constantes para determinar las siguientes propiedades de la unión:

- La tendencia a la deformación permanente bajo tensiones mantenidas, es decir, por fluencia.

- Tiempo durante el cual una tensión puede ser soportada (denominada resistencia a la fluencia).

Como norma general los ensayos de rotura por fluencia son importantes en el estudio de uniones adhesivas. Solo algunas uniones con adhesivos termoestables no presentan deformación por fluencia apreciable, sino que fallan de repente bajo la acción de una carga mantenida.

Las condiciones para ensayar uniones adhesivas a la rotura por fluencia por su propio peso están normalizadas en ASTM D 1780-62. En esta norma se incluyen dos métodos:

a.) Método D 2293-64T, ensayo de fluencia mediante cargas de compresión de una junta de solape: las dimensiones de la probeta son $12,7 \mathrm{~mm}$ de longitud de solape, espesor de los sustratos de 1,6 mm, y la longitud fuera de solape de los sustratos de $6,3 \mathrm{~mm}$. Esta junta se monta entre una arandela y un manguito en un tornillo grande ranurado y con un muelle cargado a compresión. Debido a que esta disposición es tan compacta, el aparato se puede colocar fácilmente en una caja fría o en una estufa para poder realizar el ensayo a distintas temperaturas, siempre que la carga se realice a la temperatura del ensayo.

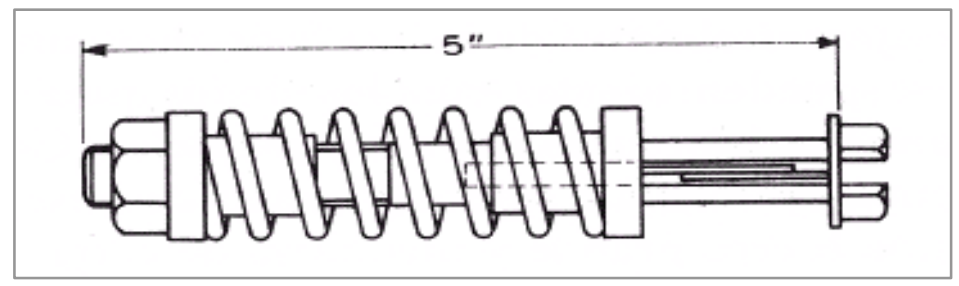

Figura 28. Método D 2293-64T. 
b.) Método D 2294-64T, ensayo de fluencia mediante carga de tracción de una junta de solape: en la máquina de tracción se usa un tirante de carga para comprimir el muelle. Es imprescindible que la probeta y el aparato de ensayo se encuentren a la temperatura del ensayo cuando se carga.

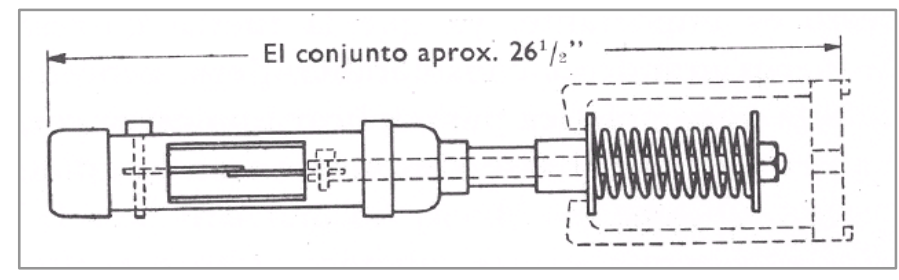

Figura 29. Método D 2294-64T.

\section{* Ensayo de tracción:}

Los ensayos de tracción se realizan con esfuerzos perpendiculares al plano de la junta adhesiva. Se define resistencia a la tracción como la máxima carga por unidad de área necesaria para romper la unión.

Estos ensayos se aplican para determinar los siguientes datos:

- Calidad del adhesivo.

- Resistencia.

- Tensiones de deformación.

Uno de los métodos empleados en este tipo de ensayo es el método ASTM D 897-49, ensayo de tracción para juntas de metal. Es conveniente utilizar probetas cortas, tipo cápsula. Estas probetas tienen un saliente anular que favorece la sujeción en las mordazas con forma de "U" de la máquina de ensayo. El otro extremo de la probeta es la superficie de unión donde se aplicará adhesivo para formar la unión con la otra media probeta similar a esta.
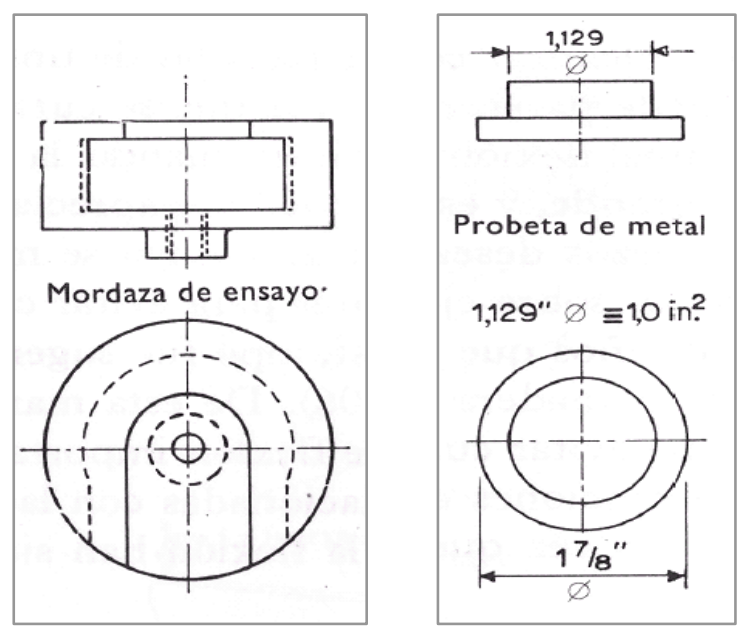

Figura 30. Ensayo de tracción con probeta tipo cápsula (ASTM D 897-49). 
Pero este método plantea problemas de excentricidad de la carga produciendo sobre la junta esfuerzos de tracción no uniformes. Estos problemas de excentricidad son debidos a las amplias tolerancias de las mordazas y a la ausencia de autoalineamiento.

Para superar estas dificultades se desarrolló el método ASTM D 1344-57, ensayo de tracción con solape en cruz. Este método evita las cargas excéntricas por medio del giro de las mordazas sobre ejes perpendiculares. El método se diseñó, en principio, para ensayar uniones de madera, pero su aplicación se ha ampliado a materiales tales como vidrio, metales, compuestos, etc.

El inconveniente que presenta este método de ensayo es que si se emplean grandes relaciones de espesor/longitud puede existir flexión bajo carga, lo que puede provocar variaciones apreciables en el estado uniforme de los esfuerzos deseados.

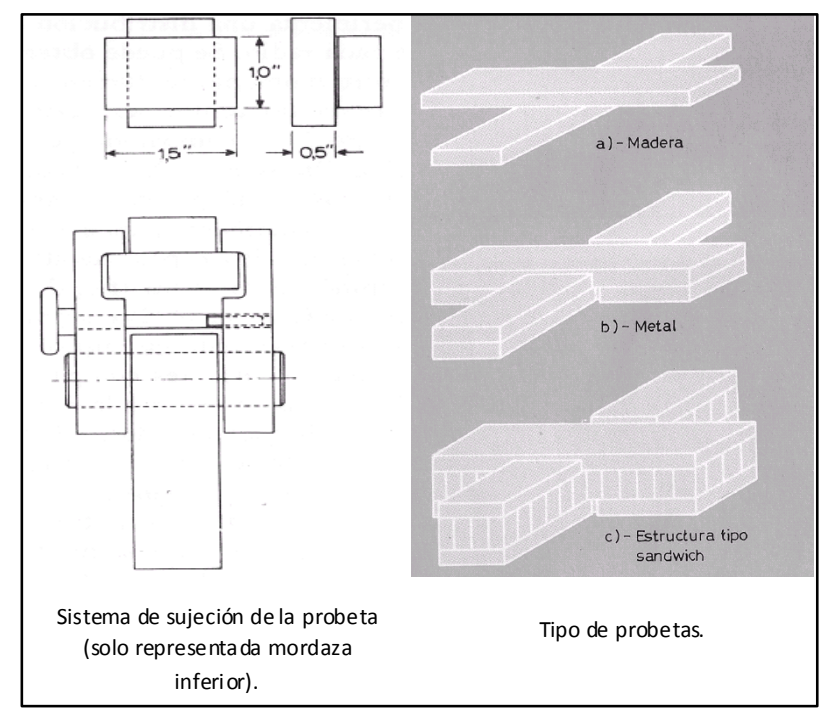

Figura 31. Ensayo de tracción con solape cruzado.

Otro método utilizado en el ensayo de tracción es el que emplea probetas unidas con adhesivos rígidos. Este método, ASTM D 2095-62T, adopta un sistema centrado en el que la carga es completamente axial.

En este ensayo se rectifican barras cortas de 37,5 mm (1,5”) de longitud, y de sección transversal rectangular o redonda. Cada probeta presenta un taladro normal al eje, y cuando se ensamblan en el posicionador, para llevar a cabo el proceso de curado, estos taladros se deben situar de tal manera que formen un ángulo recto entre ellos. La junta podrá girar sobre dos ejes perpendiculares, de este modo se evitan las excentricidades de la carga. 


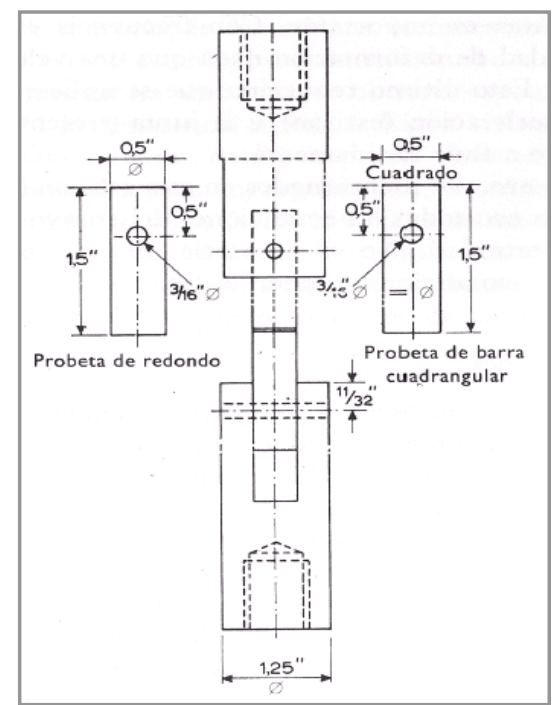

Figura 32. Mordazas y probetas para el ensayo de tracción (método ASTM D 2095-62T) con sistema centrado y carga axial.

\section{* Ensayo de esfuerzo cortante:}

Estos ensayos son frecuentemente empleados debido a su fácil montaje y además porque son muy económicos.

Los esfuerzos cortantes o tensiones de cizallamiento son el resultado de la acción de esfuerzos en un plano paralelo al plano de la unión adhesiva.

El ensayo más común y sencillo es el que utiliza juntas por superposición simple. Se emplean probetas rectangulares de metal con un espesor de $1,6 \mathrm{~mm}$, y una longitud de superposición de $12,7 \mathrm{~mm}$.

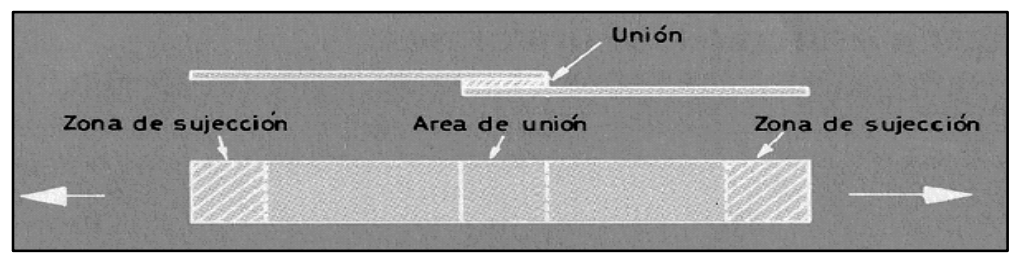

Figura 33. Juntas por superposición simple.

En este ensayo es difícil conseguir una tensión de cizallamiento pura, pero como en las condiciones reales de trabajo de la junta esta tampoco se va a producir, esta limitación no presenta inconveniente. Sin embargo, si es importante evitar el deslizamiento de las mordazas de sujeción durante el ensayo y cumplir con las cotas de sujeción especificadas. Un deslizamiento de las mordazas del orden de la mitad del espesor de la capa de adhesivo, produce importantes variaciones en el valor de la resistencia obtenida en el ensayo. 
Si se representa la distribución de las tensiones en una gráfica, se obtiene una curva parabólica, donde los valores más altos tienen lugar en los extremos de la unión adhesiva. Conforme se avanza hacia el centro de la unión, los valores de la tensión decrecen, esto indica que el adhesivo en esta zona central tiene muy poca influencia sobre la resistencia total.

Mediante estos ensayos se ha comprobado que la resistencia de unión es proporcional al ancho de la probeta. Sin embargo, si se aumenta la longitud de la superposición, la resistencia disminuye debido a la concentración de tensiones que se produce en los extremos de la junta.

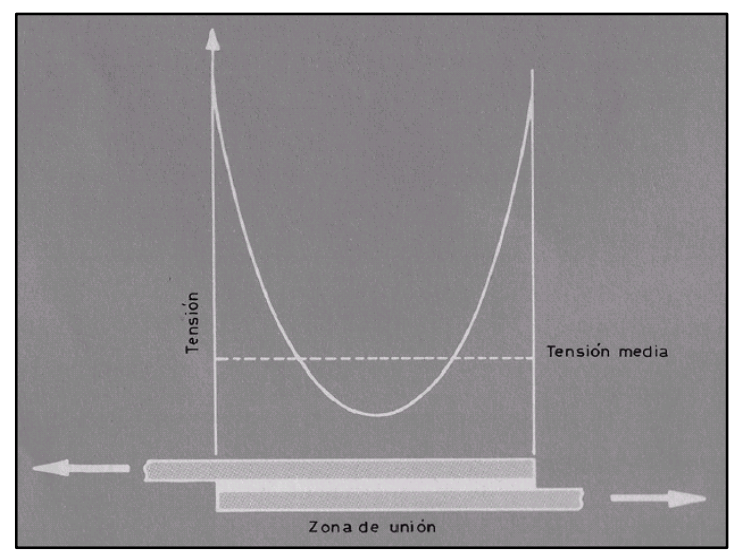

Figura 34. Representación de la distribución de tensiones en un ensayo de esfuerzos cortantes.

Para eliminar las tensiones de pelado y flexión que aparecen durante el ensayo en la junta simple, se emplean juntas de paneles grandes o de láminas delgadas unidas de forma que todo el conjunto quede superpuesto, y al que se le practica una ranura a cada lado de la unión adhesiva.

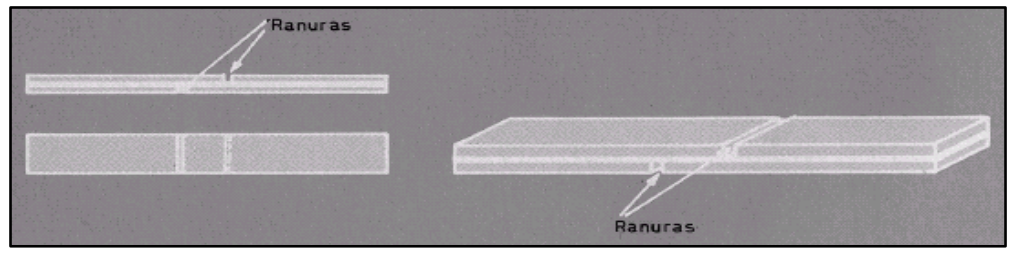

Figura 35. Superposición de juntas de paneles o de láminas delgadas.

Un ensayo recientemente normalizado es el ensayo a cizalla de disco, ASTM D 21-82-63T. Este ensayo consiste en un disco metálico de $625 \mathrm{~mm}^{2}$ de superficie adherido a una probeta rectangular. Dicha unión es insertada en una herramienta de cizallamiento que soporta el disco en su periferia. El sustrato rectangular se fuerza hacia abajo por compresión a través de una ranura en la herramienta, con lo que el área de unión se somete a esfuerzo cortante (ver Figura 36 ). 


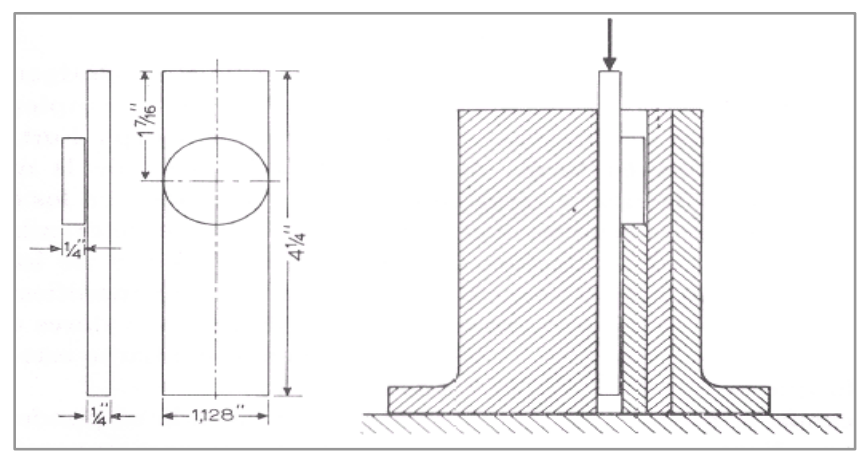

Figura 36. Ensayo a esfuerzos cortantes sobre disco.

* Ensayo de cizalla en juntas por solape:

Este ensayo, ASTM D 1002-64, utiliza juntas de metal de $25 \mathrm{~mm}$ de ancho y 1,6 mm de espesor. La longitud de solape máxima se calcula a partir de la relación entre el esfuerzo cortante medio del adhesivo estimado para su rotura y el límite de proporcionalidad del metal.

Es imprescindible que las mordazas estén correctamente alineadas, ya que una desalineación de aproximadamente la mitad del espesor del sustrato puede provocar diferencias significativas en la resistencia de la unión.

En este tipo de ensayo, se recomienda el empleo de juntas de doble solape, de esta manera se evita la flexión de los sustratos y las cargas de rotura asociadas. Aunque estas juntas de doble solape se diseñan para eliminar las tensiones de pelado y por ello debería tener un amplio uso, en la práctica se prefiere el empleo de las juntas de solape simple debido a la simplicidad de su preparación.

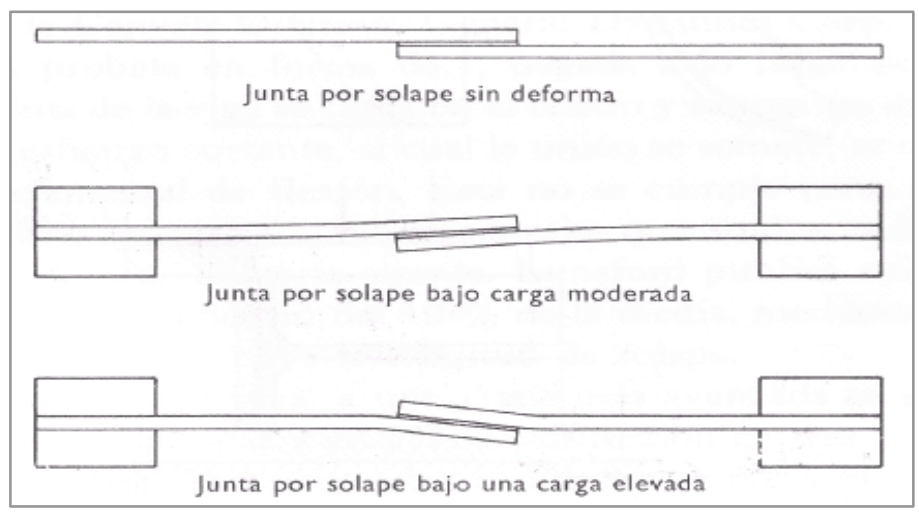

Figura 37. Deformación de los sustratos de una junta por solape fuera de la región solapada. 


\section{MATERIALES EMPLEADOS.}

\subsection{Adhesivos: descripción técnica del producto.}

Los adhesivos analizados en este proyecto son los que se describen a continuación:

\section{Loctite Hysol 9464 A \& B:}

Es un adhesivo epoxi bicomponente tenaz en forma de resina más endurecedor. La resina contiene componentes epoxidícos, y su textura es pastosa de color blanco. El endurecedor posee una composición en base a amina: isoforonadiamina, $\mathrm{N}$-aminoetilpiperacina, fenol y piperacina. Se trata de una pasta de color negro.

Las características de este producto son las siguientes:

- Permite la adhesión de sustratos distintos entre sí.

- Rápida resistencia a manipulación rápida.

- Buena resistencia a pelado.

- Buena resistencia a cizalla-tracción.

- Alta conductividad térmica.

- Fácilmente mezclable.

- Curado acelerado por calor.

- Tiempo de manipulación del adhesivo mezclado es de 15-20 minutos a temperatura ambiente. Temperaturas más elevadas y cantidades más grandes acortan ese tiempo de manipulación.

El adhesivo Loctite Hysol 9464 está formulado para una rápida manipulación y curado. Las piezas unidas pueden manipularse pasadas 3-4 horas del ensamblado de la unión, siempre que la temperatura sea ambiental. Si se somete la unión adhesiva a una temperatura de $60^{\circ} \mathrm{C}$, el curado del adhesivo se lleva a cabo en 2 horas. Sin embargo, si la temperatura alcanza $82^{\circ} \mathrm{C}$, la duración del proceso de curado se reduce a 1 hora. No obstante, las propiedades finales se alcanzan en 3 días a temperatura ambiente.

\section{Silano Modificado Terostat MS 939:}

El segundo adhesivo de estudio ha sido un adhesivo/sellador elástico en base a polímero de silano modificado, cuya marca comercial es Terostat MS 939.

Se trata de un adhesivo monocomponente que cura por reacción con la humedad ambiental, y con un aspecto pastoso de color negro o blanco. 
Las características de este producto son las siguientes:

- Es especialmente resistente al descolgamiento proporcionando una alta adhesión.

- No contiene solventes, isocianatos, siliconas y PVC.

- Presenta una buena adhesión sin imprimaciones en la mayoría de los sustratos.

- Es compatible con los sistemas de pintura comúnmente utilizados.

- Tiene una buena resistencia a la radiación UV, por lo tanto, puede ser usado para aplicaciones interiores y exteriores.

- El tiempo de curado puede ser acelerado incrementado la temperatura y humedad.

\subsection{Adhesivos reactivos en base a epoxi bicomponente tenaz.}

Los adhesivos epoxi son generalmente adhesivos bicomponentes en forma de resina más activador. Se caracterizan por general uniones de elevada rigidez y por su gran capacidad de relleno de holgura.

Una vez premezclados los componentes del adhesivo, la polimerización comienza lentamente, por lo que los sustratos sobre los que se ha aplicado este tipo de adhesivo se deben mantener en posición hasta alcanzar la resistencia a la manipulación.

En el pasado, la mayoría de los adhesivos epoxi se formulaban como bicomponentes que debían ser mezclados rápidamente antes de ser empleados y tenían una vida de mezcla limitada. En la actualidad, existen adhesivos epoxi monocomponentes con un agente endurecedor que se libera únicamente por reacción a alta temperatura.

Los adhesivos epoxi tiene la siguiente composición:

- Monómeros: en base a epoxis.

- Agentes de curado: en base a aminas, mercaptanos, imidazolas, anhídridos, etc.

- Cargas como aluminio, sílice, etc.: empleadas para minimizar los fenómenos de contracción y expansión del adhesivo.

- Espesantes.

- Pigmentos.

- Resinas diluyentes de bajo peso molecular: para reducir la viscosidad, mejorar la tenacidad o la flexibilidad, la capacidad de mojado, la resistencia térmica, etc.

- Aceleradores del curado a temperatura ambiente: como fenoles o derivados fenólicos.

- A veces se añade polvo de aluminio: para mejorar la conductividad térmica del adhesivo modificando las etapas de curado a elevada temperatura.

Los adhesivos epoxis ofrecen ventajas sobre las uniones remachadas metal-metal. La principal ventaja es económica, ya que con las uniones adhesivas se consigue reducir el coste de mano de obra. Otra ventaja es que en las uniones con adhesivos epoxi las tensiones se distribuyen uniformemente sobre la superficie, produciendo una unión más fuerte y resistente a la fatiga y 
permitiendo el uso de recubrimientos metálicos delgados, los cuales se distorsionarían si se utilizaran remaches. También hacen posible la creación de contornos uniformes, importantes en los aeroplanos de alta velocidad. Y por último, permiten unir metales diferentes sin que existan problemas de corrosión.

Otras ventajas que presentan los epoxis son las siguientes:

- Adhieren casi todos los sustratos: debido a los grupos epóxidos, hidroxilos, aminos y otros grupos polares, los epoxis tienen una gran adhesión a metales, vidrio y cerámica. Pueden ser formulados para dar mezclas de viscosidad baja con humectación mejorada, esparcimiento y acción penetrante.

- Cohesión: la fuerza cohesiva dentro de la línea de cola es tan grande y la adhesión de los epoxis a otros materiales en tan buena, que la falla sobre tensión ocurre en uno de los sustratos en lugar de en el epoxi o en la interfase.

- Poseen un encogimiento bajo: como consecuencia, se forma una tensión menor en la junta adhesiva y la unión resulta más fuerte.

- Gran relleno de holgura.

- Alta resistencia a cizalla y a tracción.

- Son adhesivos muy rígidos. Por lo tanto, solo presentan resistencia a pelado y a impacto en formulaciones flexibles, como por ejemplo epoxi-nitrilo.

- Aunque son dieléctricos y aislantes térmicos, pueden ser modificados para ser conductores de la electricidad y del calor. También se pueden adicionar cargas como fibra de vidrio para mejorar las características mecánicas, o cargas como microesferas neumáticas para disminuir la densidad.

- Buena resistencia química.

- Buena resistencia a la humedad y solventes.

- Se pueden mecanizar.

- Resisten temperaturas de hasta $180^{\circ} \mathrm{C}$.

A pesar de estas propiedades o ventajas, los epoxis presentan las siguientes limitaciones:

- Presentan problemas de absorción y difusión de la humedad.

- Sistemas de alto rendimiento bicomponentes y con necesidad de calor, al menos en la etapa de post-curado.

- Problemas de tiempos de curado, vida de la mezcla y necesidad de temperatura para conseguir un alto grado de reticulación.

Los adhesivos epoxis se emplean en muchas aplicaciones:

- Aditivos para hormigones y elementos de construcción.

- Adhesivos estructurales para la industria aeronáutica.

- Fabricación de materiales compuestos.

- Recubrimientos superficiales.

- Electrónica: circuitos impresos, encapsulación, relleno, etc.

- Imprimaciones. 
Dentro de los adhesivos epoxis destacan los epoxis tenaces. Este tipo de adhesivo contiene en su formulación caucho, nitrilo o polisulfuro, que precipita en forma dispersa cuando endurece. Con la adición del caucho se mejoran las características del adhesivo frente a los esfuerzos de pelado, sobre todo a bajas temperaturas, en donde otros epoxis (por ejemplo nylon-epoxi) pierden todas sus propiedades de flexibilidad.

Los adhesivos epoxis tenaces poseen la misma composición que los epoxis estándar. La adición de modificadores mejora el rendimiento mecánico del adhesivo. Los aditivos se encuentran en el adhesivo en forma de dispersión.

Los epoxis tenaces se comercializan en forma de sistemas bicomponentes y monocomponentes con un agente endurecedor, el cual solo se libera por reacción a alta temperatura.

Las ventajas que presentan los epoxis tenaces se enumeran a continuación:

- Poseen una elevada estructuralidad.

- Tenacidad moderada con elongaciones a la rotura bajas y medias.

- Buena resistencia química.

- Resistencia a la fatiga.

- Adhieren casi todos los sustratos.

- Gran relleno de holgura.

- Se pueden mecanizar.

- Resistencias a temperaturas de hasta $180^{\circ} \mathrm{C}$.

Las desventajas que muestran son las siguientes:

- Presentan problemas de adsorción y difusión de la humedad.

- Problemas en la dosificación de los sistemas de alto rendimiento bicomponentes y con necesidad de calor, al menos en la etapa de post-curado.

- Problemas de tiempos de curado, vida de la mezcla y necesidad de temperatura para conseguir un alto grado de reticulación.

- Los epoxis tenaces monocomponentes deben conservarse a temperaturas muy bajas, $-40^{\circ} \mathrm{C}$.

Las aplicaciones de los epoxis tenaces son:

- Adhesivos estructurales para la industria aeronáutica.

- Adhesivos estructurales para la industria espacial.

- Adhesivos estructurales para la industria naval.

- Adhesivos estructurales para aplicaciones con relleno de holgura.

- Encapsulado y relleno en aplicaciones electrónicas. 


\subsection{Adhesivos elásticos en base a polímero de silano modificado.}

Un adhesivo elástico es capaz de deformarse bajo un esfuerzo relativamente bajo y recuperar la forma inicial una vez que el citado esfuerzo desaparece.

Los adhesivos elásticos se encuentran comercialmente como fluidos, más o menos viscosos, en dos formatos:

$\checkmark$ Sistemas monocomponentes o RTV-1: el adhesivo cura por reacción con la humedad ambiental. El proceso de curado ocurre desde el exterior del cordón aplicado hacia el interior. Conforme avanza la polimerización, el adhesivo se vuelve cada vez más impermeable a la humedad, dificultando la polimerización de las capas interiores. Esto limita la capacidad de relleno y la velocidad de curado.

El proceso de curado de un adhesivo flexible monocomponente transcurre en dos etapas:

1.) Formación de piel: la velocidad de formación de piel está determinada por la velocidad de la reacción de entrecruzamiento.

2.) Curado en profundidad: la velocidad de curado en profundidad es un proceso controlado por la difusión de la molécula de agua, por lo tanto, depende de la temperatura y la humedad.

$\checkmark$ Sistemas bicomponentes o RTV-2: el adhesivo reacciona con el segundo componente, el cual se suele añadir durante el proceso de dosificación mediante boquillas mezcladoras. Los tiempos de curado son muy inferiores a los de los sistemas monocomponentes, por lo que se suelen emplear en líneas de producción automatizadas.

Se conocen numerosas familias químicas de adhesivos que pueden formularse como elásticas, pero en este proyecto solo se estudiarán los silanos modificados.

Los silanos modificados fueron descubiertos en Japón hace más de dos décadas. Su consumo en la industria de la construcción es superior al consumo de las siliconas y los poliuretanos.

Los silanos modificados se basan en poliéteres terminados con grupos siloxanos. La reacción de polimerización sucede a través de los grupos siloxano terminales, iniciada por la humedad ambiental o la adición de un segundo componente. Como subproducto de reacción se genera metanol en baja concentración, lo que minimiza los olores. Esta reacción comienza en la capa más exterior y continúa hacia el interior del cordón, como consecuencia se limita el ancho de cordón y se alargan los tiempos de curado.

La reacción de curado es una policondensación que sucede en dos etapas:

1.) Liberación de los grupos extremos.

2.) Entrecruzamiento de los prepolímeros. 


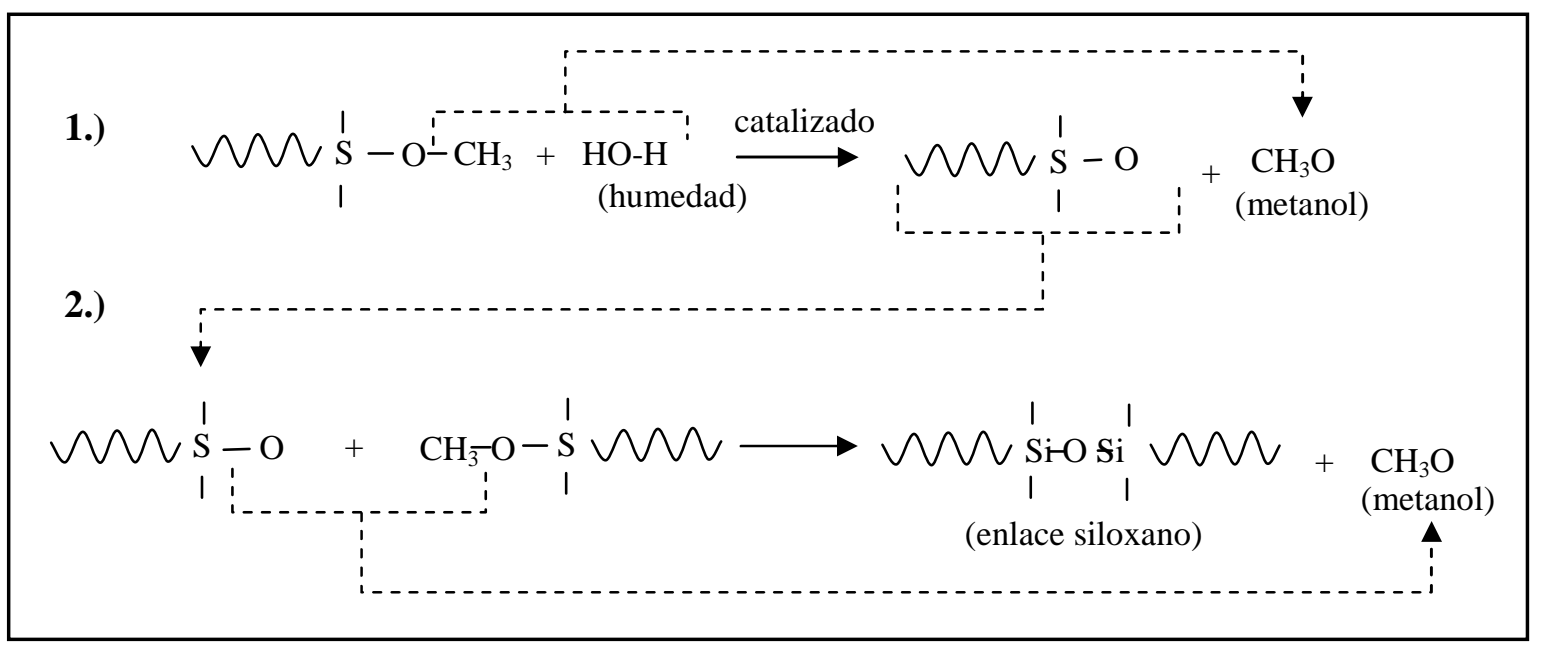

Figura 38. Etapas de curado de los silanos modificados monocomponentes.

En los silanos modificados la formación de piel tiene lugar entre los 10 y los 30 minutos posteriores a su aplicación.

Los silanos modificados permiten incluir en su composición agentes promotores de la adhesión, antioxidantes, absorbentes de la luz UV, catalizadores, plastificantes, pigmentos y cargas.

Los silanos modificados presentan las siguientes ventajas:

- Buena adhesividad y sellado sobre una amplia variedad de sustratos, incluyendo la amplia mayoría de los polímeros.

- Presentan viscosidades bajas antes del curado, lo cual facilita su dosificación.

- Presentan una buena capacidad de relleno de holguras y capacidad de sellado.

- Permanecen flexibles entre $-40^{\circ} \mathrm{C}$ y $100^{\circ} \mathrm{C}$.

- Buena resistencia a los productos químicos.

- Buena resistencia a la radiación UV.

- $\quad$ El adhesivo aplicado se puede pintar.

- Producen subproductos de bajo olor (metanol).

Como desventaja:

- Inhiben el curado de los poliuretanos debido a que generan metanol durante su curado.

Las aplicaciones de los silanos modificamos se detallan a continuación:

- Industria del transporte.

- Industria de la automoción.

- Industria de la construcción.

- Revestimiento de paneles metálicos para la industria de la construcción.

- Sellado de paneles de cemento y sellado de marcos. 
- Sellado de paneles de aluminio, acero, piedra, materiales compuestos y cerámicas en aplicaciones exteriores.

- Sellado de azulejos para aplicaciones diversas.

- Electromecánica.

- Construcción y reparación de remolques.

- Construcción de contenedores.

- Construcción de puertas y ventanas.

- Construcción de maquinaria agrícola.

- Aparatos electrodomésticos.

- Sistemas de ventilación.

\subsection{Sustratos.}

Los sustratos que se han empleado en las uniones adhesivas son los siguientes:

Probetas de acero al carbono. Las dimensiones de las probetas son $100 \mathrm{~mm}$ de largo, 25 $\mathrm{mm}$ de ancho y espesor del orden de $1,5 \mathrm{~mm}$. Estas probetas recibirán la denominación, a lo largo de este texto, de probetas de acero blanco debido a que presentan un acabado blanco.

Probetas de acero base FePo2G Z225 (estas probetas cumplen la Norma Europea EN 10142, "Bandas (chapas y bobinas), de acero bajo en carbono, galvanizadas en continuo por inmersión en caliente para conformación en frío"), tratadas superficialmente con un recubrimiento orgánico (cumpliendo la Norma EU 10169, "Productos planos de acero recubiertos en continuo de materiales orgánicos (precalentados)"). La composición del recubrimiento orgánico es distinta dependiendo de si se trata de la capa exterior o de la capa interior:

- Capa exterior o superior: recubrimiento de poliéster. Espesor de la capa 0,07 mm. Es de color rojo.

- Capa interior o inferior: recubrimiento de poliéster epoxi (proporción 1:1). Espesor de la capa $0,03 \mathrm{~mm}$. Es de color gris.

Las dimensiones de estas probetas son $100 \mathrm{~mm}$ de largo, $25 \mathrm{~mm}$ de ancho y espesor del orden de $0,8 \mathrm{~mm}$.

Probetas de acero galvanizado. Las dimensiones son $100 \mathrm{~mm}$ de largo, $25 \mathrm{~mm}$ de ancho y espesor del orden de $1,40 \mathrm{~mm}$. 


\subsection{Galvanizado de los aceros.}

El proceso de galvanizado consiste en recubrir con zinc fundido la superficie del acero para protegerlo de la corrosión. La razón de utilizar zinc y no otro metal como recubrimiento, se debe a gran capacidad de sacrificio que posee este elemento para proteger el acero base.

Los métodos más importantes para obtener el acero galvanizado son inmersión en caliente y electrodeposición o galvanizado electrolítico. Sin embargo, a continuación se describen diferentes métodos de galvanizado:

* Inmersión en caliente: este proceso consiste en sumergir el acero a recubrir en una cuba que contiene zinc fundido. Se utilizan diferentes tipos de aleaciones de zinc con otros metales.

* Electrodeposición: en este proceso la aplicación de zinc se realiza utilizando corriente eléctrica en un sistema electroquímico.

* Galvanizado electrolítico: la lámina de acero es transportada de forma continua a través de un tanque de galvanización, y electroquímicamente se aplica el recubrimiento de zinc. El tanque de galvanizado se recubre de corriente eléctrica. La electrogalvanización se lleva a cabo a temperatura normal y alta velocidad, de este modo los productos obtenidos después de galvanizar contienen las propiedades básicas del metal base, es decir, se consigue que las piezas conservan excelentes características mecánicas. Con este proceso se obtienen espesores de la capa de zinc bajos, como consecuencia los recubrimientos son menos resistentes a la corrosión que los conseguidos por medio de un proceso de galvanizado por inmersión en caliente.

* Galvanizado tradicional 99.9\% zinc: es el método de galvanización más empleado. Se puede realizar en líneas de galvanización en continuo o en procesos por piezas.

* Galvano-recocido con recubrimiento hierro-zinc: se obtiene por medio de un proceso de inmersión en caliente. Inmediatamente después de pasar por el baño de zinc fundido, la lámina galvanizada se precalienta a $500^{\circ} \mathrm{C}$, como consecuencia el hierro se funde en la capa de zinc formando un recubrimiento completo de hierro-zinc.

* 45\% zinc y 55\% aluminio: este proceso consiste en recubrir la lámina de acero con una aleación de zinc al $45 \%$ y aluminio al $55 \%$. Con esta aleación se consigue mejorar la resistencia a la corrosión, debido a la combinación de la capacidad de sacrificio del zinc con la resistencia a la corrosión del aluminio.

* $95 \%$ zinc y 5\% aluminio: posee características parecidas al proceso anterior, solo cambia el porcentaje de los aleantes.

* Aleaciones de zinc y otros metales: últimamente se han desarrollado nuevos recubrimientos basados en aleaciones $\mathrm{Zn}-\mathrm{Ni}$, Zn-Ni-Co, Zn-Co-Cr, Zn-Co-Mo. También se utiliza un recubrimiento con doble capa, constituida por una aleación de Zn$\mathrm{Ni}$ en la capa inferior, para mejorar la resistencia a la corrosión, y una aleación de $\mathrm{Zn}-\mathrm{Fe}$ en la capa superior, para mejorar la soldabilidad. 
Cada tipo de acero galvanizado está diseñado para una aplicación específica, dependiendo del grado de protección a la corrosión que se requiera. Las principales aplicaciones de los diferentes tipos de acero galvanizado son:

- Galvanizado electrolítico: divisiones interiores, paneles decorativos, partes de automóviles, electrodomésticos y muebles metálicos.

- Galvanizado tradicional 99.9\% Zn: lámina para techos, industria de refrigeración y aire acondicionado, carrocerías, vallas.

- Galvano-recocido con recubrimiento de Fe-Zn: industria automotriz, fabricación de elementos eléctricos y materiales de construcción.

- $\quad$ Recubrimientos $45 \mathrm{Zn}-55 \mathrm{Al}$ y $95 \mathrm{Zn}-5 \mathrm{Al}$ : productos para techos y cerramientos exteriores.

- $\quad$ Aleaciones de zinc y otros metales: para uso automotriz.

El proceso de galvanizado en continuo se realiza principalmente en siete etapas:

1. Entrada y soldadura.

2. Limpieza y pretratamiento.

3. Recocido.

4. Galvanizado.

5. Enfriamiento.

6. Inspección.

7. Acondicionamiento superficial y tratamiento químico.

8. Presentación final y empaquetado.

1. Entrada y soldadura: A ser un proceso en continuo se debe garantizar que la línea esté alimentada con acero laminado. Para conseguir esto se suelda la punta del rollo que se inicia con la cola del rollo que está terminando. La línea normalmente cuenta con fosos de acumulación para que el resto de los procesos no se paren mientras se realiza la soldadura de los rollos.

2. Limpieza y pretratamiento: La superficie de la lámina que se va a galvanizar debe estar limpia de suciedad y restos de aceites procedentes de los procesos de fabricación, para evitar una mala adherencia del zinc sobre el metal base. Para ello, la lámina se somete a desengrase en soluciones alcalinas o en un agente desengrasante eliminador de grasa, polvo y suciedad. Luego, se realizará un enjuague de la lámina (proceso de neutralizado). Posteriormente, la lámina es sometida a un proceso de decapado: el material será sumergido en unos baños ácidos, generalmente soluciones de ácido clorhídrico o ácido sulfúrico, con el fin de eliminar las impurezas y óxidos formados, y así obtener una superficie químicamente limpia.

3. Recocido: Se realiza un proceso de recocido para disminuir la dureza superficial con la que llega el material de la planta de laminación en frío, y obtener de esta forma un acero galvanizado maleable. Las etapas de este proceso son las siguientes: 
- Fuego directo: en esta etapa calentamos la lámina con llama directa, alcanzándose temperaturas entre los 600 y $700{ }^{\circ} \mathrm{C}$. Se utilizará una atmósfera reductora para terminar de limpiar la superficie de la lámina.

- Sección de tubos radiantes: el calentamiento de la lámina continúa hasta alcanzar temperaturas entre los 700 y $800^{\circ} \mathrm{C}$. Una vez alcanzado este intervalo de temperaturas, se mantiene la temperatura durante un determinado tiempo para homogeneizar la estructura del acero. Esta etapa se realiza en una atmósfera reductora compuesta de nitrógeno e hidrógeno.

- Sección de enfriamiento: se enfría la lámina hasta alcanzar una temperatura aproximada de $450{ }^{\circ} \mathrm{C}$. Posteriormente, la lámina es conducida por un túnel con atmósfera reductora hasta la cuba de galvanizado.

4. Galvanizado: La lámina, que proviene del horno de recocido, es sometida al proceso de galvanizado por inmersión en caliente en un baño de zinc a una temperatura de aproximadamente $450{ }^{\circ} \mathrm{C}$. La adición de aluminio al baño de zinc permite lograr una mayor adherencia del recubrimiento. El espesor del recubrimiento de zinc es proporcional al tiempo de inmersión. Por lo tanto, para eliminar el posible exceso de zinc y conseguir la cantidad y el espesor deseados, la lámina será sometida a un proceso de barrido, en el cual el material pasará por entre dos cuchillas de aire a gran presión.

5. Enfriamiento: Finalizado el proceso de galvanizado, la lámina pasa a una torre de enfriamiento con colchones de aire y un tanque de enfriamiento final en agua.

6. Inspección: La lámina se somete a una inspección para verificar que las especificaciones solicitadas por el cliente (espesor del recubrimiento) se cumplen.

7. Acondicionamiento superficial y tratamiento químico: La lámina se somete a un proceso de acondicionamiento superficial para garantizar una óptima superficie para posteriores procesos de pintura y doblado. Se aplicará un baño de ácido crómico para obtener una película de protección contra la corrosión durante el período de almacenamiento y transporte del material.

8. Presentación final y empaquetado: Como último paso se enrolla o se corta el material galvanizado a las dimensiones finales requeridas por el cliente, y se realiza el proceso de empaque del producto terminado. 


\subsection{Recubrimientos superficiales en base a pinturas.}

La pintura es un producto que se presenta en forma líquida y que se transforma en una película sólida, continua y opaca una vez que se ha secado. La pintura se adhiere tenazmente al sustrato sobre el que se aplica, confiriéndole el color del pigmento que presenta su composición.

La mayoría de los componentes de las pinturas son naturales, y no necesitan cambios químicos para ser usados. Sin embargo, si deben lavarse, molerse, filtrase, combinarse o ser sometidos a otros procesos para que adquieran las propiedades y la uniformidad requeridas. Otros componentes se fabrican gracias a largos y costosos procesos físicos y químicos que requieren grandes instalaciones e inversiones.

Los componentes de las pinturas se pueden dividir en cuatro clases:

- Aglutinante: es un producto de naturaleza oleosa o resinosa, que tiene la capacidad de formar una película protectora sobre la superficie pintada. La película formada contiene cierta cantidad de partículas minerales denominadas pigmentos. Los aglutinantes también se suele denominar formadores de película o filmógenos, ligantes, vehículos sólidos y vehículos no volátiles. Con el término "vehículo" se hace referencia a toda la parte líquida de los recubrimientos orgánicos, sean o no volátiles.

- Pigmentos: son de diferentes colores, sólidos y están finamente divididos. Proporcionan las siguientes propiedades: color, brillo, intensidad, poder cubriente, consistencia, cuerpo, duración, índice volumétrico o factor de abultamiento, fluidez y homogeneidad, dispersabilidad, y estabilidad al calor, a la luz, a la humedad, a los agentes químicos y atmosféricos.

- Disolventes: también llamados diluyentes o volátiles. Son líquidos que se añaden a las pinturas para lograr la fluidez necesaria para una apropiada aplicación. Durante el proceso de secado y endurecimiento de la capa de pintura, los disolventes se evaporan dejando un residuo de pigmentos y aglomerantes que forman las películas protectoras y decorativas.

- Aditivos: se añaden en pequeñas cantidades para modificar características generales de las pinturas, como velocidad de secado, fluidez, etc.

Existen diferentes tipos de pinturas:

- Pinturas orgánicas: Como por ejemplo aceite de linaza u otros aceites, barnices, resinas alquídicas modificadas con aceite. Algunas de las propiedades que presentan este tipo de pinturas son: buena adherencia, buena humectabilidad, poca resistencia al oxígeno, poca resistencia al agua y escasa resistencia a electrolitos. Debido a estas propiedades, las pinturas orgánicas expuestas a ambientes agresivos pierden rápidamente su capacidad de protección y se convierten en recubrimientos débiles y esponjosos, lo que acelera la corrosión del acero.

- Pinturas plásticas: Poseen buena resistencia al oxígeno, buena resistencia al agua, buena resistencia a electrolitos, buena permeabilidad, buena resistencia a la abrasión, buena resistencia a impactos, algunas limitaciones a la adherencia y poca humectabilidad. Son ejemplos de esta clase de pintura: las pinturas vinílicas, epoxi, acrílicas, clorocaucho, poliuretano. Las pinturas plásticas son más permeables que las orgánicas, como consecuencia, tienen una mayor capacidad para formar una barrera protectora contra la acción de agentes externos. Esta excelente resistencia contra la oxidación, puede 
mejorarse si se aplica la película de pintura de forma continua, sin poros, grietas o burbujas.

- Pinturas inorgánicas: El pigmento que poseen proporciona protección catódica al sustrato, pero presentan baja humectabilidad y penetración. Debido a esto, es necesario una preparación superficial del sustrato para crear cierta rugosidad superficial y garantizar un buen anclaje.

Se pueden encontrar diversos procesos de curado para las pinturas:

- Oxidación: el aglutinante reacciona con el oxígeno del aire. Este proceso también se conoce como polimerización auto-oxidante. No es un proceso de curado frecuente en el ámbito industrial.

- Evaporación: el formador de la película se queda en la superficie mientras que el disolvente que formaba parte de la película escapa a la atmósfera. De este modo se obtiene una película sólida. Algunos ejemplos de recubrimientos orgánicos que experimentan este proceso de curado son: lacas nitrocelulósicas, lacas vinílicas, acrílicos.

- Condensación: la capa superficial sólida se forma debido a la reacción de dos o más componentes de la película. Como ejemplo de este tipo de proceso de curado se pueden citar las pinturas epoxílicas.

- Coalescencia: cuando el disolvente abandona la película líquida se produce la coalescencia de las partículas dispersas para formar películas continuas y homogéneas. Un ejemplo es el látex.

Los mecanismos de protección de los recubrimientos orgánicos son los siguientes:

- Efecto barrera: La capa de recubrimiento orgánico aísla al metal de su contacto con el medio ambiente. Impide el acceso de la humedad y el oxígeno del aire. Pero esta protección es muy limitada, debido a que la mayoría de los recubrimientos son muy permeables al oxígeno y al agua. Para mejorar este efecto barrera, se deben dar sucesivas capas de recubrimiento, así se consigue disminuir el número de poros.

- Resistencia iónica: Es el principal mecanismo de protección. La capa de recubrimiento dificulta el movimiento de los iones del electrolito, logrando una polarización de concentración.

- Efecto inhibidor: Cuando se añaden a los recubrimientos orgánicos pigmentos con efecto inhibidor se logra reducir la velocidad de corrosión del metal. 


\section{PREPARACIÓN DE LA UNIÓN ADHESIVA.}

\subsection{Tratamiento superficial.}

El tratamiento superficial de los sustratos tiene una gran influencia sobre la resistencia de las uniones adhesivas.

Para conseguir una óptima adhesión, y como consecuencia una buena resistencia y una larga durabilidad de la unión, se han eliminado los restos de grasa y suciedad de la superficie de los sustratos por medio de una limpieza con acetona. Este sistema ha resultado ser sencillo, rápido, económico y no ha producido ninguna alteración significativa en las características de las superficies tratadas.

La aplicación de este tratamiento superficial ha sido suficiente en las probetas que tienen un pretratamiento de protección contra la corrosión, probetas de acero galvanizado y probetas de acero con recubrimiento orgánico.

En el caso de las probetas de acero sin ningún pretratamiento superficial contra la oxidación, ha sido necesario realizar una limpieza previa con agua y jabón para eliminar los restos de aceites procedentes del proceso de fabricación. Inmediatamente después de este proceso de desengrase, las probetas se han secado para evitar la oxidación. Y finalmente, para asegurar la eliminación de los contaminantes superficiales, se ha realizado el frotado con acetona.

Después de finalizar la limpieza con acetona, las probetas se dejan secar al aire antes de aplicar el adhesivo. Es muy importante que no queden restos de acetona, de lo contrario existirán zonas de la superficie del sustrato sin adhesivo y la unión resultante será inadecuada, acelerándose el fallo de la junta.

\subsection{Descripción del proceso de ensamblaje.}

A continuación se describen los pasos que se han seguido en el proceso de ensamblaje de la unión adhesiva de las probetas:

1. Tratamiento superficial de los sustratos: limpieza de la superficie con disolvente. Se limpia la superficie de los sustratos impregnando en acetona un papel de celulosa. Esta operación de frotado se repite varias veces.

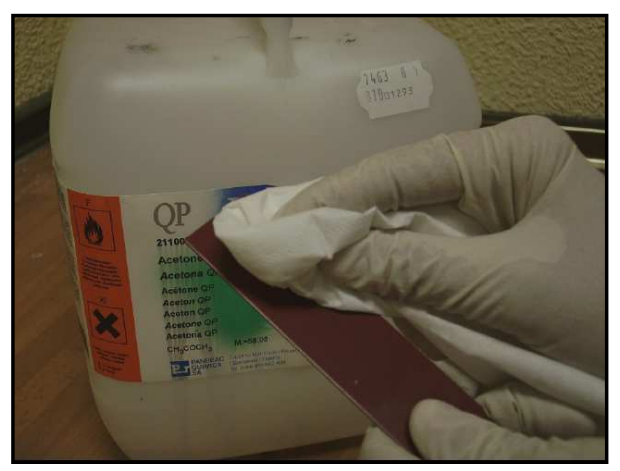

Figura 39. Limpieza superficie sustratos. 
2. Aplicación del adhesivo: se ha aplicado el adhesivo sobre una de las dos superficies a unir mediante una pistola difusora y posteriormente se ha extendido con ayuda de una espátula. La capa o película adhesiva debe ser tan delgada como sea posible, sin llegar a una unión insuficiente, para conseguir la máxima fuerza y rigidez de la capa de adhesivo en la unión.
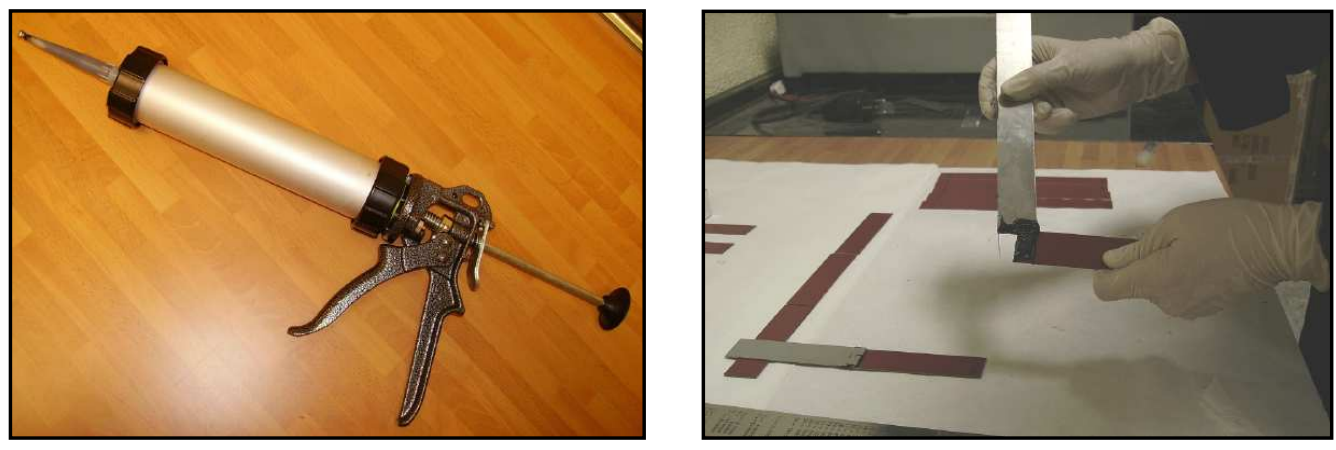

Figura 40. Aplicación del adhesivo.

3. Ensamblaje de las piezas: las piezas se han ensamblado inmediatamente después de aplicar el adhesivo. Durante el proceso de curado o endurecimiento ha existido un contacto uniforme y sin movimientos para garantizar un proceso de adherencia impecable, y se ha mantenido una presión constante sobre la unión adhesiva.
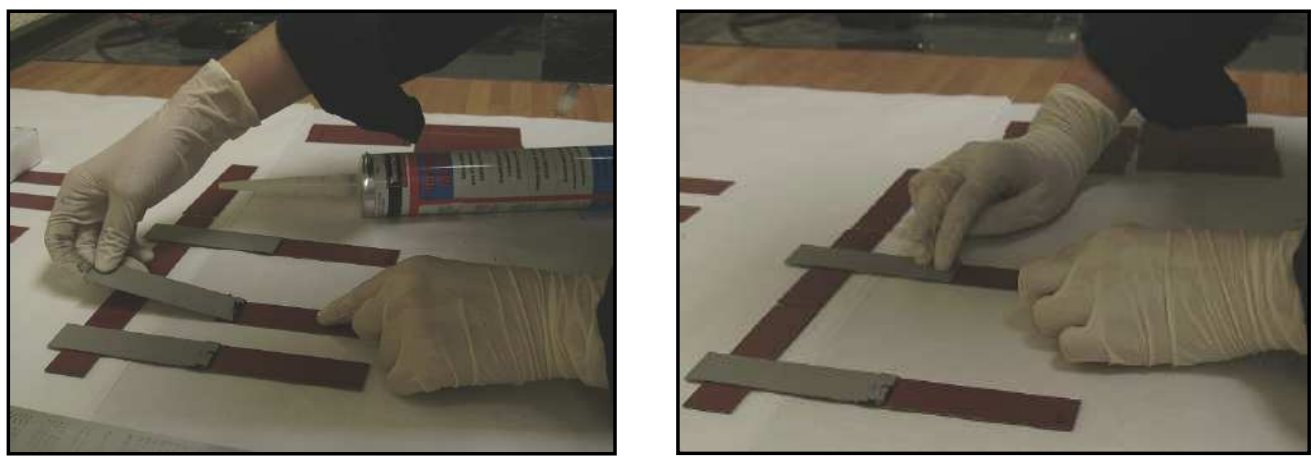

Figura 41. Ensamblaje de las piezas. 
4. Medición de las probetas: se han medido con ayuda de un proyector de perfiles, de la marca Nikon modelo V-12A. Las medidas que se toman son: longitud de solape, espesor de los sustratos y espesor de la zona de unión. El espesor del adhesivo será la diferencia entre el espesor de la unión y el espesor de los sustratos.

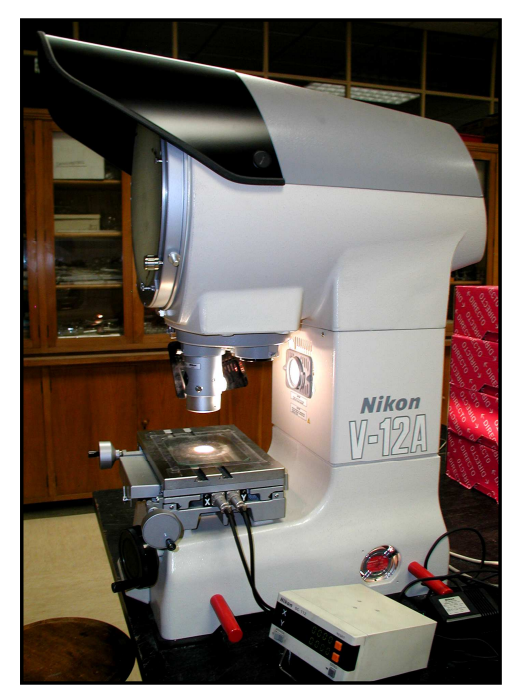

Figura 42. Proyector de perfiles. 


\section{ENSAYOS REALIZADOS.}

\subsection{Ensayo de cizalladura por tracción a solape simple.}

Para realizar este ensayo se ha seguido la norma: UNE-EN 1495, "Determinación de la resistencia a la cizalladura por tracción de juntas pegadas de sustratos rígidos".

La máquina empleada para llevar a cabo este tipo de ensayo es una máquina universal de ensayos electromecánicos de la marca INSTRON modelo 1362. Dicha máquina presenta un cabezal móvil con un par de torsión de $50 \mathrm{Nm}$. Los ensayos se han realizado a velocidad de desplazamiento constante.
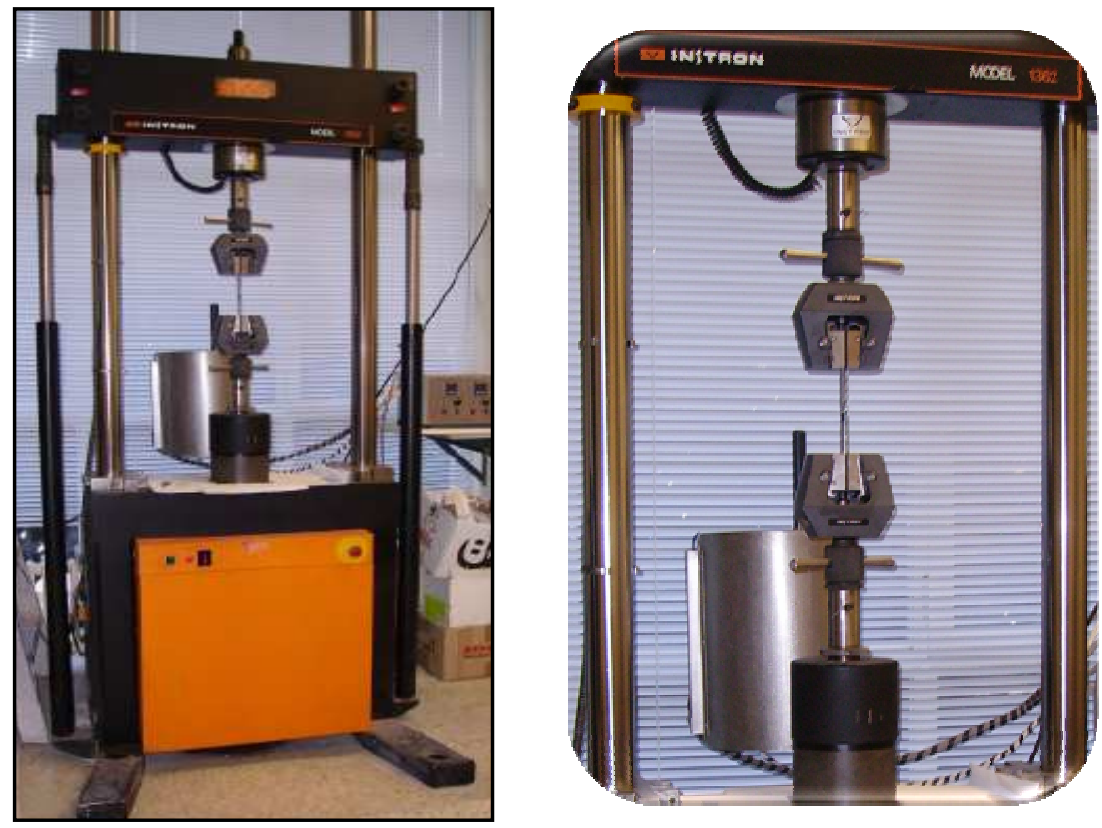

Figura 43. Máquina universal para ensayos de cizalladura.

Para las uniones realizadas con adhesivo epoxi bicomponente Loctite Hysol 9464, se han realizado un total de veinticuatro ensayos de cizalladura, distribuidos de la siguiente forma:

\section{$\square$ Probetas de acero blanco:}

- Tiempo de curado mínimo de 3 días: serie compuesta de seis probetas.

$\square$ Probetas de acero recubierto de poliéster (pintura color rojo):

- Tiempo de curado mínimo de 3 días: serie compuesta de seis probetas.

- Probetas de acero recubierto de poliéster epoxi (pintura color gris):

- Tiempo de curado mínimo de 3 días: serie compuesta de seis probetas.

$\square$ Probetas de acero galvanizado:

- Tiempo de curado mínimo de 3 días: serie compuesta de seis probetas. 
En el caso de las uniones con adhesivo silano modifica Terostat MS 939, se han realizado un total de ciento treinta y ocho ensayos de cizalladura, distribuidos de la siguiente forma:

\section{$\square$ Probetas de acero blanco:}

- Tiempo de curado 3 días: serie 1 constituida por doce probetas.

- Tiempo de curado 7 días: serie 2 constituida por dieciocho probetas.

- Tiempo de curado 14 días: serie 3 constituida por doce probetas.

Probetas de acero recubierto de poliéster (pintura color rojo):

- Tiempo de curado 3 días: serie 4 constituida por doce probetas.

- Tiempo de curado 7 días: serie 5 constituida por doce probetas.

- Tiempo de curado 14 días: serie 6 constituida por doce probetas.

Probetas de acero recubierto de poliéster epoxi (pintura color gris):

- Tiempo de curado 3 días: serie 7 constituida por doce probetas.

- Tiempo de curado 7 días: serie 8 constituida por doce probetas.

- Tiempo de curado 14 días: serie 9 constituida por doce probetas.

\section{$\square$ Probetas de acero galvanizado:}

- Tiempo de curado 3 días: serie 10 constituida por doce probetas.

- Tiempo de curado 7 días: serie 11 constituida por doce probetas. 


\subsection{Ensayo de cizalladura por fatiga a solape simple.}

Para realizar este ensayo se ha seguido la norma: UNE-EN ISO 9664, "Métodos de ensayo para resistencia a la fatiga por esfuerzo de cizalla de adhesivos estructurales (Julio 1996)".

La máquina universal de ensayos que se ha utilizado para realizar la fatiga es de la marca MTS modelo 810, compuesta de un grupo hidráulico y un grupo de presión (o suministro eléctrico).
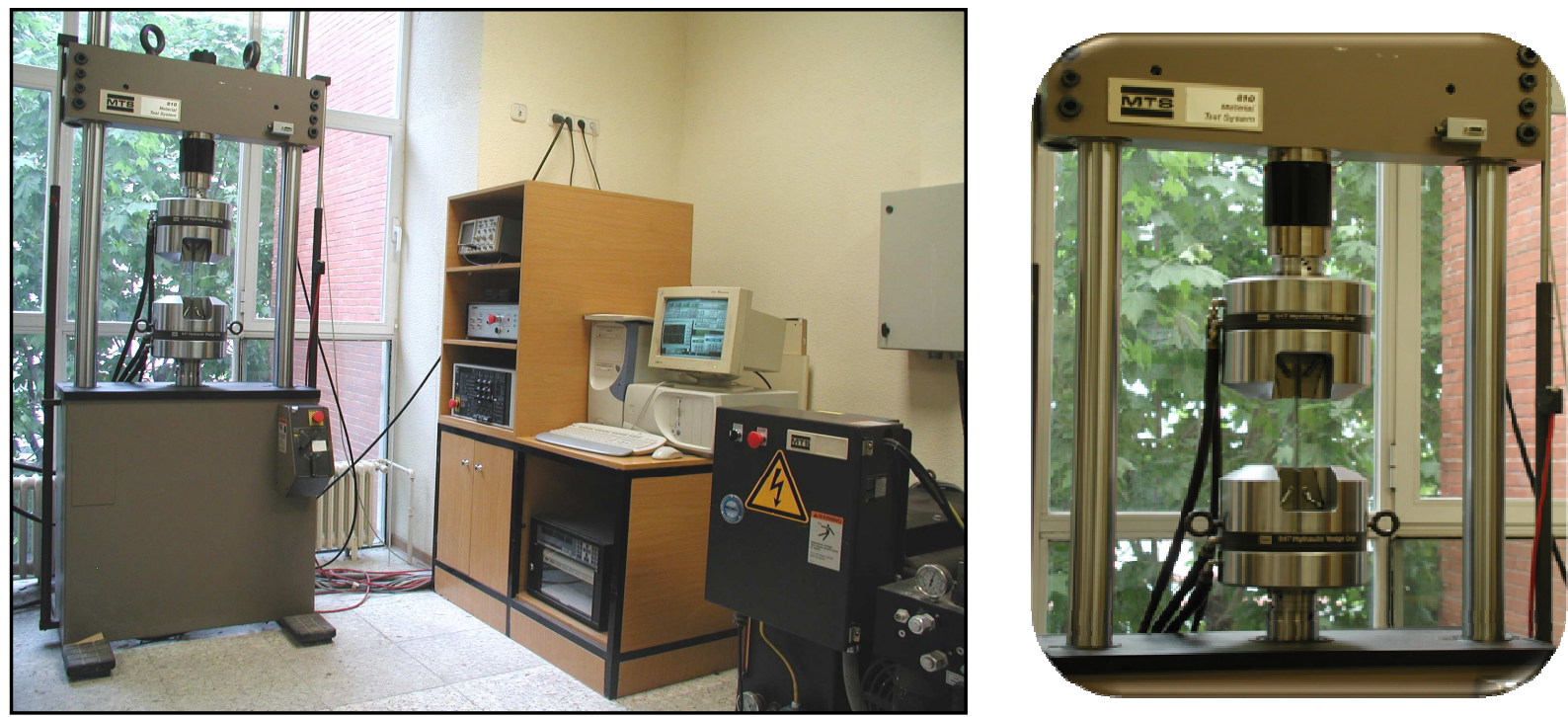

Figura 44. Máquina universal para ensayos de fatiga..

Se han llevado a cabo treinta y ocho ensayos de fatiga en el caso del adhesivo epoxi bicomponente Loctite Hysol 9464, y sesenta ensayos de fatiga con el adhesivo silano modificado Terostat MS 939.

No se han realizado ensayos con los cuatro tipos de probetas que se han empleado en los ensayos de cizalladura. Aquí solo se han analizado las probetas que han obtenido los mejores valores de tensión de rotura en los ensayos de cizalladura.

Para el adhesivo epoxi bicomponente Loctite Hysol 9464, los mejores resultados se han logrado con las probetas de acero con recubrimiento de poliéster epoxi y acero blanco.

Estos dos tipos de aceros junto con el acero galvanizado, han obtenido los mejores resultados en el caso de las uniones adhesivas con silano modificado Terostat MS 939.

La máquina durante el ensayo de fatiga realiza un ciclo sinusoidal de tensión-tensión con una relación de tensiones de $\mathrm{R}=0,1$. La frecuencia de ensayo ha sido de $5 \mathrm{~Hz}$. La tensión máxima escogida está comprendida entre el $30 \%$ y $70 \%$ de la tensión máxima alcanzada en el ensayo de cizalladura. Los ciclos máximos de rotura son $10^{6}$.

Los ensayos han consistido en someter cuatro probetas a los diferentes niveles de tensión contándose en cada uno de ellos el número de ciclos $\mathrm{N}$ que transcurren hasta la rotura. Con estos ensayos se obtiene un diagrama donde se representa la tensión frente al número de ciclos. Este conjunto de ensayos permite la obtención de las curvas SN o curva Wöhler del comportamiento a 
fatiga de las uniones adhesivas, y el valor del límite de resistencia máxima a fatiga por debajo del cual no se produce fallo de la unión por fatiga.

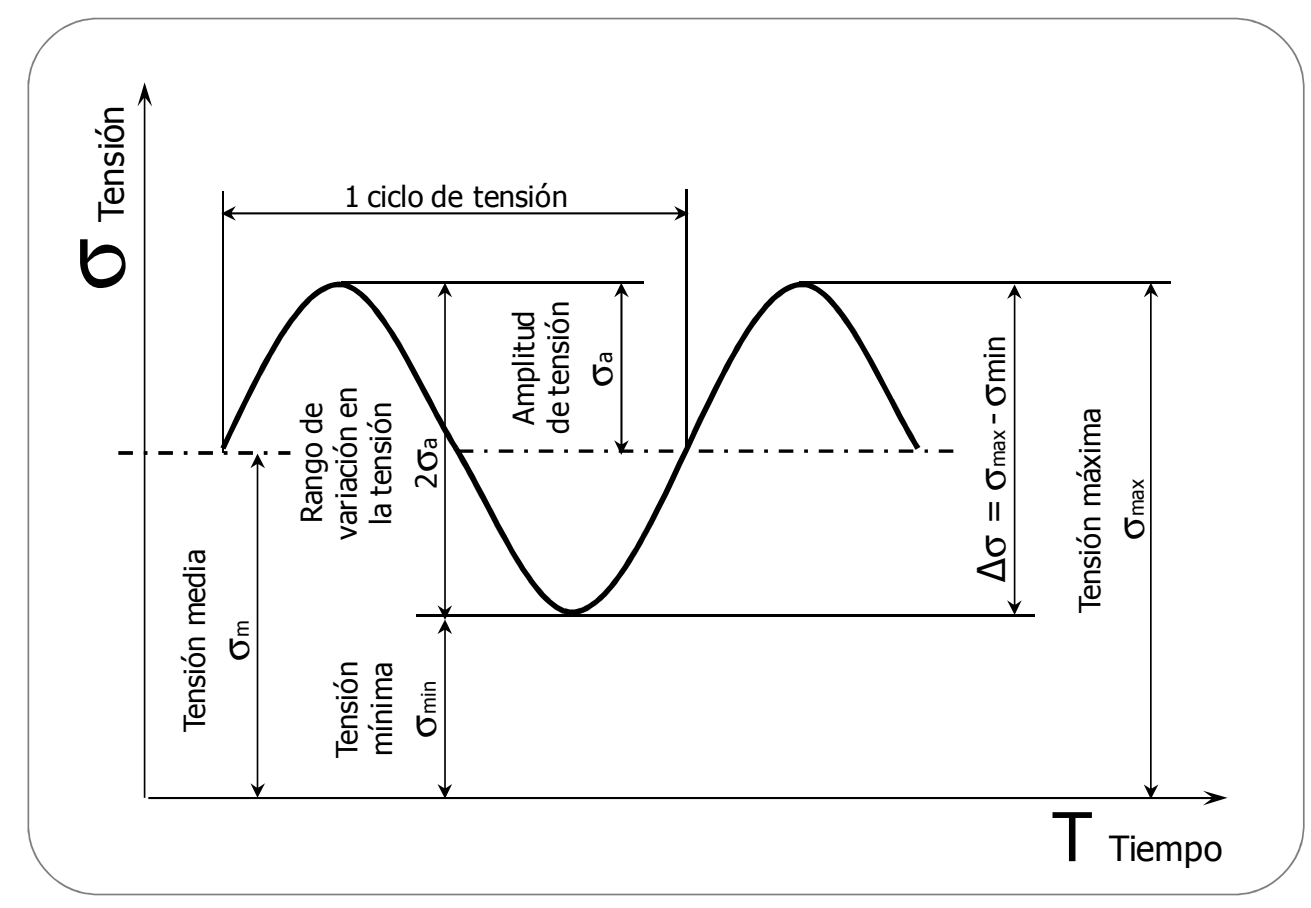

Figura 45. Ciclo de tensión de fatiga.

\subsection{Ensayo de Resistencia Residual.}

Las muestras que han superado el ensayo de fatiga, es decir, aquellas que han completa $10^{6}$ ciclos de carga sin romperse han sido sometidas a ensayos de cizalla por tracción para determinar la resistencia residual, siguiendo la norma UNE-EN 1495.

Se han realizado un total de catorce ensayos, tres en el caso de las uniones adhesivas con epoxi bicomponente, y once para las muestras unidas con adhesivo silano modificado. 


\section{ANÁLISIS DE LOS RESULTADOS DEL ENSAYO DE TRACCIÓN A CIZALLADURA SIMPLE CON EPOXI BICOMPONENTE LOCTITE HYSOL 9464.}

\subsection{Probetas de acero blanco y adhesivo epoxi.}

La siguiente tabla describe los resultados obtenidos en los ensayos de cizalladura para las probetas de acero blanco y epoxi bicomponente Loctite Hysol 9464:

Tabla 2. Resultados de probetas de acero blanco.

\begin{tabular}{|c|c|c|c|c|c|c|c|c|}
\hline \multirow{2}{*}{\multicolumn{5}{|c|}{$\begin{array}{ll}\text { ENSAYO: } & \text { Cizalladura } \\
\text { UNIÓN: } & \text { Adhesiva-Loctite-Hysol } 9464\end{array}$}} & FR medio & 4,58 & TR medio & 13,58 \\
\hline & & & & & $\mathrm{s}(\mathrm{N} / \mathrm{mm} 2)$ & 0,60 & $\mathrm{~s}(\mathrm{~N} / \mathrm{mm} 2)$ & 1,58 \\
\hline \multirow{2}{*}{\multicolumn{5}{|c|}{$\begin{array}{l}\text { SUPERFICIE: } \quad \text { Acero blanco } \\
\text { PREP. SUPERFICIAL: Limpieza con agua y jabón + } \\
\qquad \begin{array}{l}\text { Limpieza con acetona }\end{array}\end{array}$}} & $\mathrm{CV}(\%)$ & 13,15 & $\mathrm{CV}(\%)$ & 11,63 \\
\hline & & & & & $\mathbf{A} \%$ & 98,83 & $\mathbf{C} \%$ & 1,17 \\
\hline \multicolumn{5}{|c|}{ CURADO (DÍAS): $\quad 3$} & I medio & 13,47 & t medio & 0,16 \\
\hline \multirow[b]{2}{*}{ Probeta } & \multirow[b]{2}{*}{$\begin{array}{l}\text { Fuerza } \\
\text { Rotura } \\
\text { kN }\end{array}$} & \multirow[b]{2}{*}{$\begin{array}{l}\text { Tensión } \\
\text { Rotura } \\
\text { MPa }\end{array}$} & \multicolumn{2}{|c|}{ Rotura \% } & \multicolumn{4}{|c|}{ Dimensiones de la probeta en $\mathrm{mm}$} \\
\hline & & & Adhesiva & Cohesiva & b & $\begin{array}{l}\text { Long. } \\
\text { Solape } \\
\text { I (mm) }\end{array}$ & $\begin{array}{l}\text { Espesor } \\
\text { capa } \\
\mathrm{t}(\mathrm{mm})\end{array}$ & $\begin{array}{l}\text { Espesor } \\
\text { unión adh. } \\
\text { e }(\mathrm{mm})\end{array}$ \\
\hline $7 \mathrm{~F}$ & 4,50 & 13,16 & 100 & $\mathbf{0}$ & 25,00 & 13,680 & 0,135 & 2,830 \\
\hline $8 \mathrm{~F}$ & 5,13 & 15,37 & 93 & 7 & 25,00 & 13,350 & 0,190 & 2,810 \\
\hline $9 \mathrm{~F}$ & 3,44 & 10,61 & 100 & 0 & 25,00 & 12,975 & 0,210 & 2,860 \\
\hline $10 \mathrm{~F}$ & 4,50 & 13,41 & 100 & 0 & 25,00 & 13,425 & 0,200 & 2,930 \\
\hline $11 \mathrm{~F}$ & 5,33 & 15,23 & 100 & 0 & 25,00 & 14,000 & 0,155 & 2,860 \\
\hline $12 \mathrm{~F}$ & 4,58 & 13,71 & 100 & 0 & 25,00 & 13,360 & 0,075 & 2,760 \\
\hline
\end{tabular}

El máximo valor de espesor de capa junto con el mínimo valor de longitud de solape, provocan un descenso en la tensión, alcanzándose el valor mínimo. Se alcanza la máxima tensión de rotura cuando la rotura de la unión adhesiva presenta el mayor porcentaje de cohesión.

Como la probeta número $8 \mathrm{~F}$ alcanza la máxima tensión independientemente del comportamiento del espesor de capa y longitud de solape, no se va a tener en cuenta en el análisis de cómo influyen estos parámetros sobre la tensión de rotura.

En la Figura 46 se puede observar el efecto que provoca un aumento de espesor de capa sobre la tensión de rotura. El mínimo valor de espesor provoca un aumento de la tensión. Sin embargo, su máximo valor implica un descenso de la tensión.

Se puede observar que las probetas $7 \mathrm{~F}$ y $11 \mathrm{~F}$ sufriendo ambas un aumento tanto de espesor de capa como de longitud de solape, sus tensiones se comportan de forma distinta. Esto se debe a que la probeta $11 \mathrm{~F}$ alcanza su longitud máxima, y como consecuencia, independientemente de lo que haga el espesor, se produce un aumento de la tensión de rotura. 


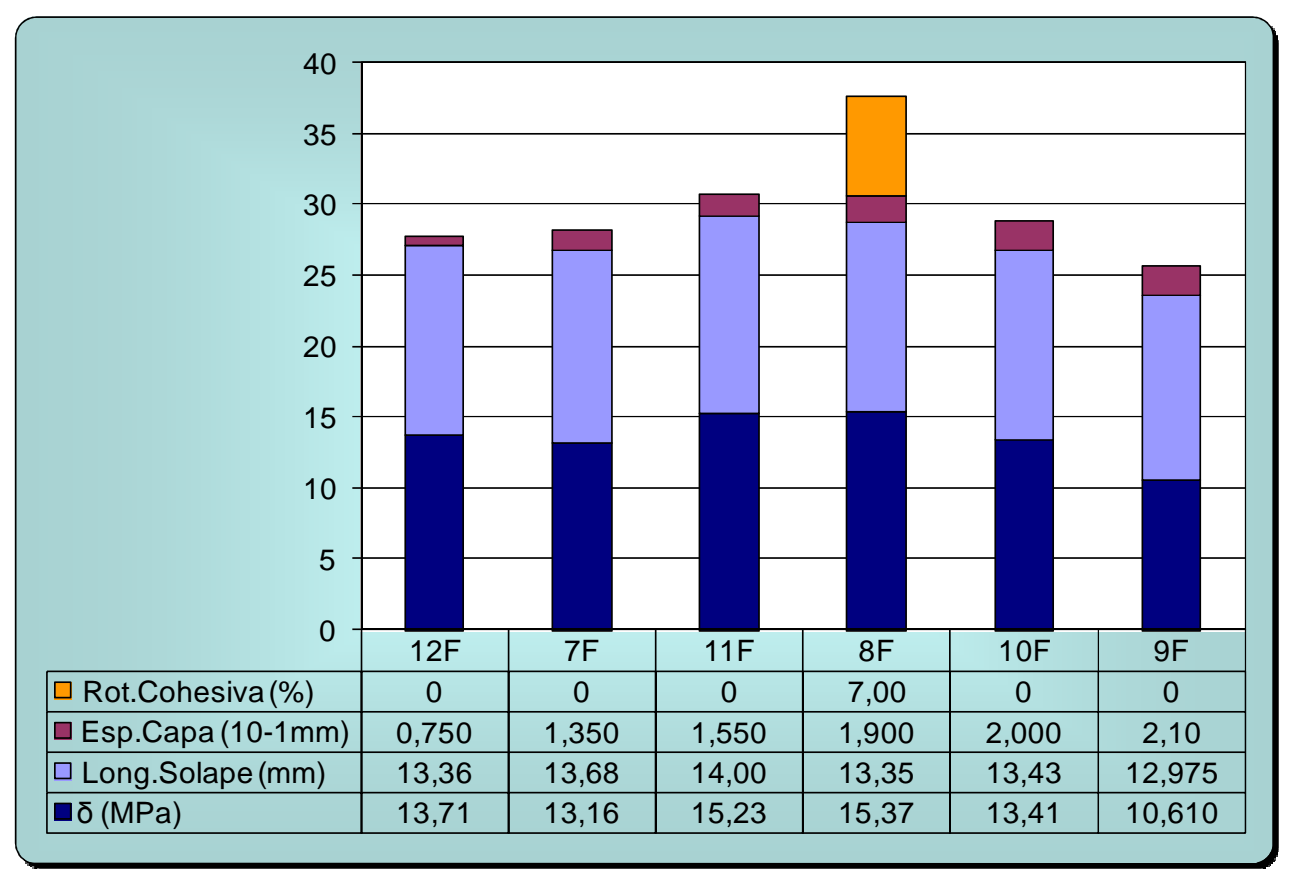

Figura 46. Influencia del espesor de capa adhesiva.

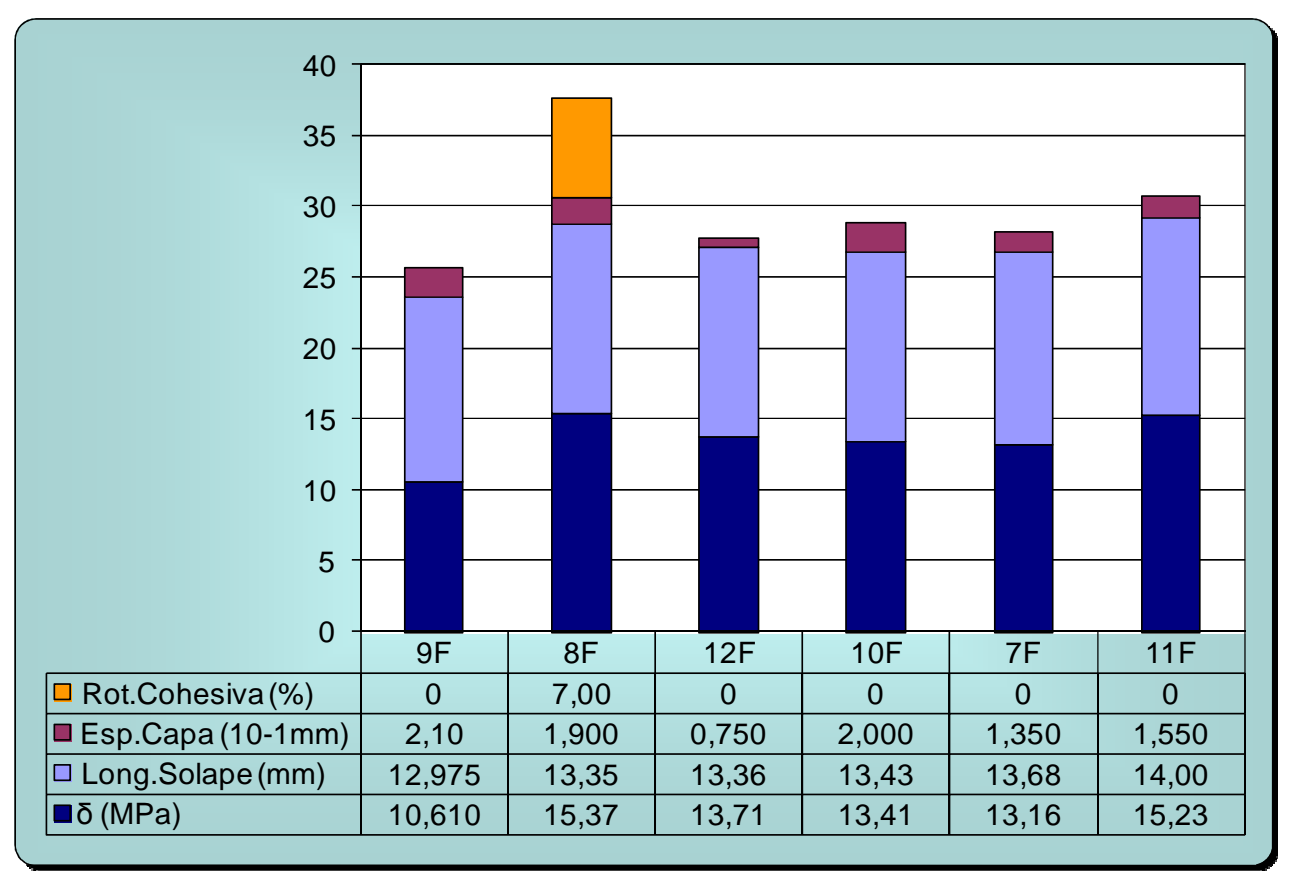

Figura 47. Influencia de la longitud de solape. 
En la Figura 47 se analiza la influencia del aumento de la longitud de solape sobre la tensión de rotura. Se puede apreciar que los valores mínimo y máximo de la longitud de solape tienen un efecto contrario al que producían estos límites en el caso del espesor de capa: un mínimo de longitud implica un descenso de tensión y un máximo causa un aumento de dicho valor. Las probetas $12 \mathrm{~F}$ y $7 \mathrm{~F}$ muestran una evolución de la tensión diferente ante un mismo comportamiento del espesor y longitud. Es debido a que la probeta $12 \mathrm{~F}$ alcanza el mínimo valor de espesor de capa, lo que provoca un aumento de la tensión independientemente del valor de la longitud de solape.

Las conclusiones para el comportamiento de la tensión de rotura en probetas de acero blanco y epoxi bicomponente son las siguientes:

$\checkmark \mathrm{Si}$ existe rotura mixta de la junta adhesiva, el mayor porcentaje de rotura cohesiva implica la tensión máxima.

$\checkmark$ Si conjuntamente se alcanza el máximo de espesor de capa adhesiva y el mínimo de longitud de solape, se obtiene la tensión mínima.

$\checkmark$ El espesor de capa adhesiva mínimo implica un crecimiento de la tensión de rotura.

$\checkmark$ La longitud de solape máxima implica un crecimiento de la tensión.

$\checkmark$ Para valores de espesor y longitud distintos a los mencionados en los anteriores puntos, el comportamiento de la tensión es: si aumenta el espesor de capa adhesiva y disminuye la longitud de solape, se consigue un aumento de la tensión.

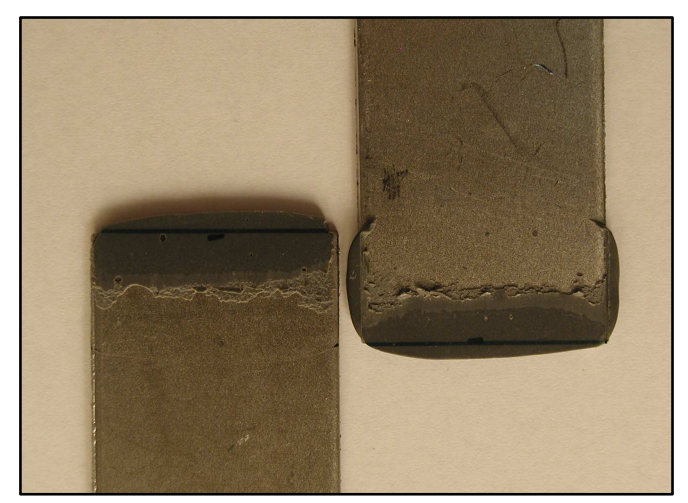

Figura 48. Rotura $100 \%$ adhesiva de probetas de acero blanco. 


\subsection{Probetas de acero recubierto de poliéster y adhesivo epoxi.}

La siguiente tabla describe los resultados obtenidos en los ensayos de cizalladura para las uniones adhesivas de acero recubierto de poliéster con epoxi bicomponente Loctite Hysol 9464:

Tabla 3. Resultados de probetas de acero recubierto de poliéster.

\begin{tabular}{|c|c|c|c|c|c|c|c|c|}
\hline \multirow{2}{*}{\multicolumn{5}{|c|}{$\begin{array}{ll}\text { ENSAYO: } & \text { Cizalladura } \\
\text { UNIÓN: } & \text { Adhesiva-Loctite-Hysol } 9464\end{array}$}} & FR medio & 1,34 & TR medio & 4,00 \\
\hline & & & & & $\mathrm{s}(\mathrm{N} / \mathrm{mm} 2)$ & 0,28 & $\mathrm{~s}(\mathrm{~N} / \mathrm{mm} 2)$ & 0,96 \\
\hline \multirow{2}{*}{\multicolumn{5}{|c|}{$\begin{array}{ll}\text { SUPERFICIE: } & \text { Recubrimiento Poliéster } \\
\text { PREP. SUPERFICIAL: Limpieza acetona }\end{array}$}} & $\mathrm{CV}(\%)$ & 21,14 & $\mathrm{CV}(\%)$ & 23,88 \\
\hline & & & & & $A \%$ & 100,00 & $\mathrm{C} \%$ & 0,00 \\
\hline \multicolumn{5}{|c|}{ CURADO (DÍAS): $\quad 3$} & I medio & 13,46 & t medio & 0,36 \\
\hline \multirow[b]{2}{*}{ Probeta } & \multirow[b]{2}{*}{$\begin{array}{c}\text { Fuerza } \\
\text { Rotura } \\
\text { kN }\end{array}$} & \multirow[b]{2}{*}{$\begin{array}{c}\text { Tensión } \\
\text { Rotura } \\
\mathrm{MPa}\end{array}$} & \multicolumn{2}{|c|}{ Rotura \% } & \multicolumn{4}{|c|}{ Dimensiones de la probeta en $\mathrm{mm}$} \\
\hline & & & Adhesiva & Cohesiva & b & $\begin{array}{l}\text { Long. } \\
\text { Solape } \\
\text { I (mm) }\end{array}$ & $\begin{array}{l}\text { Espesor } \\
\text { capa } \\
t(\mathrm{~mm})\end{array}$ & $\begin{array}{l}\text { Espesor } \\
\text { unión adh. } \\
\text { e }(\mathrm{mm})\end{array}$ \\
\hline $1 \mathrm{~F}$ & 1,52 & 4,77 & 100 & $\mathbf{0}$ & 25,00 & 12,750 & 0,200 & 1,550 \\
\hline $2 \mathrm{~F}$ & 1,18 & 3,54 & 100 & $\mathbf{0}$ & 25,00 & 13,350 & 0,360 & 1,490 \\
\hline $4 \mathrm{~F}$ & 1,14 & 3,30 & 100 & $\mathbf{0}$ & 25,00 & 13,800 & 0,500 & 1,420 \\
\hline $5 \mathrm{~F}$ & 1,80 & 5,45 & 100 & 0 & 25,00 & 13,200 & 0,530 & 1,350 \\
\hline $6 \mathrm{~F}$ & 1,04 & 2,92 & 100 & 0 & 25,00 & 14,200 & 0,230 & 1,600 \\
\hline
\end{tabular}

El máximo espesor de capa produce un aumento en el valor de la tensión de rotura. Por el contrario, el máximo valor de longitud de solape implica la mínima tensión.

En la Figura 49 se muestra la influencia del aumento de la longitud de solape en la tensión de rotura. Se aprecia un descenso de la tensión de rotura cuando la longitud de solape aumenta, independientemente del valor del espesor de capa y siempre que este parámetro no alcance su valor máximo, porque de ser así se produce un crecimiento de la tensión.

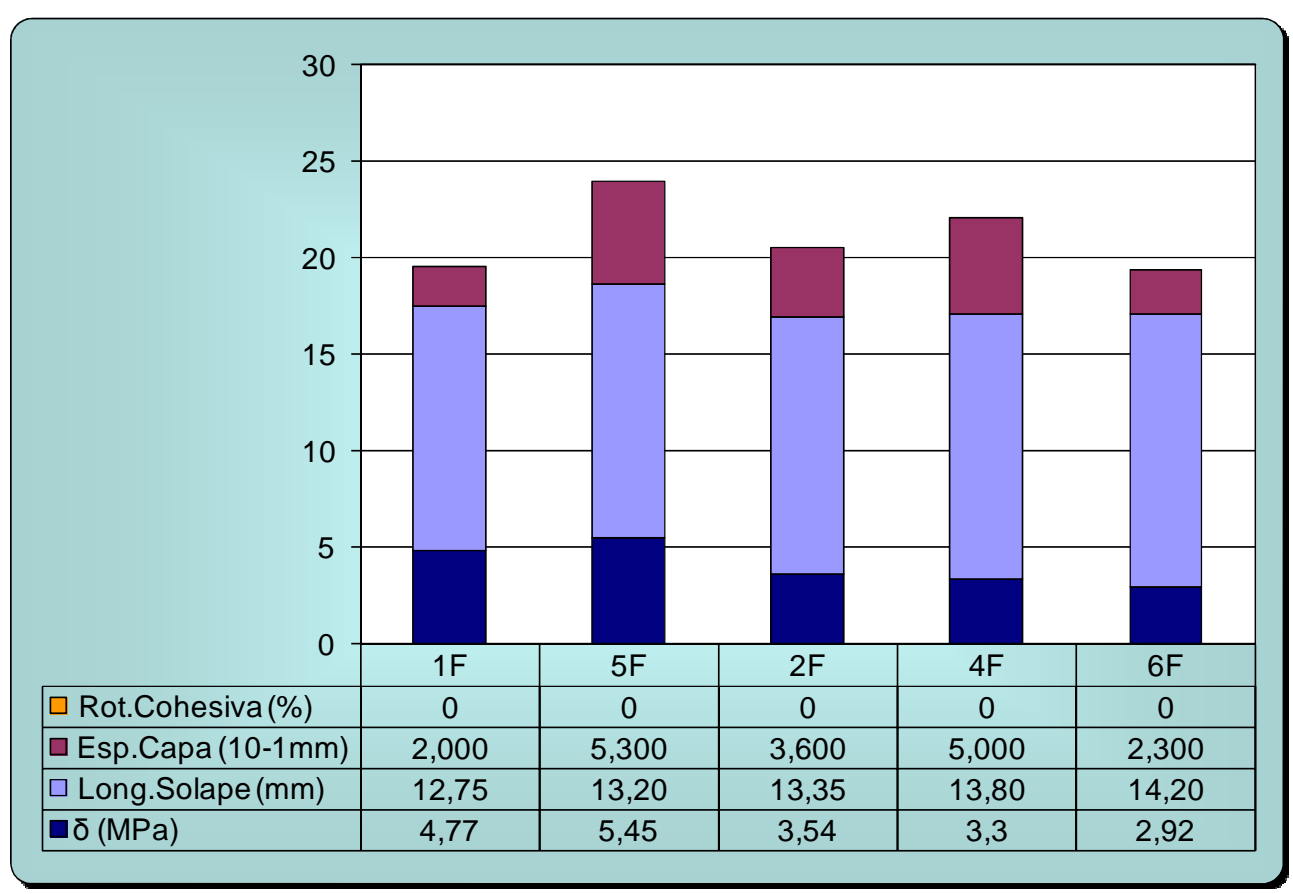

Figura 49. Influencia de la longitud de solape. 
En la siguiente figura se puede observar la evolución de la tensión con un aumento del espesor de capa y se pueden confirmar las conclusiones que se han obtenido anteriormente:

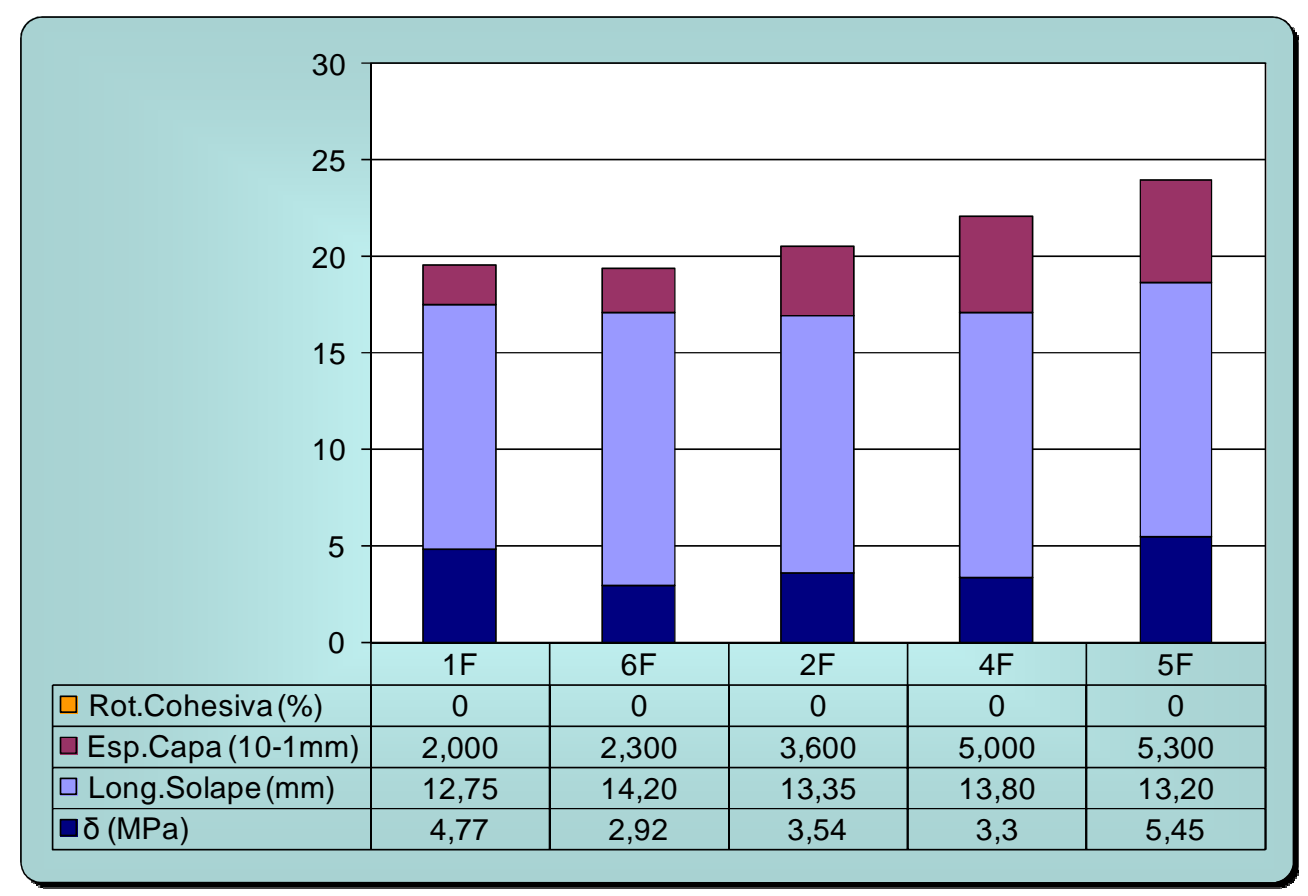

Figura 50. Influencia del espesor de capa adhesiva..

Por lo tanto, se puede concluir que el comportamiento de la tensión de rotura en probetas de acero recubierto de poliéster es el siguiente:

$\checkmark$ Alcanzar el espesor de capa adhesiva máximo implica, independientemente de la variación que sufra la longitud de solape, un aumento de la tensión de capa.

$\checkmark$ Cuando el espesor de capa posee un valor distinto de su máximo, la tensión se ve influida solo por la longitud de solape, de tal manera que se comporta de forma inversa a como lo hace la longitud de solape.

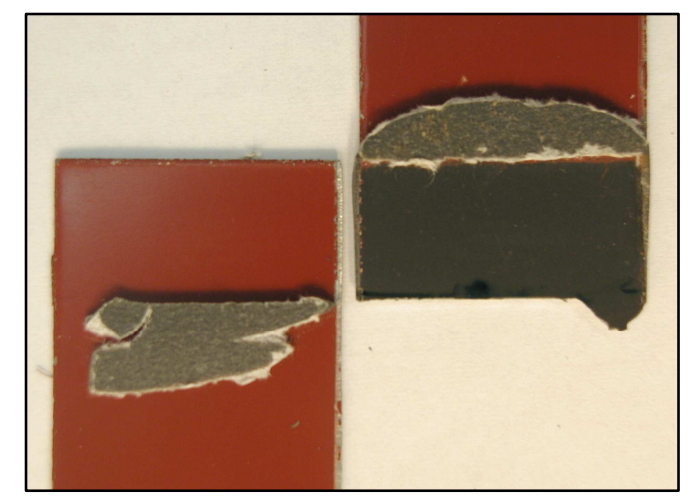

Figura 51. Rotura 100\% adhesiva de probetas de acero con recubrimiento de poliéster. 


\subsection{Probetas de acero recubierto de poliéster epoxi y adhesivo epoxi.}

Los resultados conseguidos en los ensayos de cizalladura para las pobretas de acero recubierto de poliéster epoxi y epoxi bicomponente Loctite Hysol 9464 se detallan en la siguiente tabla:

Tabla 4. Resultados de probetas de acero recubierto de poliéster epoxi.

\begin{tabular}{|c|c|c|c|c|c|c|c|c|}
\hline \multirow{2}{*}{\multicolumn{5}{|c|}{$\begin{array}{ll}\text { ENSAYO: } & \text { Cizalladura } \\
\text { UNIÓN: } & \text { Adhesiva-Loctite-Hysol } 9464\end{array}$}} & FR medio & 7,09 & TR medio & 21,95 \\
\hline & & & & & $\mathrm{s}(\mathrm{N} / \mathrm{mm} 2)$ & 0,48 & $\mathrm{~s}(\mathrm{~N} / \mathrm{mm} 2)$ & 1,64 \\
\hline \multirow{3}{*}{\multicolumn{5}{|c|}{$\begin{array}{lc}\text { SUPERFICIE: } & \text { Recubrimiento Poliéster Epoxi } \\
\text { PREP. SUPERFICIAL: Limpieza acetona } \\
\text { CURADO (DÍAS): }\end{array}$}} & $\mathrm{CV}(\%)$ & 6,77 & $\mathrm{CV}(\%)$ & 7,47 \\
\hline & & & & & $A \%$ & 69,50 & $\mathrm{C} \%$ & 30,50 \\
\hline & & 3 & & & I medio & 12,93 & t medio & 0,19 \\
\hline \multirow[b]{2}{*}{ Probeta } & \multirow[b]{2}{*}{$\begin{array}{c}\text { Fuerza } \\
\text { Rotura } \\
\text { kN }\end{array}$} & \multirow[b]{2}{*}{$\begin{array}{l}\text { Tensión } \\
\text { Rotura } \\
\text { MPa }\end{array}$} & \multicolumn{2}{|c|}{ Rotura \% } & \multicolumn{4}{|c|}{ Dimensiones de la probeta en $\mathrm{mm}$} \\
\hline & & & Adhesiva & Cohesiva & b & $\begin{array}{l}\text { Long. } \\
\text { Solape } \\
\text { I (mm) }\end{array}$ & $\begin{array}{c}\text { Espesor } \\
\text { capa } \\
t(\mathrm{~mm})\end{array}$ & $\begin{array}{c}\text { Espesor } \\
\text { unión adh. } \\
\text { e }(\mathrm{mm})\end{array}$ \\
\hline 1 & 6,55 & 20,79 & 58 & 42 & 25 & 12,600 & 0,145 & 1,420 \\
\hline 2 & 7,34 & 23,88 & 77 & 23 & 25 & 12,295 & 0,165 & 1,660 \\
\hline 3 & 6,37 & 18,94 & 82 & 18 & 25 & 13,450 & 0,335 & 1,470 \\
\hline 4 & 7,46 & 23,13 & 70 & 30 & 25 & 12,900 & 0,200 & 1,670 \\
\hline 5 & 7,10 & 22,36 & 60 & 40 & 25 & 12,700 & 0,095 & 1,700 \\
\hline 6 & 7,70 & 22,62 & 70 & 30 & 25 & 13,615 & 0,200 & 1,790 \\
\hline
\end{tabular}

Como se puede observar, se logra el valor más alto de tensión de rotura cuando la longitud de solape es mínima. Y cuando el espesor de capa es máximo se llega al mínimo valor de tensión.

En la tabla también se muestra que el menor valor de tensión se obtiene con el menor porcentaje de rotura cohesiva, sin embargo, un aumento de este parámetro no implica un aumento de la tensión.

Para realizar un mejor análisis de la evolución de la tensión no se tendrán en cuenta las probetas con las cuales se obtienen los valores máximo y mínimo de tensión, ya que el comportamiento de dichas probetas cambia con respecto al del resto debido a se alcanza en un caso la mínima longitud de solape y en el otro el máximo espesor de capa.

En la Figura 52 se describe el efecto que tiene el aumento de espesor de capa en la tensión de rotura. Como se puede comprobar, frente a un aumento tanto del espesor de capa como de la longitud de solape, la tensión de rotura aumenta.

Si el espesor de capa no sufre ninguna variación (probeta 6F) y la longitud aumenta, se produce una disminución de la tensión.

También se deduce que un aumento del espesor junto con un descenso de la longitud, implica un crecimiento de la tensión. 


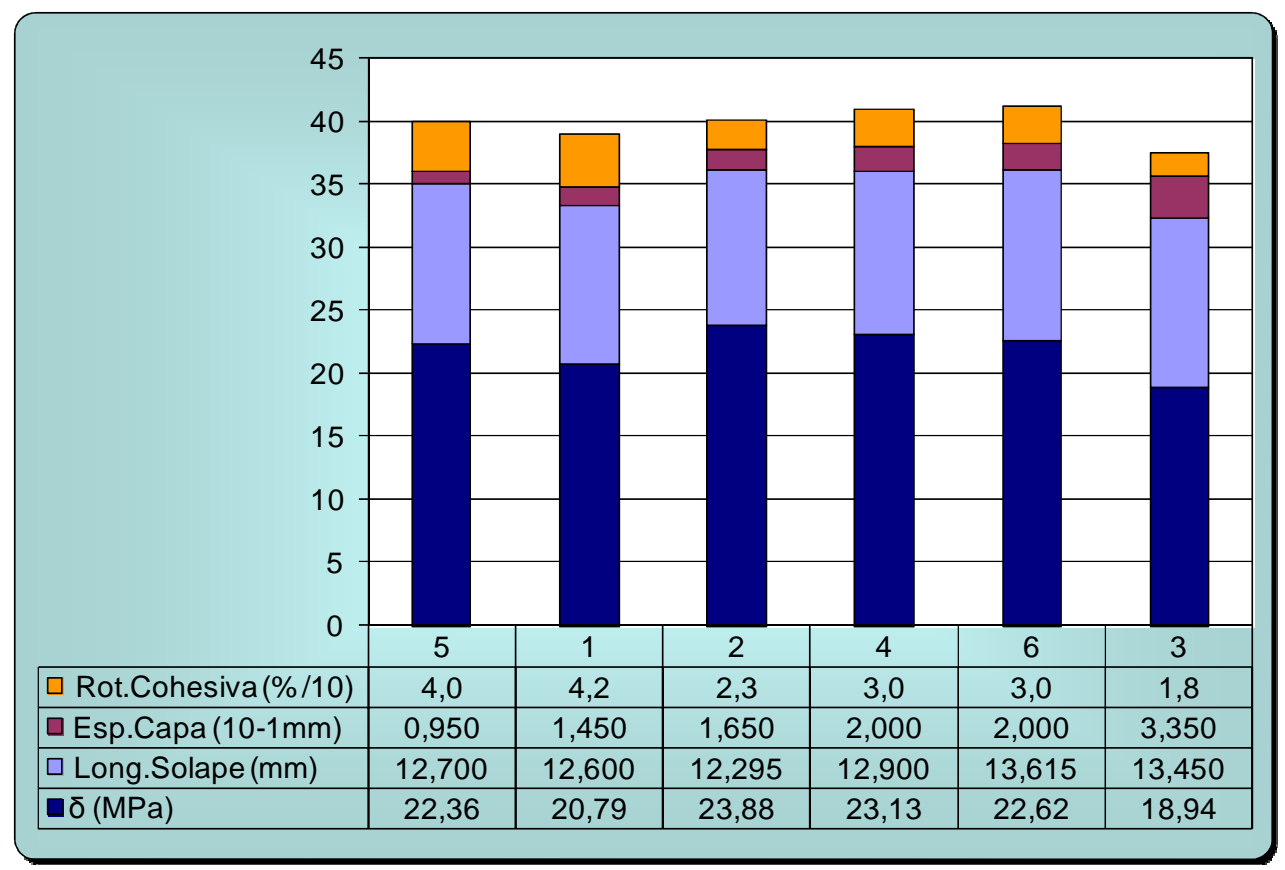

Figura 52. Influencia del espesor de capa adhesiva.

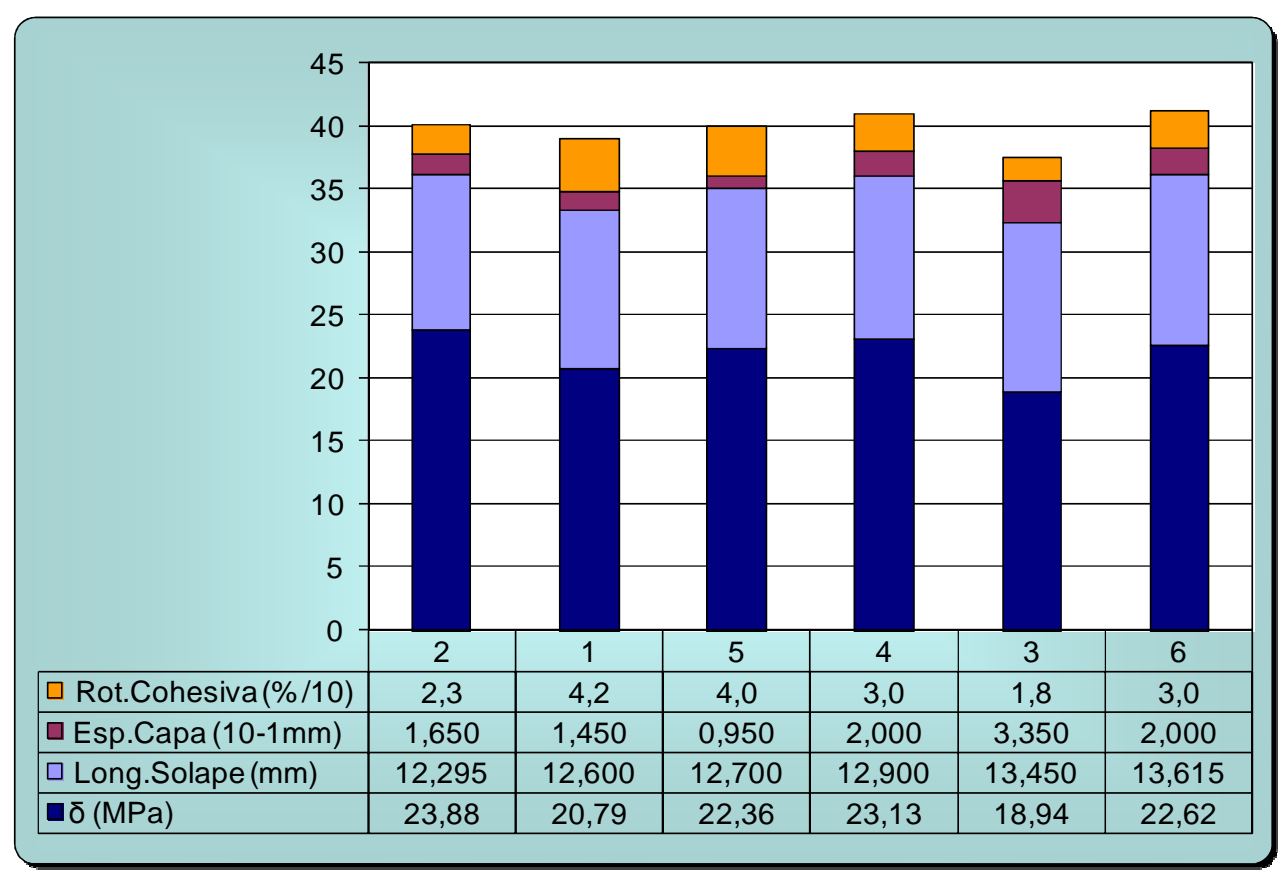

Figura 53. Influencia de la longitud de solape. 
Para contrastar estas conclusiones parciales, se pasa a examinar la variación que sufre la tensión de rotura con el aumento de la longitud de solape. Como se puede observar en la Figura 53, las conclusiones anteriormente mencionadas son confirmadas.

Por lo tanto, se puede concluir que el comportamiento de la tensión de rotura en probetas de acero recubierto de poliéster epoxi es el siguiente:

$\checkmark$ Cuando se alcanza el máximo valor de espesor de capa, la tensión decrece independientemente del valor de la longitud de solape.

$\checkmark$ Cuando se alcanza la mínima longitud de solape, se obtiene un aumento de la tensión de forma independiente al valor del espesor de capa adhesiva.

$\checkmark$ La tensión de rotura aumenta cuando aumenta el espesor de capa (siempre que este parámetro no alcance su valor máximo), independientemente del valor de la longitud de solape.

$\checkmark$ Si espesor de capa no sufre variación, aunque aumente la longitud de solape se produce un descenso en el valor de la tensión.

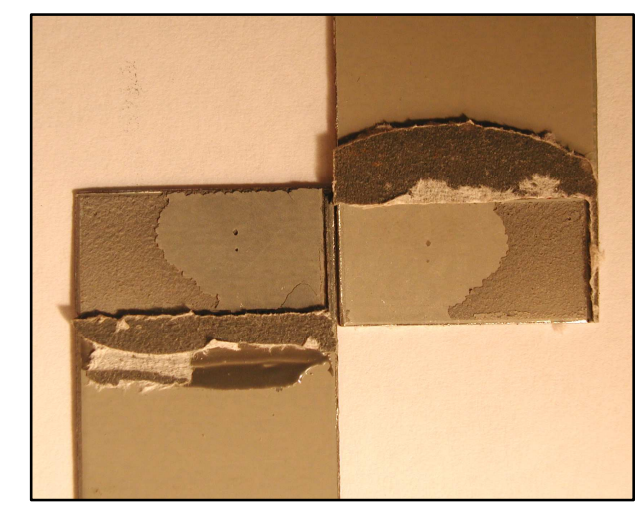

Figura 54. Rotura $42 \%$ cohesiva de probetas de acero con recubrimiento de poliéster epoxi. 


\subsection{Probetas de acero galvanizado y adhesivo epoxi.}

Los resultados correspondientes a los ensayos de cizalladura para las uniones de acero galvanizado con adhesivo epoxi bicomponente Loctite Hysol 9464 se detallan en la siguiente tabla:

Tabla 5. Resultados de probetas de acero galvanizado.

\begin{tabular}{|c|c|c|c|c|c|c|c|c|}
\hline \multirow{2}{*}{\multicolumn{5}{|c|}{\begin{tabular}{|ll} 
ENSAYO: & Cizalladura \\
UNIÓN: & Adhesiva-Loctite-Hysol 9464
\end{tabular}}} & FR medio & 3,44 & TR medio & 10,82 \\
\hline & & & & & $\mathrm{s}(\mathrm{N} / \mathrm{mm} 2)$ & 0,40 & $\mathrm{~s}(\mathrm{~N} / \mathrm{mm} 2)$ & 1,57 \\
\hline \multirow{2}{*}{\multicolumn{5}{|c|}{$\begin{array}{l}\text { UNIÓN: } \quad \text { Adhesiva-Loctite-Hysol } 9464 \\
\text { SUPERFICIE: } \quad \text { Acero Galvanizado } \\
\text { PREP. SUPERFICIAL: Limpieza acetona }\end{array}$}} & $\mathrm{CV}(\%)$ & 11,73 & $\mathrm{CV}(\%)$ & 14,49 \\
\hline & & & & & $A \%$ & 100,00 & C \% & 0,00 \\
\hline \multicolumn{5}{|c|}{ CURADO (DÍAS): $\quad 3$} & I medio & 12,76 & t medio & 0,24 \\
\hline \multirow[b]{2}{*}{ Probeta } & \multirow[b]{2}{*}{$\begin{array}{c}\text { Fuerza } \\
\text { Rotura } \\
\text { kN }\end{array}$} & \multirow[b]{2}{*}{$\begin{array}{c}\text { Tensión } \\
\text { Rotura } \\
\mathrm{MPa}\end{array}$} & \multicolumn{2}{|c|}{ Rotura \% } & \multicolumn{4}{|c|}{ Dimensiones de la probeta en $\mathrm{mm}$} \\
\hline & & & Adhesiva & Cohesiva & $b$ & $\begin{array}{l}\text { Long. } \\
\text { Solape } \\
\text { I (mm) }\end{array}$ & $\begin{array}{c}\text { Espesor } \\
\text { capa } \\
t(\mathrm{~mm})\end{array}$ & $\begin{array}{c}\text { Espesor } \\
\text { unión adh. } \\
\text { e }(\mathrm{mm})\end{array}$ \\
\hline 1 & 3,72 & 11,83 & 100 & 0 & 25 & 12,580 & 0,190 & 2,760 \\
\hline 2 & 3,12 & 9,54 & 100 & 0 & 25 & 13,080 & 0,250 & 2,690 \\
\hline 3 & 3,79 & 12,42 & 100 & 0 & 25 & 12,205 & 0,180 & 2,700 \\
\hline 4 & 3,05 & 9,00 & 100 & 0 & 25 & 13,555 & 0,160 & 2,770 \\
\hline 5 & 3,98 & 12,81 & 100 & 0 & 25 & 12,425 & 0,290 & 2,710 \\
\hline 6 & 2,96 & 9,32 & 100 & 0 & 25 & 12,700 & 0,370 & 2,620 \\
\hline
\end{tabular}

Se puede observar que la mínima tensión de rotura se consigue cuando se alcanza conjuntamente la máxima longitud de solape y el mínimo espesor de capa.

A continuación se muestra la influencia que tiene un aumento del espesor de capa sobre la tensión de rotura.

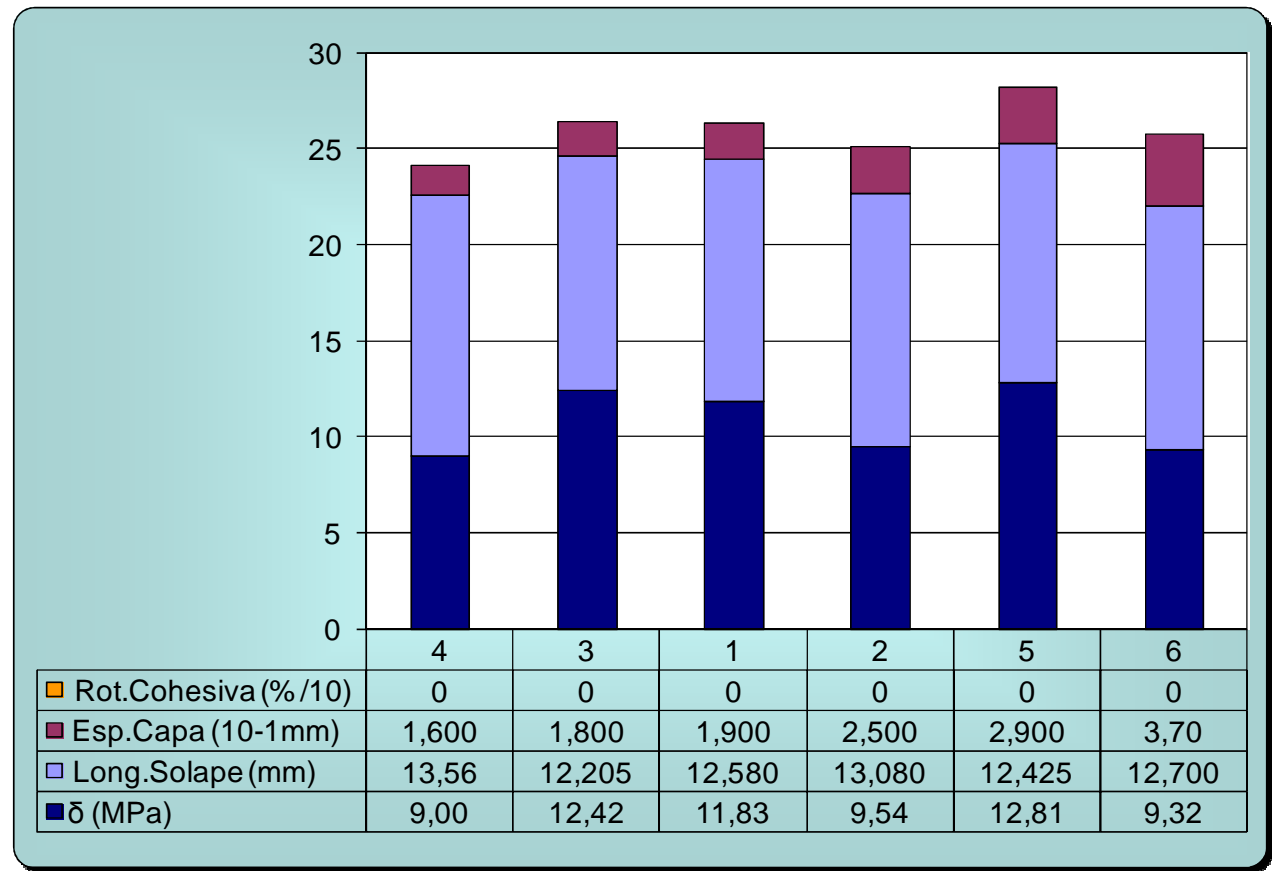

Figura 55. Influencia del espesor de capa adhesiva. 
Se puede observar el siguiente comportamiento:

- Si aumenta tanto la longitud de solape como el espesor de capa adhesiva, se produce un descenso de la tensión.

- Si aumenta el espesor de capa y disminuye la longitud de solape, se logra un aumento de la tensión.

En la Figura 56 se estudia el efecto que provoca el aumento de la longitud de solape en la tensión de rotura.

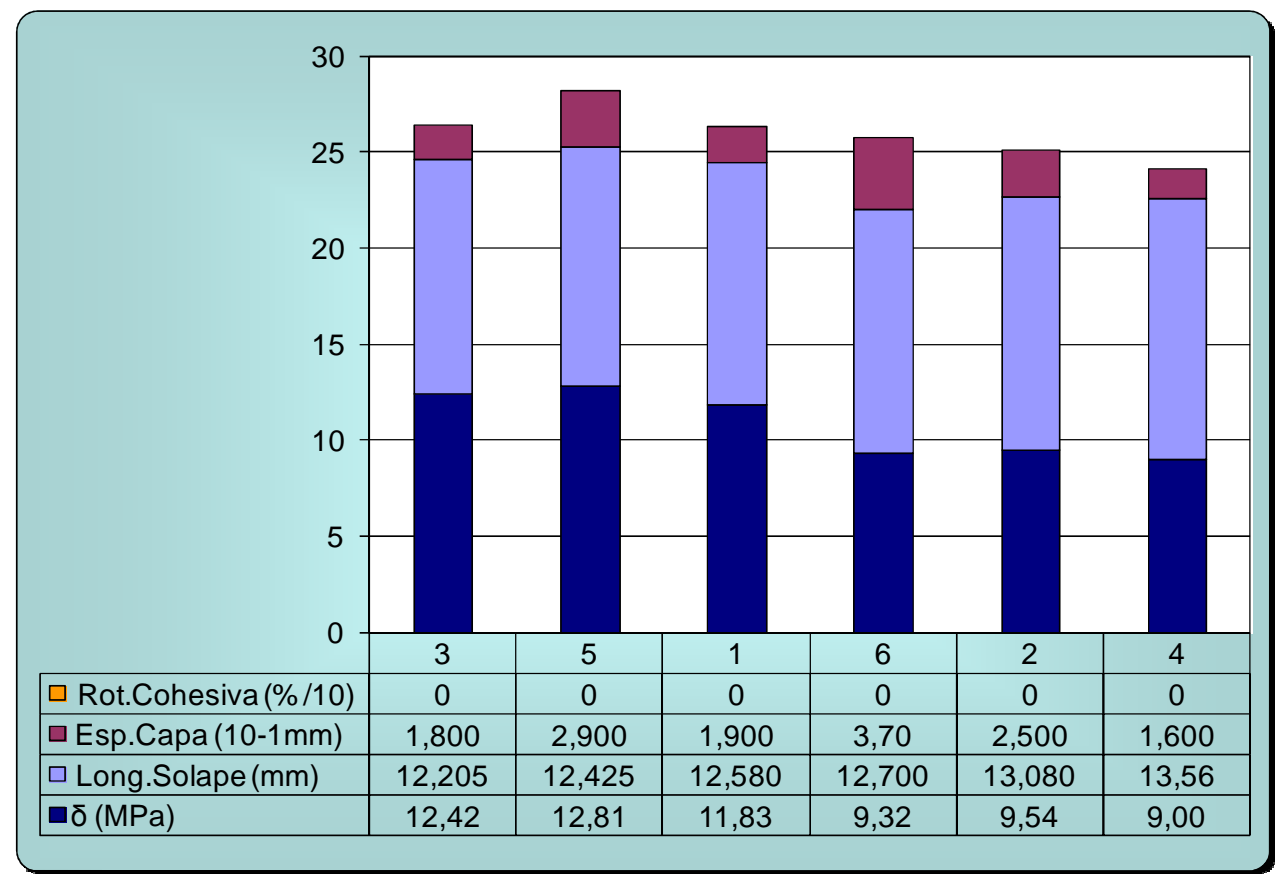

Figura 56. Influencia de la longitud de solape.

Se deducen las siguientes contradicciones:

- En las probetas 5 y 6 un aumento de los dos parámetros, longitud de solape y espesor de capa adhesiva, producen un efecto inverso sobre la tensión. En el caso de la probeta 6, el descenso de la tensión puede deberse preferentemente al hecho de alcanzar el valor máximo de espesor de capa. Aunque se admita este comportamiento como cierto, no implica que se pueda afirmar que un aumento de los dos parámetros provoque un aumento de la tensión (comportamiento que presenta probeta 5), porque de ser así se está contradiciendo las conclusiones parciales obtenidas en la Figura 55. Por lo tanto, es aconsejable no incorporar en el estudio la probeta 5, debido a que su valor máximo de tensión de rotura se ha podido conseguir por azar. Como se ha comprobado en estudios anteriores de probetas, los valores máximos y mínimos de la tensión de rotura se alcanzan cuando se obtienen estos valores límites en la longitud o espesor. 
- También se observa en la Figura 56 que un aumento de la longitud de solape junto con un descenso del espesor de capa, siempre que no se alcancen los valores máximo de longitud y mínimo de espesor, logran un crecimiento de la tensión de rotura. Esto contradice lo confirmado en la Figura 55. Se demuestra que debe realizarse un análisis doble, primero se observará el comportamiento de las probetas que alcanzan los valores máximo o mínimo de longitud y espesor, y posteriormente se examinará sólo las probetas con valores intermedios entre ambos límites.

Por lo tanto, se puede concluir que el comportamiento de la tensión de rotura en probetas de acero galvanizado es el siguiente:

$\checkmark$ Cuando se alcanzan los valores máximo de longitud de solape y mínimo de espesor de capa, se obtiene la mínima tensión de rotura.

$\checkmark$ Alcanzar el máximo valor de espesor de capa implica un descenso en el valor de la tensión.

$\checkmark$ Para valores diferentes a los citados en los dos puntos anteriores, se demuestra:

* Un aumento de los dos parámetros supone un descenso en la tensión.

* Un aumento del espesor de capa junto con un descenso de la longitud de solape provoca un crecimiento de la tensión.

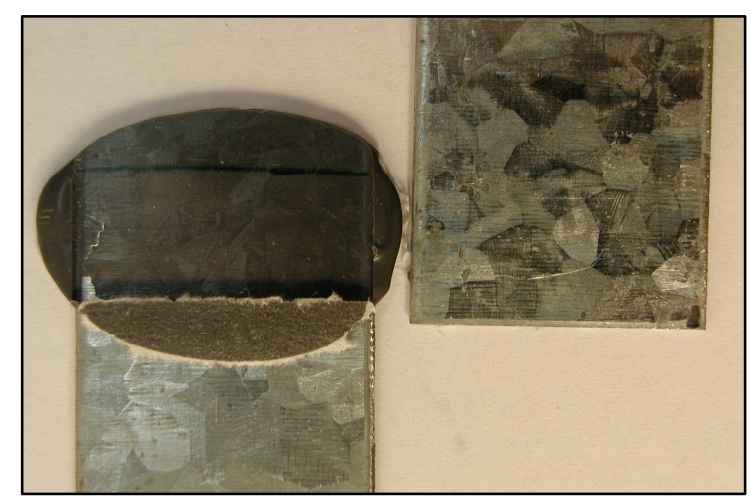

Figura 57. Rotura $100 \%$ adhesiva de probetas de acero galvánico. 


\subsection{Comparación de resultados para probetas unidas con adhesivo epoxi bicomponente Loctite Hysol 9464.}

A continuación se muestra una comparación de los valores obtenidos en los ensayos de tracción a cizalladura simple con el fin de poder discutir cuál es el acabo superficial que alcanza los mejores resultados de resistencia de unión.

Tabla 6. Comparación de resultados de probetas unidas con adhesivo epoxi bicomponente.

\begin{tabular}{|c||c|c|c|c|c|c|}
\hline Superficie & $\begin{array}{c}\text { Longitud Solape } \\
(\mathbf{m m})\end{array}$ & $\begin{array}{c}\text { Espesor Capa } \\
(\mathbf{m m})\end{array}$ & $\begin{array}{c}\text { Fuerza Rotura } \\
\text { (kN) }\end{array}$ & $\begin{array}{c}\text { Tensión Rotura } \\
\text { (MPa) }\end{array}$ & $\begin{array}{c}\text { \%Rotura } \\
\text { Adhesiva }\end{array}$ & $\begin{array}{c}\text { \%Rotura } \\
\text { Cohesiva }\end{array}$ \\
\hline \hline Ac. Blanco & 13,47 & 0,16 & 4,58 & 13,58 & 99 & 1 \\
\hline $\begin{array}{c}\text { Ac. Recubrimiento } \\
\text { orgánico poliéster } \\
\text { (pint.roja) }\end{array}$ & 13,46 & 0,36 & 1,34 & 4,27 & 100 & 0 \\
\hline $\begin{array}{c}\text { Ac. Recubrimiento } \\
\text { orgánico poliéster epoxi } \\
\text { (pint.gris) }\end{array}$ & 12,93 & 0,19 & 7,09 & 21,95 & 69 & 31 \\
\hline Ac. Galvanizado & 12,76 & 0,24 & 3,44 & 10,82 & 100 & 0 \\
\hline
\end{tabular}

Los resultados de los ensayos de cizalladura por tracción a solape simple muestran que las probetas de acero con recubrimiento de poliéster epoxi han alcanzado valores muy superiores a los conseguidos en el resto de las uniones. Por lo tanto, se recomienda la utilización de este tipo de unión adhesiva en cualquier aplicación que esté sometida a esfuerzos de cizalladura para alcanzar los máximos valores de resistencia de unión, es decir, la mayor tensión de rotura y el mayor porcentaje de rotura cohesiva.

Una segunda opción será el empleo de probetas de acero blanco. Se alcanzan buenos resultados de tensión de rotura, aunque el fallo de la unión es principalmente adhesivo, rotura poco deseada.

Con las probetas de acero con recubrimiento de poliéster se obtienen los peores resultados: una tensión de rotura muy baja y siempre se tendrá un fallo de la junta de tipo adhesivo. Con las probetas de acero galvanizado se logra una tensión de rotura media, pero al igual que sucede con las probetas con recubrimiento de poliéster, la rotura siempre es adhesiva. En un principio se pensó que estas probetas serían las que proporcionarían los mejores resultados de resistencia de unión, debido al pretratamiento superficial que poseen contra la corrosión. Por lo tanto, estas uniones no serán recomendadas para aplicaciones sometidas a esfuerzos de cizalladura.

El fallo adhesivo se ha debido a que no se han conseguido las mejores condiciones de adhesión, y el adhesivo está trabajando por debajo de sus posibilidades. El sistema de adhesión utilizado no es, por tanto, el más adecuado para este tipo de preparación superficial. La modificación de la superficie mediante un lijado para aumentar la rugosidad superficial, podría haber supuesto una mejora en la adhesión, pero no se ha realizado, ya que el objetivo de esta tesis era el estudio del comportamiento sobre la superficie estándar, evitando los encarecimientos inherentes a cualquier proceso adicional de preparación superficial. 

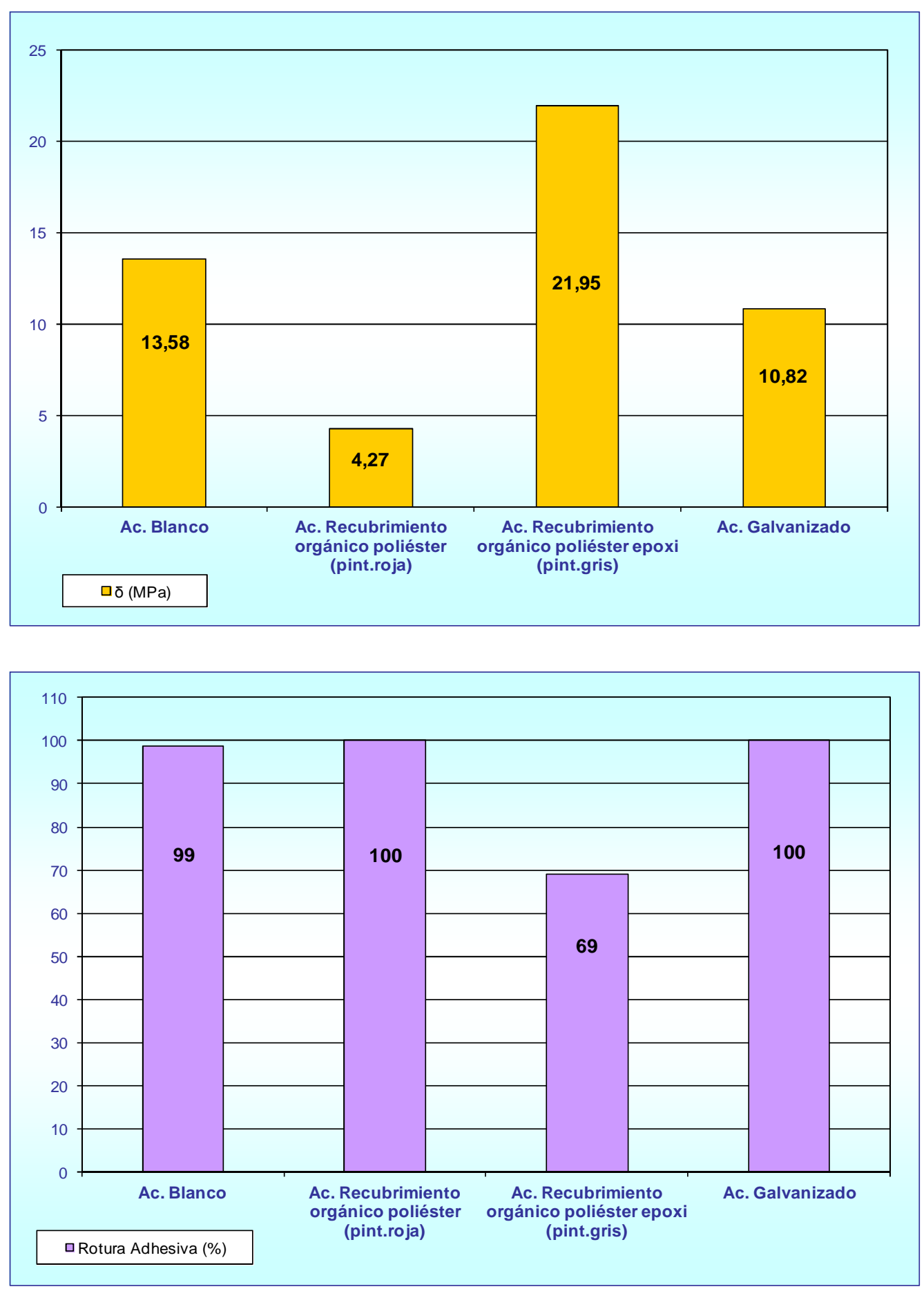

Figura 58. Comparación de la Tensión de Rotura y del porcentaje de Rotura Adhesiva. 


\section{ANÁLISIS DE LOS RESULTADOS DEL ENSAYO DE TRACCIÓN A CIZALLADURA SIMPLE CON SILANO MODIFICADO TEROSTAT MS} 939.

\subsection{Probetas de acero blanco y adhesivo silano modificado.} dieciocho.

Se han realizado tres series de ensayos, dos compuestas por doce probetas y una por

Se ha elegido modificar el tiempo del proceso de curado del adhesivo para estudiar la influencia que tiene este parámetro de unión, junto con la influencia de las variaciones que sufren la longitud de solape y el espesor de capa, sobre el porcentaje de rotura cohesiva (fallo adhesivo o fallo cohesivo) y sobre la resistencia de unión (tensión de rotura).

\subsubsection{Resultados y conclusiones para probetas con un tiempo de curado de 3 días:}

La siguiente tabla describe los resultados obtenidos en los ensayos de cizalladura para las probetas de acero blanco con tres días de curado:

Tabla 7. Resultados de probetas de acero blanco con 3 días de curado.

\begin{tabular}{|c|c|c|c|c|c|c|c|c|}
\hline \multirow{2}{*}{\multicolumn{5}{|c|}{$\begin{array}{ll}\text { ENSAYO: } & \text { Cizalladura } \\
\text { UNIÓN: } & \text { Adhesiva-Terostat-MS } 939\end{array}$}} & FR medio & 1,14 & TR medio & 3,41 \\
\hline & & & & & $\mathrm{s}(\mathrm{N} / \mathrm{mm} 2)$ & 0,18 & $\mathrm{~s}(\mathrm{~N} / \mathrm{mm} 2)$ & 0,50 \\
\hline \multirow{2}{*}{\multicolumn{5}{|c|}{$\begin{array}{l}\text { SUPERFICIE: } \quad \text { Acero blanco } \\
\text { PREP. SUPERFICIAL: Limpieza con agua y jabón + } \\
\text { Limpieza con acetona }\end{array}$}} & $\mathrm{CV}(\%)$ & 15,87 & $\mathrm{CV}(\%)$ & 14,71 \\
\hline & & & & & $A \%$ & 63,33 & $\mathbf{C} \%$ & 36,67 \\
\hline \multicolumn{5}{|c|}{ CURADO (DÍAS): $\quad \mathbf{3}$} & I medio & 13,33 & t medio & 0,31 \\
\hline \multirow[b]{2}{*}{ Probeta } & \multirow[b]{2}{*}{$\begin{array}{l}\text { Fuerza } \\
\text { Rotura } \\
\mathrm{kN}\end{array}$} & \multirow[b]{2}{*}{$\begin{array}{c}\text { Tensión } \\
\text { Rotura } \\
\text { MPa }\end{array}$} & \multicolumn{2}{|c|}{ Rotura \% } & \multicolumn{4}{|c|}{ Dimensiones de la probeta en $\mathrm{mm}$} \\
\hline & & & Adhesiva & Cohesiva & $b$ & $\begin{array}{l}\text { Long. } \\
\text { Solape } \\
\text { I (mm) }\end{array}$ & $\begin{array}{c}\text { Espesor } \\
\text { capa } \\
t(\mathrm{~mm})\end{array}$ & $\begin{array}{c}\text { Espesor } \\
\text { unión adh. } \\
e(\mathrm{~mm})\end{array}$ \\
\hline 1FT3d & 1,00 & 2,96 & 90 & 10 & 25,00 & 13,515 & 0,370 & 3,150 \\
\hline 2FT3d & 0,97 & 2,96 & 85 & 15 & 25,00 & 13,155 & 0,435 & 3,235 \\
\hline 3FT3d & 1,17 & 3,46 & 85 & 15 & 25,00 & 13,480 & 0,170 & 2,970 \\
\hline 4FT3d & 0,86 & 2,71 & 45 & 55 & 25,00 & 12,720 & 0,375 & 3,170 \\
\hline 5FT3d & 1,20 & 3,73 & 80 & 20 & 25,00 & 12,825 & 0,360 & 3,210 \\
\hline 6FT3d & 1,25 & 3,58 & 25 & 75 & 25,00 & 13,955 & 0,215 & 3,030 \\
\hline 7FT3d & 1,01 & 3,22 & 85 & 15 & 25,00 & 12,550 & 0,090 & 2,895 \\
\hline 8FT3d & 0,87 & 2,64 & 50 & 50 & 25,00 & 13,175 & 0,635 & 3,475 \\
\hline 9FT3d & 1,43 & 4,36 & 30 & 70 & 25,00 & 13,170 & 0,170 & 2,985 \\
\hline 10FT3d & 1,35 & 4,01 & 85 & 15 & 25,00 & 13,475 & 0,205 & 2,995 \\
\hline 11FT3d & 1,29 & 3,70 & 55 & 45 & 25,00 & 13,940 & 0,385 & 3,210 \\
\hline 12FT3d & 1,23 & 3,53 & 45 & 55 & 25,00 & 13,960 & 0,325 & 3,135 \\
\hline
\end{tabular}

Como se puede observar, se ha alcanzado la máxima tensión de rotura cuando se ha obtenido el segundo valor más bajo de espesor de capa adhesiva y cuando tiene lugar la rotura de unión con un elevado porcentaje de cohesión. El mínimo valor de tensión de rotura se obtiene al alcanzarse el máximo valor de espesor de capa. 
Analizando la evolución de la tensión de rotura con la longitud de solape, detallada en la Figura 59, se obtienen las siguientes conclusiones, independientemente del porcentaje de rotura cohesiva obtenida:

- Si aumenta tanto la longitud de solape como el espesor de capa, se produce una disminución de la tensión de rotura. Esto se cumple para todas las probetas excepto para la número 11.

- Un aumento de la longitud y una disminución del espesor, provoca un aumento en la tensión de rotura, excepto en la probeta número 6.

- Si disminuye tanto la longitud como el espesor, la tensión de rotura aumenta, excepto en la probeta número 1 .

En la Figura 60 se muestra la influencia que tiene la variación del espesor de capa adhesiva en la tensión de rotura. Un estudio de esta figura muestra las siguientes conclusiones:

- Si aumenta tanto el espesor de capa como la longitud de solape, se produce una disminución de la tensión de rotura, excepto para las probetas 9 y 11.

- Una disminución del espesor de capa junto con un aumento de la longitud de solape, produce un aumento de la tensión de rotura, excepto en la probeta 12.

- Si disminuye tanto del espesor de capa como la longitud de solape, se provoca un aumento de la tensión de rotura, excepto en las probetas 4 y 7.

- Se puede observar que la tensión de rotura presenta el mismo comportamiento que el espesor de capa, cuando la longitud de solape y el porcentaje de unión cohesiva no muestran ninguna variación.

- Si por el contrario, solo se mantiene constante el valor de la longitud y varían tanto el espesor como el porcentaje de rotura cohesiva, será este último factor el que tenga una mayor influencia sobre la tensión de rotura, es decir, ambas evolucionaran de igual manera.

Una vez analizados ambos diagramas se puede concluir que, en líneas generales, el comportamiento de la tensión de rotura en probetas de acero blanco con un proceso de curado de tres días es el siguiente:

$\checkmark$ Cuando la longitud de solape y el espesor de capa presentan el mismo comportamiento, la tensión de rotura evolucionará de forma contraria, independientemente de los valores del porcentaje de rotura.

$\checkmark$ Cuando ambos parámetros tiene una evolución inversa, la tensión de rotura se verá más influenciada por la longitud de solape, mostrando ambos un comportamiento similar.

$\checkmark$ La tensión de rotura evolucionará de la misma forma que el espesor de capa de la unión adhesiva, cuando la longitud de solape y el porcentaje de unión cohesiva permanezcan constantes.

$\checkmark$ La tensión de rotura evolucionará de manera similar que el porcentaje de rotura cohesiva, cuando la longitud de solape no sufra modificaciones e independientemente de la variación del espesor de capa. 


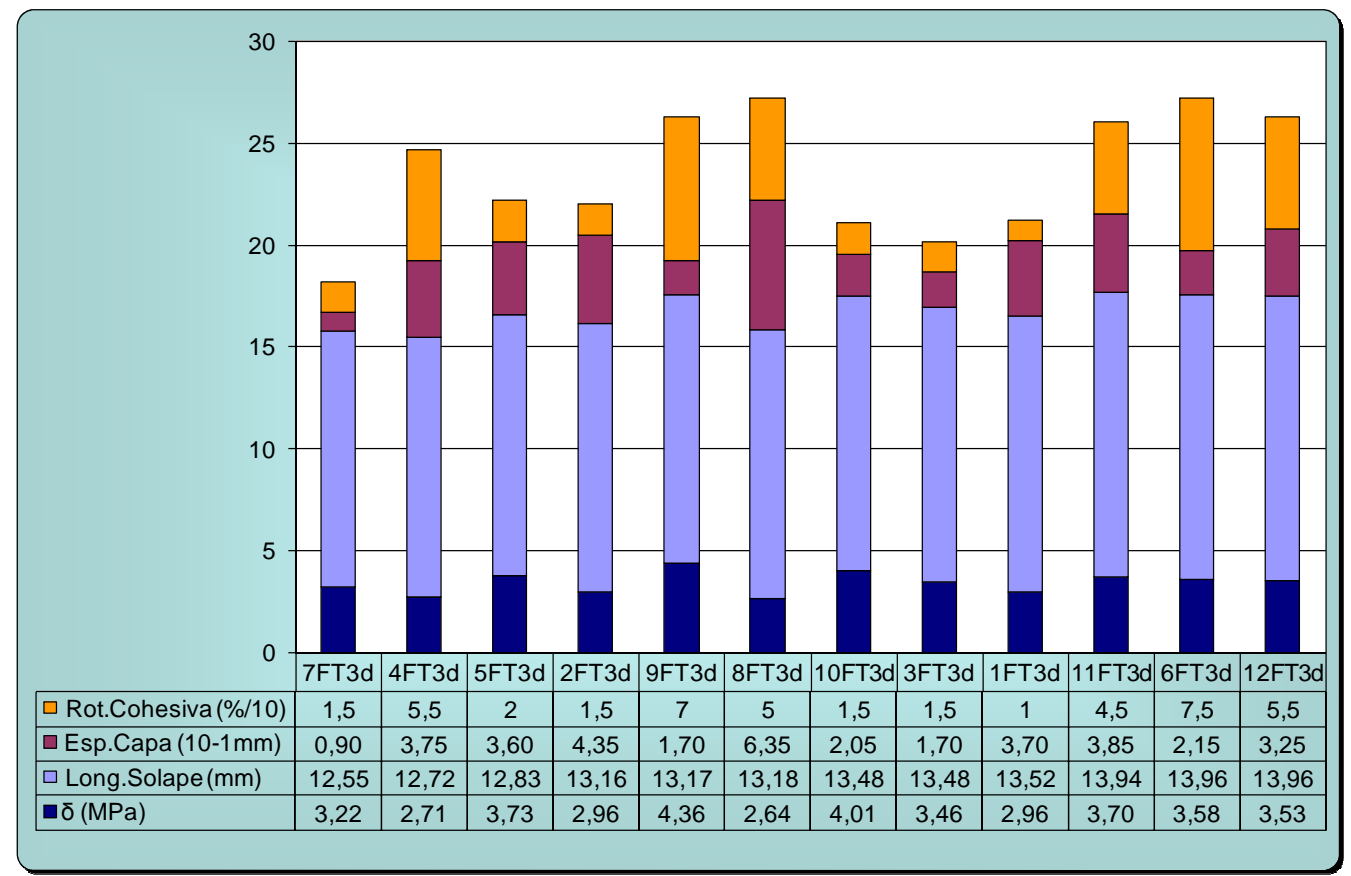

Figura 59. Influencia de la longitud de solape.

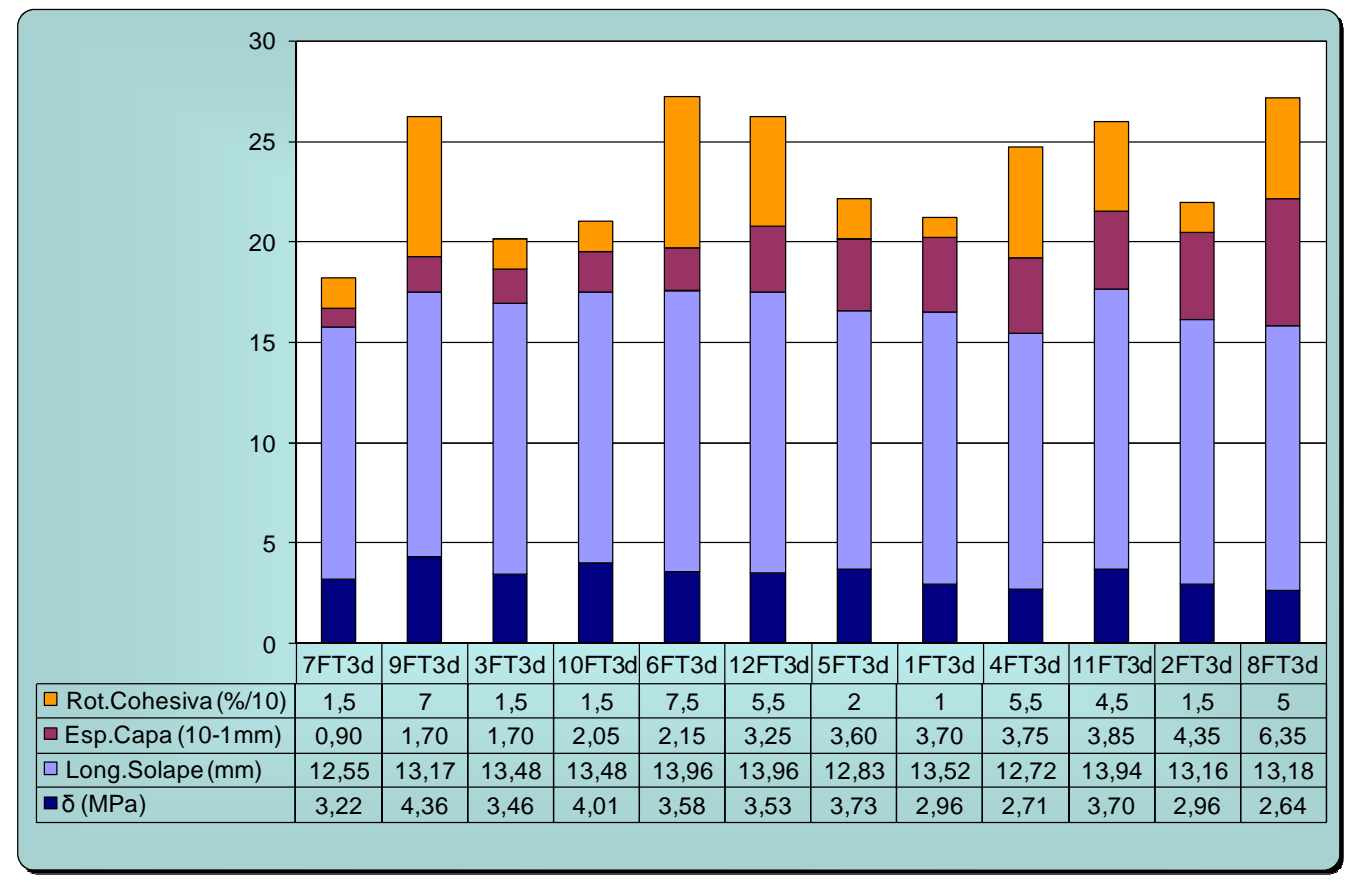

Figura 60. Influencia del espesor de capa adhesiva. 


\subsubsection{Resultados y conclusiones para probetas con un tiempo de curado de 7 días:}

Los resultados correspondientes a las probetas de acero blanco con siete días de curado se detallan en la siguiente tabla:

Tabla 8. Resultados de probetas de acero blanco con 7 días de curado.

\begin{tabular}{|c|c|c|c|c|c|c|c|c|}
\hline & FR medio & 1,19 & TR medio & 3,17 \\
\hline \multirow{3}{*}{\multicolumn{5}{|c|}{$\begin{array}{l}\text { UNIÓN: Adhesiva-Terostat-MS } 939 \\
\text { SUPERFICIE: } \quad \text { Acero blanco } \\
\text { PREP. SUPERFICIAL: Limpieza con agua y jabón + } \\
\quad \text { Limpieza con acetona }\end{array}$}} & $\mathrm{s}(\mathrm{N} / \mathrm{mm} 2)$ & 0,22 & $\mathrm{~s}(\mathrm{~N} / \mathrm{mm} 2)$ & 0,38 \\
\hline & & & & & CV(\%) & 18,64 & $\mathrm{CV}(\%)$ & 11,99 \\
\hline & & & & & $A \%$ & 14,00 & $\mathrm{C} \%$ & 86,00 \\
\hline \multicolumn{5}{|c|}{ CURADO (DÍAS): $\quad \mathbf{7}$} & I medio & 14,91 & t medio & 0,30 \\
\hline \multirow[b]{2}{*}{ Probeta } & \multirow[b]{2}{*}{$\begin{array}{l}\text { Fuerza } \\
\text { Rotura } \\
\text { kN }\end{array}$} & \multirow[b]{2}{*}{$\begin{array}{c}\text { Tensión } \\
\text { Rotura } \\
\mathrm{MPa}\end{array}$} & \multicolumn{2}{|c|}{ Rotura \% } & \multicolumn{4}{|c|}{ Dimensiones de la probeta en $\mathrm{mm}$} \\
\hline & & & Adhesiva & Cohesiva & $b$ & $\begin{array}{l}\text { Long. } \\
\text { Solape } \\
\text { I (mm) }\end{array}$ & $\begin{array}{c}\text { Espesor } \\
\text { capa } \\
t(\mathrm{~mm})\end{array}$ & $\begin{array}{c}\text { Espesor } \\
\text { unión adh. } \\
\text { e }(\mathrm{mm})\end{array}$ \\
\hline 1FT7d & 0,91 & 2,41 & 40 & 60 & 25,00 & 15,130 & 0,425 & 3,150 \\
\hline $2 \mathrm{FT7d}$ & 1,12 & 3,00 & 35 & 65 & 25,00 & 14,890 & 0,410 & 3,160 \\
\hline $3 \mathrm{FT7d}$ & 1,09 & 2,70 & 13 & 87 & 25,00 & 16,225 & 0,270 & 2,900 \\
\hline $4 \mathrm{FT7d}$ & 1,32 & 3,05 & 13 & 87 & 25,00 & 17,335 & 0,240 & 2,970 \\
\hline $5 \mathrm{FT7d}$ & 1,48 & 3,57 & 2 & 98 & 25,00 & 16,545 & 0,500 & 3,295 \\
\hline $6 F T 7 d$ & 1,29 & 3,18 & 2 & 98 & 25,00 & 16,220 & 0,305 & 2,965 \\
\hline 7FT7d & 1,15 & 3,01 & 0 & 100 & 25,00 & 15,355 & 0,595 & 3,285 \\
\hline $8 \mathrm{FT7d}$ & 1,30 & 3,40 & 0 & 100 & 25,00 & 15,320 & 0,595 & 3,405 \\
\hline 9FT7d & 1,48 & 3,54 & 0 & 100 & 25,00 & 16,670 & 0,335 & 3,105 \\
\hline 10FT7d & 1,17 & 3,21 & 5 & 95 & 25,00 & 14,580 & 0,125 & 2,975 \\
\hline $11 \mathrm{FT7d}$ & 1,43 & 3,64 & 0 & 100 & 25,00 & 15,740 & 0,370 & 3,180 \\
\hline $12 \mathrm{FT} 7 \mathrm{~d}$ & 1,66 & 3,96 & 2 & 98 & 25,00 & 16,820 & 0,290 & 3,130 \\
\hline 13FT7d & 0,91 & 2,92 & 20 & 80 & 25,00 & 12,505 & 0,175 & 2,855 \\
\hline 14FT7d & 1,01 & 2,76 & 45 & 55 & 25,00 & 14,540 & 0,310 & 3,135 \\
\hline $15 \mathrm{FT} 7 \mathrm{~d}$ & 1,18 & 3,49 & 25 & 75 & 25,00 & 13,500 & 0,155 & 2,975 \\
\hline $16 \mathrm{FT7d}$ & 1,05 & 3,26 & 35 & 65 & 25,00 & 12,875 & 0,145 & 2,970 \\
\hline $17 \mathrm{FT7d}$ & 0,95 & 3,23 & 5 & 95 & 25,00 & 11,810 & 0,140 & 2,910 \\
\hline $18 \mathrm{FT} 7 \mathrm{~d}$ & 0,84 & 2,73 & 10 & 90 & 25,00 & 12,350 & 0,060 & 2,810 \\
\hline
\end{tabular}

La máxima tensión de rotura se produce cuando se alcanza un alto valor tanto en el porcentaje de rotura cohesiva como en la longitud de solape. Mientras que el mínimo valor de tensión de rotura se obtiene con un bajo porcentaje de rotura cohesiva y un alto valor en el espesor de capa adhesiva.

A continuación se estudia el efecto que tiene la longitud de solape sobre la tensión de rotura. Las conclusiones que se deducen de la Figura 61 son:

- Cuando la longitud de solape, el espesor de capa y el porcentaje de rotura cohesiva evolucionan de igual manera (los tres aumentan o los tres disminuyen), la tensión de rotura mostrará el mismo comportamiento que esos tres factores.

- Cuando la longitud de solape y el espesor de capa muestran un comportamiento homólogo, y el porcentaje de rotura cohesiva presenta una evolución inversa (longitud y espesor aumentan mientras que rotura cohesiva disminuye, o longitud y espesor disminuyen mientras que rotura cohesiva aumenta), se observa una mayor influencia del porcentaje de rotura cohesiva sobre la tensión de rotura; por lo tanto, ambas tiene el 
mismo comportamiento y contrario a la evolución conjunta de la longitud y espesor. Este comportamiento se observa en todas las probetas excepto en la 13 y 18.

- La rotura cohesiva, al igual que antes, tendrá mayor influencia sobre la tensión de rotura cuando la longitud de solape y el espesor de capa evolucionen de manera contraria. Es decir:

- en aquellos casos donde la longitud de solape aumenta y el espesor de capa disminuye, el comportamiento de la tensión de rotura será similar a la evolución del porcentaje de rotura cohesiva: aumentará cuando esta aumente y disminuirá cuando esta disminuya. Este comportamiento se observa en todas las probetas menos en las probetas 12 y 16 . La tensión de rotura en estas probetas evoluciona de la misma manera que la longitud de solape, e inversamente al espesor capa y rotura cohesiva.

- de manera similar ocurre en los casos donde la longitud de solape disminuye y el espesor de capa aumenta: la tensión de rotura evoluciona de igual manera que la rotura cohesiva, excepto en las probetas 9 y 13. En estos casos la tensión de rotura y la longitud de solape evolucionan de manera similar y contraria al espesor de capa y rotura cohesiva.

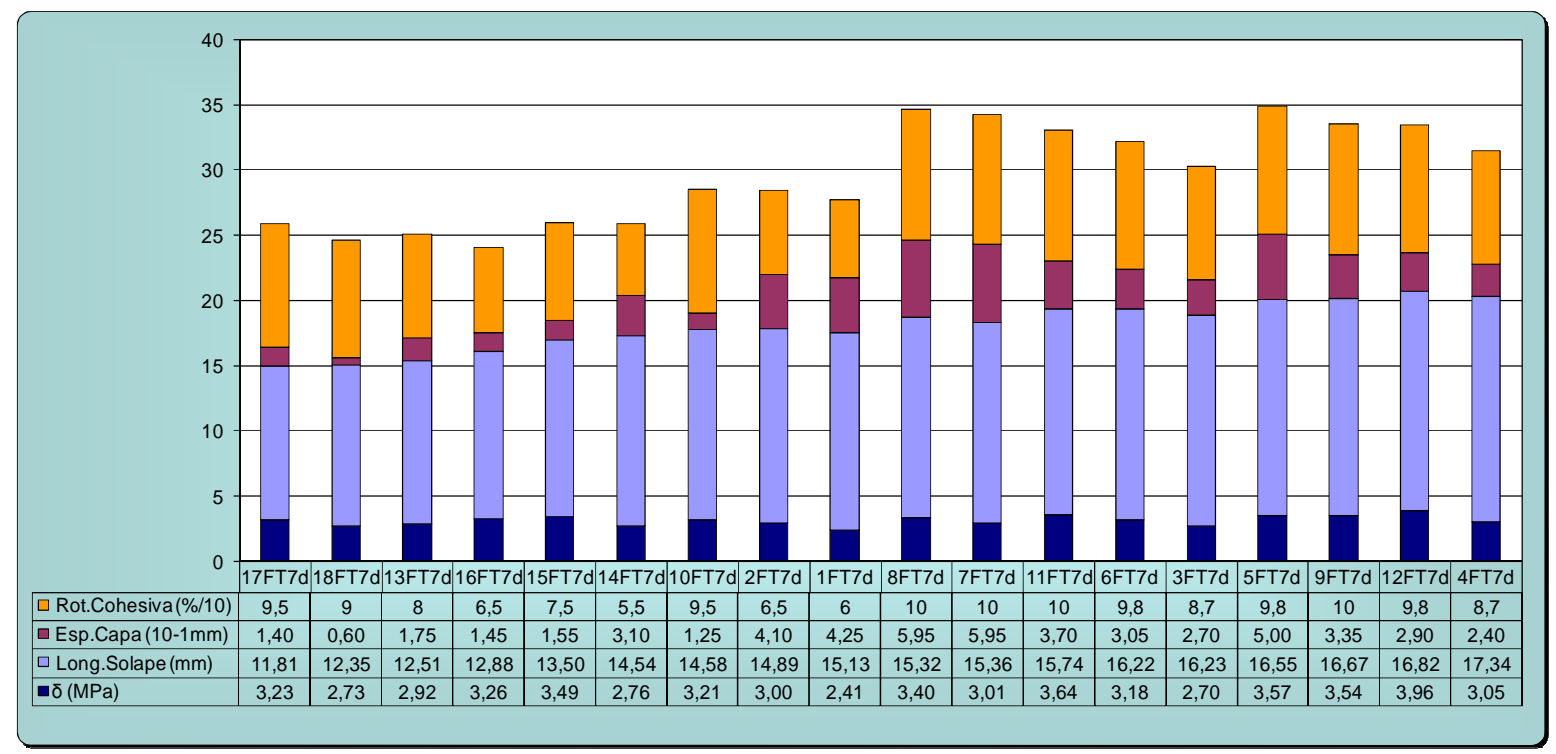

Figura 61. Influencia de la longitud de solape.

Con el fin de confirmar las conclusiones detalladas anteriormente o de obtener otras nuevas, se examina la Figura 62, donde se representa la evolución de la tensión de rotura en función del aumento del espesor de capa. Se verifican las siguientes conclusiones:

- Cuando la longitud de solape, el espesor de capa y el porcentaje de rotura cohesiva evolucionan de igual manera, la tensión de rotura mostrará la misma evolución que esos tres factores. 
- Cuando la longitud de solape y el espesor de capa muestran un comportamiento homólogo y el porcentaje de rotura cohesiva presenta una evolución inversa, la tensión de rotura presentará un comportamiento similar a la rotura cohesiva y contrario, por lo tanto, a la longitud de solape y espesor de capa.

Sin embargo, se observan las siguientes contradicciones:

- Cuando el espesor de capa y la longitud de solape evolucionen de manera contraria, la tensión de rotura ya no se verá influida por la evolución del porcentaje de rotura. En esta ocasión, la tensión seguirá una evolución similar a la longitud de solape, independientemente del porcentaje de rotura cohesiva:

- En aquellos casos donde el espesor de capa aumenta y la longitud de solape disminuye, la tensión de rotura decrece independientemente de la evolución del porcentaje de rotura cohesiva, excepto en las probetas 11 y 17 .

- La tensión de rotura crece cuando el espesor de capa disminuye y la longitud de solape aumenta, excepto en las probetas 9 y 10.

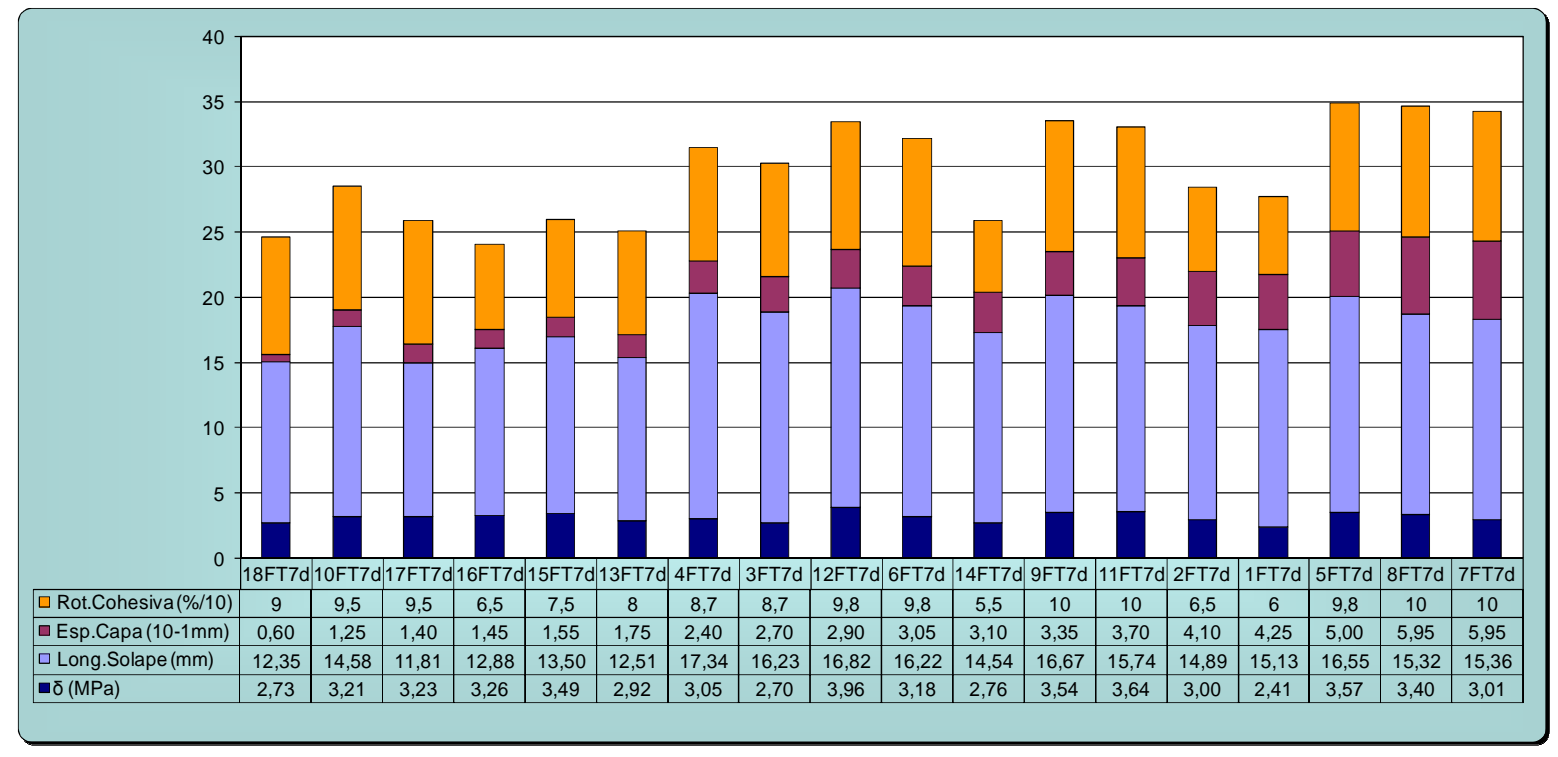

Figura 62. Influencia del espesor de capa adhesiva.

Una vez analizados ambos diagramas se puede concluir que, en líneas generales, el comportamiento de la tensión de rotura en probetas de acero blanco con un proceso de curado de siete días es el siguiente:

$\checkmark$ Cuando longitud de solape y espesor de capa evolucionan de igual forma, será el porcentaje de rotura cohesiva el factor que mayor influencia tenga sobre el comportamiento de la tensión de rotura, evolucionando ambos de forma similar.

$\checkmark$ Cuando longitud de solape y espesor de capa evolucionan de forma inversa, no se puede concretar que parámetro influye en mayor medida sobre el comportamiento de la tensión de rotura. 


\subsubsection{Resultados y conclusiones para probetas con un tiempo de curado de 14 días:}

Los resultados correspondientes a las probetas de acero blanco con catorce días de curado se detallan en la siguiente tabla:

Tabla 9. Resultados de probetas de acero blanco con 14 días de curado.

\begin{tabular}{|c|c|c|c|c|c|c|c|c|}
\hline \multirow{2}{*}{\multicolumn{5}{|c|}{\begin{tabular}{|ll} 
ENSAYO: & Cizalladura \\
UNIÓN: & Adhesiva-Terostat-MS 939
\end{tabular}}} & FR medio & 1,16 & TR medio & 3,44 \\
\hline & & & & & $\mathrm{s}(\mathrm{N} / \mathrm{mm} 2)$ & 0,23 & $\mathrm{~s}(\mathrm{~N} / \mathrm{mm} 2)$ & 0,64 \\
\hline \multirow{2}{*}{\multicolumn{5}{|c|}{ 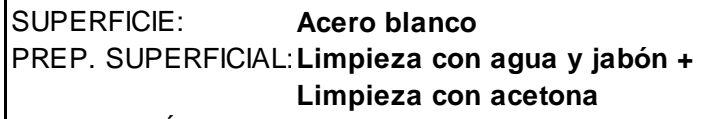 }} & $\mathrm{CV}(\%)$ & 19,57 & $\mathrm{CV}(\%)$ & 18,53 \\
\hline & & & & & $A \%$ & 66,75 & $\mathbf{C} \%$ & 33,25 \\
\hline \multicolumn{5}{|c|}{ CURADO (DÍAS): $\quad 14$} & I medio & 13,53 & t medio & 0,26 \\
\hline \multirow[b]{2}{*}{ Probeta } & \multirow[b]{2}{*}{$\begin{array}{l}\text { Fuerza } \\
\text { Rotura } \\
\text { kN }\end{array}$} & \multirow[b]{2}{*}{$\begin{array}{l}\text { Tensión } \\
\text { Rotura } \\
\text { N/mm2 }\end{array}$} & \multicolumn{2}{|c|}{ Rotura \% } & \multicolumn{4}{|c|}{ Dimensiones de la probeta en $\mathrm{mm}$} \\
\hline & & & Adhesiva & Cohesiva & $b$ & $\begin{array}{l}\text { Long. } \\
\text { Solape } \\
\text { I (mm) }\end{array}$ & $\begin{array}{c}\text { Espesor } \\
\text { capa } \\
t(\mathrm{~mm})\end{array}$ & $\begin{array}{c}\text { Espesor } \\
\text { unión adh. } \\
\text { e (mm) }\end{array}$ \\
\hline $1 \mathrm{~F} 14 \mathrm{~d}$ & 1,36 & 4,29 & 82 & 18 & 25,00 & 12,675 & 0,150 & 3,010 \\
\hline $2 \mathrm{~F} 14 \mathrm{~d}$ & 1,43 & 4,16 & 82 & 18 & 25,00 & 13,790 & 0,185 & 2,935 \\
\hline 3F14d & 1,18 & 3,26 & 82 & 18 & 25,00 & 14,490 & 0,115 & 2,930 \\
\hline $4 \mathrm{~F} 14 \mathrm{~d}$ & 0,99 & 3,13 & 85 & 15 & 25,00 & 12,690 & 0,315 & 3,100 \\
\hline $5 \mathrm{~F} 14 \mathrm{~d}$ & 1,02 & 3,10 & 85 & 15 & 25,00 & 13,105 & 0,335 & 3,215 \\
\hline $6 \mathrm{~F} 14 \mathrm{~d}$ & 0,86 & 2,80 & 85 & 15 & 25,00 & 12,230 & 0,315 & 3,205 \\
\hline 7F14d & 0,72 & 2,20 & 80 & 20 & 25,00 & 13,150 & 0,580 & 3,375 \\
\hline $8 \mathrm{~F} 14 \mathrm{~d}$ & 1,09 & 3,13 & 25 & 75 & 25,00 & 13,905 & 0,180 & 2,975 \\
\hline 9F14d & 1,25 & 3,40 & 90 & 10 & 25,00 & 14,660 & 0,200 & 3,050 \\
\hline $10 \mathrm{~F} 14 \mathrm{~d}$ & 1,21 & 3,30 & 30 & 70 & 25,00 & 14,710 & 0,365 & 3,230 \\
\hline $11 \mathrm{~F} 14 \mathrm{~d}$ & 1,51 & 4,39 & 60 & 40 & 25,00 & 13,760 & 0,180 & 3,065 \\
\hline $12 \mathrm{~F} 14 \mathrm{~d}$ & 1,35 & 4,09 & 15 & 85 & 25,00 & 13,180 & 0,200 & 3,060 \\
\hline
\end{tabular}

Como muestra la tabla de resultados, la mínima tensión de rotura se alcanza cuando se obtiene el máximo espesor de capa adhesiva. La máxima tensión se consigue para valores bajos de espesor de capa.

En la Figura 63 se muestra la influencia de la longitud de solape sobre la tensión de rotura. Analizando esta figura se comprueba lo siguiente, independientemente del progreso del porcentaje de rotura cohesiva:

- La tensión de rotura presenta la misma evolución que la longitud de solape, cuando este parámetro presenta un comportamiento inverso al del espesor de capa. Esto se cumple para todas las probetas excepto para la número 8.

- Sin embargo, cuando longitud de solape y el espesor de capa tienen una evolución similar, la tensión de rotura muestra un comportamiento contrario, excepto en las probetas 3 y 9.

En la siguiente Figura 64 se detalla la influencia que tiene el aumento del espesor de capa adhesiva en la tensión de rotura. A partir de su estudio se deducen las siguientes conclusiones:

- Cuando el espesor de capa de la unión adhesiva y la longitud de solape evolucionan de forma contraria, la tensión de rotura presenta un comportamiento inverso al espesor y, por tanto, similar a la longitud, conclusión que coincide con la mencionada en la Figura 63. Este progreso de la tensión se cumple en todas las probetas excepto en las número 2 y 8. 
- Sin embargo, cuando el espesor de capa y la longitud de solape evolucionan conjuntamente, la tensión de rotura se comporta de forma similar a dichos parámetros, excepto en las probetas 4 y 5.

Una vez analizados ambos diagramas se puede concluir que el comportamiento de la tensión de rotura en probetas de acero blanco con un proceso de curado de catorce días es el siguiente:

$\checkmark$ Cuando longitud de solape y espesor de capa evolucionan de forma inversa, la tensión de rotura presenta un progreso similar a la longitud e inverso al espesor, independientemente del comportamiento del porcentaje de rotura cohesiva.

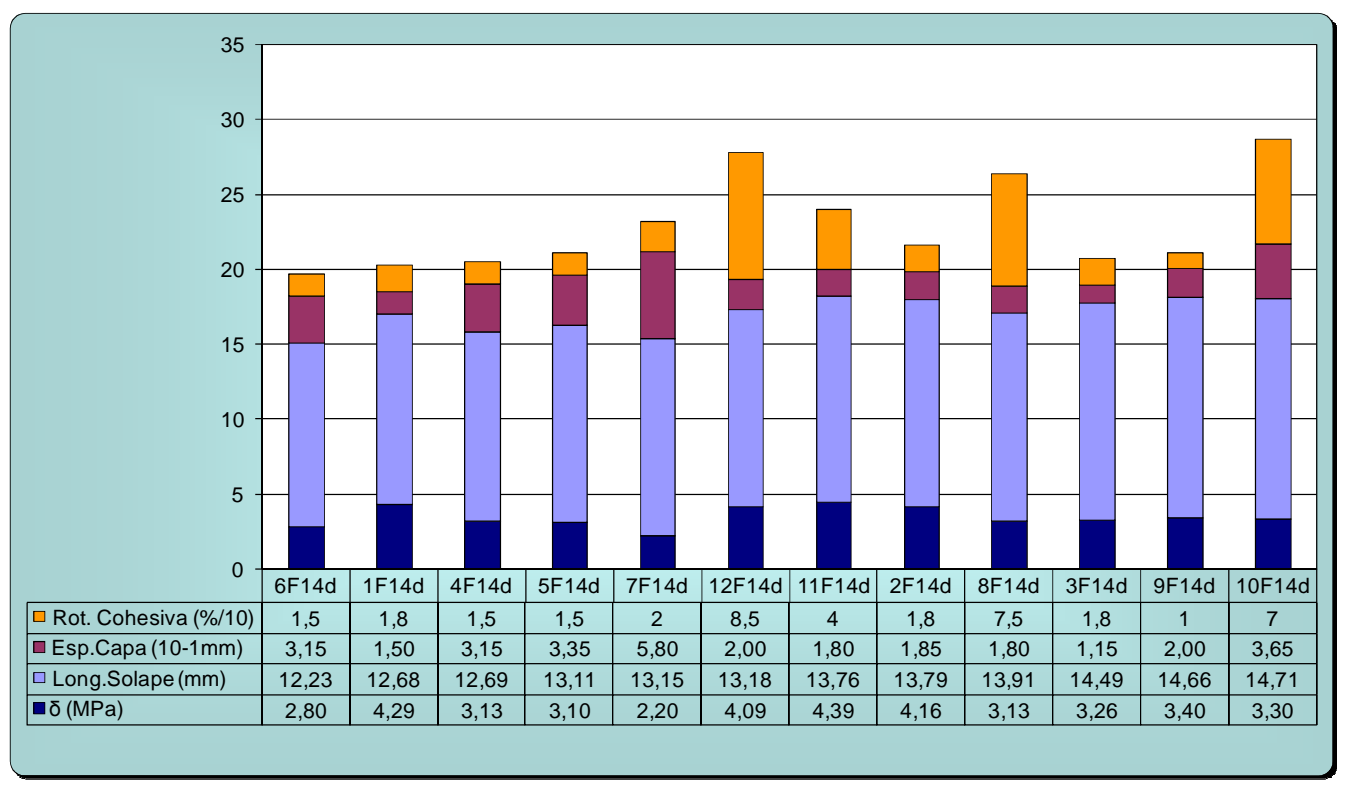

Figura 63. Influencia de la longitud de solape.

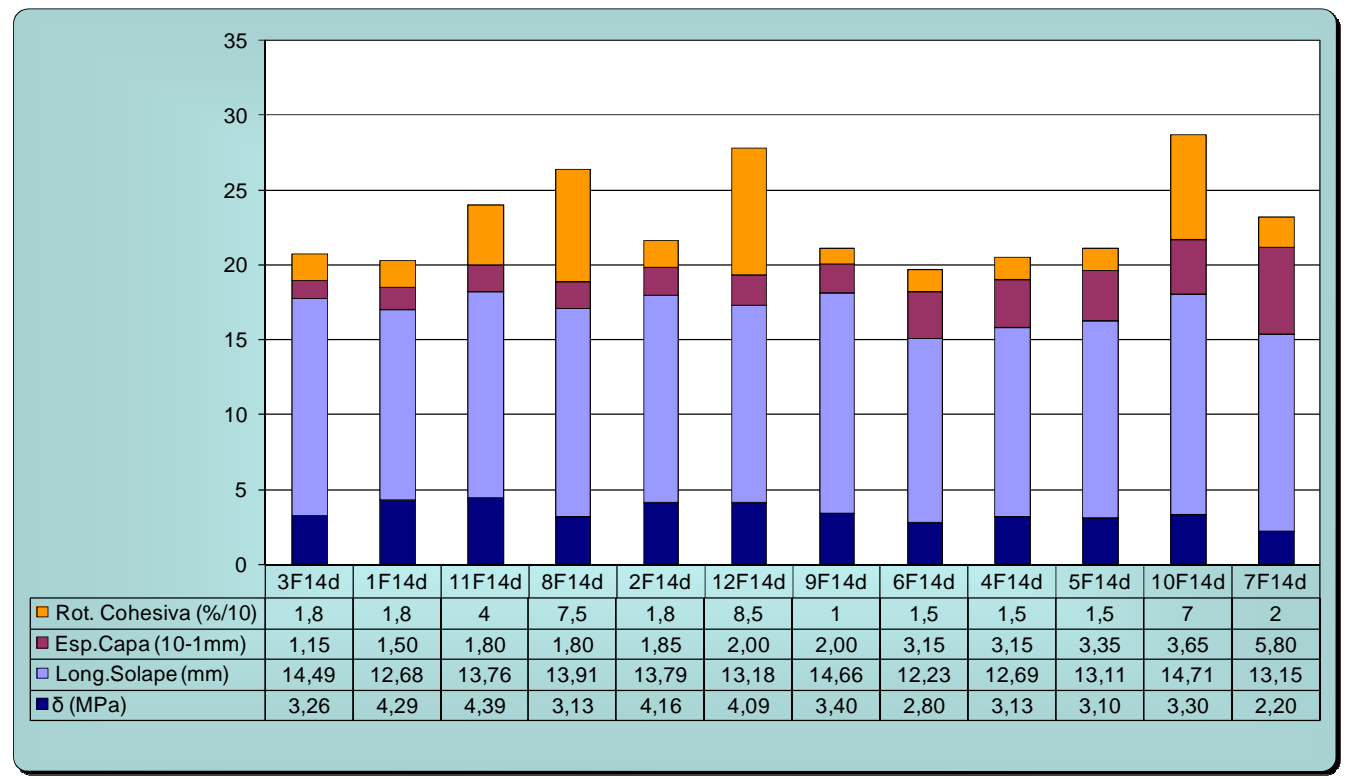

Figura 64. Influencia del espesor de capa adhesiva. 


\subsubsection{Análisis de la influencia del tiempo de curado en probetas de acero blanco:}

En la siguiente tabla se especifican los valores medios de los principales parámetros de unión para los diferentes tiempos de curado que se han estudiado:

Tabla 10. Comparación de resultados de probetas de acero blanco.

\begin{tabular}{|c||c|c|c|c|c|c|}
\hline $\begin{array}{c}\text { Tiempo } \\
\text { Curado }\end{array}$ & $\begin{array}{c}\text { Longitud Solape } \\
(\mathbf{m m})\end{array}$ & $\begin{array}{c}\text { Espesor Capa } \\
\mathbf{( m m})\end{array}$ & $\begin{array}{c}\text { Fuerza Rotura } \\
\mathbf{( k N )}\end{array}$ & $\begin{array}{c}\text { Tensión Rotura } \\
\text { (MPa) }\end{array}$ & $\begin{array}{c}\text { \%Rotura } \\
\text { Adhesiva }\end{array}$ & $\begin{array}{c}\text { \%Rotura } \\
\text { Cohesiva }\end{array}$ \\
\hline \hline 3 días & 13,33 & 0,31 & 1,14 & 3,41 & 63 & 37 \\
\hline 7 días & 14,91 & 0,30 & 1,18 & 3,17 & 14 & 86 \\
\hline 14 días & 13,53 & 0,26 & 1,17 & 3,44 & 67 & 33 \\
\hline
\end{tabular}

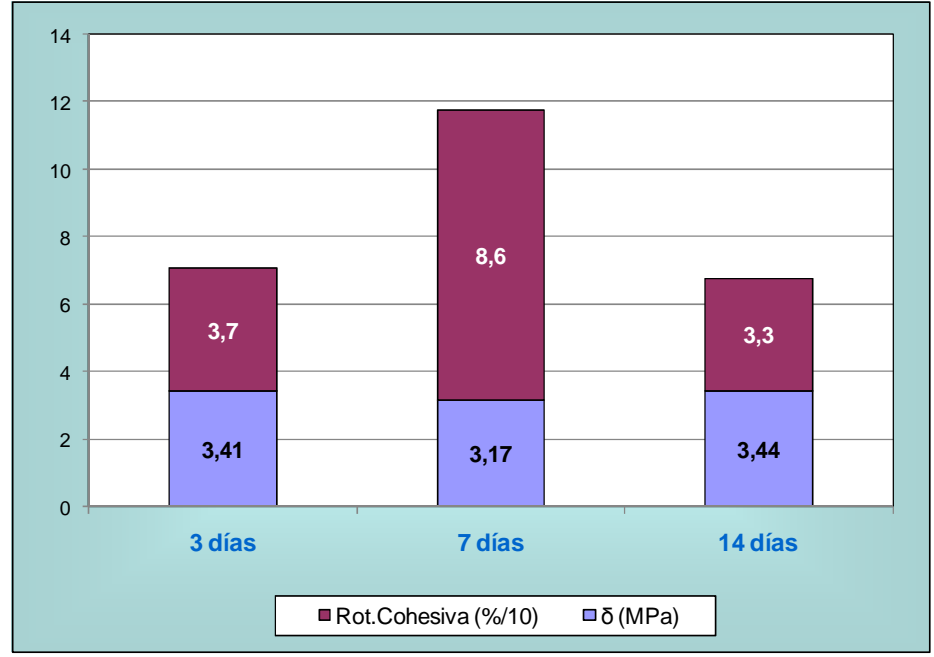

Figura 65. Influencia del Tiempo de Curado.

Se puede comprobar que un aumento del tiempo de curado no mejora la fuerza de rotura de la unión adhesiva en probetas de acero blanco unidas con adhesivo silano modificado. Debido a que no se aprecia ninguna influencia del tiempo de curado del adhesivo sobre la resistencia de unión, cuando se someta ese tipo de uniones adhesivas a ensayos de fatiga, se podrá elegir indistintamente el tiempo de curado. 


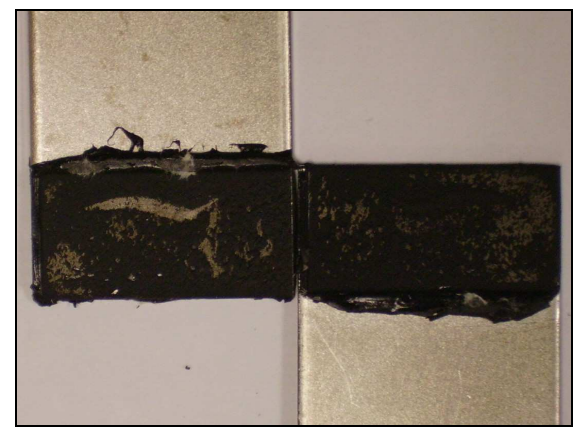

Figura 66. Rotura $70 \%$ cohesiva de probetas con 3 días de curado.

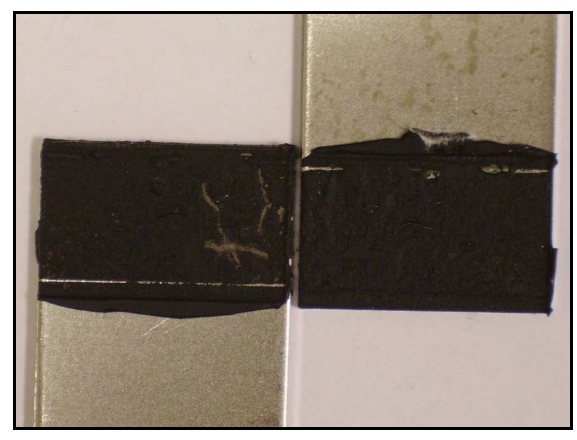

Figura 68. Rotura $100 \%$ cohesiva de probetas con 7 días de curado.

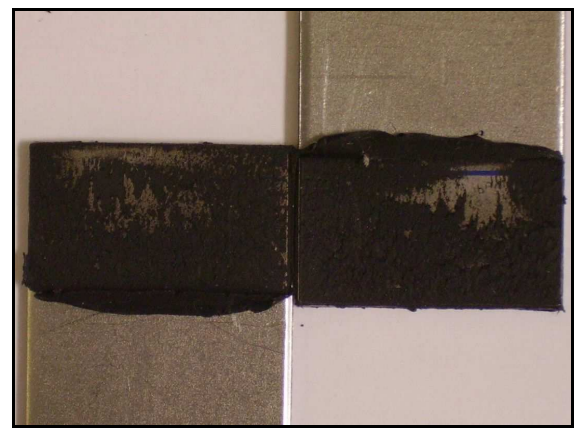

Figura 70. Rotura $75 \%$ cohesiva de probetas con 14 días de curado.

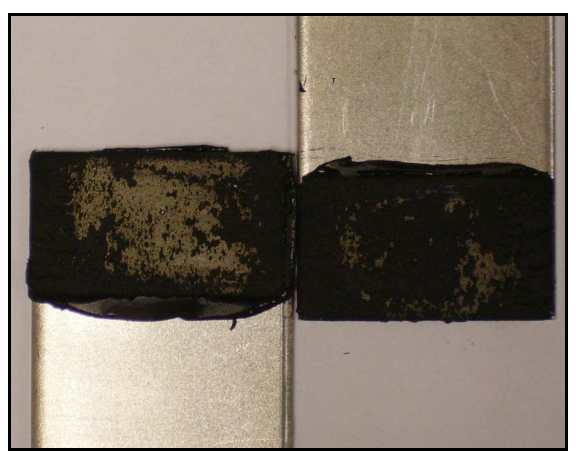

Figura 67. Rotura $45 \%$ cohesiva de probetas con 3 días de curado.

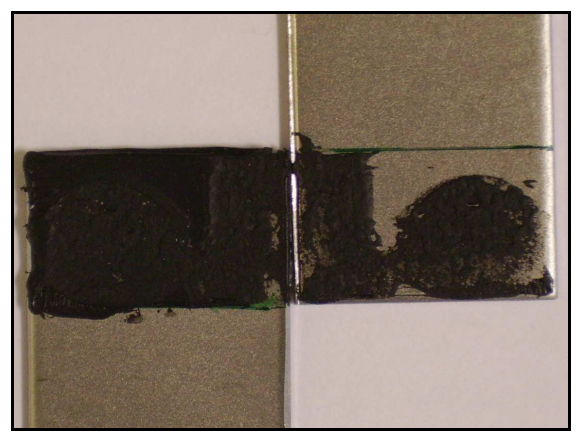

Figura 69. Rotura 55\% cohesiva de probetas con 7 días de curado.

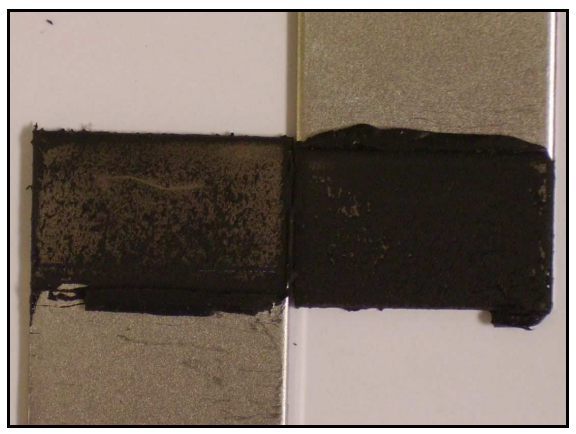

Figura 71. Rotura $10 \%$ cohesiva de probetas con 14 días de curado. 


\subsection{Probetas de acero recubierto de poliéster y adhesivo silano modificado.}

Se han realizado tres series de ensayos, cada una compuesta por doce probetas.

Al igual que en el caso de las probetas de acero blanco, se modificará el tiempo de curado del adhesivo y a continuación se observarán las variaciones que sufren la longitud de solape, espeso de capa y porcentaje de rotura cohesiva, y su influencia sobre la tensión de rotura.

\subsubsection{Resultados $y$ conclusiones para probetas con un tiempo de curado de 3 días:}

La siguiente tabla describe los resultados obtenidos en los ensayos de cizalladura para las probetas de acero recubierto de poliéster con tres días de curado:

Tabla 11. Resultados de probetas de acero recubierto de poliéster con 3 días de curado.

\begin{tabular}{|c|c|c|c|c|c|c|c|c|}
\hline \multirow{5}{*}{\multicolumn{5}{|c|}{$\begin{array}{ll}\text { ENSAYO: } & \text { Cizalladura } \\
\text { UNIÓN: } & \text { Adhesiva-Terostat-MS } 939 \\
\text { SUPERFICIE: } \quad \text { Recubrimiento Poliéster } \\
\text { PREP. SUPERFICIAL: Limpieza acetona } \\
\text { CURADO (DÍAS): } \quad \mathbf{3}\end{array}$}} & \multirow{3}{*}{$\begin{array}{c}\text { FR medio } \\
\mathrm{s}(\mathrm{N} / \mathrm{mm} 2) \\
\mathrm{CV}(\%)\end{array}$} & \multirow{2}{*}{\begin{tabular}{l|}
0,85 \\
0,14
\end{tabular}} & \multirow{2}{*}{$\begin{array}{l}\text { TR medio } \\
\mathrm{s}(\mathrm{N} / \mathrm{mm} 2)\end{array}$} & 2,56 \\
\hline & & & & & & & & 0,43 \\
\hline & & & & & & 16,57 & $\mathrm{CV}(\%)$ & 16,61 \\
\hline & & & & & $\mathrm{A} \%$ & 14,33 & C \% & 85,67 \\
\hline & & & & & I medio & 13,28 & t medio & 0,24 \\
\hline & & & $\overline{\text { Rot }}$ & a \% & "Dim & $\overline{s i o n e s} d t$ & probeta en & $\overline{m m}$ \\
\hline Probeta & $\begin{array}{c}\text { Rotura } \\
\text { kN }\end{array}$ & $\begin{array}{l}\text { Rotura } \\
\mathrm{MPa}\end{array}$ & Adhesiva & Cohesiva & $b$ & $\begin{array}{l}\text { Long. } \\
\text { Solape } \\
\text { I (mm) }\end{array}$ & $\begin{array}{c}\text { Espesor } \\
\text { capa } \\
t(m m)\end{array}$ & $\begin{array}{c}\text { Espesor } \\
\text { unión adh. } \\
e(\mathrm{~mm})\end{array}$ \\
\hline $1 \mathrm{~F} 3 \mathrm{~d}$ & 0,70 & 2,12 & 20 & 80 & 25,00 & 13,140 & 0,130 & 1,755 \\
\hline $2 \mathrm{~F} 3 \mathrm{~d}$ & 0,78 & 2,50 & 22 & 78 & 25,00 & 12,455 & 0,260 & 1,820 \\
\hline 3F3d & 0,87 & 2,68 & 5 & 95 & 25,00 & 13,020 & 0,325 & 1,870 \\
\hline $4 \mathrm{~F} 3 \mathrm{~d}$ & 0,83 & 2,40 & 2 & 98 & 25,00 & 13,830 & 0,265 & 1,815 \\
\hline $5 F 3 d$ & 0,91 & 2,56 & 0 & 100 & 25,00 & 14,180 & 0,255 & 1,835 \\
\hline $6 \mathrm{~F} 3 \mathrm{~d}$ & 0,72 & 2,23 & 0 & 100 & 25,00 & 12,870 & 0,130 & 1,800 \\
\hline $7 F 3 d$ & 0,74 & 2,32 & 20 & 80 & 25,00 & 12,810 & 0,385 & 1,985 \\
\hline $8 \mathrm{~F} 3 \mathrm{~d}$ & 1,19 & 3,42 & 3 & 97 & 25,00 & 13,885 & 0,215 & 1,795 \\
\hline 9F3d & 1,04 & 3,30 & 0 & 100 & 25,00 & 12,605 & 0,225 & 1,795 \\
\hline $10 \mathrm{~F} 3 \mathrm{~d}$ & 0,69 & 1,97 & 92 & 8 & 25,00 & 14,060 & 0,185 & 1,790 \\
\hline $11 \mathrm{~F} 3 \mathrm{~d}$ & 0,82 & 2,33 & 3 & 97 & 25,00 & 14,030 & 0,235 & 1,810 \\
\hline $12 \mathrm{~F} 3 \mathrm{~d}$ & 0,89 & 2,84 & 5 & 95 & 25,00 & 12,500 & 0,210 & 1,820 \\
\hline
\end{tabular}

Se observa que la mínima tensión de rotura se alcanza cuando se obtiene el mínimo porcentaje de rotura cohesiva. Sin embargo, la máxima tensión se produce cuando se alcanza un valor alto, no el máximo, de porcentaje de rotura cohesiva. 
En la Figura 72 se especifica la variación que sufre la tensión de rotura cuando se produce un aumento de la longitud de solape. Se extraen las conclusiones siguientes:

- La tensión de rotura se comporta de igual manera que la longitud de solape, espesor de capa y porcentaje de rotura cohesiva, cuando estos tres factores sufren el mismo tipo de variación.

- Cuando la longitud de solape y el espesor de capa evolucionan de forma no homogénea, la tensión de rotura se comportará de forma semejante al porcentaje de rotura cohesiva.

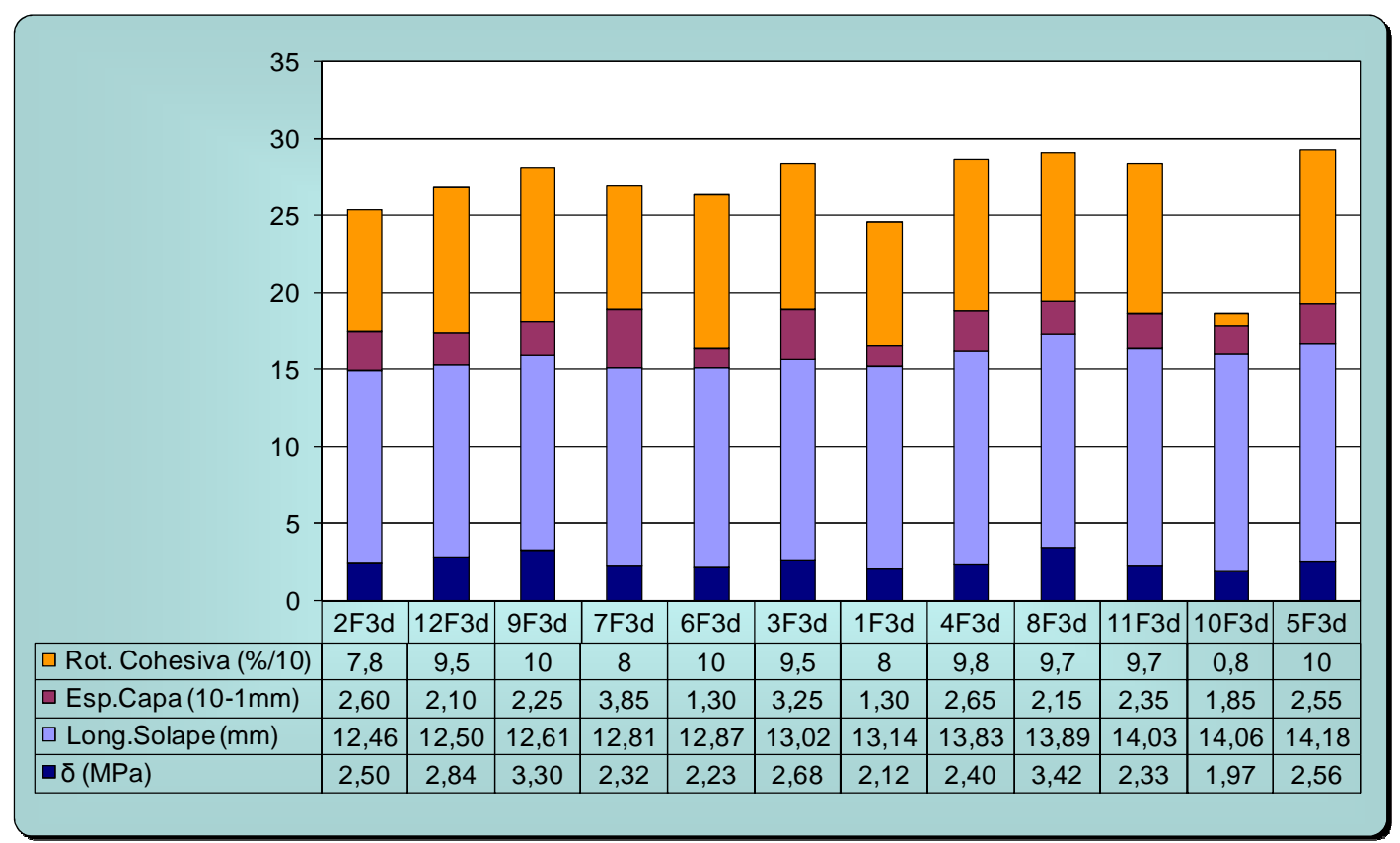

Figura 72. Influencia de la longitud de solape.

La Figura 73 muestra la evolución de la tensión de rotura en función del aumento del espesor de capa adhesiva. Analizando este diagrama se pueden verificar las conclusiones obtenidas en la Figura 72: la tensión de rotura presenta la misma variación que el porcentaje de rotura cohesiva tanto en los casos donde el espesor de capa y la longitud de solape tienen el mismo comportamiento como en los casos donde presentan una evolución contraria.

Por lo tanto, se puede concluir que el comportamiento de la tensión de rotura en probetas de acero recubierto de poliéster con un proceso de curado de tres días es el siguiente:

$\checkmark$ Existe una fuerte influencia del porcentaje de rotura cohesiva sobre la tensión de rotura, de tal manera que ambos evolución de forma semejante e independientemente de la variación que sufra el espesor de capa y la longitud de solape. 


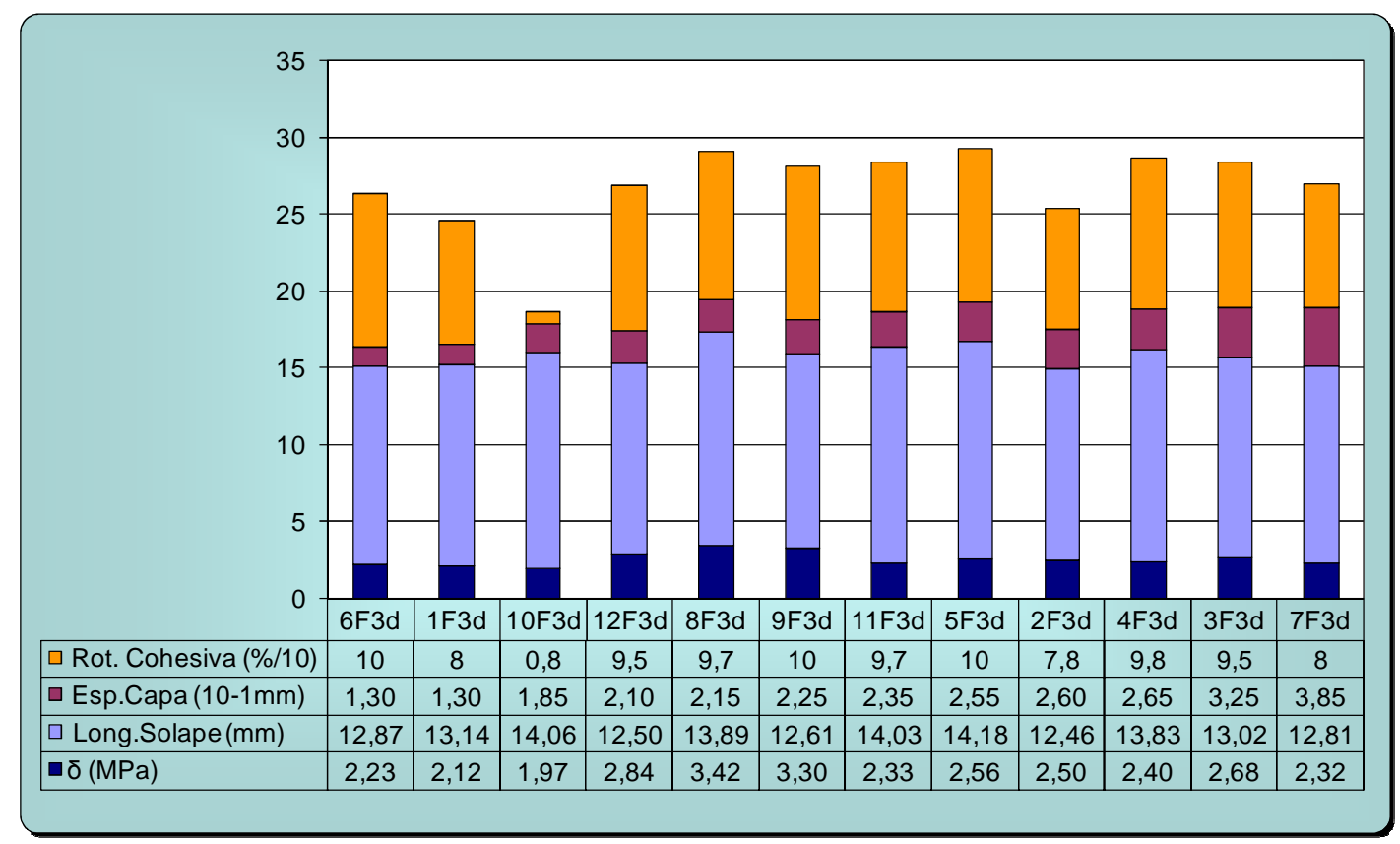

Figura 73. Influencia del espesor de capa adhesiva. 


\subsubsection{Resultados y conclusiones para probetas con un tiempo de curado de 7 días:}

Los resultados correspondientes a las probetas de acero recubierto de poliéster con siete días de curado se detallan en la siguiente tabla:

Tabla 12. Resultados de probetas de acero recubierto de poliéster con 7 días de curado.

\begin{tabular}{|c|c|c|c|c|c|c|c|c|}
\hline \multirow{5}{*}{\multicolumn{5}{|c|}{$\begin{array}{ll}\text { ENSAYO: } & \text { Cizalladura } \\
\text { UNIÓN: } \quad \text { Adhesiva-Terostat-MS } 939 \\
\text { SUPERFICIE: } \quad \text { Recubrimiento Poliéster } \\
\text { PREP. SUPERFICIAL Limpieza acetona } \\
\text { CURADO (DÍAS): } \quad \mathbf{7} \\
\end{array}$}} & \multirow{3}{*}{$\begin{array}{c}\text { FR medio } \\
\mathrm{s}(\mathrm{N} / \mathrm{mm} 2) \\
\mathrm{CV}(\%)\end{array}$} & \multirow{2}{*}{$\begin{array}{l}1,18 \\
0,21\end{array}$} & \multirow{2}{*}{$\begin{array}{l}\text { TR medio } \\
\mathrm{s}(\mathrm{N} / \mathrm{mm} 2)\end{array}$} & \multirow{2}{*}{$\begin{array}{l}2,85 \\
0,54\end{array}$} \\
\hline & & & & & & & & \\
\hline & & & & & & 18,15 & $\mathrm{CV}(\%)$ & 18,93 \\
\hline & & & & & A\% & 24,83 & C \% & 75,17 \\
\hline & & & & & I medio & 16,54 & t medio & 0,42 \\
\hline & & & Rotc & ra \% & $\overline{\overline{D i m}}$ & siones $d t$ & probeta en & $\mathrm{mm}$ \\
\hline Probeta & $\begin{array}{c}\text { Rotura } \\
k N\end{array}$ & $\begin{array}{l}\text { Rotura } \\
\mathrm{N} / \mathrm{mm} 2\end{array}$ & Adhesiva & Cohesiva & $b$ & $\begin{array}{l}\text { Long. } \\
\text { Solape } \\
\text { I (mm) }\end{array}$ & $\begin{array}{c}\text { Espesor } \\
\text { capa } \\
t(\mathrm{~mm})\end{array}$ & $\begin{array}{c}\text { Espesor } \\
\text { unión adh. } \\
e(\mathrm{~mm})\end{array}$ \\
\hline 1F7d & 1,35 & 3,49 & 0 & 100 & 25,00 & 15,510 & 0,235 & 1,850 \\
\hline $2 \mathrm{~F} 7 \mathrm{~d}$ & 1,40 & 3,39 & 0 & 100 & 25,00 & 16,510 & 0,540 & 2,175 \\
\hline $3 F 7 d$ & 1,29 & 3,04 & 0 & 100 & 25,00 & 16,895 & 0,450 & 2,020 \\
\hline $4 \mathrm{~F} 7 \mathrm{~d}$ & 1,31 & 3,37 & 7 & 93 & 25,00 & 15,515 & 0,575 & 2,225 \\
\hline $5 \mathrm{~F} 7 \mathrm{~d}$ & 1,10 & 2,70 & 25 & 75 & 25,00 & 16,320 & 0,585 & 2,175 \\
\hline $6 \mathrm{~F} 7 \mathrm{~d}$ & 1,34 & 3,18 & 4 & 96 & 25,00 & 16,830 & 0,415 & 2,045 \\
\hline $7 F 7 d$ & 1,33 & 3,17 & 10 & 90 & 25,00 & 16,750 & 0,410 & 1,950 \\
\hline $8 \mathrm{~F} 7 \mathrm{~d}$ & 0,73 & 1,74 & 30 & 70 & 25,00 & 16,830 & 0,285 & 1,885 \\
\hline 9F7d & 0,95 & 2,33 & 95 & 5 & 25,00 & 16,260 & 0,460 & 2,000 \\
\hline 10F7d & 1,01 & 2,56 & 25 & 75 & 25,00 & 15,770 & 0,425 & 1,995 \\
\hline $11 \mathrm{~F} 7 \mathrm{~d}$ & 1,39 & 3,17 & 3 & 97 & 25,00 & 17,570 & 0,325 & 1,835 \\
\hline $12 \mathrm{~F} 7 \mathrm{~d}$ & 0,93 & 2,10 & 99 & 1 & 25,00 & 17,700 & 0,355 & 1,950 \\
\hline
\end{tabular}

Como muestra la tabla, la máxima tensión de rotura se logra cuando se alcanza el máximo valor de porcentaje de rotura cohesiva y el mínimo valor tanto en el espesor de capa como en la longitud de solape. Cuando se obtiene valores altos de longitud de solape junto con valores bajos de espesor de capa, se tiene la mínima tensión de rotura.

En las Figura 74 y 75 se especifica la evolución de la tensión de rotura con la longitud de solape y el espesor de capa, respectivamente.

Al igual que sucedía en el caso de las probetas con un tiempo de curado de tres días, el comportamiento de la tensión de rotura en probetas de acero recubierto de poliéster con un proceso de curado de siete días es el siguiente:

$\checkmark$ La tensión de rotura muestra la misma evolución que el porcentaje de rotura cohesiva, independientemente del comportamiento del espesor de capa y la longitud de solape. 


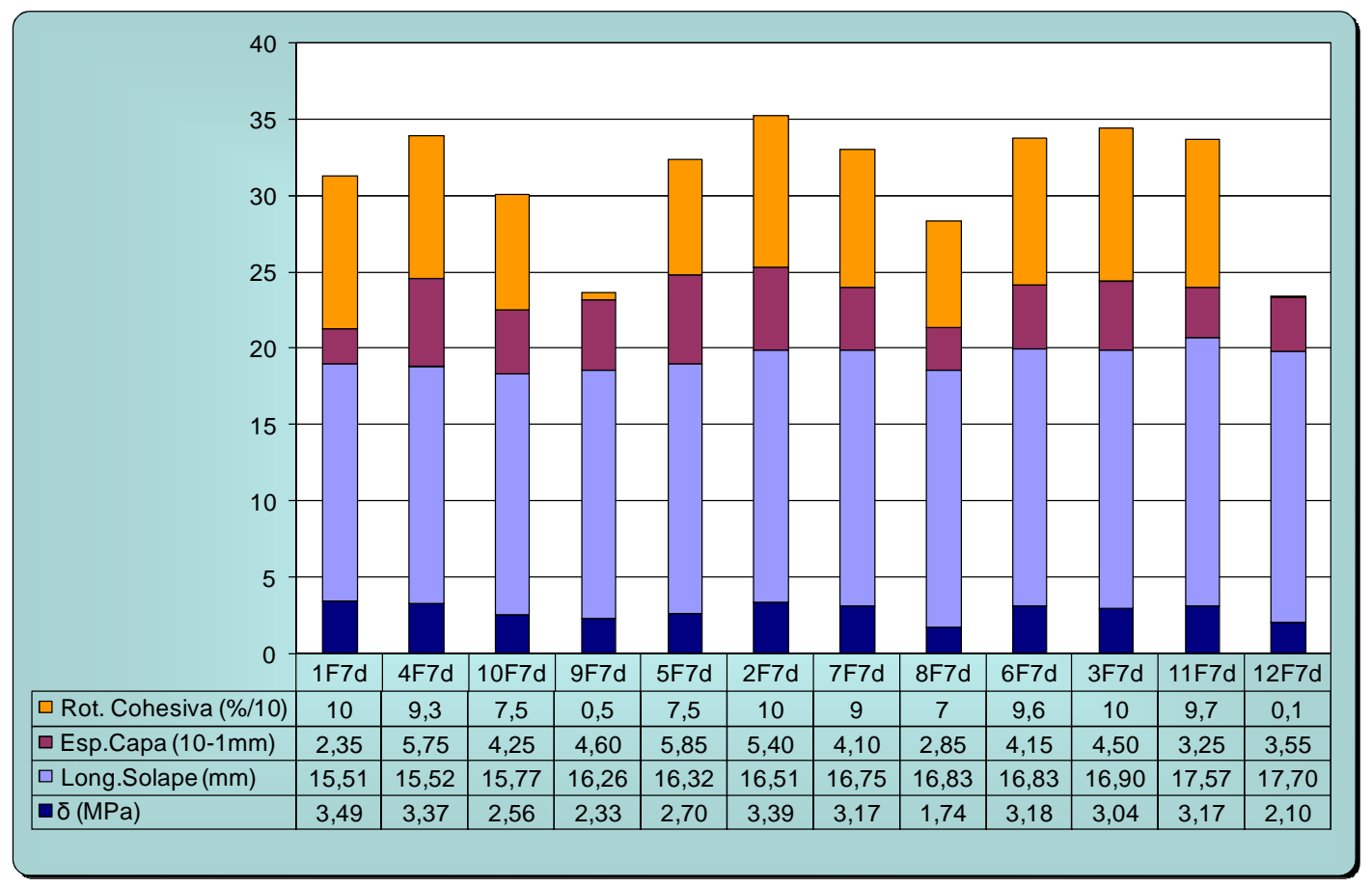

Figura 74. Influencia de la longitud de solape.

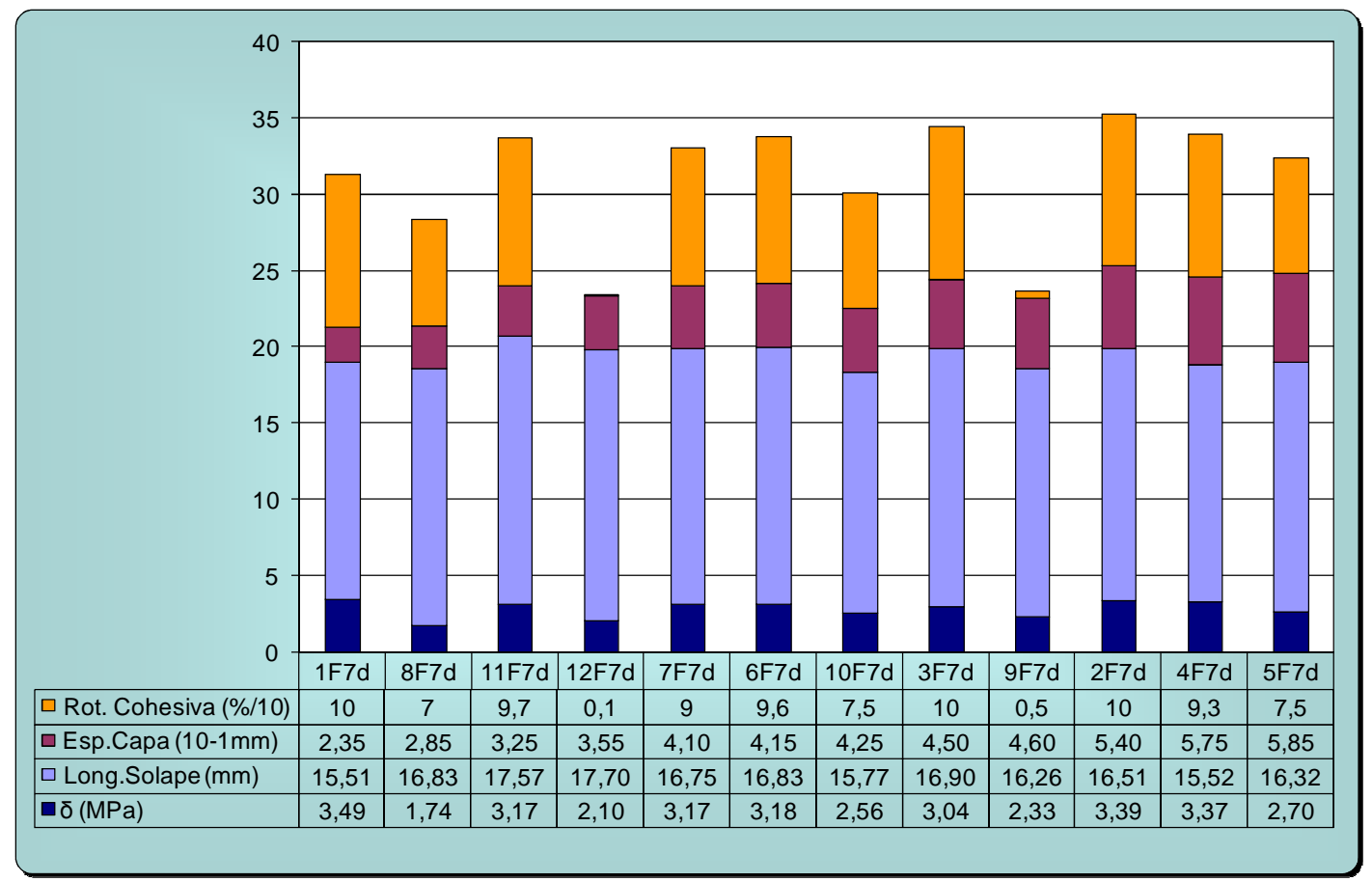

Figura 75. Influencia del espesor de capa adhesiva. 


\subsubsection{Resultados y conclusiones para probetas con un tiempo de curado de 14 días:}

Los resultados correspondientes a las probetas de acero recubierto de poliéster con catorce días de curado se detallan en la siguiente tabla:

Tabla 13. Resultados de probetas de acero recubierto de poliéster con 14 días de curado.

\begin{tabular}{|c|c|c|c|c|c|c|c|c|}
\hline \multirow{5}{*}{\multicolumn{5}{|c|}{$\begin{array}{lll}\text { ENSAYO: } & \text { Cizalladura } \\
\text { UNIÓN: } & \text { Adhesiva-Terostat-MS } 939 \\
\text { SUPERFICIE: } & \text { Recubrimiento Poliéster } \\
\text { PREP. SUPERFICIAL: } & \text { Limpieza acetona } \\
\text { CURADO (DÍAS): } & \mathbf{1 4} \\
\end{array}$}} & \multirow{3}{*}{$\begin{array}{c}\text { FR medio } \\
\mathrm{s}(\mathrm{N} / \mathrm{mm} 2) \\
\mathrm{CV}(\%)\end{array}$} & \multirow{2}{*}{$\begin{array}{l}0,99 \\
0,16\end{array}$} & \multirow{2}{*}{$\begin{array}{l}\text { TR medio } \\
\mathrm{s}(\mathrm{N} / \mathrm{mm} 2)\end{array}$} & \multirow{2}{*}{$\begin{array}{l}\mathbf{2 , 9 9} \\
0,49\end{array}$} \\
\hline & & & & & & & & \\
\hline & & & & & & 16,37 & CV $(\%)$ & 16,38 \\
\hline & & & & & $A \%$ & 65,50 & $\mathbf{C} \%$ & 34,50 \\
\hline & & & & & I medio & 13,32 & t medio & 0,24 \\
\hline & & & ( Rotl & ra\% & 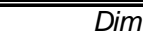 & iones $d t$ & probeta en & $\mathrm{mm}$ \\
\hline Probeta & $\begin{array}{c}\text { Rotura } \\
k N\end{array}$ & $\begin{array}{l}\text { Rotura } \\
\mathrm{N} / \mathrm{mm} 2\end{array}$ & Adhesiva & Cohesiva & $b$ & $\begin{array}{l}\text { Long. } \\
\text { Solape } \\
\text { I (mm) }\end{array}$ & $\begin{array}{c}\text { Espesor } \\
\text { capa } \\
t(\mathrm{~mm})\end{array}$ & $\begin{array}{c}\text { Espesor } \\
\text { unión adh. } \\
\text { e }(\mathrm{mm})\end{array}$ \\
\hline 1F14d & 1,30 & 3,94 & 17 & 83 & 25,00 & 13,160 & 0,255 & 1,860 \\
\hline $2 \mathrm{~F} 14 \mathrm{~d}$ & 1,13 & 3,33 & 17 & 83 & 25,00 & 13,525 & 0,375 & 2,015 \\
\hline $3 F 14 d$ & 0,88 & 2,88 & 75 & 25 & 25,00 & 12,280 & 0,160 & 1,775 \\
\hline 4F14d & 0,87 & 2,80 & 45 & 55 & 25,00 & 12,420 & 0,155 & 1,785 \\
\hline $5 \mathrm{~F} 14 \mathrm{~d}$ & 0,98 & 2,87 & 98 & 2 & 25,00 & 13,630 & 0,335 & 1,930 \\
\hline $6 \mathrm{~F} 14 \mathrm{~d}$ & 0,81 & 2,56 & 99 & 1 & 25,00 & 12,630 & 0,310 & 1,905 \\
\hline $7 F 14 d$ & 0,90 & 2,74 & 95 & 5 & 25,00 & 13,130 & 0,205 & 1,800 \\
\hline $8 \mathrm{~F} 14 \mathrm{~d}$ & 0,82 & 2,11 & 90 & 10 & 25,00 & 15,520 & 0,195 & 1,840 \\
\hline $9 \mathrm{~F} 14 \mathrm{~d}$ & 1,23 & 3,53 & 20 & 80 & 25,00 & 13,930 & 0,290 & 1,900 \\
\hline 10F14d & 1,18 & 3,60 & 50 & 50 & 25,00 & 13,140 & 0,230 & 1,830 \\
\hline $11 \mathrm{~F} 14 \mathrm{~d}$ & 0,90 & 2,75 & 90 & 10 & 25,00 & 13,160 & 0,230 & 1,885 \\
\hline $12 \mathrm{~F} 14 \mathrm{~d}$ & 0,92 & 2,76 & 90 & 10 & 25,00 & 13,335 & 0,190 & 1,770 \\
\hline
\end{tabular}

La tabla de resultados muestra que la máxima tensión de rotura es alcanzada cuando se obtiene el máximo valor de porcentaje de rotura cohesiva. De forma contrario, para valores mínimos en el porcentaje de rotura cohesiva, se logra la mínima tensión. También se observa que la mínima tensión de rotura sucede cuando se alcanza el máximo valor de longitud de solape. El comportamiento de la tensión en función del porcentaje de rotura, es similar al que presentaban las probetas con un tiempo de curado de tres días.

Un estudio de la Figura 76, influencia del aumento de la longitud solape sobre la tensión de rotura, demuestra que la variación tanto de la longitud de solape como del espesor de capa no influye en el comportamiento de la tensión. Es el porcentaje de rotura cohesiva el factor que mayor dominio tiene sobre la evolución de la tensión de rotura, mostrando ambos la misma conducta. 


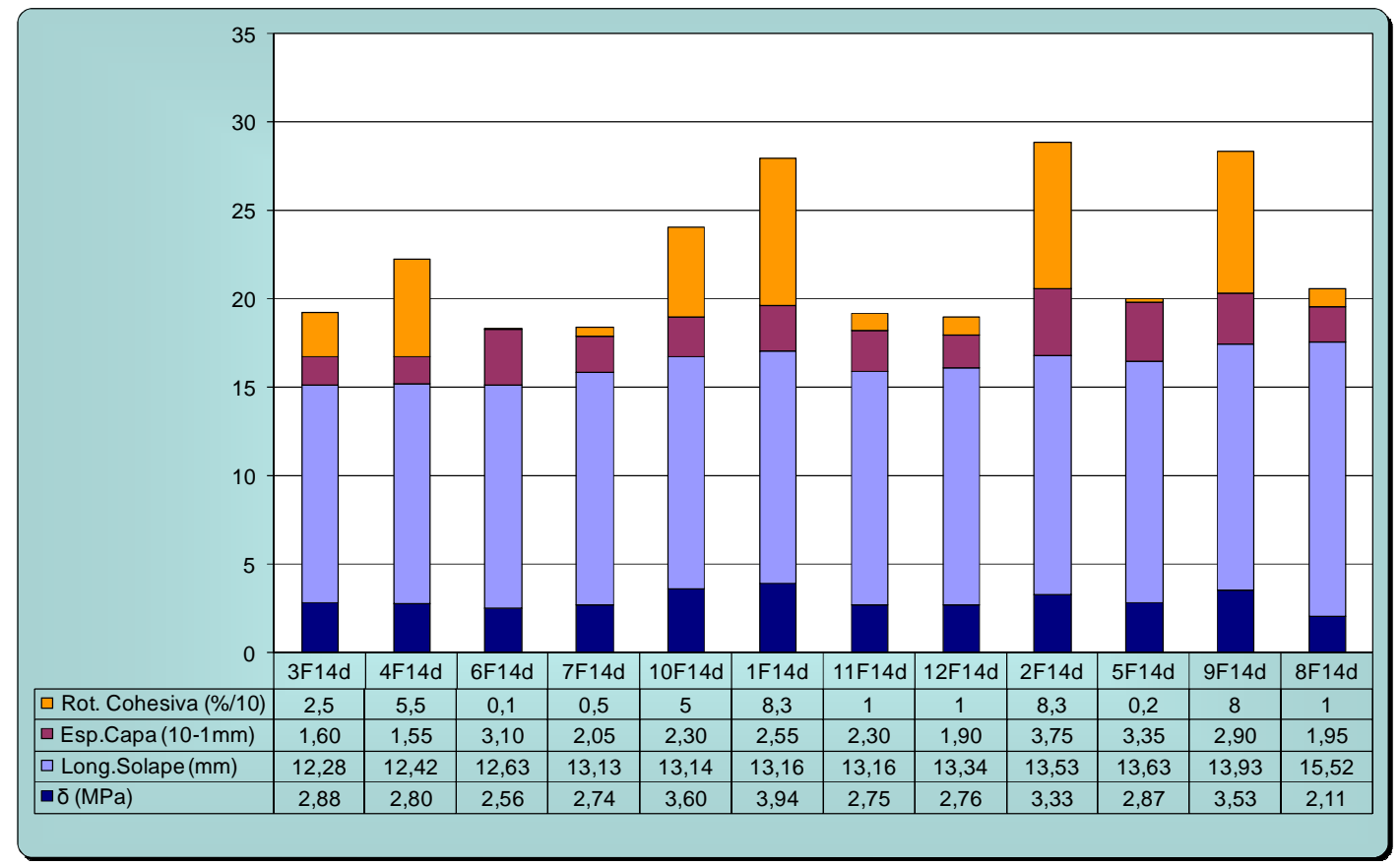

Figura 76. Influencia de la longitud de solape.

En la Figura 77 se muestra la influencia que tiene un aumento del espesor de capa sobre la tensión de rotura, deduciéndose las siguientes conclusiones:

- Cuando la evolución del espesor de capa y de la longitud de solape son semejantes, la tensión de rotura muestra un comportamiento similar al porcentaje de rotura cohesiva.

- Sin embargo, cuando la evolución del espesor y de la longitud son contrarios, la influencia del porcentaje de rotura cohesiva no es total sobre la tensión de rotura. La tensión de rotura no solo aumentará cuando lo haga el porcentaje de rotura, sino que también presentará un crecimiento cuando aquel disminuye. Este crecimiento de la tensión de rotura coincide con un aumento del espesor de capa de unión adhesiva. Este comportamiento de la tensión de rotura contrario a la evolución del porcentaje de rotura cohesiva que se acaba de detallar, sólo lo presentan dos probetas.

Por lo tanto, se puede afirmar en líneas generales, que la evolución de la tensión de rotura en probetas de acero recubierto de poliéster con un proceso de curado de catorce días es, al igual que sucedía en el caso de las probetas con un tiempo de curado de tres y siete días, el siguiente:

$\checkmark$ La tensión de rotura evoluciona de forma similar al porcentaje de rotura cohesiva, independientemente del comportamiento del espesor de capa y la longitud de solape. 


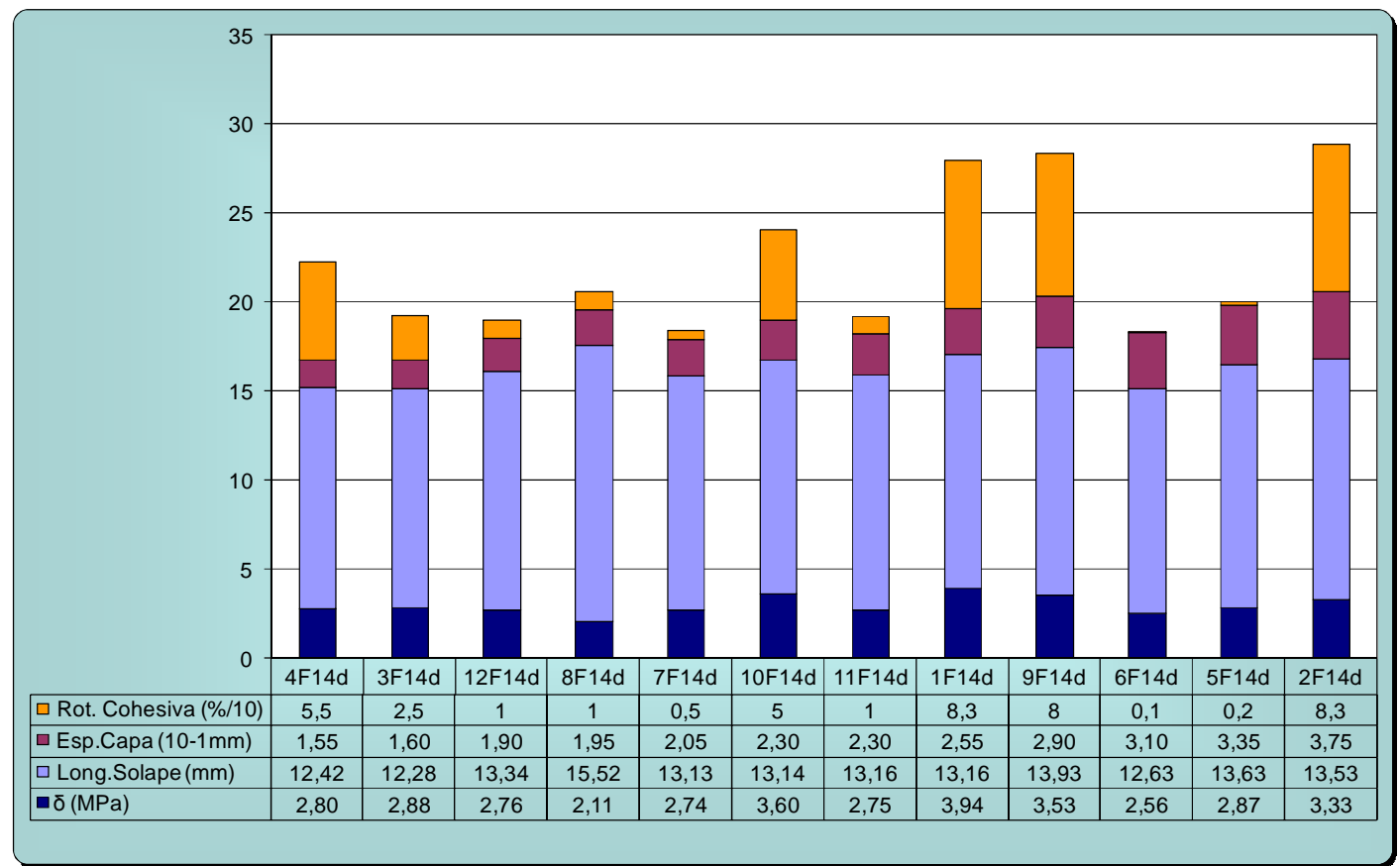

Figura 77. Influencia del espesor de capa adhesiva. 


\subsubsection{Análisis de la influencia del tiempo de curado en probetas de acero recubierto de poliéster:}

En la siguiente tabla se especifican los valores medios de los principales parámetros de unión para los diferentes tiempos de curado que se han estudiado:

Tabla 14. Comparación de resultados de probetas de acero recubierto de poliéster.

\begin{tabular}{|c||c|c|c|c|c|c|}
\hline $\begin{array}{c}\text { Tiempo } \\
\text { Curado }\end{array}$ & $\begin{array}{c}\text { Longitud Solape } \\
(\mathbf{m m})\end{array}$ & $\begin{array}{c}\text { Espesor Capa } \\
\mathbf{( m m})\end{array}$ & $\begin{array}{c}\text { Fuerza Rotura } \\
\mathbf{( k N )}\end{array}$ & $\begin{array}{c}\text { Tensión Rotura } \\
\text { (MPa) }\end{array}$ & $\begin{array}{c}\text { \%Rotura } \\
\text { Adhesiva }\end{array}$ & $\begin{array}{c}\text { \%Rotura } \\
\text { Cohesiva }\end{array}$ \\
\hline \hline 3 días & 13,28 & 0,24 & 0,85 & 2,56 & 14 & 86 \\
\hline 7 días & 16,54 & 0,42 & 1,18 & 2,86 & 25 & 75 \\
\hline 14 días & 13,32 & 0,24 & 0,99 & 2,99 & 66 & 35 \\
\hline
\end{tabular}

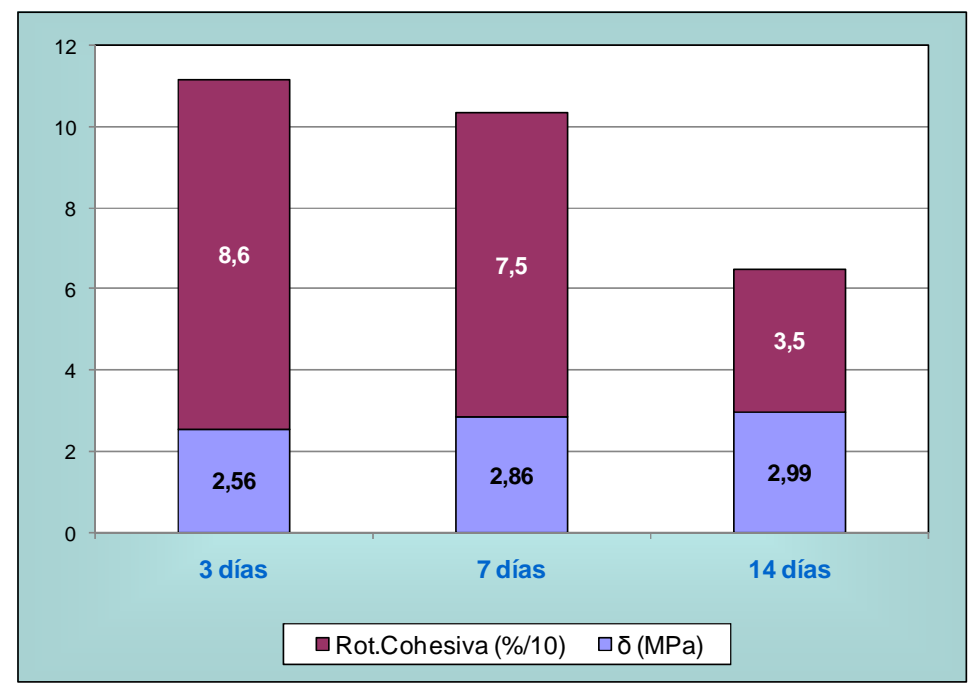

Figura 78. Influencia del Tiempo de Curado.

De forma similar a lo que ocurría en el caso de las probetas de acero blanco, en el caso de las probetas de acero recubierto de poliéster tampoco se observa una notable mejoría en el valor de la fuerza de rotura de la unión adhesiva al aumentar el tiempo de curado del adhesivo de estudio. Esto será una ventaja porque permite reducir los tiempos de curado de las uniones adhesivas con este tipo de sustrato. 


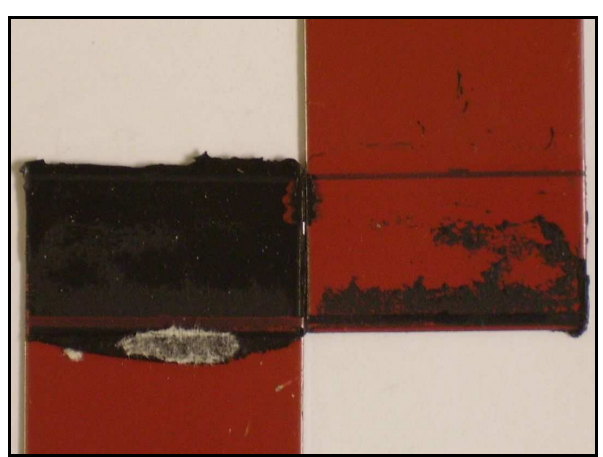

Figura 79. Rotura $8 \%$ cohesiva de probetas con 3 días de curado.

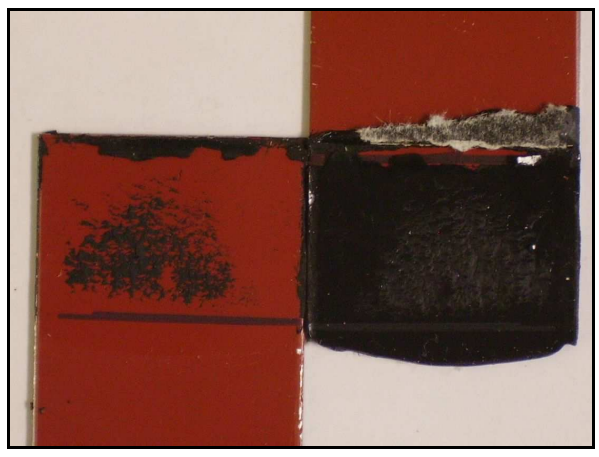

Figura 81. Rotura 1\% cohesiva de probetas con 7 días de curado.

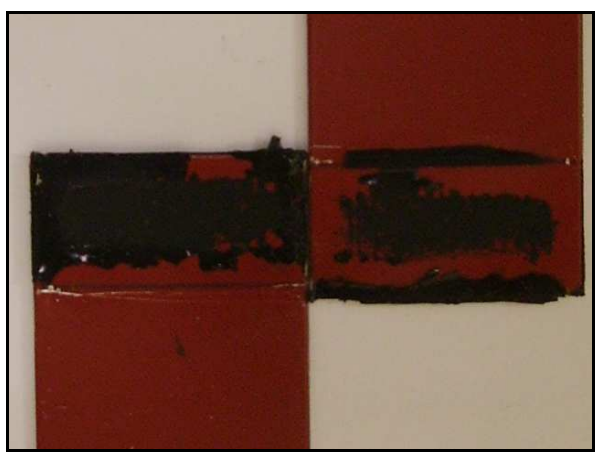

Figura 83. Rotura 25\% cohesiva de probetas con 14 días de curado.

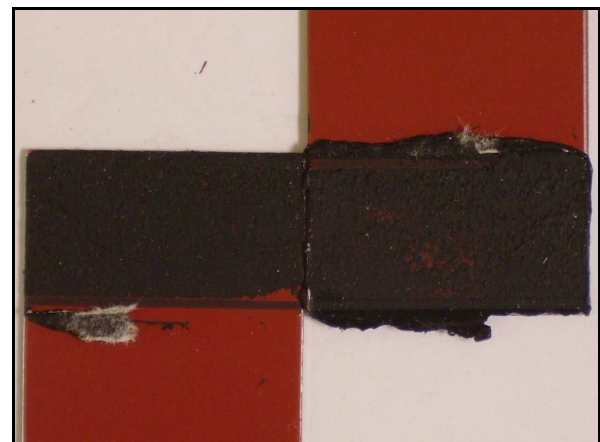

Figura 80. Rotura $100 \%$ cohesiva de probetas con 3 días de curado.

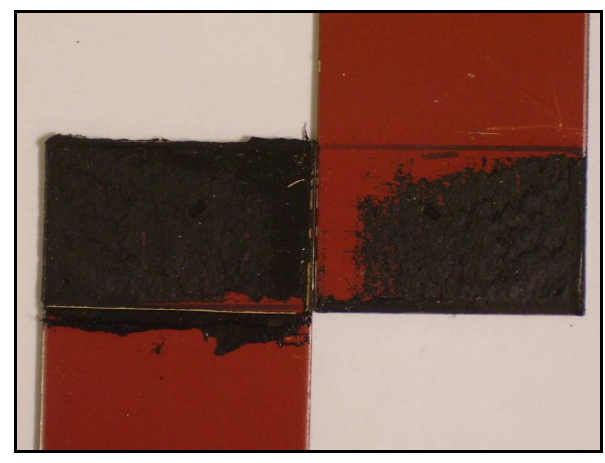

Figura 82. Rotura $70 \%$ cohesiva de probetas con 7 días de curado.

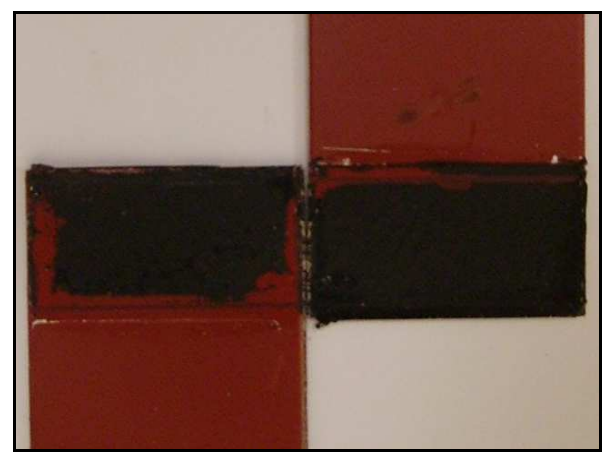

Figura 84. Rotura $83 \%$ cohesiva de probetas con 14 días de curado. 


\subsection{Probetas de acero recubierto de poliéster epoxi y adhesivo silano modificado.}

Se han realizado tres series de ensayos, compuestas cada una por doce probetas.

Se modificará tanto el tiempo de curado del adhesivo como el espesor de capa y la longitud de solape, para analizar la influencia de estos parámetros sobre el porcentaje de rotura cohesiva y la tensión de rotura.

\subsubsection{Resultados y conclusiones para probetas con un tiempo de curado de 3 días:}

Los resultados del ensayo de cizalladura para probetas de acero recubierto de poliéster epoxi se recogen en las siguientes tablas:

Tabla 15. Resultados de probetas de acero recubierto de poliéster epoxi con 3 días de curado.

\begin{tabular}{|c|c|c|c|c|c|c|c|c|}
\hline \multirow{5}{*}{\multicolumn{5}{|c|}{$\begin{array}{lll}\text { ENSAYO: } & \text { Cizalladura } \\
\text { UNIÓN: } \quad \text { Adhesiva-Terostat-MS } 939 \\
\text { SUPERFICIE: } \quad \quad \text { Recubrimiento Poliéster Epoxi } \\
\text { PREP. SUPERFICIAL: } \\
\text { Cimpieza acetona } \\
\text { CURADO (DÍAS): } \quad \mathbf{3} \\
\end{array}$}} & \multirow{3}{*}{$\begin{array}{c}\text { FR medio } \\
\mathrm{s}(\mathrm{N} / \mathrm{mm} 2) \\
\mathrm{CV}(\%)\end{array}$} & \multirow{2}{*}{$\begin{array}{l}1,22 \\
0,08\end{array}$} & \multirow{2}{*}{$\begin{array}{l}\text { TR medio } \\
\mathrm{s}(\mathrm{N} / \mathrm{mm} 2)\end{array}$} & \multirow{2}{*}{$\begin{array}{l}3,79 \\
0,21\end{array}$} \\
\hline & & & & & & & & \\
\hline & & & & & & 6,85 & CV(\%) & 5,54 \\
\hline & & & & & $\mathbf{A} \%$ & 5,83 & C \% & 94,17 \\
\hline & & & & & I medio & 12,87 & t medio & 0,11 \\
\hline & Fuerza & & Rot & $\%$ & $\operatorname{Dim}$ & iones $d t$ & probeta en & $\mathrm{nm}$ \\
\hline Probeta & $\begin{array}{c}\text { Rotura } \\
k N\end{array}$ & $\begin{array}{l}\text { Rotura } \\
\mathrm{MPa}\end{array}$ & Adhesiva & Cohesiva & $b$ & $\begin{array}{l}\text { Long. } \\
\text { Solape } \\
\text { I ( } \mathrm{mm})\end{array}$ & $\begin{array}{c}\text { Espesor } \\
\text { capa } \\
t(\mathrm{~mm})\end{array}$ & $\begin{array}{c}\text { Espesor } \\
\text { unión adh. } \\
e(\mathrm{~mm})\end{array}$ \\
\hline 1F3d & 1,38 & 4,06 & 5 & 95 & 25,00 & 13,610 & 0,100 & 1,710 \\
\hline $2 F 3 d$ & 1,23 & 3,78 & 5 & 95 & 25,00 & 12,975 & 0,085 & 1,690 \\
\hline $3 F 3 d$ & 1,05 & 3,28 & 10 & 90 & 25,00 & 12,785 & 0,065 & 1,665 \\
\hline $4 \mathrm{~F} 3 \mathrm{~d}$ & 1,24 & 3,97 & 2 & 98 & 25,00 & 12,450 & 0,130 & 1,745 \\
\hline $5 F 3 d$ & 1,30 & 3,83 & 7 & 93 & 25,00 & 13,545 & 0,130 & 1,750 \\
\hline $6 \mathrm{~F} 3 \mathrm{~d}$ & 1,30 & 3,84 & 2 & 98 & 25,00 & 13,500 & 0,125 & 1,755 \\
\hline $7 F 3 d$ & 1,16 & 3,52 & 5 & 95 & 25,00 & 13,175 & 0,140 & 1,765 \\
\hline $8 \mathrm{~F} 3 \mathrm{~d}$ & 1,24 & 4,05 & 5 & 95 & 25,00 & 12,240 & 0,080 & 1,705 \\
\hline 9F3d & 1,18 & 3,69 & 10 & 90 & 25,00 & 12,730 & 0,090 & 1,700 \\
\hline $10 \mathrm{~F} 3 \mathrm{~d}$ & 1,14 & 3,80 & 5 & 95 & 25,00 & 11,990 & 0,115 & 1,740 \\
\hline $11 \mathrm{~F} 3 \mathrm{~d}$ & 1,17 & 3,73 & 7 & 93 & 25,00 & 12,570 & 0,155 & 1,745 \\
\hline $12 \mathrm{~F} 3 \mathrm{~d}$ & 1,25 & 3,87 & 7 & 93 & 25,00 & 12,910 & 0,145 & 1,740 \\
\hline
\end{tabular}

Los resultados obtenidos de los ensayos confirman que la máxima tensión de rotura se logra cuando se alcanza la máxima longitud de solape, y la mínima tensión de rotura tiene lugar con el menor espesor de capa adhesiva. 
En la Figura 85 se representa la evolución que sufre la tensión de rotura debida a un aumento de la longitud de solape. Se pueden extraer las siguientes conclusiones:

- Cuando la longitud de solape y el espesor de capa evolucionan conjuntamente y no existe ninguna variación en el porcentaje de rotura, la tensión de rotura tiene un comportamiento contrario a dichos parámetros.

- Cuando la longitud de solape y el espesor de capa muestran un comportamiento similar y contrario al porcentaje de rotura cohesiva, la variación de tensión se verá influenciada solo por el porcentaje de rotura, mostrando la misma evolución que este.

- Cuando la longitud de solape, el espesor de capa y el porcentaje rotura cohesiva se comportan de la misma manera, no se puede obtener una conclusión definitiva sobre la evolución de la tensión de rotura. Será necesario analizar la Figura 86, influencia de un aumento del espesor de capa sobre la tensión de rotura, para intentar deducir más conclusiones

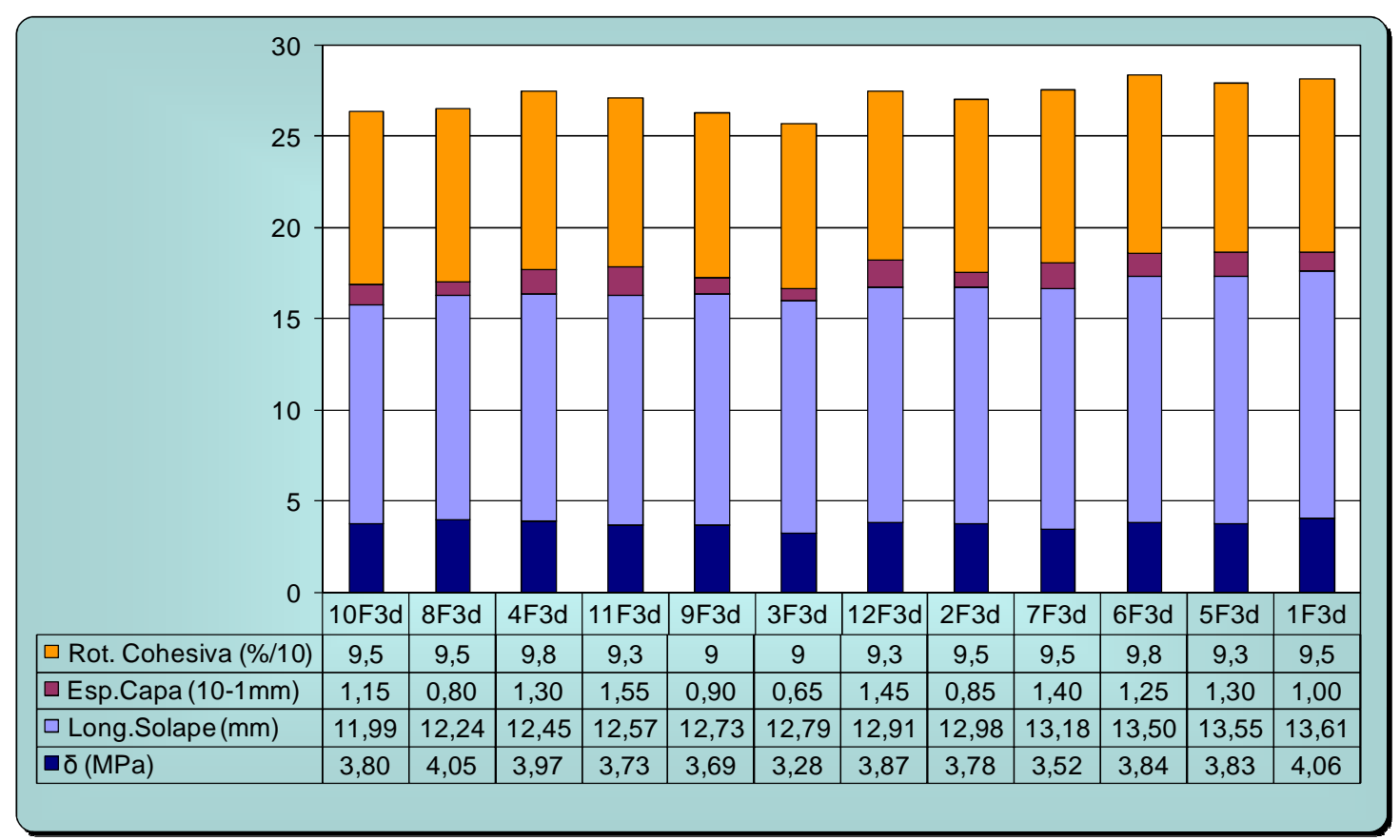

Figura 85. Influencia de la longitud de solape.

Las conclusiones que se deducen del análisis del diagrama mostrado en la Figura 86 se enumeran a continuación:

- Se observa que la tensión de rotura muestra un comportamiento igual que los tres factores de estudio cuando estos varían de forma similar (los tres aumentan o disminuyen conjuntamente).

- También se confirma que la evolución conjunta del espesor de capa y de la longitud de solape sin que exista variación en el porcentaje de rotura cohesiva, provoca que la tensión de rotura evolucione de forma contraria. 


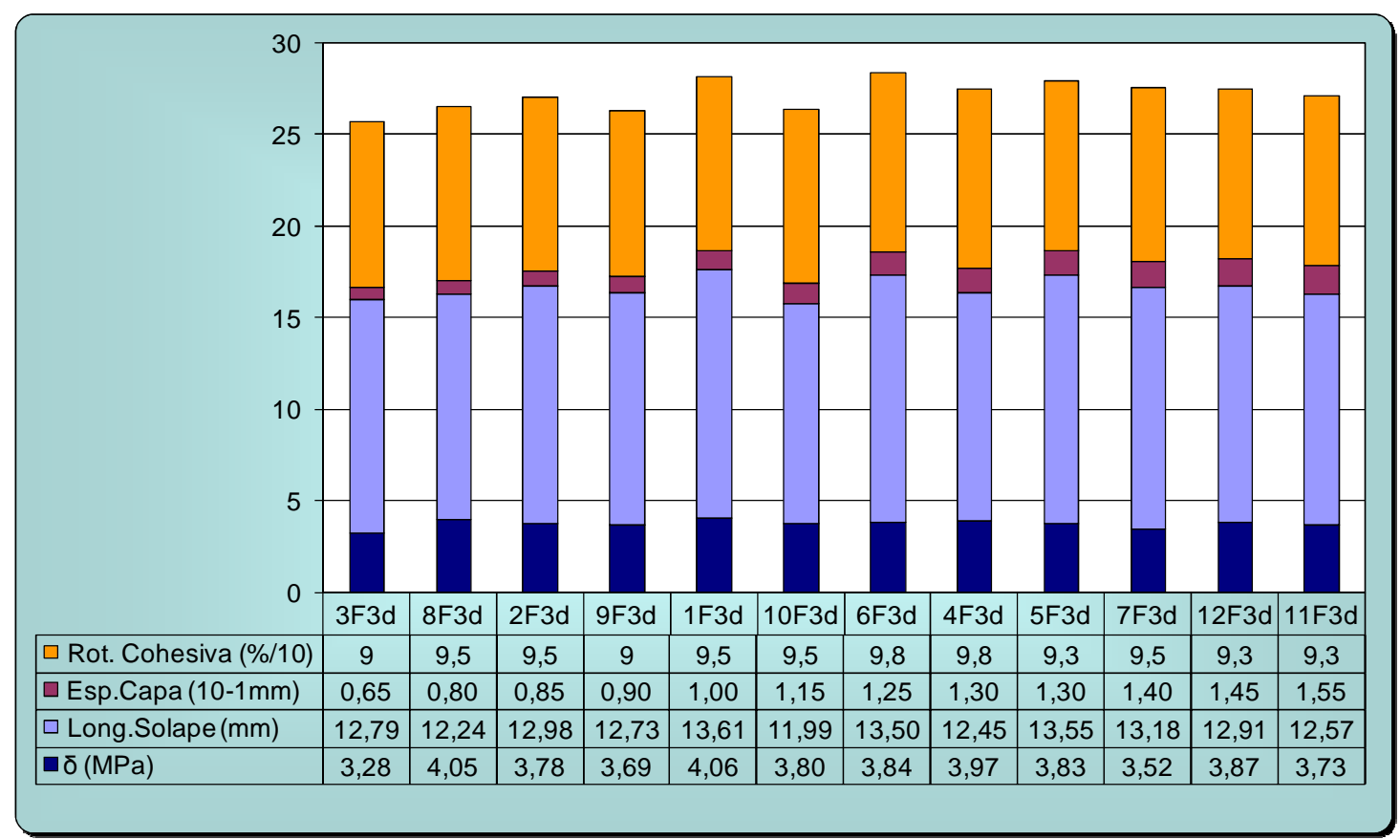

Figura 86. Influencia del espesor de capa adhesiva.

Al analizar las Figura 85 y 86 no se obtienen conclusiones definitivas sobre cuál es el comportamiento de la tensión de rotura cuando el espesor de capa y de la longitud de solape evolucionan de forma opuesta.

Por lo tanto, se puede concluir que el comportamiento de la tensión de rotura en probetas de acero recubierto de poliéster epoxi con un proceso de curado de tres días es el siguiente:

$\checkmark$ Cuando la longitud de solape y el espesor de capa evolucionan de forma similar y no existe ninguna variación en el porcentaje de rotura cohesiva, la tensión de rotura presenta un comportamiento opuesto a la longitud de solape y al espesor de capa adhesiva. 


\subsubsection{Resultados y conclusiones para probetas con un tiempo de curado de 7 días:}

Los resultados correspondientes a las probetas de acero recubierto de poliéster epoxi con siete días de curado se detallan en la siguiente tabla:

Tabla 16. Resultados de probetas de acero recubierto de poliéster epoxi con 7 días de curado.

\begin{tabular}{|c|c|c|c|c|c|c|c|c|}
\hline \multirow{2}{*}{\multicolumn{5}{|c|}{$\begin{array}{ll}\text { ENSAYO: } & \text { Cizalladura } \\
\text { UNIÓN: } & \text { Adhesiva-Terostat-MS } 939\end{array}$}} & FR medio & 1,13 & TR medio & 3,65 \\
\hline & & & & & $\mathrm{s}(\mathrm{N} / \mathrm{mm} 2)$ & 0,05 & $\mathrm{~s}(\mathrm{~N} / \mathrm{mm} 2)$ & 0,22 \\
\hline \multirow{3}{*}{\multicolumn{5}{|c|}{$\begin{array}{lc}\text { AdNIUIN: } & \text { Recubrimiento Poliéster Epoxi } \\
\text { SUPERFICIE: } & \text { RREP. SUPERFICIAL: } \\
\text { Pimpieza acetona } \\
\text { CURADO (DÍAS): } & 7\end{array}$}} & CV(\%) & 4,84 & $\mathrm{CV}(\%)$ & 6,06 \\
\hline & & & & & $\mathbf{A} \%$ & 10,83 & C \% & 89,17 \\
\hline & & & & & I medio & 12,36 & t medio & 0,21 \\
\hline \multirow[b]{2}{*}{ Probeta } & \multirow[b]{2}{*}{$\begin{array}{c}\text { Fuerza } \\
\text { Rotura } \\
\text { kN }\end{array}$} & \multirow[b]{2}{*}{$\begin{array}{l}\text { Tensión } \\
\text { Rotura } \\
\mathrm{MPa}\end{array}$} & \multicolumn{2}{|c|}{ Rotura \% } & \multicolumn{4}{|c|}{ Dimensiones de la probeta en $\mathrm{mm}$} \\
\hline & & & Adhesiva & Cohesiva & $b$ & $\begin{array}{l}\text { Long. } \\
\text { Solape } \\
\text { I (mm) }\end{array}$ & $\begin{array}{c}\text { Espesor } \\
\text { capa } \\
t(\mathrm{~mm})\end{array}$ & $\begin{array}{c}\text { Espesor } \\
\text { unión adh. } \\
e(\mathrm{~mm})\end{array}$ \\
\hline 1F7d & 1,24 & 3,83 & 2 & 98 & 25,00 & 12,945 & 0,185 & 1,785 \\
\hline 2 F7d & 1,06 & 3,36 & 25 & 75 & 25,00 & 12,610 & 0,160 & 1,760 \\
\hline $3 F 7 d$ & 1,09 & 3,36 & 20 & 80 & 25,00 & 13,015 & 0,250 & 1,855 \\
\hline $4 \mathrm{~F} 7 \mathrm{~d}$ & 1,05 & 3,31 & 22 & 78 & 25,00 & 12,705 & 0,230 & 1,840 \\
\hline $5 \mathrm{~F} 7 \mathrm{~d}$ & 1,07 & 3,38 & 22 & 78 & 25,00 & 12,670 & 0,245 & 1,870 \\
\hline $6 \mathrm{~F} 7 \mathrm{~d}$ & 1,18 & 3,86 & 2 & 98 & 25,00 & 12,270 & 0,155 & 1,800 \\
\hline 7F7d & 1,12 & 3,78 & 5 & 95 & 25,00 & 11,825 & 0,145 & 1,725 \\
\hline $8 \mathrm{~F} 7 \mathrm{~d}$ & 1,18 & 3,87 & 15 & 85 & 25,00 & 12,180 & 0,170 & 1,780 \\
\hline 9F7d & 1,11 & 3,86 & 10 & 90 & 25,00 & 11,450 & 0,120 & 1,720 \\
\hline 10F7d & 1,15 & 3,74 & 5 & 95 & 25,00 & 12,290 & 0,250 & 1,905 \\
\hline $11 \mathrm{~F} 7 \mathrm{~d}$ & 1,12 & 3,66 & 2 & 98 & 25,00 & 12,210 & 0,320 & 1,920 \\
\hline $12 \mathrm{~F} 7 \mathrm{~d}$ & 1,17 & 3,84 & 0 & 100 & 25,00 & 12,160 & 0,280 & 1,895 \\
\hline
\end{tabular}

Como se puede observar, la mínima tensión de rotura se produce cuando el espesor de capa es máximo. La máxima tensión de rotura se logra para valores bajos de longitud de solape.

Del estudio de la Figura 87, influencia de la longitud de solape sobre la tensión de rotura, se deducen las siguientes conclusiones:

- Cuando el comportamiento de la longitud de solape es similar al del espesor de capa y contrario al del porcentaje de rotura cohesiva, la tensión de rotura evoluciona de la misma manera que el porcentaje de rotura.

- Si la longitud de solape se comporta de la misma manera que el porcentaje de rotura cohesiva y de forma contraria al espesor de capa, la tensión de rotura tendrá una evolución igual que el porcentaje de rotura y, por lo tanto, similar a la longitud de solape.

- Si la longitud de solape presenta una evolución opuesta al espesor de capa y al porcentaje de rotura cohesiva, no se puede obtener una conclusión definitiva, por lo que es necesario analizar la influencia del espesor de capa sobre la tensión de rotura. 


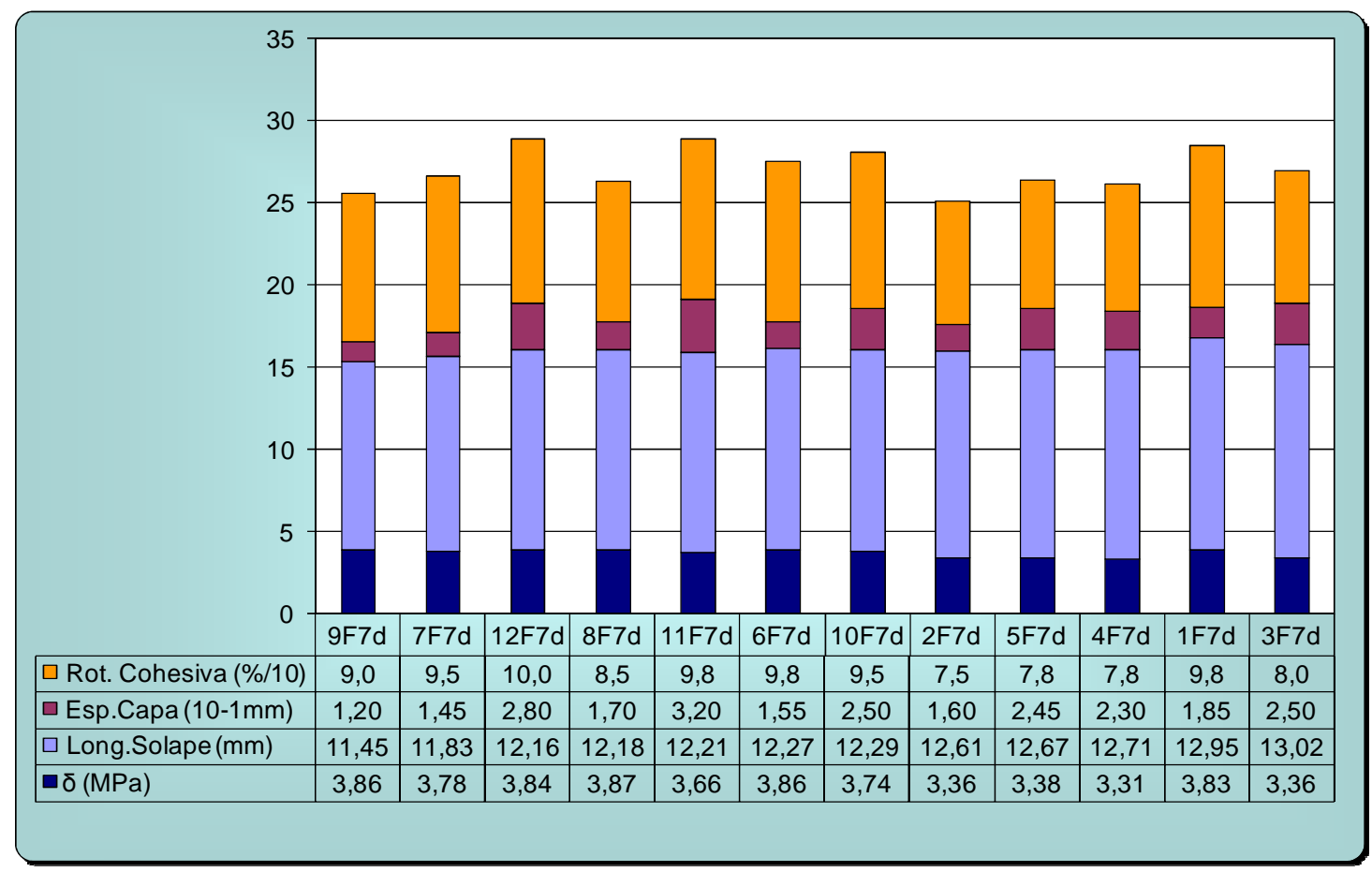

Figura 87. Influencia de la longitud de solape.

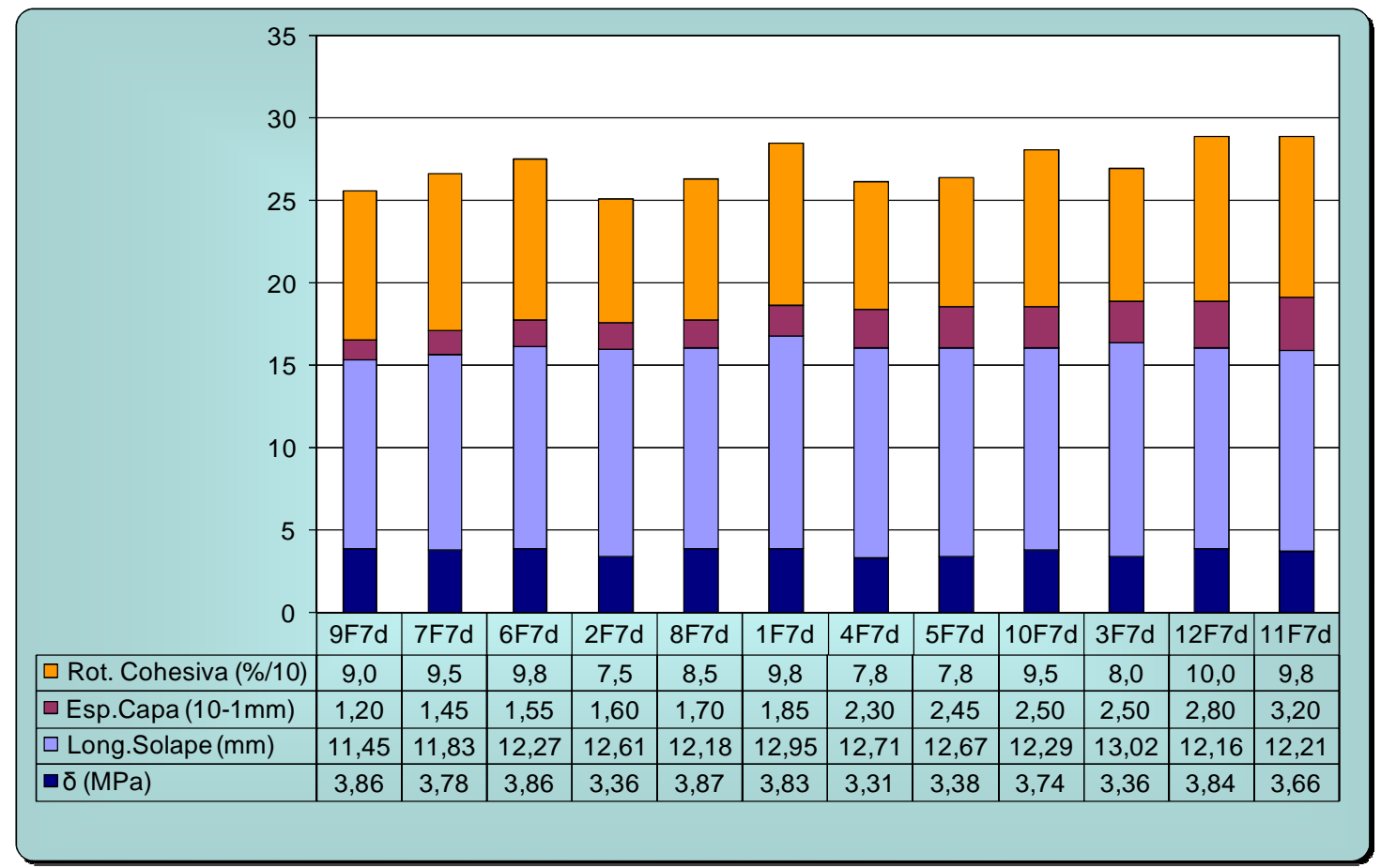

Figura 88. Influencia del espesor de capa adhesiva. 
En el análisis de la Figura 88, influencia de un aumento en el espesor de capa adhesiva, se extraen las siguientes conclusiones:

- Cuando el espesor de capa varía de forma similar a la longitud de solape y de forma opuesta al porcentaje de rotura cohesiva, la tensión de rotura presenta el mismo comportamiento que el porcentaje de rotura.

- Si el espesor de capa evoluciona de forma contraria a la longitud de solape y al porcentaje de rotura, serán estos factores los que mayor influencia tengan en el comportamiento de la tensión de rotura, provocando que la tensión presente la misma variación que estos últimos factores y contraria al espesor de capa.

- Si el espesor de capa se comporta de la misma manera que el porcentaje de rotura cohesiva y de forma contraria a la longitud de solape, la tensión de rotura tendrá una evolución igual que el porcentaje de roturacohesiva y, por lo tanto, similar al espesor.

Por lo tanto, se puede concluir que el comportamiento de la tensión de rotura en probetas de acero recubierto de poliéster epoxi con un proceso de curado de siete días es el siguiente:

$\checkmark$ Independientemente del comportamiento que presenten la longitud de solape y el espesor de capa, será el porcentaje de rotura cohesiva el factor que mayor influencia tenga sobre la tensión de rotura, presentando ambas la misma evolución. 


\subsubsection{Resultados y conclusiones para probetas con un tiempo de curado de 14 días:}

Los resultados correspondientes a las probetas de acero recubierto de poliéster epoxi con catorce días de curado se detallan en la siguiente tabla:

Tabla 17. Resultados de probetas de acero recubierto de poliéster epoxi con 14 días de curado.

\begin{tabular}{|c|c|c|c|c|c|c|c|c|}
\hline \multirow{2}{*}{\multicolumn{5}{|c|}{$\begin{array}{ll}\text { ENSAYO: } & \text { Cizalladura } \\
\text { UNIÓN: } & \text { Adhesiva-Terostat-MS } 939\end{array}$}} & FR medio & 1,55 & TR medio & 4,07 \\
\hline & & & & & $\mathrm{s}(\mathrm{N} / \mathrm{mm} 2)$ & 0,15 & $\mathrm{~s}(\mathrm{~N} / \mathrm{mm} 2)$ & 0,29 \\
\hline \multirow{2}{*}{\multicolumn{5}{|c|}{$\begin{array}{ll}\text { SUPERFICIE: } & \text { Recubrimiento Poliéster Epoxi } \\
\text { PREP. SUPERFICIAL: Limpieza acetona }\end{array}$}} & CV(\%) & 9,85 & $\mathrm{CV}(\%)$ & 7,01 \\
\hline & & & & & $\mathrm{A} \%$ & 0,00 & C \% & 100,00 \\
\hline \multicolumn{5}{|c|}{ CURADO (DÍAS): $\quad 14$} & I medio & 15,18 & t medio & 0,16 \\
\hline \multirow[b]{2}{*}{ Probeta } & \multirow[b]{2}{*}{$\begin{array}{c}\text { Fuerza } \\
\text { Rotura } \\
k N\end{array}$} & \multirow[b]{2}{*}{$\begin{array}{c}\text { Tensión } \\
\text { Rotura } \\
\text { MPa }\end{array}$} & \multicolumn{2}{|c|}{ Rotura \% } & \multicolumn{4}{|c|}{ Dimensiones de la probeta en $\mathrm{mm}$} \\
\hline & & & Adhesiva & Cohesiva & $b$ & $\begin{array}{l}\text { Long. } \\
\text { Solape } \\
\text { I (mm) }\end{array}$ & $\begin{array}{c}\text { Espesor } \\
\text { capa } \\
t(\mathrm{~mm})\end{array}$ & $\begin{array}{c}\text { Espesor } \\
\text { unión adh. } \\
e(\mathrm{~mm})\end{array}$ \\
\hline 1F14d & 1,53 & 4,13 & 0 & 100 & 25,00 & 14,845 & 0,190 & 1,730 \\
\hline $2 \mathrm{~F} 14 \mathrm{~d}$ & 1,66 & 4,25 & 0 & 100 & 25,00 & 15,595 & 0,210 & 1,770 \\
\hline $3 F 14 d$ & 1,59 & 4,28 & 0 & 100 & 25,00 & 14,895 & 0,210 & 1,745 \\
\hline $4 \mathrm{~F} 14 \mathrm{~d}$ & 1,38 & 3,76 & 0 & 100 & 25,00 & 14,665 & 0,155 & 1,695 \\
\hline $5 F 14 d$ & 1,48 & 4,18 & 0 & 100 & 25,00 & 14,160 & 0,115 & 1,755 \\
\hline $6 F 14 d$ & 1,73 & 4,22 & 0 & 100 & 25,00 & 16,400 & 0,165 & 1,715 \\
\hline $7 F 14 d$ & 1,39 & 3,87 & 0 & 100 & 25,00 & 14,355 & 0,225 & 1,815 \\
\hline $8 F 14 d$ & 1,22 & 3,31 & 0 & 100 & 25,00 & 14,735 & 0,100 & 1,705 \\
\hline 9F14d & 1,78 & 4,31 & 0 & 100 & 25,00 & 16,460 & 0,115 & 1,675 \\
\hline $10 \mathrm{~F} 14 \mathrm{~d}$ & 1,61 & 4,21 & 0 & 100 & 25,00 & 15,300 & 0,190 & 1,725 \\
\hline 11F14d & 1,66 & 4,33 & 0 & 100 & 25,00 & 15,305 & 0,120 & 1,700 \\
\hline $12 \mathrm{~F} 14 \mathrm{~d}$ & 1,56 & 4,02 & 0 & 100 & 25,00 & 15,470 & 0,140 & 1,700 \\
\hline
\end{tabular}

De los resultados recogidos en la tabla se observa que la mínima tensión de rotura se alcanza cuando el espesor de capa es mínimo. La máxima tensión de rotura se logra para valores bajos del espesor de capa. En esta serie de probetas el fallo de la unión adhesiva siempre ha sido cohesivo.

La Figura 89 muestra la influencia que tiene el aumento de la longitud de solape adhesiva en la tensión de rotura, y la Figura 90 representa la influencia que tiene el aumento del espesor de capa adhesiva sobre la tensión de rotura.

El análisis de ambos diagramas no permite la obtención de conclusiones concluyentes sobre cuál es la evolución de la tensión de rotura en función del comportamiento del espesor de capa y de la longitud de solape. 


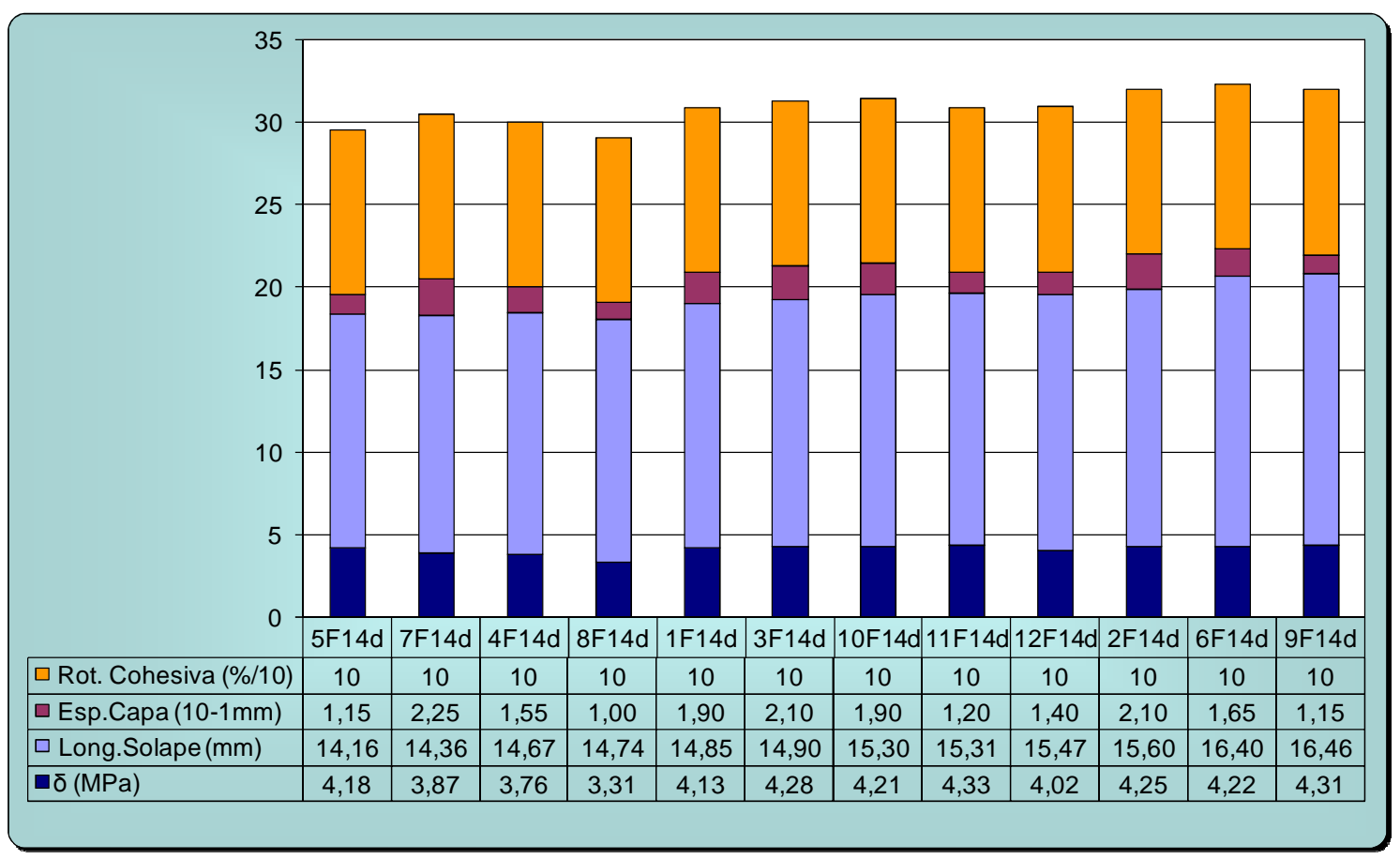

Figura 89. Influencia de la longitud de solape.

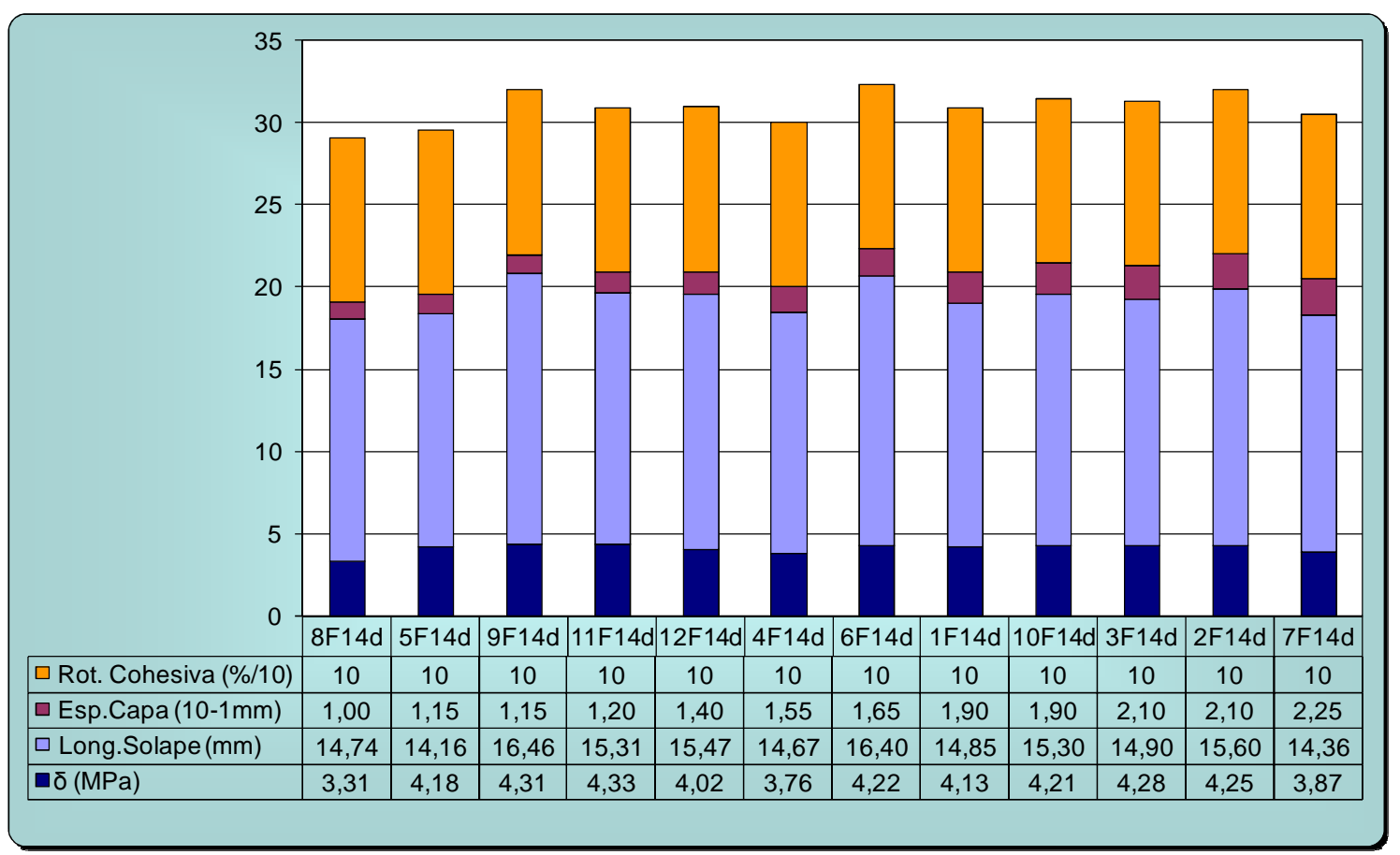

Figura 90. Influencia del espesor de capa adhesiva. 


\subsubsection{Análisis de la influencia del tiempo de curado en probetas de acero recubierto de poliéster epoxi:}

En la siguiente tabla se especifican los valores medios de los principales parámetros de unión para los diferentes tiempos de curado que se han estudiado:

Tabla 18. Comparación de resultados de probetas de acero recubierto de poliéster epoxi.

\begin{tabular}{|c||c|c|c|c|c|c|}
\hline $\begin{array}{c}\text { Tiempo } \\
\text { Curado }\end{array}$ & $\begin{array}{c}\text { Longitud Solape } \\
\text { (mm) }\end{array}$ & $\begin{array}{c}\text { Espesor Capa } \\
\text { (mm) }\end{array}$ & $\begin{array}{c}\text { Fuerza Rotura } \\
\text { (kN) }\end{array}$ & $\begin{array}{c}\text { Tensión Rotura } \\
\text { (MPa) }\end{array}$ & $\begin{array}{c}\text { \%Rotura } \\
\text { Adhesiva }\end{array}$ & $\begin{array}{c}\text { \%Rotura } \\
\text { Cohesiva }\end{array}$ \\
\hline \hline 3 días & 12,87 & 0,11 & 1,22 & 3,79 & 6 & 94 \\
\hline 7 días & 12,36 & 0,21 & 1,13 & 3,65 & 11 & 89 \\
\hline 14 días & 15,18 & 0,16 & 1,55 & 4,07 & 0 & 100 \\
\hline
\end{tabular}

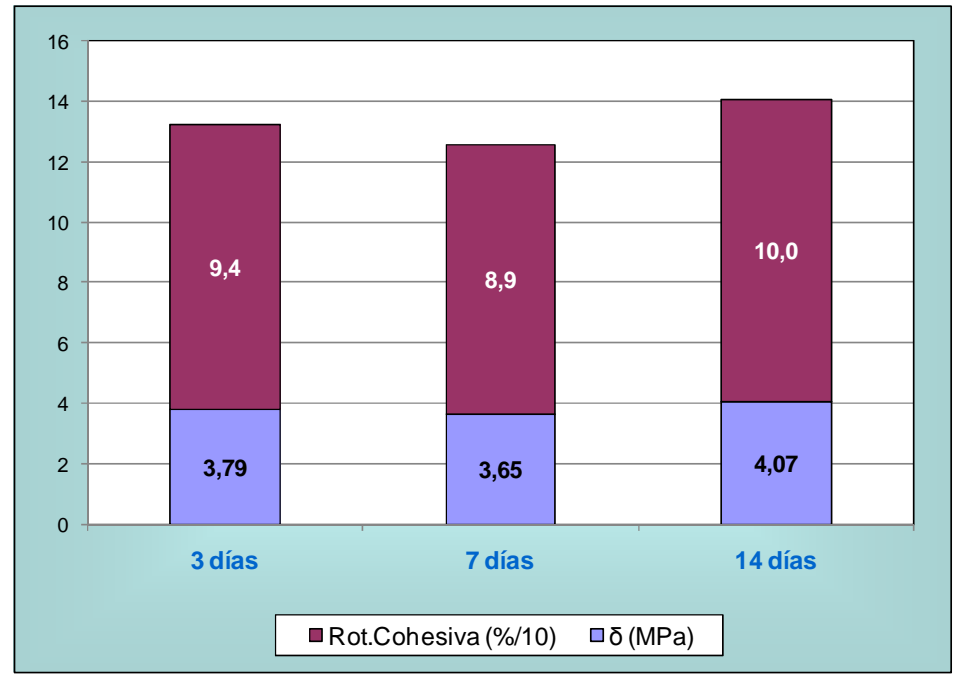

Figura 91. Influencia del Tiempo de Curado.

Se puede comprobar que un aumento del tiempo de curado no mejora la fuerza de rotura de la unión adhesiva en probetas de acero recubierto de poliéster epoxi unidas con adhesivo silano modificado. Debido a que no se aprecia ninguna influencia del tiempo de curado del adhesivo sobre la resistencia de unión, cuando se someta ese tipo de uniones adhesivas a ensayos de fatiga, se podrá elegir indistintamente el tiempo de curado. 


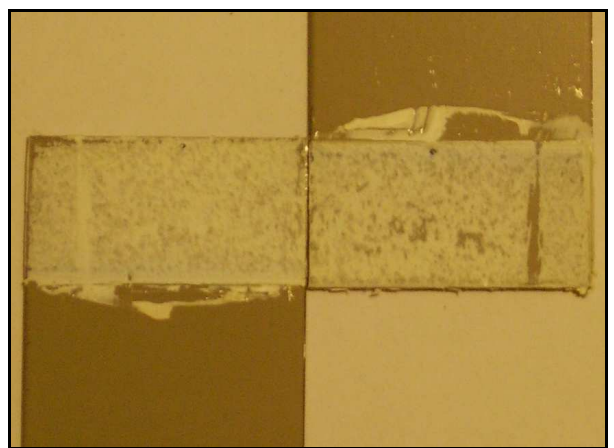

Figura 92. Rotura $90 \%$ cohesiva de probetas con 3 días de curado.

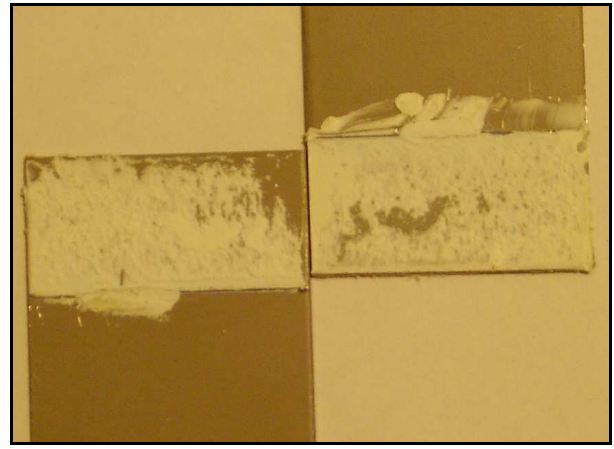

Figura 93. Rotura $80 \%$ cohesiva de probetas con 7 días de curado.

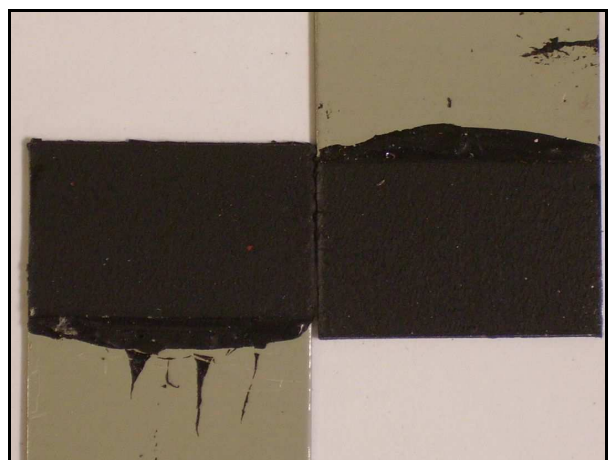

Figura 94. Rotura $100 \%$ cohesiva de probetas con 14 días de curado. 


\subsection{Probetas de acero galvanizado y adhesivo silano modificado.}

Se han realizado dos series de ensayos, compuestas por doce probetas.

En ambas series se ha conservado el mismo proceso de preparación de la unión adhesiva y solo se ha modificado el tiempo de curado del adhesivo. A continuación se ha estudiado la influencia de las variaciones que sufren la longitud de solape, el espesor de capa y el porcentaje de rotura cohesiva sobre la resistencia de unión (tensión de rotura).

\subsubsection{Resultados y conclusiones para probetas con un tiempo de curado de 3 días:}

La siguiente tabla describe los resultados obtenidos en los ensayos de cizalladura para las probetas de acero galvanizado con tres días de curado:

Tabla 19. Resultados de probetas de acero galvanizado con 3 días de curado.

\begin{tabular}{|c|c|c|c|c|c|c|c|c|}
\hline \multirow{5}{*}{\multicolumn{5}{|c|}{$\begin{array}{ll}\text { ENSAYO: } & \text { Cizalladura } \\
\text { UNIÓN: } & \text { Adhesiva-Terostat-MS } 939 \\
\text { SUPERFICIE: } \quad \text { Acero Galvanizado } \\
\text { PREP. SUPERFICIAL: } & \text { Limpieza con acetona } \\
\text { CURADO (DÍAS): } & \mathbf{3} \\
\end{array}$}} & \multirow{3}{*}{$\begin{array}{c}\text { FR medio } \\
\mathrm{s}(\mathrm{N} / \mathrm{mm} 2) \\
\mathrm{CV}(\%)\end{array}$} & \multirow{2}{*}{$\begin{array}{l}\mathbf{1 , 1 5} \\
0,16\end{array}$} & \multirow{3}{*}{$\begin{array}{c}\text { TR medio } \\
\mathrm{s}(\mathrm{N} / \mathrm{mm} 2) \\
\mathrm{CV}(\%)\end{array}$} & \multirow{2}{*}{$\begin{array}{l}3,45 \\
0,43\end{array}$} \\
\hline & & & & & & & & \\
\hline & & & & & & 14,29 & & 12,47 \\
\hline & & & & & $\mathbf{A} \%$ & 10,58 & C $\%$ & 89,42 \\
\hline & & & & & I medio & 13,29 & t medio & 0,23 \\
\hline & & & Rot & ra \% & Dim & iones $d$ & probeta en & $\mathrm{mm}$ \\
\hline Probeta & $\begin{array}{c}\text { Rotura } \\
k N\end{array}$ & $\begin{array}{l}\text { Rotura } \\
\mathrm{N} / \mathrm{mm} 2\end{array}$ & Adhesiva & Cohesiva & $b$ & $\begin{array}{l}\text { Long. } \\
\text { Solape } \\
\text { I (mm) }\end{array}$ & $\begin{array}{c}\text { Espesor } \\
\text { capa } \\
t(\mathrm{~mm})\end{array}$ & $\begin{array}{c}\text { Espesor } \\
\text { unión adh. } \\
e(\mathrm{~mm})\end{array}$ \\
\hline 1F3d & 1,34 & 4,06 & 5 & 95 & 25,00 & 13,150 & 0,290 & 3,045 \\
\hline $2 F 3 d$ & 1,22 & 3,58 & 5 & 95 & 25,00 & 13,635 & 0,235 & 2,960 \\
\hline $3 F 3 d$ & 1,01 & 3,19 & 20 & 80 & 25,00 & 12,690 & 0,190 & 2,815 \\
\hline $4 \mathrm{~F} 3 \mathrm{~d}$ & 0,80 & 2,57 & 10 & 90 & 25,00 & 12,530 & 0,270 & 2,910 \\
\hline $5 F 3 d$ & 1,38 & 3,90 & 5 & 95 & 25,00 & 14,115 & 0,175 & 2,950 \\
\hline $6 \mathrm{~F} 3 \mathrm{~d}$ & 1,08 & 3,37 & 7 & 93 & 25,00 & 12,780 & 0,285 & 2,940 \\
\hline $7 F 3 d$ & 1,12 & 3,57 & 25 & 75 & 25,00 & 12,545 & 0,240 & 2,930 \\
\hline $8 \mathrm{~F} 3 \mathrm{~d}$ & 1,13 & 3,53 & 20 & 80 & 25,00 & 12,775 & 0,175 & 2,960 \\
\hline 9F3d & 1,17 & 3,52 & 5 & 95 & 25,00 & 13,305 & 0,285 & 3,040 \\
\hline $10 \mathrm{~F} 3 \mathrm{~d}$ & 1,40 & 3,89 & 5 & 95 & 25,00 & 14,380 & 0,145 & 2,900 \\
\hline 11F3d & 0,99 & 2,70 & 15 & 85 & 25,00 & 14,640 & 0,235 & 3,025 \\
\hline $12 \mathrm{~F} 3 \mathrm{~d}$ & 1,12 & 3,46 & 5 & 95 & 25,00 & 12,900 & 0,220 & 2,840 \\
\hline
\end{tabular}

Como se observa en la tabla, cuando se consigue el valor máximo de espesor de capa y porcentaje de rotura cohesiva, se alcanza la máxima tensión de rotura. Y cuando se obtiene el mínimo valor de espesor de capa, se logra la mínima tensión de rotura.

La variación que sufre la tensión de rotura con un aumento de la longitud de solape se puede observar en la Figura 95. Analizando este diagrama no se pueden extraen conclusiones definitivas, por lo que se toma la decisión de excluir del estudio las probetas que alcanzan los valores máximos y mínimos de longitud de solape y espesor de capa adhesiva (probetas números 1, 4, 10 y 11), debido a que se observan en estos valores un comportamiento diferente de la tensión de rotura respecto a los valores intermedios. 
Según las conclusiones obtenidas de la tabla mostrada al inicio de este apartado, se podría esperar que la tensión aumentara al crecer el espesor de capa y disminuyera al descender la longitud de solape. A continuación, se demuestra que estas afirmaciones no son del todo ciertas al examinar solamente los valores intermedios:

- Cuando no existe variación en el porcentaje de rotura cohesiva, y la longitud de solape y el espesor de capa sufren variaciones similares, es decir, las dos aumentan o las dos disminuyen al mismo tiempo, se logra un aumento en el valor de la tensión de rotura.

- Independientemente del comportamiento del porcentaje de rotura cohesiva, cuando la longitud de solape y el espesor de capa evolucionan de forma contraria, la tensión de rotura mostrará la misma variación que la longitud de solape. Esto sucede en todas las probetas excepto en la 3.

- Cuando la longitud de solape se mantiene constante, se verifica que la tensión de rotura aumenta cuando el espesor de capa y el porcentaje de rotura cohesiva disminuyen conjuntamente, y disminuye cuando ambos factores aumentan.

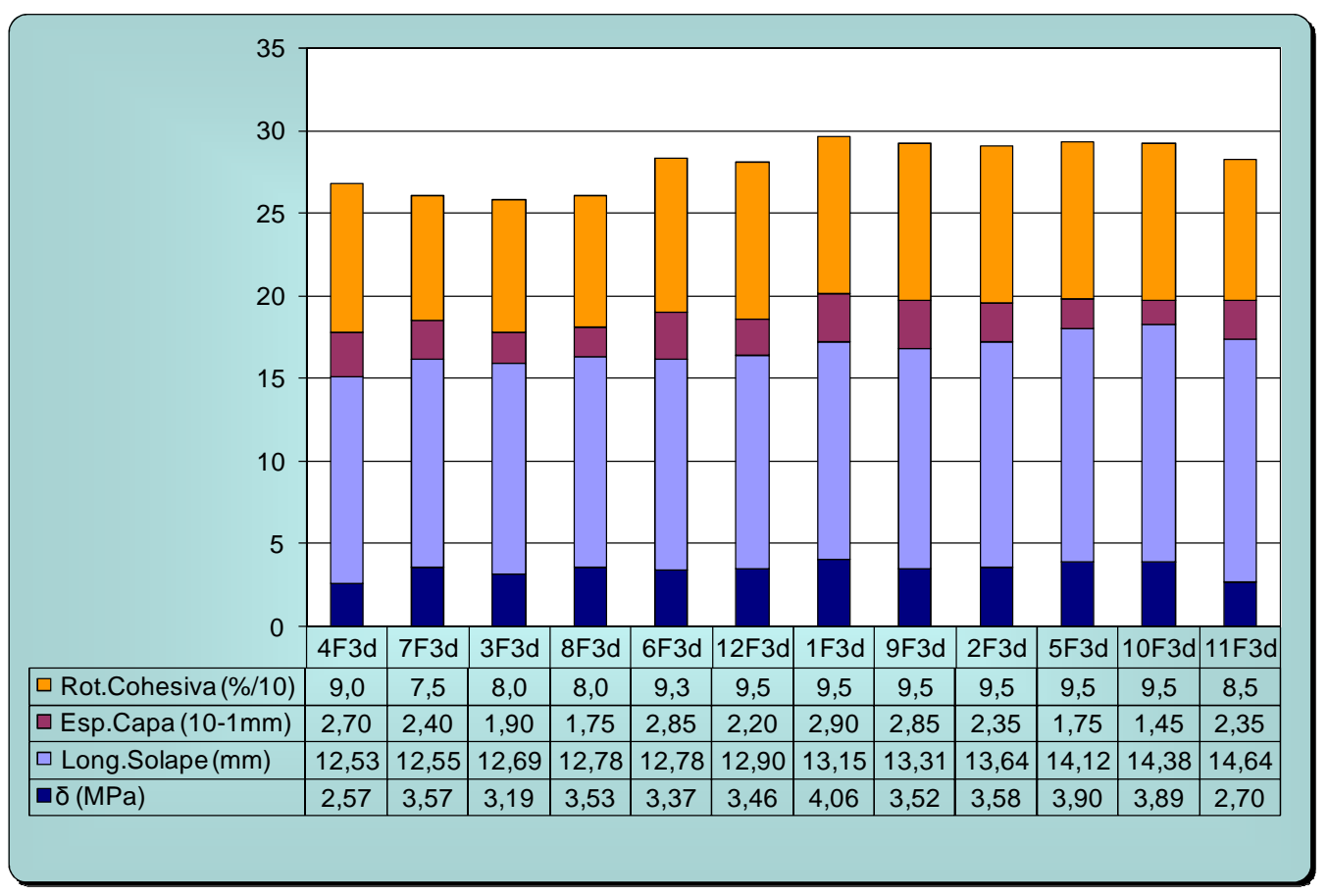

Figura 95. Influencia de la longitud de solape.

En la Figura 96 se muestra la influencia que tiene el aumento del espesor de capa adhesiva en la tensión de rotura. Analizando este diagrama se deducen las siguientes conclusiones:

- Independientemente del comportamiento del porcentaje de rotura cohesiva, cuando la longitud de solape y el espesor de capa evolucionan de forma semejante, la tensión tendrá el mismo comportamiento.

- En los casos donde no exista variación del espesor de capa, la tensión presentará el mismo comportamiento que el porcentaje de rotura cohesiva, independientemente de la evolución de la longitud de solape. 
Cuando el espesor de capa y la longitud de solape sufren variaciones contrarias, no se pueden extraen conclusiones definitivas, por lo que se toma la de excluir del estudio las probetas que alcanzan los valores máximos y mínimos de longitud y espesor. De esta forma se obtiene una nueva conclusión:

- Cuando el espesor de capa muestra un comportamiento contrario a la evolución conjunta de la longitud de solape y el porcentaje de rotura cohesiva, la tensión de rotura sufrirá una variación contraria al espesor de capa y, por lo tanto, semejante a la longitud de solape y el porcentaje de rotura cohesiva.

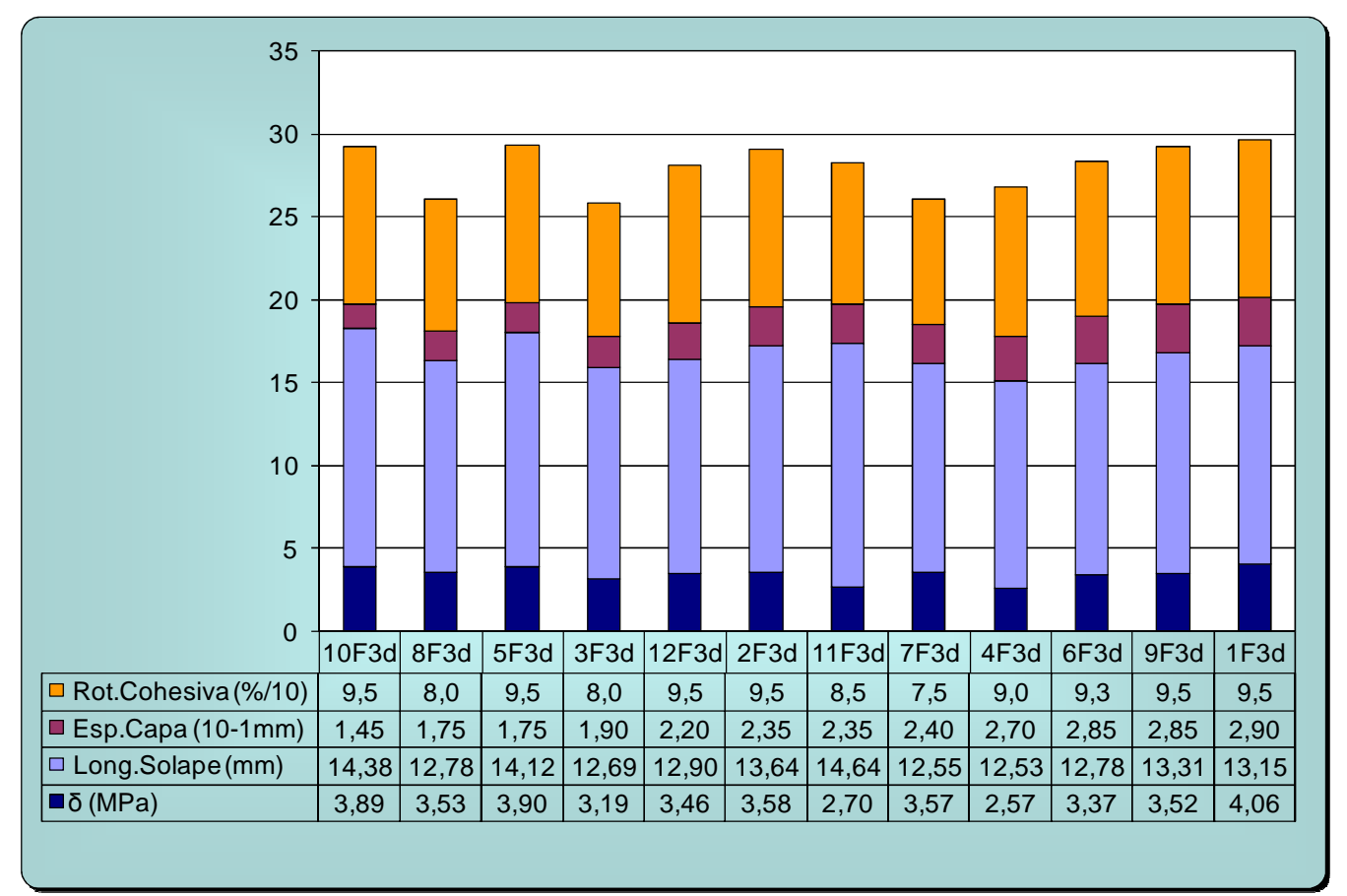

Figura 96. Influencia del espesor de capa adhesiva.

Una vez analizados los diagramas sin incluir los valores máximos y mínimos de espesor de capa y longitud de solape, se puede concluir de forma global que el comportamiento de la tensión de rotura en pobretas de acero galvanizado con un proceso de curado de tres días es el siguiente:

$\checkmark$ Cuando el porcentaje de rotura cohesiva se mantiene constante, y la longitud de solape y el espesor de capa evolucionan de forma similar, la tensión de rotura presentará el mismo comportamiento que estos dos parámetros.

$\checkmark$ Independientemente del comportamiento del porcentaje de rotura cohesiva, cuando la longitud de solape y el espesor de capa evolucionan de forma contraria, la longitud tendrá una mayor influencia sobre la tensión de rotura, mostrando ambas el mismo comportamiento.

$\checkmark$ Cuando la longitud de solape no sufre variación, la tensión de rotura muestra un comportamiento contrario a la evolución conjunta del espesor de capa y el porcentaje de rotura cohesiva.

$\checkmark$ En los casos donde el espesor de capa permanece constante, la tensión de rotura presentará el mismo comportamiento que el porcentaje de rotura cohesiva, independientemente de la evolución de la longitud de solape. 


\subsubsection{Resultados y conclusiones para probetas con un tiempo de curado de 7 días:}

Los resultados correspondientes a las probetas de acero galvanizado con siete días de curado se detallan en la siguiente tabla:

Tabla 20. Resultados de probetas de acero galvanizado con 7 días de curado.

\begin{tabular}{|c|c|c|c|c|c|c|c|c|}
\hline \multirow{5}{*}{\multicolumn{5}{|c|}{\begin{tabular}{ll|l|} 
ENSAYO: & Cizalladura \\
UNIÓN: & Adhesiva-Terostat-MS 939 \\
SUPERFICIE: $\quad$ Acero Galvanizado \\
PREP. SUPERFICIAL: & Limpieza con acetona \\
CURADO (DÍAS): $\quad 7$
\end{tabular}}} & \multirow{3}{*}{$\begin{array}{c}\text { FR medio } \\
\mathrm{s}(\mathrm{N} / \mathrm{mm} 2) \\
\mathrm{CV}(\%)\end{array}$} & \multirow{2}{*}{$\begin{array}{l}1,62 \\
0,25 \\
\end{array}$} & \multirow{2}{*}{$\begin{array}{l}\text { TR medio } \\
\mathrm{s}(\mathrm{N} / \mathrm{mm} 2)\end{array}$} & \multirow{2}{*}{$\begin{array}{l}3,78 \\
0,52\end{array}$} \\
\hline & & & & & & & & \\
\hline & & & & & & 15,24 & CV(\%) & 13,70 \\
\hline & & & & & $\mathrm{A} \%$ & 3,67 & C \% & 96,33 \\
\hline & & & & & I medio & 17,08 & t medio & 0,37 \\
\hline & & & ㄱot & a \% & D Dim & iones de & probeta en & $\mathrm{nm}$ \\
\hline Probeta & $\begin{array}{c}\text { Fuerza } \\
\text { Rotura } \\
\text { kN }\end{array}$ & $\begin{array}{c}\text { Rotura } \\
\mathrm{MPa}\end{array}$ & Adhesiva & Cohesiva & $b$ & $\begin{array}{l}\text { Long. } \\
\text { Solape } \\
\text { I (mm) }\end{array}$ & $\begin{array}{c}\text { Espesor } \\
\text { capa } \\
t(\mathrm{~mm})\end{array}$ & $\begin{array}{c}\text { Espesor } \\
\text { unión adh. } \\
e(\mathrm{~mm})\end{array}$ \\
\hline $1 F 7 d$ & 1,68 & 3,81 & 1 & 99 & 25,00 & 17,585 & 0,420 & 3,075 \\
\hline $2 F 7 d$ & 1,47 & 3,45 & 2 & 98 & 25,00 & 17,050 & 0,520 & 3,080 \\
\hline $3 F 7 d$ & 1,90 & 4,39 & 2 & 98 & 25,00 & 17,260 & 0,265 & 3,030 \\
\hline $4 \mathrm{~F} 7 \mathrm{~d}$ & 1,86 & 4,27 & 1 & 99 & 25,00 & 17,400 & 0,330 & 2,995 \\
\hline $5 F 7 d$ & 1,58 & 3,57 & 2 & 98 & 25,00 & 17,670 & 0,425 & 3,160 \\
\hline $6 \mathrm{~F} 7 \mathrm{~d}$ & 1,87 & 4,37 & 1 & 99 & 25,00 & 17,125 & 0,300 & 3,020 \\
\hline $7 F 7 d$ & 1,01 & 2,62 & 20 & 80 & 25,00 & 15,340 & 0,425 & 3,205 \\
\hline $8 \mathrm{~F} 7 \mathrm{~d}$ & 1,38 & 3,24 & 3 & 97 & 25,00 & 16,975 & 0,395 & 3,095 \\
\hline 9F7d & 1,71 & 4,08 & 2 & 98 & 25,00 & 16,715 & 0,580 & 3,285 \\
\hline 10F7d & 1,83 & 4,29 & 5 & 95 & 25,00 & 17,025 & 0,200 & 2,905 \\
\hline $11 \mathrm{~F} 7 \mathrm{~d}$ & 1,49 & 3,44 & 3 & 97 & 25,00 & 17,275 & 0,210 & 2,980 \\
\hline $12 \mathrm{~F} 7 \mathrm{~d}$ & 1,66 & 3,78 & 2 & 98 & 25,00 & 17,575 & 0,350 & 3,080 \\
\hline
\end{tabular}

Se verifica, estudiando la tabla de valores obtenidos a partir del ensayo de cizalladura, que cuando la longitud de solape adquiere su mínimo se alcanza la mínima tensión de rotura y mínimo porcentaje de rotura cohesiva. Mientras que el límite máximo de la tensión de rotura se logra para valores bajos de espesor de capa y valores altos de porcentaje de rotura cohesiva.

Para analizar la evolución de la tensión de rotura, se examina el efecto que provoca un aumento de la longitud de solape. Las conclusiones que se deducen de la Figura 97 son:

- Cuando la longitud de solape, el espesor de capa y el porcentaje de rotura cohesiva, evolucionan de igual manera (los tres aumentan o los tres disminuyen), la tensión de rotura mostrará el mismo comportamiento que esos tres factores. Excepto para las probetas números 2 y 10. Comportamiento similar al de las probetas de acero blanco con un proceso de curado de siete días. 
- Cuando solamente muestran un comportamiento homólogo la longitud de solape y el espesor de capa, y el porcentaje de rotura cohesiva presenta una evolución inversa (longitud y espesor aumentan mientras que rotura cohesiva disminuye, o cuando longitud y espesor disminuyen mientras que rotura cohesiva aumenta), se puede observar que será mayor la influencia del porcentaje de rotura cohesiva sobre la tensión de rotura; por lo tanto, ambas tiene el mismo comportamiento y contrario a la evolución conjunta de la longitud de solape y espesor de capa. Este comportamiento también lo mostraban las probetas de acero blanco con un proceso de curado de siete días.

- Cuando la longitud de solape y el porcentaje de rotura cohesiva evolucionan de forma conjunta y contraria al espesor de capa, la variación de la tensión de rotura será análoga a la longitud de solape y porcentaje de rotura cohesiva.

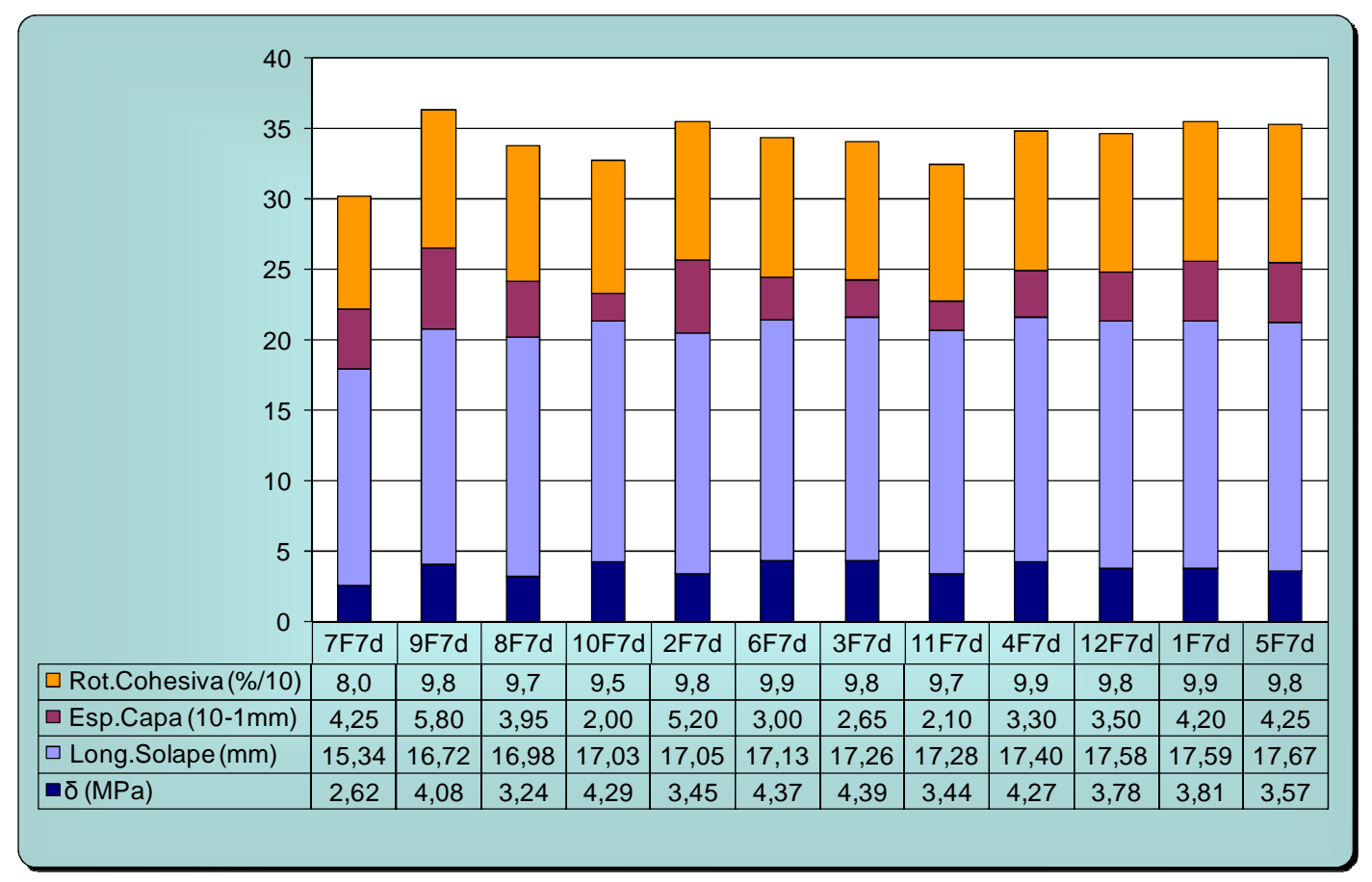

Figura 97. Influencia de la longitud de solape.

Analizando la Figura 98, donde se representa la evolución de la tensión de rotura en función del aumento del espesor de capa, se verifican las dos últimas conclusiones que se acaban de detallar en el estudio de la Figura 97. 


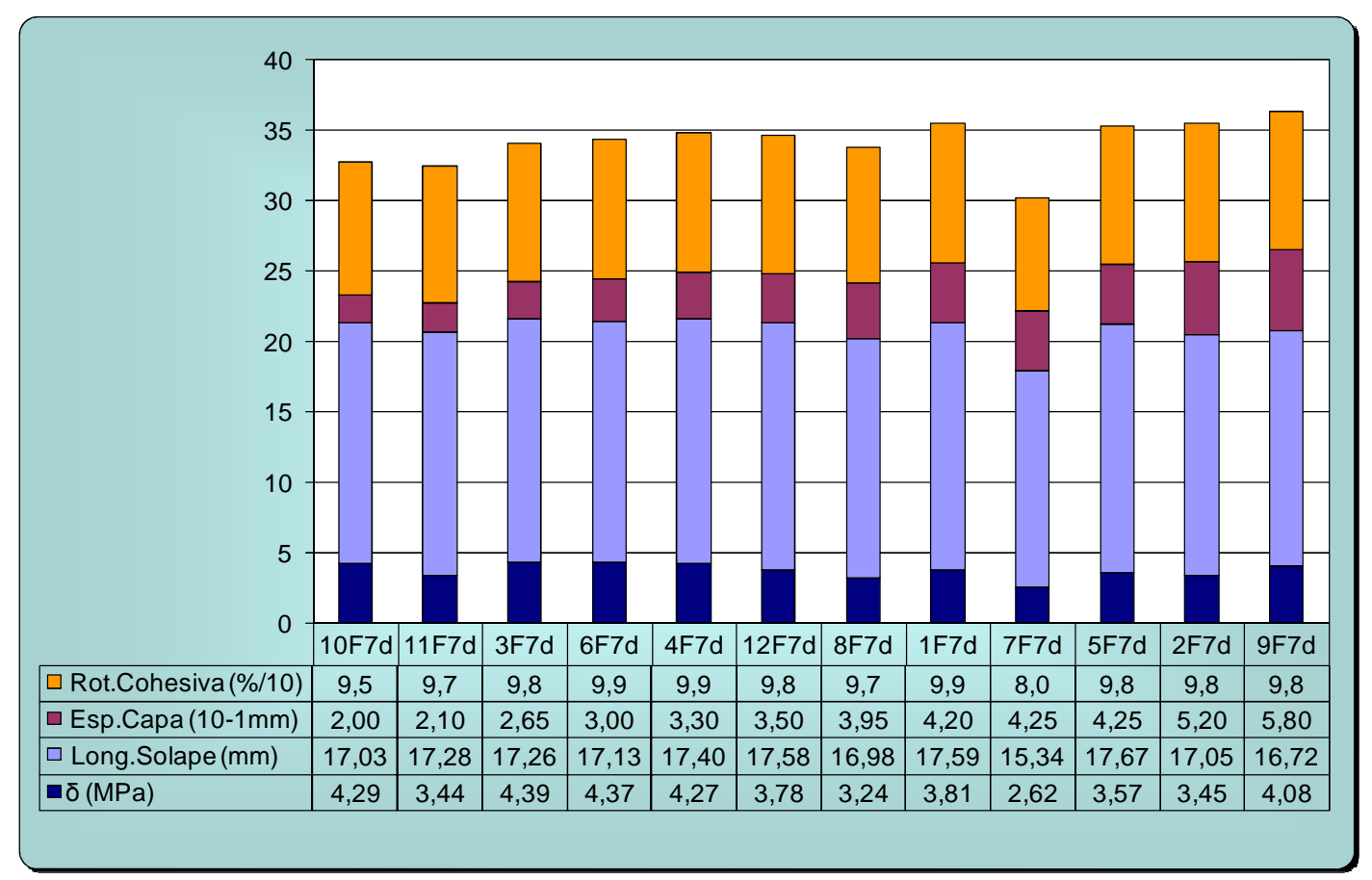

Figura 98. Influencia del espesor de capa adhesiva.

Se puede resumir que el comportamiento de la tensión de rotura en probetas de acero galvanizado con un proceso de curado de siete días es el siguiente:

$\checkmark$ La tensión de rotura muestra la misma evolución que el porcentaje de rotura cohesiva, cuando espesor de capa y la longitud de solape evolucionan de manera semejante.

$\checkmark$ Cuando la longitud de solape y el porcentaje de rotura cohesiva evolucionan de forma semejante y contraria al espesor de capa, la tensión de rotura muestra un comportamiento igual al de los dos primeros factores. 


\subsubsection{Influencia del tiempo de curado en probetas de acero galvanizado:}

En la siguiente tabla se especifican los valores medios de los principales parámetros de unión para los diferentes tiempos de curado que se han estudiado:

Tabla 21. Comparación de resultados de probetas de acero galvanizado.

\begin{tabular}{|c||c|c|c|c|c|c|}
\hline $\begin{array}{c}\text { Tiempo } \\
\text { Curado }\end{array}$ & $\begin{array}{c}\text { Longitud Solape } \\
(\mathbf{m m})\end{array}$ & $\begin{array}{c}\text { Espesor Capa } \\
(\mathbf{m m})\end{array}$ & $\begin{array}{c}\text { Fuerza Rotura } \\
\mathbf{( k N )}\end{array}$ & $\begin{array}{c}\text { Tensión Rotura } \\
\text { (MPa) }\end{array}$ & $\begin{array}{c}\text { \%Rotura } \\
\text { Adhesiva }\end{array}$ & $\begin{array}{c}\text { \%Rotura } \\
\text { Cohesiva }\end{array}$ \\
\hline \hline 3 días & 13,29 & 0,23 & 1,15 & 3,45 & 11 & 89 \\
\hline 7 días & 17,08 & 0,37 & 1,62 & 3,78 & 4 & 96 \\
\hline
\end{tabular}

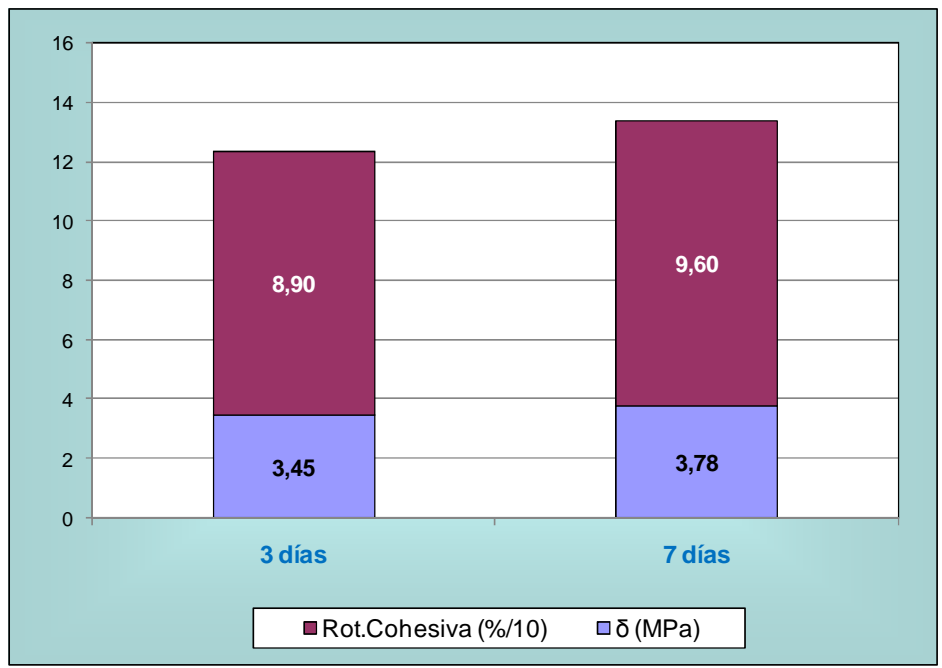

Figura 99. Influencia del Tiempo de Curado.

Como muestran los datos recogidos en la tabla anterior, en las probetas de acero galvanizado se obtiene un ligero crecimiento en el valor de la fuerza de rotura al aumentar el tiempo de curado del adhesivo, pero como este aumento no es significativo se puede afirmar que le tiempo de curado no influye en el valor de la tensión de rotura. Esto permitirá realizar uniones con un tiempo mínimo de tres días.

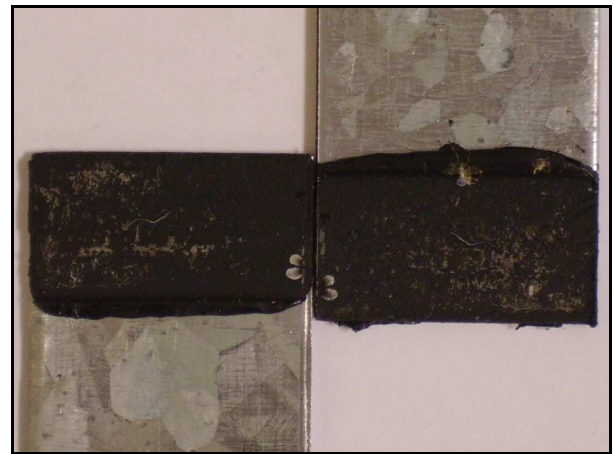

Figura 100. Rotura $75 \%$ cohesiva de probetas con 3 días curado

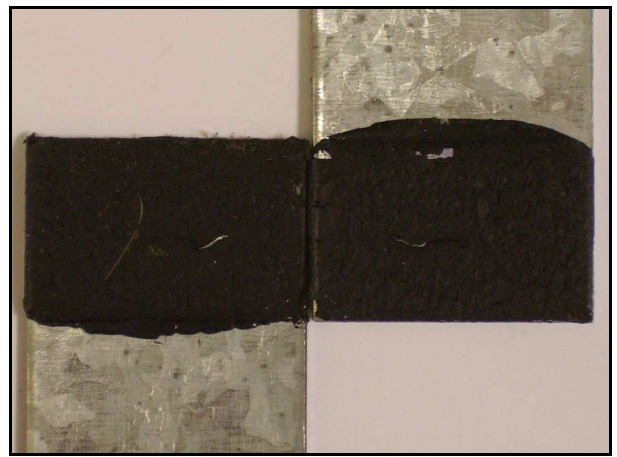

Figura 101. Rotura $99 \%$ cohesiva de probetas con 7 días curado 


\subsection{Comparación de resultados para probetas unidas con adhesivo silano modificado Terostat MS 939.}

La Tabla 22 muestra una comparación de los valores obtenidos en los ensayos de tracción a cizalladura simple con el fin de poder discutir cuál es el acabo superficial que alcanza los mejores resultados de resistencia de unión.

Tabla 22. Comparación de resultados de probetas unidas con adhesivo silano modificado.

\begin{tabular}{|c|c|c|c|c|c|c|}
\hline Superficie & $\begin{array}{l}\text { Longitud Solape } \\
\text { (mm) }\end{array}$ & $\begin{array}{c}\text { Espesor Capa } \\
(\mathrm{mm})\end{array}$ & $\begin{array}{c}\text { Fuerza Rotura } \\
\text { (kN) }\end{array}$ & $\begin{array}{c}\text { Tensión Rotura } \\
\text { (MPa) }\end{array}$ & $\begin{array}{c}\text { \%Rotura } \\
\text { Adhesiva }\end{array}$ & $\begin{array}{l}\text { \%Rotura } \\
\text { Cohesiva }\end{array}$ \\
\hline \multicolumn{7}{|l|}{ Tiempo Curado } \\
\hline Ac. Blanco & 13,33 & 0,31 & 1,14 & 3,41 & 63 & 37 \\
\hline $\begin{array}{c}\text { Ac. Recubrimiento orgánico } \\
\text { poliéster (pint.roja) }\end{array}$ & 13,28 & 0,24 & 0,85 & 2,56 & 14 & 86 \\
\hline $\begin{array}{l}\text { Ac. Recubrimiento orgánico } \\
\text { poliéster epoxi (pint.gris) }\end{array}$ & 12,87 & 0,11 & 1,22 & 3,79 & 6 & 94 \\
\hline Ac. Galvanizado & 13,29 & 0,23 & 1,15 & 3,45 & 11 & 89 \\
\hline \multicolumn{7}{|l|}{ Tiempo Curado } \\
\hline Ac. Blanco & 14,91 & 0,30 & 1,18 & 3,17 & 14 & 86 \\
\hline $\begin{array}{c}\text { Ac. Recubrimiento orgánico } \\
\text { poliéster (pint.roja) }\end{array}$ & 16,54 & 0,42 & 1,18 & 2,86 & 25 & 75 \\
\hline $\begin{array}{l}\text { Ac. Recubrimiento orgánico } \\
\text { poliéster epoxi (pint.gris) }\end{array}$ & 12,36 & 0,21 & 1,13 & 3,65 & 11 & 89 \\
\hline Ac. Galvanizado & 17,08 & 0,37 & 1,62 & 3,78 & 4 & 96 \\
\hline \multicolumn{7}{|l|}{ Tiempo Curado } \\
\hline Ac. Blanco & 13,53 & 0,26 & 1,17 & 3,44 & 67 & 33 \\
\hline $\begin{array}{c}\text { Ac. Recubrimiento orgánico } \\
\text { poliéster (pint.roja) }\end{array}$ & 13,32 & 0,24 & 0,99 & 2,99 & 66 & 35 \\
\hline $\begin{array}{c}\text { Ac. Recubrimiento orgánico } \\
\text { poliéster epoxi (pint.gris) }\end{array}$ & 15,18 & 0,16 & 1,55 & 4,07 & 0 & 100 \\
\hline \multicolumn{7}{|l|}{ Valores Medios } \\
\hline Ac. Blanco & 13,92 & 0,29 & 1,16 & 3,34 & 48 & 52 \\
\hline $\begin{array}{c}\text { Ac. Recubrimiento orgánico } \\
\text { poliéster (pint.roja) }\end{array}$ & 14,38 & 0,30 & 1,01 & 2,80 & 35 & 65 \\
\hline $\begin{array}{c}\text { Ac. Recubrimiento orgánico } \\
\text { poliéster epoxi (pint.gris) }\end{array}$ & 13,47 & 0,16 & 1,30 & 3,84 & 6 & 94 \\
\hline Ac. Galvanizado & 15,19 & 0,30 & 1,39 & 3,62 & 7 & 93 \\
\hline
\end{tabular}

Los ensayos de cizalladura por tracción a solape simple revelan que los mejores resultados de resistencia de unión se alcanzan con las probetas de acero recubierto de poliéster epoxi. Por lo tanto, al igual que ocurría con las uniones con adhesivo epoxi bicomponente, será este tipo de unión adhesiva el que se recomiende en aplicaciones estructurales sometidas a esfuerzos de cizalladura con el fin de lograr la mayor tensión de rotura y el mayor porcentaje de rotura cohesiva.

Una segunda opción será el empleo de probetas de acero galvanizado. Este tipo de probetas alcanzan buenos resultados de tensión de rotura, y valores en el porcentaje de rotura cohesiva similares a los obtenidos con las probetas de acero recubierto de poliéster epoxi.

Las probetas de acero blanco muestran resultados muy bajos en el porcentaje de rotura cohesiva. Sin embargo, los valores de tensión de rotura obtenidos son bastante altos.

Serán las probetas de acero recubierto de poliéster las que no se recomendarán para aplicaciones sometidas a esfuerzos de cizalladura debido a que son las probetas que obtienen la menor tensión de rotura junto con unos valores de porcentaje de rotura cohesiva regulares. 
El porcentaje de fallo adhesivo que aparece en las probetas de acero blanco y acero recubierto de poliéster, señalan que no se han conseguido unas buenas condiciones de adhesión, ya sea por una baja interacción entre el sustrato y el adhesivo o por una inadecuada preparación superficial previa a la aplicación del adhesivo. Es por lo tanto, fundamental una preparación superficial para lograr las mejores condiciones de adhesión

El alto porcentaje de rotura cohesiva que se ha obtenido en las probetas de acero recubierto de poliéster epoxi y en las probetas de acero galvanizado, ha permitido la utilización de un sistema de preparación previo a la aplicación del adhesivo muy sencillo, lo que permite estudiar el comportamiento de los aceros recubiertos en un estado de recepción, evitando con ello los encarecimientos inherentes a cualquier proceso adicional de preparación superficial.
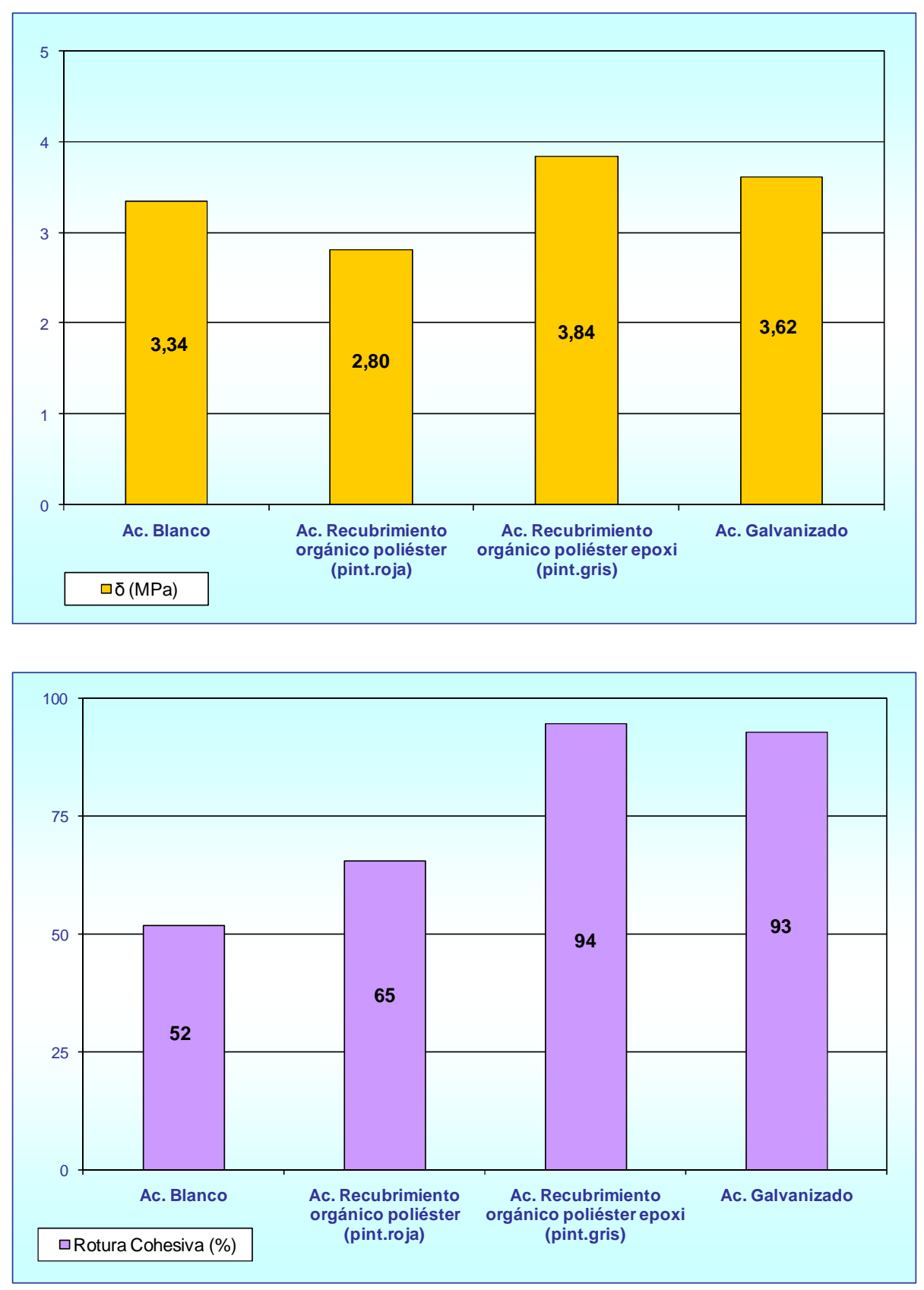

Figura 102. Comparación de la Tensión de Rotura y del porcentaje de Rotura Cohesiva. 


\section{COMPARACIÓN DE RESULTADOS PARA PROBETAS UNIDAS CON ADHESIVO EPOXI BICOMPONENTE LOCTITE HYSOL 9464 Y SILANO MODIFICADO TEROSTAT MS 939.}

A continuación se muestra una tabla de valores y un diagrama para realizar una comparación entre los dos tipos de adhesivo de composición química diferente: adhesivo epoxi bicomponente Loctite Hysol 9464 y silano modificado Terostat MS 939.

Tabla 23. Comparación de resultados de probetas unidas con adhesivo epoxi bicomponente y silano modificado.

\begin{tabular}{|c|c|c|c|c|c|c|}
\hline Superficie & Adhesivo & $\begin{array}{l}\text { Longitud Solape } \\
\qquad(\mathrm{mm})\end{array}$ & $\begin{array}{c}\text { Espesor Capa } \\
(\mathrm{mm})\end{array}$ & $\begin{array}{c}\text { Fuerza Rotura } \\
\text { (kN) }\end{array}$ & $\begin{array}{c}\text { Tensión Rotura } \\
\text { (MPa) }\end{array}$ & $\begin{array}{l}\text { \%Rotura } \\
\text { Cohesiva }\end{array}$ \\
\hline Ac. Blanco & \begin{tabular}{|c|} 
TEROSTAT MS \\
939 \\
\end{tabular} & 13,92 & 0,29 & 1,16 & 3,34 & 52 \\
\hline Ac. Blanco & $\begin{array}{c}\text { LOCTITE HYSOL } \\
9464\end{array}$ & 13,47 & 0,16 & 4,58 & 13,58 & 1 \\
\hline $\begin{array}{c}\text { Ac. Recubrimiento } \\
\text { orgánico poliéster } \\
\text { (pint.roja) }\end{array}$ & $\begin{array}{c}\text { TEROSTAT MS } \\
939\end{array}$ & 14,38 & 0,30 & 1,01 & 2,80 & 65 \\
\hline $\begin{array}{c}\text { Ac. Recubrimiento } \\
\text { orgánico poliéster } \\
\text { (pint.roja) }\end{array}$ & $\begin{array}{c}\text { LOCTITE HYSOL } \\
9464\end{array}$ & 13,46 & 0,36 & 1,34 & 4,27 & 0 \\
\hline $\begin{array}{l}\text { Ac. Recubrimiento } \\
\text { orgánico poliéster } \\
\text { epoxi (pint.gris) }\end{array}$ & $\begin{array}{c}\text { TEROSTAT MS } \\
939\end{array}$ & 13,47 & 0,16 & 1,30 & 3,84 & 94 \\
\hline $\begin{array}{l}\text { Ac. Recubrimiento } \\
\text { orgánico poliéster } \\
\text { epoxi (pint.gris) }\end{array}$ & $\begin{array}{l}\text { LOCTITE HYSOL } \\
9464\end{array}$ & 12,93 & 0,19 & 7,09 & 21,95 & 31 \\
\hline Ac. Galvanizado & $\begin{array}{c}\text { TEROSTAT MS } \\
939\end{array}$ & 15,19 & 0,30 & 1,39 & 3,62 & 93 \\
\hline Ac. Galvanizado & $\begin{array}{c}\text { LOCTITE HYSOL } \\
9464\end{array}$ & 12,76 & 0,24 & 3,44 & 10,82 & 0 \\
\hline
\end{tabular}

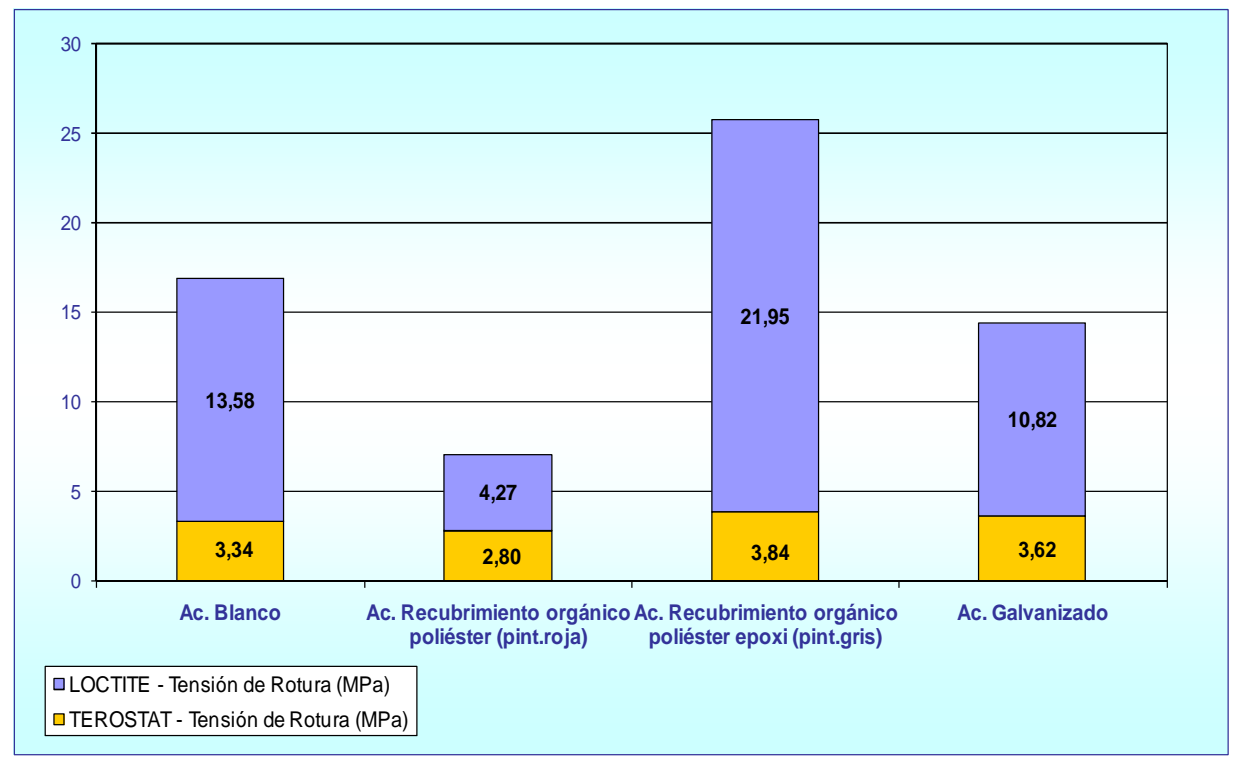

Figura 103. Comparación de la tensión de rotura entre adhesivo Loctite y Terostat. 
Como se puede observar en la tabla de valores, el adhesivo epoxi Loctite Hysol 9464 muestra mejores resultados en la tensión de rotura, mientras que el adhesivo silano modificado Terostat MS 969 presenta un mejor comportamiento en el tipo de rotura cohesiva.

Los ensayos de cizalladura por tracción a solape simple realizados con ambos tipos de adhesivos, revelan que la mayor tensión de rotura y el mayor porcentaje de rotura cohesiva se logran con las probetas de acero recubierto de poliéster epoxi.

De igual forma, los dos tipos de adhesivos muestran los valores más bajos de resistencia de unión con el acero recubierto de poliéster. 


\section{ANÁLISIS DE LOS RESULTADOS DEL ENSAYO DE FATIGA CON EPOXI BICOMPONENTE LOCTITE HYSOL 9464.}

\subsection{Probetas de acero blanco y adhesivo epoxi.}

Como ya se ha comentado en capitales anteriores, la máquina durante el ensayo de fatiga realiza un ciclo sinusoidal de tensión de tal forma que la tensión máxima escogida esta comprendida entre el $30 \%$ y $70 \%$ de la tensión máxima alcanzada en el ensayo de cizalladura, dicha tensión ha sido $4,5 \mathrm{kN}$. El perfil de cargas utilizado en los ensayos de fatiga se detalla en la Tabla 24.

Tabla 24. Perfil de fatiga para probetas de acero blanco.

\begin{tabular}{|c|c|c|c|c|}
\hline $\begin{array}{c}\text { \% Fureza } \\
\text { Rotura }\end{array}$ & $\begin{array}{c}\boldsymbol{\sigma m a x} \\
\mathbf{k N}\end{array}$ & $\begin{array}{c}\mathbf{\sigma m i n} \\
\mathbf{k N}\end{array}$ & $\begin{array}{c}\mathbf{A} \\
\mathbf{k N}\end{array}$ & $\begin{array}{c}\mathbf{P i} \\
\mathbf{k N}\end{array}$ \\
\hline \hline 0,7Fm & 3,15 & 0,32 & 1,42 & 1,73 \\
\hline $0,6 \mathrm{Fm}$ & 2,70 & 0,27 & 1,22 & 1,49 \\
\hline $0,5 \mathrm{Fm}$ & 2,25 & 0,23 & 1,01 & 1,24 \\
\hline $0,4 \mathrm{Fm}$ & 1,80 & 0,18 & 0,81 & 0,99 \\
\hline 0,3Fm & 1,35 & 0,14 & 0,61 & 0,74 \\
\hline
\end{tabular}

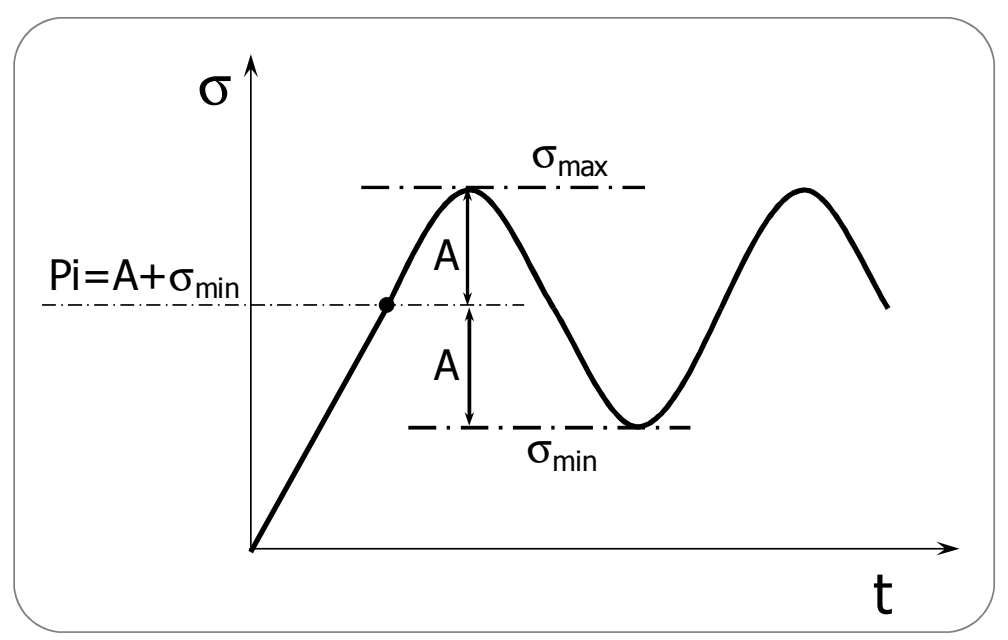

La Tabla 25 muestra los resultados obtenidos en los ensayos de fatiga de las probetas de acero blanco. Como se puede observar, conforme disminuye la tensión de rotura, aumenta el número de ciclos de carga. El mayor aumento se produce cuando la tensión de rotura es inferior a la mitad de la tensión máxima de tracción.

La Figura 104 corresponde a la Curva SN del comportamiento a fatiga de las uniones adhesivas con acero blanco, donde se puede comprobar que se ha alcanzado el límite de fatiga, es decir, la tensión por debajo de la cual no se produce la rotura y que representa el valor más grande de carga fluctuante que es capaz de soportar el material sin sufrir fallo. Este límite se localiza aproximadamente en 3,8 MPa. 
Tabla 25. Resultados de fatiga para probetas de acero blanco.

\begin{tabular}{|c|c|c|c|c|c|c|c|c|c|c|}
\hline \multirow{2}{*}{\multicolumn{7}{|c|}{$\begin{array}{ll}\text { ENSAYO: } & \text { Fatiga } \\
\text { UNIÓN: } & \text { Adhesiva-Loctite-Hysol } 9496\end{array}$}} & FR medio & 2,27 & TR medio & 6,71 \\
\hline & & & & & & & $\mathrm{s}(\mathrm{N} / \mathrm{mm} 2)$ & 0,64 & $\mathrm{~s}(\mathrm{~N} / \mathrm{mm} 2)$ & 2,03 \\
\hline \multirow{2}{*}{\multicolumn{7}{|c|}{$\begin{array}{ll}\text { SUPERFICIE: } & \text { Acero blanco } \\
\text { PREP. SUPERFICIAL: } & \text { Limpieza con agua y jabón + Limpieza con acetona }\end{array}$}} & $\mathrm{CV}(\%)$ & 28,38 & $\mathrm{CV}(\%)$ & 30,24 \\
\hline & & & & & & & $\mathrm{A} \%$ & 100,0 & $\mathbf{C} \%$ & 0,0 \\
\hline \multicolumn{7}{|c|}{$\begin{array}{llll}\text { CURADO (DÍAS): } & \mathbf{4} & \text { FIJAC. : } & \text { Libre } \\
\end{array}$} & I medio & 13,63 & t medio & 0,24 \\
\hline \multirow[b]{2}{*}{ Probeta } & \multirow[b]{2}{*}{ Ciclos } & \multirow[b]{2}{*}{$\begin{array}{c}\text { \% FR } \\
\text { ensayo } \\
\text { tracción }\end{array}$} & \multirow[b]{2}{*}{$\begin{array}{c}\text { Fuerza } \\
\text { Rotura } \\
k N\end{array}$} & \multirow[b]{2}{*}{$\begin{array}{c}\text { Tensión } \\
\text { Rotura } \\
\text { MPa }\end{array}$} & \multicolumn{2}{|c|}{ Rotura \% } & \multicolumn{4}{|c|}{ Dimensiones de la probeta en $\mathrm{mm}$} \\
\hline & & & & & Adhesiva & Cohesiva & $b$ & $\begin{array}{l}\text { Long. } \\
\text { Solape } \\
\text { I (mm) }\end{array}$ & $\begin{array}{c}\text { Espesor capa } \\
t(10-1 \mathrm{~mm})\end{array}$ & $\begin{array}{c}\text { Espesor } \\
\text { unión adh. } \\
\text { e (mm) }\end{array}$ \\
\hline 1 & 15.859 & 70 & 3,15 & 9,79 & 100 & 0 & 25,00 & 12,87 & 0,120 & 2,81 \\
\hline 16 & 2.595 & 70 & 3,15 & 9,63 & 100 & 0 & 25,00 & 13,08 & 0,055 & 2,82 \\
\hline 15 & 6.627 & 70 & 3,15 & 9,60 & 100 & 0 & 25,00 & 13,12 & 0,200 & 2,81 \\
\hline 2 & 10.801 & 70 & 3,15 & 9,43 & 100 & 0 & 25,00 & 13,36 & 0,150 & 2,92 \\
\hline 14 & 20.874 & 60 & 2,70 & 8,12 & 100 & 0 & 25,00 & 13,30 & 0,030 & 2,82 \\
\hline 4 & 27.095 & 60 & 2,70 & 8,07 & 100 & 0 & 25,00 & 13,38 & 0,240 & 2,81 \\
\hline 3 & 35.514 & 60 & 2,70 & 8,04 & 100 & 0 & 25,00 & 13,44 & 0,170 & 2,77 \\
\hline 17 & 44.783 & 60 & 2,70 & 7,56 & 100 & 0 & 25,00 & 14,28 & 0,315 & 2,78 \\
\hline 13 & 37.277 & 50 & 2,25 & 6,81 & 100 & 0 & 25,00 & 13,22 & 0,420 & 2,87 \\
\hline 5 & 76.936 & 50 & 2,25 & 6,53 & 100 & 0 & 25,00 & 13,79 & 0,215 & 2,77 \\
\hline 6 & 48.934 & 50 & 2,25 & 6,43 & 100 & 0 & 25,00 & 13,99 & 0,210 & 2,80 \\
\hline 18 & 217.006 & 50 & 2,25 & 6,23 & 100 & 0 & 25,00 & 14,45 & 0,205 & 2,84 \\
\hline 12 & 256.998 & 40 & 1,80 & 5,25 & 100 & 0 & 25,00 & 13,71 & 0,250 & 2,84 \\
\hline 7 & 301.514 & 40 & 1,80 & 5,21 & 100 & 0 & 25,00 & 13,81 & 0,390 & 2,87 \\
\hline 19 & 847.028 & 40 & 1,80 & 4,82 & 100 & 0 & 25,00 & 14,95 & 0,170 & 2,86 \\
\hline 11 & 981.793 & 30 & 1,35 & 4,24 & 100 & 0 & 25,00 & 12,73 & 0,570 & 2,74 \\
\hline 9 & 338.971 & 30 & 1,35 & 4,06 & 100 & 0 & 25,00 & 13,30 & 0,230 & 2,82 \\
\hline $10(x->)$ & 1.000 .000 & 30 & 1,35 & 3,88 & - & - & 25,00 & 13,91 & 0,440 & 2,78 \\
\hline $20(x->)$ & 1.000 .000 & 30 & 1,35 & 3,76 & - & - & 25,00 & 14,36 & 0,100 & 2,79 \\
\hline
\end{tabular}

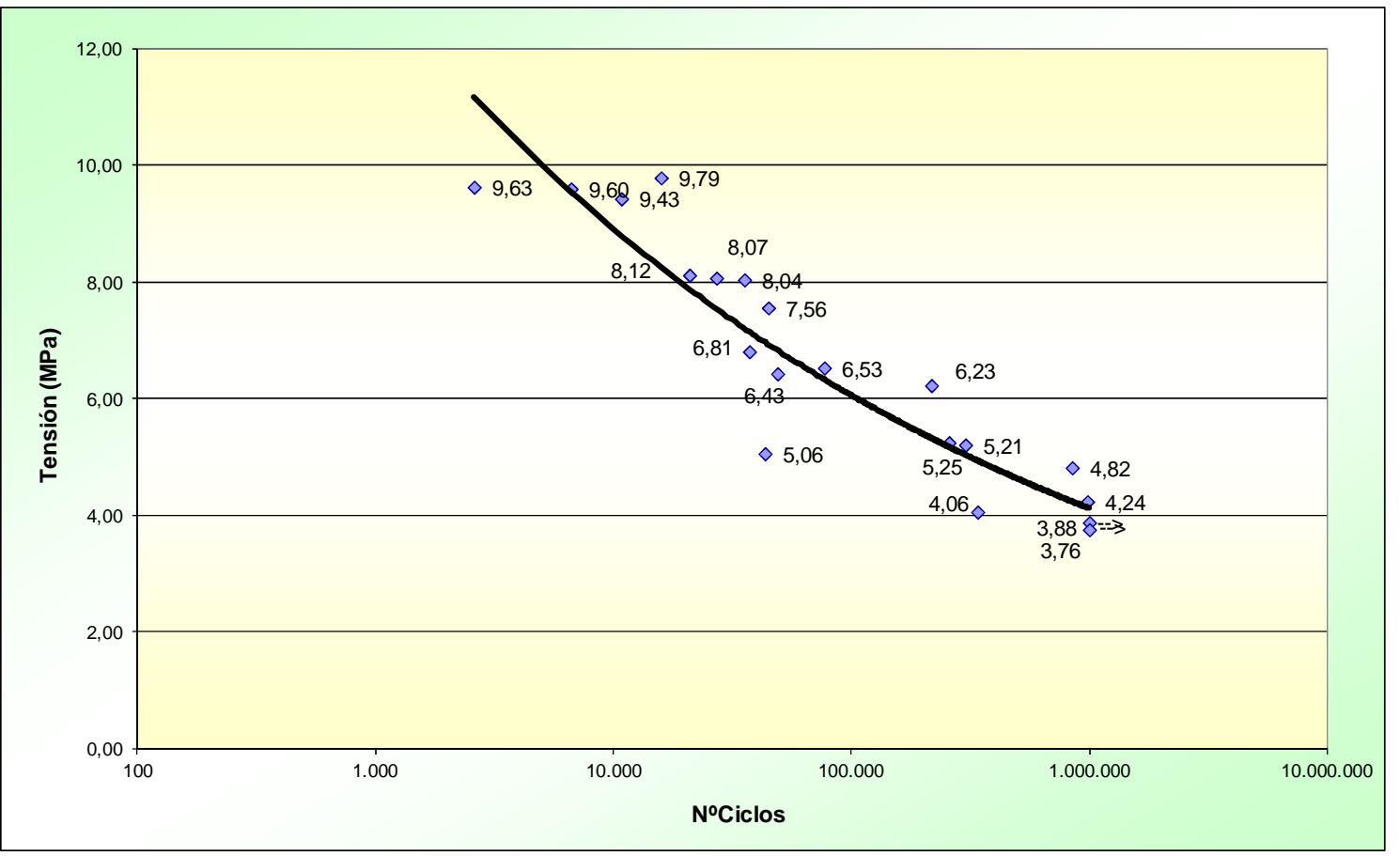

Figura 104. Curva de Wöhler del comportamiento a fatiga de uniones adhesivas con acero blanco y epoxi bicomponente. 


\subsection{Probetas de acero recubierto de poliéster epoxi y adhesivo epoxi.}

En el caso de los ensayos de fatiga de las probetas de acero recubierto de poliéster epoxi, la tensión máxima escogida vuelve a estar comprendida entre el $30 \%$ y $70 \%$ de la tensión máxima alcanzada en el ensayo de cizalladura, dicha tensión ha sido 7,09 kN. A continuación se muestra una tabla resumen con el sistema de carga introducido:

Tabla 26. Perfil de fatiga para probetas de acero recubierto de poliéster epoxi.

\begin{tabular}{|c|c|c|c|c|}
\hline $\begin{array}{c}\text { \% Fureza } \\
\text { Rotura }\end{array}$ & $\begin{array}{c}\text { бmax } \\
\mathbf{~ k N}\end{array}$ & $\begin{array}{c}\mathbf{\sigma m i n} \\
\mathbf{k N}\end{array}$ & $\begin{array}{c}\mathbf{A} \\
\mathbf{~ k N}\end{array}$ & $\begin{array}{c}\mathbf{P i} \\
\mathbf{k N}\end{array}$ \\
\hline \hline $0,7 \mathrm{Fm}$ & 4,96 & 0,50 & 2,23 & 2,73 \\
\hline $0,6 \mathrm{Fm}$ & 4,25 & 0,43 & 1,91 & 2,34 \\
\hline $0,5 \mathrm{Fm}$ & 3,55 & 0,35 & 1,60 & 1,95 \\
\hline $0,4 \mathrm{Fm}$ & 2,84 & 0,28 & 1,28 & 1,56 \\
\hline $0,3 \mathrm{Fm}$ & 2,13 & 0,21 & 0,96 & 1,17 \\
\hline
\end{tabular}

Al igual que sucede en las probetas de acero blanco, este tipo de probetas también experimenta un aumento de los ciclos de carga cuando disminuye la tensión (ver Tabla 27).

La Figura 105 muestra la curva SN del comportamiento a fatiga de uniones adhesivas con acero recubierto de poliéster epoxi, y en ella se detalla el límite de fatiga alcanzado, 6,60 MPa.

En este tipo de probetas se logra cierto porcentaje de rotura cohesiva, en algunos casos casi se alcanza el 100\%, como se puede apreciar en las figuras que aparecen a continuación (Figuras 106 hasta la 111).

Cuando se observa la rotura se aprecia que el fallo por fatiga no se produce por el crecimiento y propagación de una grieta de forma estable, es decir, su avance no se realiza a pequeños saltos cada uno de los cuales corresponde a un ciclo de tensión. El proceso de fatiga va debilitando poco a poco la unión adhesiva, y provoca que la grieta produzca el fallo por fatiga de forma inestable. 
Tabla 27. Resultados de fatiga para probetas de acero recubierto de poliéster epoxi.

\begin{tabular}{|c|c|c|c|c|c|c|c|c|c|c|}
\hline \multirow{2}{*}{\multicolumn{7}{|c|}{$\begin{array}{ll}\text { ENSAYO: } & \text { Fatiga } \\
\text { UNIÓN: } & \text { Adhesiva-Loctite-Hysol } 9496\end{array}$}} & FR medio & 3,70 & TR medio & 11,53 \\
\hline & & & & & & & $\mathrm{s}(\mathrm{N} / \mathrm{mm} 2)$ & 0,93 & $\mathrm{~s}(\mathrm{~N} / \mathrm{mm} 2)$ & 2,87 \\
\hline \multirow{2}{*}{\multicolumn{7}{|c|}{$\begin{array}{ll}\text { SUPERFICIE: } & \text { Recubrimiento Poliéster Epoxi } \\
\text { PREP. SUPERFICIAL: } & \text { Limpieza con acetona }\end{array}$}} & $\mathrm{CV}(\%)$ & 25,12 & $\mathrm{CV}(\%)$ & 24,92 \\
\hline & & & & & & & $A \%$ & 39,8 & C \% & 60,2 \\
\hline \multicolumn{2}{|c|}{ CURADO (DÍAS): } & 4 & & FIJAC. : & \multicolumn{2}{|l|}{ Libre } & I medio & 12,86 & t medio & 0,17 \\
\hline \multirow[b]{2}{*}{ Probeta } & \multirow[b]{2}{*}{ Ciclos } & \multirow[b]{2}{*}{$\begin{array}{c}\text { \% FR } \\
\text { ensayo } \\
\text { tracción }\end{array}$} & \multirow[b]{2}{*}{$\begin{array}{c}\text { Fuerza } \\
\text { Rotura } \\
\text { kN }\end{array}$} & \multirow[b]{2}{*}{$\begin{array}{c}\text { Tensión } \\
\text { Rotura } \\
\text { MPa }\end{array}$} & \multicolumn{2}{|c|}{ Rotura \% } & \multicolumn{4}{|c|}{ Dimensiones de la probeta en $\mathrm{mm}$} \\
\hline & & & & & Adhesiva & Cohesiva & $b$ & $\begin{array}{l}\text { Long. } \\
\text { Solape } \\
\text { I (mm) }\end{array}$ & $\begin{array}{c}\text { Espesor capa } \\
t(10-1 \mathrm{~mm})\end{array}$ & $\begin{array}{c}\text { Espesor } \\
\text { unión adh. } \\
\text { e }(\mathrm{mm})\end{array}$ \\
\hline 11 & 1.464 & 70 & 4,96 & 15,88 & 93 & 7 & 25,00 & 12,50 & 0,225 & 1,48 \\
\hline 14 & 2.367 & 70 & 4,96 & 15,81 & 10 & 90 & 25,00 & 12,55 & 0,095 & 1,44 \\
\hline 2 & 5.480 & 70 & 4,96 & 14,97 & 60 & 40 & 25,00 & 13,25 & 0,055 & 1,70 \\
\hline 1 & 8.524 & 70 & 4,96 & 14,05 & 40 & 60 & 25,00 & 14,13 & 0,085 & 1,54 \\
\hline 12 & 7.977 & 60 & 4,25 & 13,80 & 92 & 8 & 25,00 & 12,32 & 0,220 & 1,46 \\
\hline 5 & 25.105 & 60 & 4,25 & 13,15 & 30 & 70 & 25,00 & 12,93 & 0,190 & 1,45 \\
\hline 6 & 10.246 & 60 & 4,25 & 13,14 & 80 & 20 & 25,00 & 12,94 & 0,170 & 1,67 \\
\hline 13 & 12.687 & 60 & 4,25 & 13,11 & 5 & 95 & 25,00 & 12,97 & 0,155 & 1,50 \\
\hline 3 & 50.837 & 50 & 3,54 & 11,74 & 60 & 40 & 25,00 & 12,06 & 0,110 & 1,66 \\
\hline 7 & 63.009 & 50 & 3,54 & 11,36 & 65 & 35 & 25,00 & 12,47 & 0,320 & 1,58 \\
\hline 16 & 52.517 & 50 & 3,54 & 11,24 & 2 & 98 & 25,00 & 12,60 & 0,150 & 1,79 \\
\hline 17 & 44.794 & 50 & 3,54 & 10,84 & 14 & 86 & 25,00 & 13,06 & 0,100 & 1,42 \\
\hline 10 & 347.612 & 40 & 2,84 & 9,28 & 5 & 95 & 25,00 & 12,25 & 0,130 & 1,62 \\
\hline 20 & 263.502 & 40 & 2,84 & 8,90 & 35 & 65 & 25,00 & 12,76 & 0,150 & 1,55 \\
\hline 18 & 189.099 & 40 & 2,84 & 8,65 & 28 & 72 & 25,00 & 13,14 & 0,090 & 1,62 \\
\hline 9 & 776.947 & 40 & 2,84 & 8,55 & 18 & 82 & 25,00 & 13,29 & 0,305 & 1,44 \\
\hline $15(\mathrm{X}->)$ & 1.000 .000 & 30 & 2,13 & 6,62 & - & - & 25,00 & 12,87 & 0,190 & 1,47 \\
\hline $19(\mathrm{X}->)$ & 1.000 .000 & 30 & 2,13 & 6,39 & - & - & 25,00 & 13,33 & 0,245 & 1,44 \\
\hline
\end{tabular}

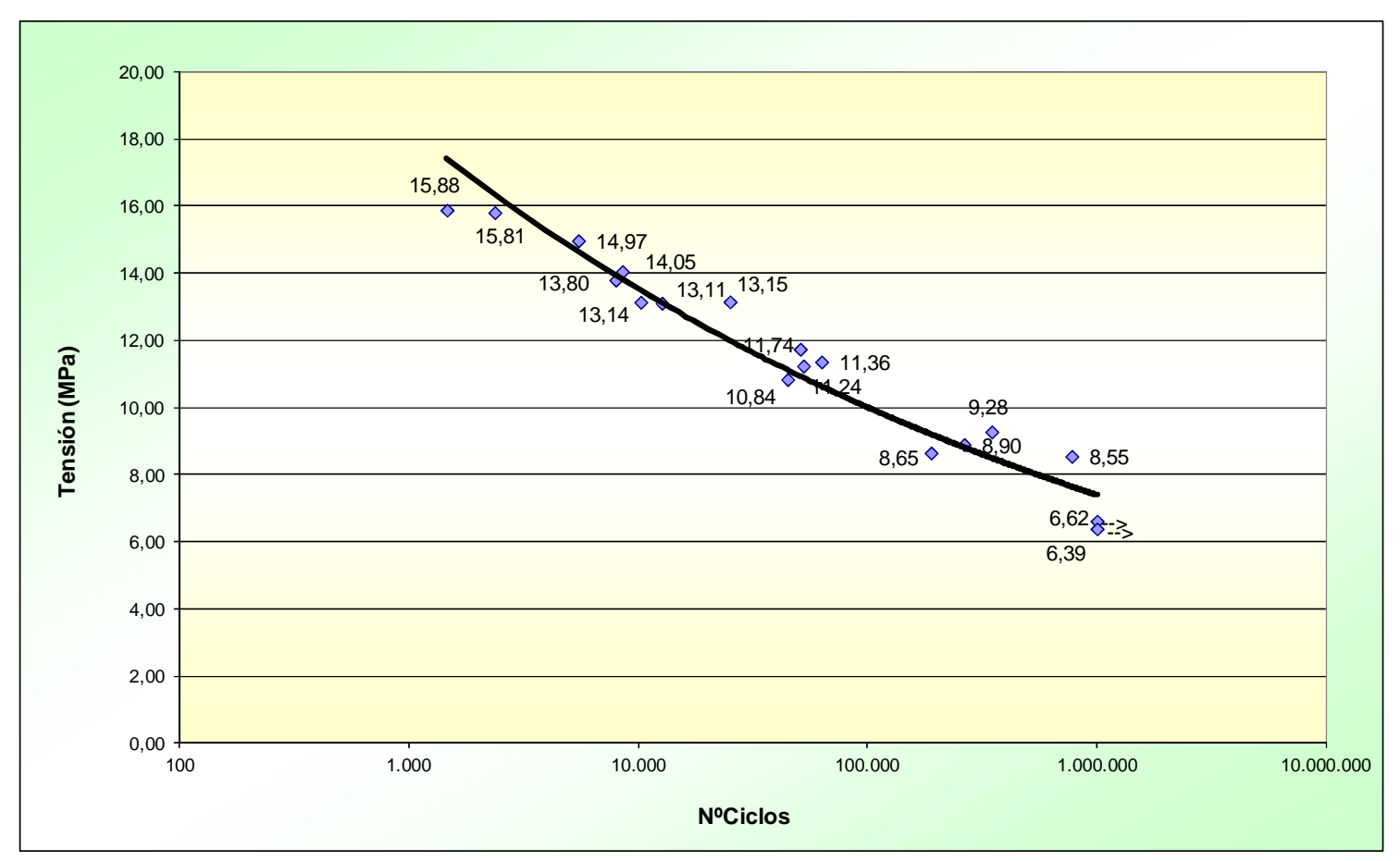

Figura 105. Curva de Wöhler del comportamiento a fatiga de uniones adhesivas con acero recubierto de epoxi y epoxi bicomponente. 


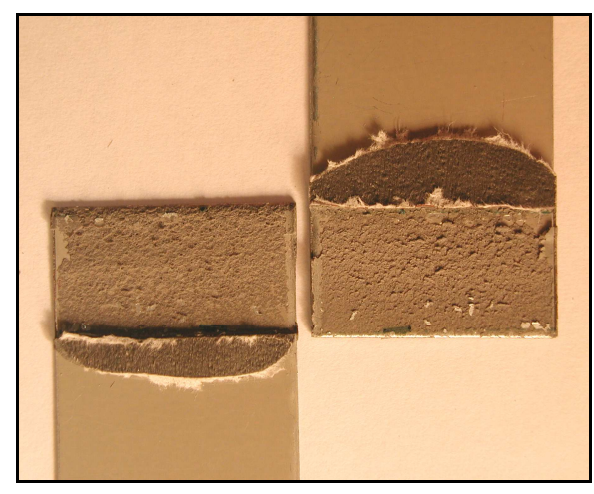

Figura 106. Probeta número 16, con un $98 \%$ de rotura cohesiva.

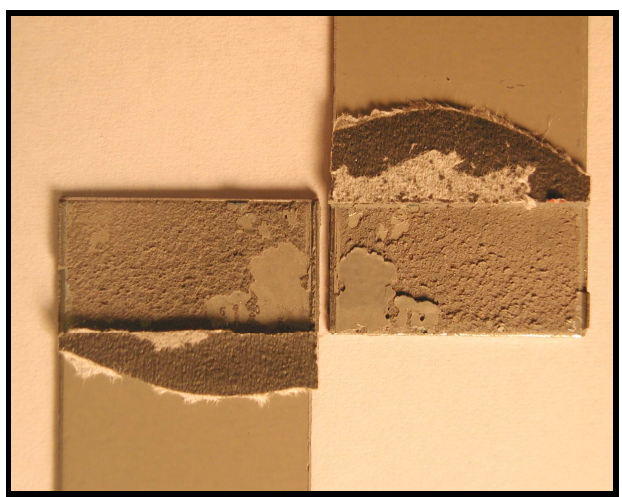

Figura 108. Probeta número 13, con un $95 \%$ de rotura cohesiva.

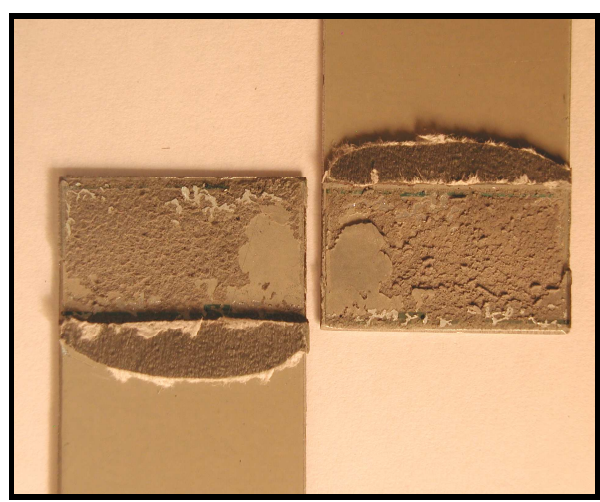

Figura 110. Probeta número 17, con un $86 \%$ de rotura cohesiva.

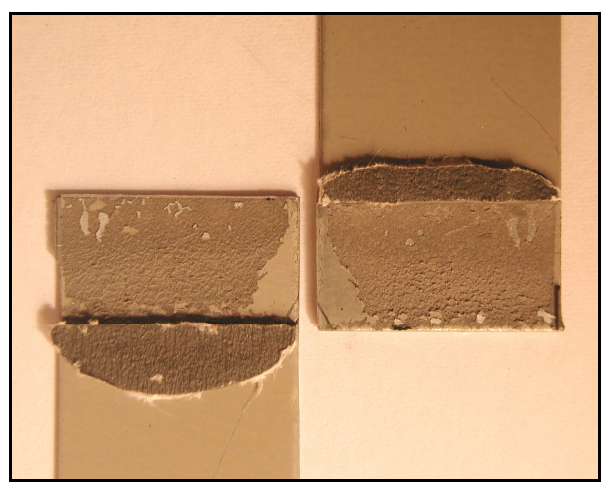

Figura 107. Probeta número 10, con un 95\% de rotura cohesiva.

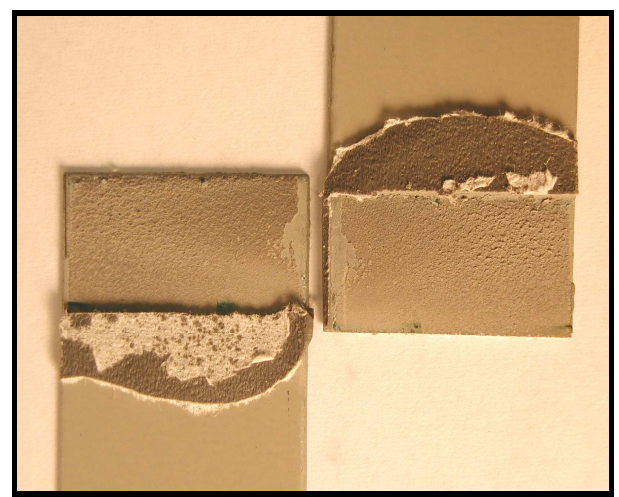

Figura 109. Probeta número 14, con un $90 \%$ de rotura cohesiva.

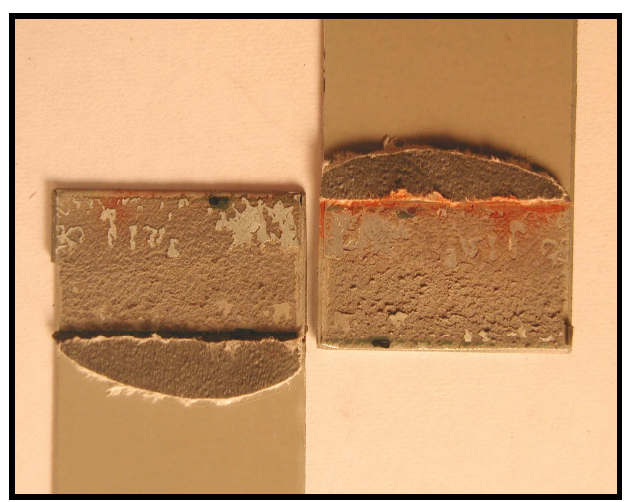

Figura 111. Probeta número 9, con un $82 \%$ de rotura cohesiva. 


\subsection{Resultados comparativos de los ensayos de fatiga.}

En el siguiente diagrama se puede comparar los resultados que se han obtenido con las probetas de acero blanco y con recubrimiento de poliéster epoxi:

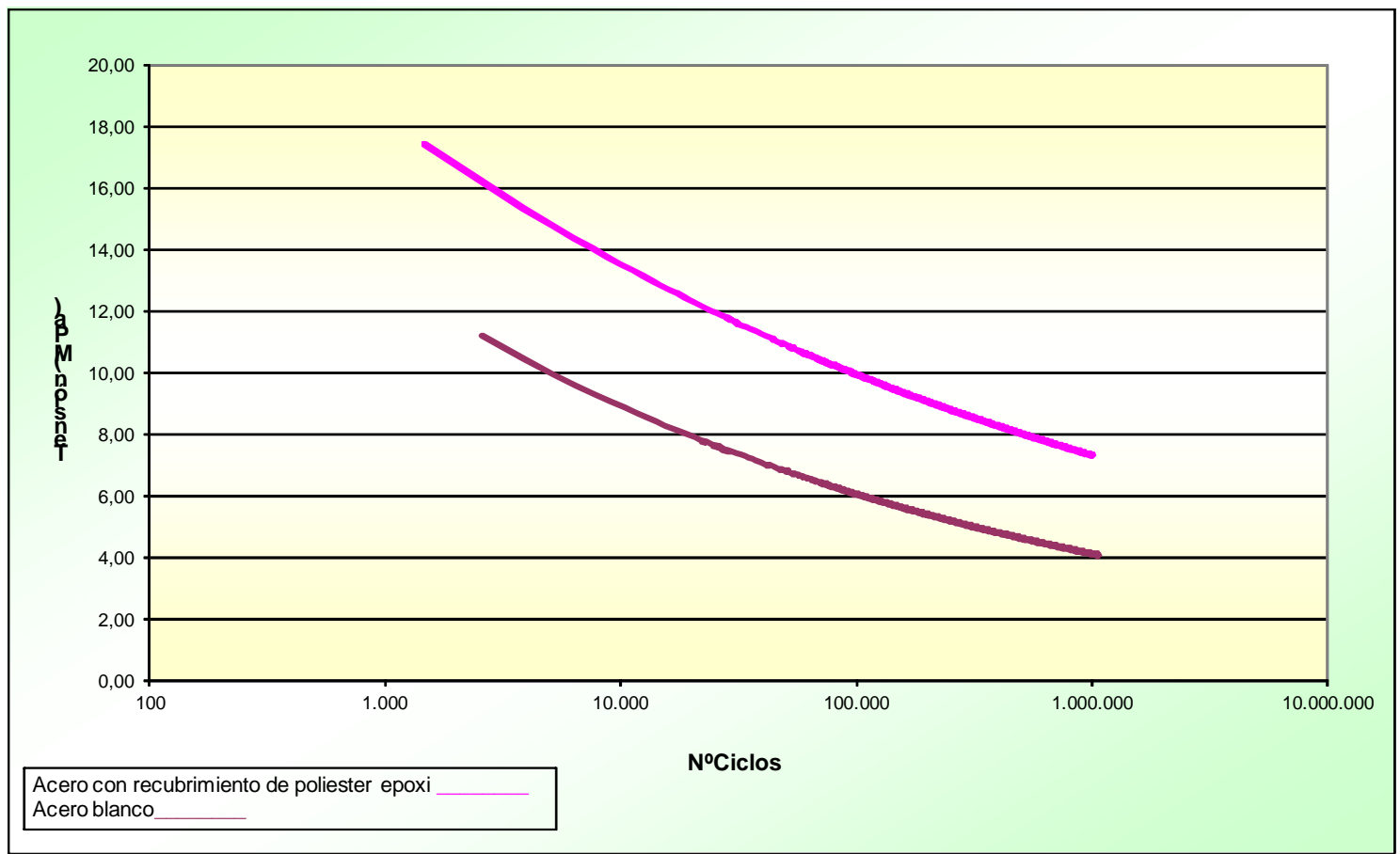

Figura 112. Comparativa entre las Curvas de Wöhler del comportamiento a fatiga.

En los resultados de los ensayos de fatiga se puede observar que conforme disminuye la tensión de rotura aumenta el número de ciclos de carga hasta llegar a rotura, como es característico en las curvas SN. El número de ciclos para rotura aumenta considerablemente cuando la tensión máxima desciende por debajo del $50 \%$ de la tensión de rotura a cizalladura. Los resultados de fatiga han proporcionado el valor de la tensión máxima que es capaz de soportar la unión sin fallar después de $10^{6}$ ciclos de carga, según se recoge en la norma UNE-EN ISO 9664.

Los resultados de los ensayos de fatiga con los aceros donde los acabados superficiales han obtenido las mejores propiedades en los ensayos estáticos, las probetas de acero blanco y las probetas de recubrimiento de poliéster epoxi, revelan un comportamiento paralelo para ambos materiales, pero son las probetas de acero con recubrimiento de poliéster epoxi las que poseen mejor comportamiento a fatiga y mayor porcentaje de rotura cohesiva.

El límite de resistencia obtenido para la tensión máxima sin que se haya producido la rotura ha sido: 3,8 MPa para el acero blanco y 6,6 MPa para el acero recubierto con pintura poliéster epoxi. El valor límite representa, aproximadamente, el $28 \%$ de la tensión de rotura en los ensayos de cizalladura en el acero blanco, y el $30 \%$ en los aceros prepintados con poliéster epoxi. Estos valores porcentuales y la forma relativamente similar de las curvas SN obtenidas para ambas superficies, indican que las condiciones de fallo en fatiga están directamente relacionadas con la resistencia estática del material. 
Los ensayos de fatiga en uniones de acero blanco han dado lugar a fallo adhesivo, al igual que ha pasado en los ensayos de cizalladura.

En cambio, en las uniones sobre acero prepintado, los ensayos de fatiga han presentado fallo cohesivo, en algunos casos, de casi el $100 \%$ de la superficie. Un análisis, mediante lupa binocular, de las zonas de las superficies con fallo aparentemente adhesivo, muestra que la rotura se ha producido en la pintura, pudiéndose identificar cómo, en muchos puntos, la superficie rota arrastra pequeñas partes metálicas. Por lo tanto, el fallo en estas zonas corresponde a una rotura del sustrato pintado, que parece tener una resistencia ligeramente superior al adhesivo, por lo que ha fallado, sólo, en aquellos puntos donde se encontraba debilitado. 


\section{ANÁLISIS DE LOS RESULTADOS DEL ENSAYO DE FATIGA CON SILANO MODIFICADO TEROSTAT MS 939.}

\subsection{Probetas de acero blanco y adhesivo silano modificado.}

El ensayo de fatiga ha consistido en la realización de un ciclo sinusoidal de tensión de tal forma que la tensión máxima escogida está comprendida entre el 30\% y $70 \%$ de la tensión máxima alcanzada en el ensayo de cizalladura, dicha tensión ha sido $1,16 \mathrm{kN}$. La siguiente tabla resume el sistema de carga introducido:

Tabla 27. Perfil de fatiga para probetas de acero blanco.

\begin{tabular}{|c|c|c|c|c|}
\hline $\begin{array}{c}\text { \% Fureza } \\
\text { Rotura }\end{array}$ & $\begin{array}{c}\mathbf{\sigma m a x} \\
\mathbf{k N}\end{array}$ & $\begin{array}{c}\mathbf{\sigma m i n} \\
\mathbf{k N}\end{array}$ & $\begin{array}{c}\mathbf{A} \\
\mathbf{~ k N}\end{array}$ & $\begin{array}{c}\mathbf{P i} \\
\mathbf{~ k N}\end{array}$ \\
\hline \hline $0,7 \mathrm{Fm}$ & 0,81 & 0,08 & 0,37 & 0,45 \\
\hline $0,6 \mathrm{Fm}$ & 0,70 & 0,07 & 0,31 & 0,38 \\
\hline $0,5 \mathrm{Fm}$ & 0,58 & 0,06 & 0,26 & 0,32 \\
\hline $0,4 \mathrm{Fm}$ & 0,47 & 0,05 & 0,21 & 0,26 \\
\hline $0,3 \mathrm{Fm}$ & 0,35 & 0,03 & 0,16 & 0,19 \\
\hline
\end{tabular}

Los resultados obtenidos de los ensayos de fatiga ejecutados sobre las probetas de acero blanco, así como la curva SN correspondiente, se muestran a continuación con detalle.

Tabla 28. Resultados de fatiga para probetas de acero blanco.

\begin{tabular}{|c|c|c|c|c|c|c|c|c|c|c|}
\hline ENSAYO: & Fatiga & & & & & & FR medio & 0,66 & TR medio & 1,93 \\
\hline UNIÓN: & Adhesiva-7 & erostat-M & 39 & & & & $\mathrm{~s}(\mathrm{~N} / \mathrm{mm} 2)$ & 0,14 & $\mathrm{~s}(\mathrm{~N} / \mathrm{mm} 2)$ & 0,43 \\
\hline PREP. SUP & ERFICIAL: & Limpieza & n agua & jabón + L & mpieza con & cetona & $\mathbf{A} \%$ & 63,00 & $\mathbf{C} \%$ & 60,13 \\
\hline & & & & & Rot & $\%$ & Dime & isiones & la probeta & $\mathrm{imm}$ \\
\hline Probeta & Ciclos & $\begin{array}{c}\text { \% FR } \\
\text { ensayo } \\
\text { tracción }\end{array}$ & $\begin{array}{c}\text { Fuerza } \\
\text { Rotura } \\
k N\end{array}$ & $\begin{array}{c}\text { Tension } \\
\text { Rotura } \\
\text { MPa }\end{array}$ & Adhesiva & Cohesiva & $b$ & $\begin{array}{l}\text { Long. } \\
\text { Solape } \\
\text { I (mm) }\end{array}$ & $\begin{array}{c}\text { Espesor } \\
\text { capa } \\
t(\mathrm{~mm})\end{array}$ & $\begin{array}{c}\text { Espesor } \\
\text { unión adh. } \\
\text { e }(\mathrm{mm})\end{array}$ \\
\hline 3FT & 1.982 & 70 & 0,81 & 2,43 & 97 & 3 & 25,00 & 13,360 & 0,345 & 3,170 \\
\hline $6 \mathrm{FT}$ & 13.055 & 70 & 0,81 & 2,38 & 25 & 75 & 25,00 & 13,630 & 0,460 & 3,260 \\
\hline $1 \mathrm{FT}$ & 14.800 & 70 & 0,81 & 2,32 & 15 & 85 & 25,00 & 13,960 & 0,500 & 3,310 \\
\hline $4 \mathrm{FT}$ & 35.264 & 70 & 0,81 & 2,46 & 5 & 95 & 25,00 & 13,150 & 0,370 & 3,190 \\
\hline $8 \mathrm{FT}$ & 85.556 & 60 & 0,70 & 2,09 & 70 & 30 & 25,00 & 13,385 & 0,280 & 3,045 \\
\hline 14FT x-> & 1.000 .000 & 50 & 0,58 & 1,70 & - & - & 25,00 & 13,650 & 0,065 & 3,025 \\
\hline 16FT x-> & 1.000 .000 & 50 & 0,58 & 1,77 & - & - & 25,00 & 13,100 & 0,165 & 3,080 \\
\hline 15FT x-> & 1.000 .000 & 40 & 0,47 & 1,44 & - & - & 25,00 & 12,900 & 0,270 & 3,170 \\
\hline 13FT x-> & 1.000 .000 & 30 & 0,35 & 0,97 & - & - & 25,00 & 14,370 & 0,310 & 3,215 \\
\hline
\end{tabular}




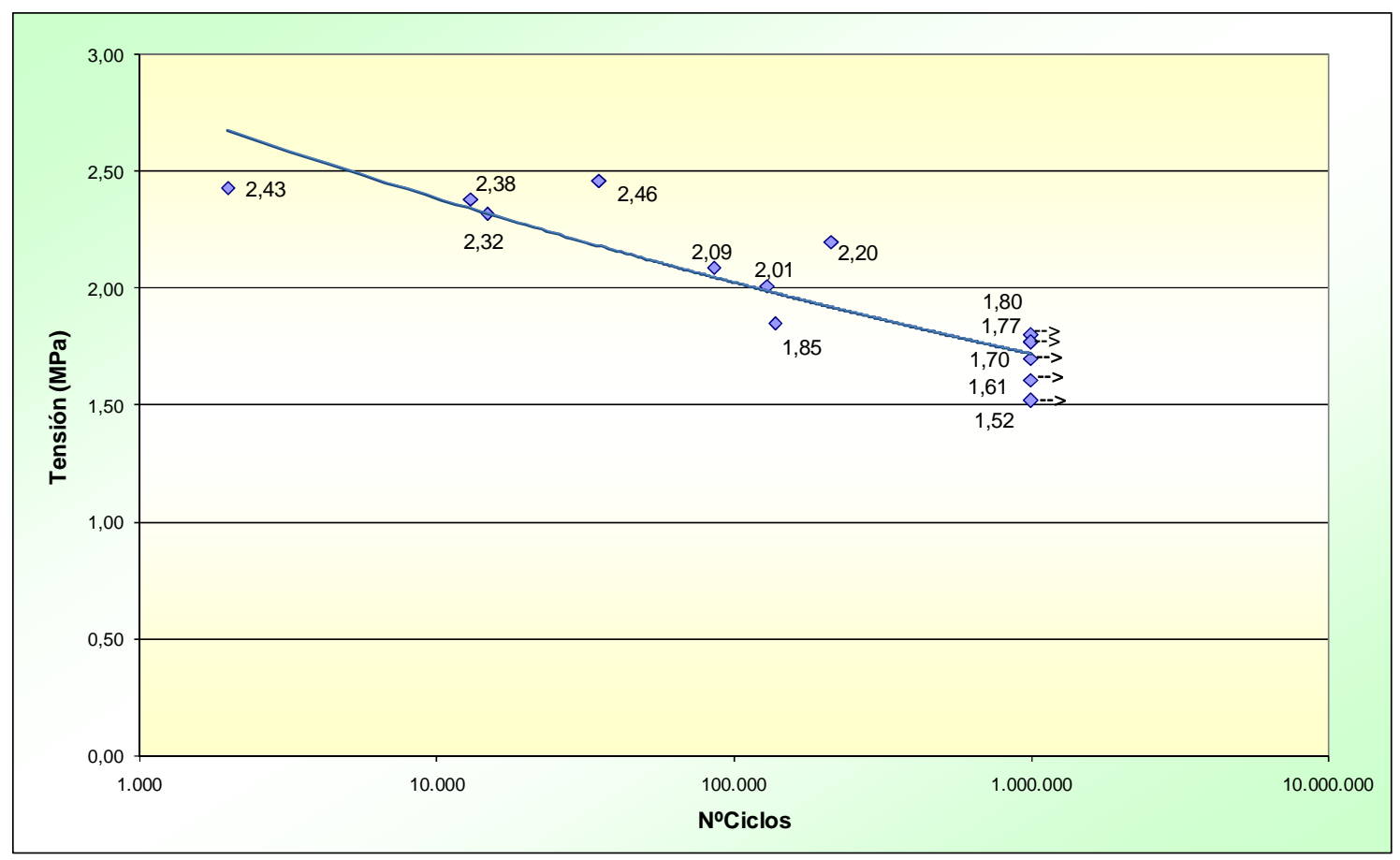

Figura 113. Curva de Wöhler del comportamiento a fatiga de uniones adhesivas con acero blanco.

Se observa un aumento en el número de ciclos de carga conforme disminuye la tensión de rotura. El mayor aumento se produce cuando la tensión de rotura es inferior a la mitad de la tensión máxima de rotura a cizalladura

En la Figura 113 también se puede ver que se ha alcanzado el límite de fatiga, es decir, la tensión por debajo de la cual no se produce la rotura y que representa el valor más grande de carga fluctuante que es capaz de soportar el material sin sufrir fallo. Este límite se localiza aproximadamente en 1,50 MPa.

Cuando se observa la rotura se aprecia que el fallo por fatiga no se produce por el crecimiento y propagación de una grieta de forma estable, es decir, su avance no se realiza a pequeños saltos cada uno de los cuales corresponde a un ciclo de tensión. El proceso de fatiga va debilitando poco a poco la unión adhesiva, y provoca que la grieta produzca el fallo por fatiga de forma inestable. 


\subsection{Probetas de acero recubierto de poliéster epoxi y adhesivo silano modificado.}

En el caso de los ensayos de fatiga de las probetas de acero recubierto de poliéster epoxi, la tensión máxima escogida vuelve a estar comprendida entre el $30 \%$ y $70 \%$ de la tensión máxima alcanzada en el ensayo de cizalladura, dicha tensión ha sido $1,30 \mathrm{kN}$. A continuación se muestra una tabla resumen con el sistema de carga introducido:

Tabla 29. Perfil de fatiga para probetas de acero recubierto de poliéster epoxi.

\begin{tabular}{|c|c|c|c|c|}
\hline $\begin{array}{c}\text { \% Fureza } \\
\text { Rotura }\end{array}$ & $\begin{array}{c}\boldsymbol{\sigma} \mathbf{m a x} \\
\mathbf{k N}\end{array}$ & $\begin{array}{c}\boldsymbol{\sigma} \mathbf{m i n} \\
\mathbf{k N}\end{array}$ & $\begin{array}{c}\mathbf{A} \\
\mathbf{~ k N}\end{array}$ & $\begin{array}{c}\mathbf{P i} \\
\mathbf{~ k N}\end{array}$ \\
\hline \hline $0,7 \mathrm{Fm}$ & 0,91 & 0,09 & 0,41 & 0,50 \\
\hline $0,6 \mathrm{Fm}$ & 0,78 & 0,08 & 0,35 & 0,43 \\
\hline $0,5 \mathrm{Fm}$ & 0,65 & 0,07 & 0,29 & 0,36 \\
\hline $0,4 \mathrm{Fm}$ & 0,52 & 0,05 & 0,23 & 0,29 \\
\hline $0,3 \mathrm{Fm}$ & 0,39 & 0,04 & 0,18 & 0,21 \\
\hline
\end{tabular}

Los resultados obtenidos de los ensayos de fatiga y la curva $\mathrm{SN}$, correspondiente a las probetas de acero recubierto de poliéster epoxi, se detallan en la siguiente tabla y gráfica.

Tabla 30. Resultados de fatiga para probetas de acero recubierto de poliéster epoxi.

\begin{tabular}{|c|c|c|c|c|c|c|c|c|c|c|}
\hline \multirow{2}{*}{\multicolumn{7}{|c|}{$\begin{array}{ll}\text { ENSAYO: } & \text { Fatiga } \\
\text { UNIÓN: } & \text { Adhesiva-Terostat-MS } 939\end{array}$}} & FR medio & 0,66 & TR medio & 1,94 \\
\hline & & & & & & & $\mathrm{s}(\mathrm{N} / \mathrm{mm} 2)$ & 0,18 & $\mathrm{~s}(\mathrm{~N} / \mathrm{mm} 2)$ & 0,51 \\
\hline \multirow{2}{*}{\multicolumn{2}{|c|}{$\begin{array}{l}\text { SUPERFICIE: } \\
\text { PREP. SUPERFICIAL: } \\
\text { CURADO (DÍAS): }\end{array}$}} & \multirow{2}{*}{\multicolumn{5}{|c|}{$\begin{array}{l}\text { Recubrimiento Poliéster Epoxi } \\
\text { Limpieza con acetona }\end{array}$}} & CV $(\%)$ & 27,03 & CV(\%) & 26,27 \\
\hline & & & & & & & $\mathrm{A} \%$ & 39,6 & $\mathbf{C} \%$ & 65,7 \\
\hline \multirow[b]{2}{*}{ Probeta } & \multirow[b]{2}{*}{ Ciclos } & \multirow[b]{2}{*}{$\begin{array}{c}\text { \% FR } \\
\text { ensayo } \\
\text { tracción }\end{array}$} & \multirow[b]{2}{*}{$\begin{array}{c}\text { Fuerza } \\
\text { Rotura } \\
k N\end{array}$} & \multirow[b]{2}{*}{$\begin{array}{c}\text { Tensión } \\
\text { Rotura } \\
\text { MPa }\end{array}$} & \multicolumn{2}{|c|}{ Rotura \% } & \multicolumn{4}{|c|}{ Dimensiones de la probeta en $\mathrm{mm}$} \\
\hline & & & & & Adhesiva & Cohesiva & $b$ & $\begin{array}{l}\text { Long. } \\
\text { Solape } \\
\text { I (mm) }\end{array}$ & $\begin{array}{c}\text { Espesor } \\
\text { capa } \\
t(\mathrm{~mm})\end{array}$ & $\begin{array}{c}\text { Espesor } \\
\text { unión adh. } \\
\text { e }(\mathrm{mm})\end{array}$ \\
\hline $21 \mathrm{FT}$ & 7.736 & 70 & 0,91 & 2,84 & 2 & 98 & 25,00 & 12,830 & 0,145 & 1,705 \\
\hline 7FT & 59.159 & 70 & 0,91 & 2,51 & 90 & 10 & 25,00 & 14,495 & 0,170 & 1,815 \\
\hline 9FT & 101.933 & 70 & 0,91 & 2,57 & 32 & 68 & 25,00 & 14,190 & 0,145 & 1,720 \\
\hline $2 \mathrm{FT}$ & 276.141 & 70 & 0,91 & 2,32 & 62 & 38 & 25,00 & 15,660 & 0,190 & 1,775 \\
\hline $20 F T$ & 27.290 & 60 & 0,78 & 2,30 & 2 & 98 & 25,00 & 13,555 & 0,160 & 1,740 \\
\hline $5 \mathrm{FT}$ & 124.095 & 60 & 0,78 & 2,34 & 15 & 85 & 25,00 & 13,305 & 0,090 & 1,720 \\
\hline $25 \mathrm{FT}$ & 162.434 & 60 & 0,78 & 2,22 & 5 & 95 & 25,00 & 14,080 & 0,100 & 1,735 \\
\hline $15 \mathrm{FT}$ & 217.698 & 50 & 0,65 & 1,92 & 53 & 47 & 25,00 & 13,555 & 0,235 & 1,795 \\
\hline 10FT & 265.417 & 50 & 0,65 & 1,95 & 35 & 65 & 25,00 & 13,315 & 0,130 & 1,740 \\
\hline $12 \mathrm{FT}$ & 301.012 & 50 & 0,65 & 1,93 & 45 & 55 & 25,00 & 14,390 & 0,160 & 1,755 \\
\hline $22 \mathrm{FT}$ & 322.586 & 50 & 0,65 & 2,08 & 70 & 30 & 25,00 & 12,525 & 0,090 & 1,710 \\
\hline $24 \mathrm{FT}$ & 394.860 & 40 & 0,52 & 1,64 & 57 & 43 & 25,00 & 12,675 & 0,065 & 1,755 \\
\hline 17FT & 495.035 & 40 & 0,52 & 1,47 & 25 & 75 & 25,00 & 14,130 & 0,125 & 1,755 \\
\hline $6 \mathrm{FT}$ & 983.045 & 40 & 0,52 & 1,52 & 100 & 0 & 25,00 & 13,670 & 0,190 & 1,790 \\
\hline $18 \mathrm{FT} x->$ & 1.000 .000 & 40 & 0,52 & 1,57 & - & - & 25,00 & 13,290 & 0,155 & 1,740 \\
\hline 13FT & 957.932 & 30 & 0,39 & 1,16 & 20 & 80 & 25,00 & 13,475 & 0,185 & 1,795 \\
\hline 3FT $x->$ & 1.000 .000 & 30 & 0,39 & 1,03 & - & - & 25,00 & 15,105 & 0,155 & 1,765 \\
\hline $8 \mathrm{FT} x->$ & 1.000 .000 & 30 & 0,39 & 1,14 & - & - & 25,00 & 13,650 & 0,145 & 1,760 \\
\hline
\end{tabular}




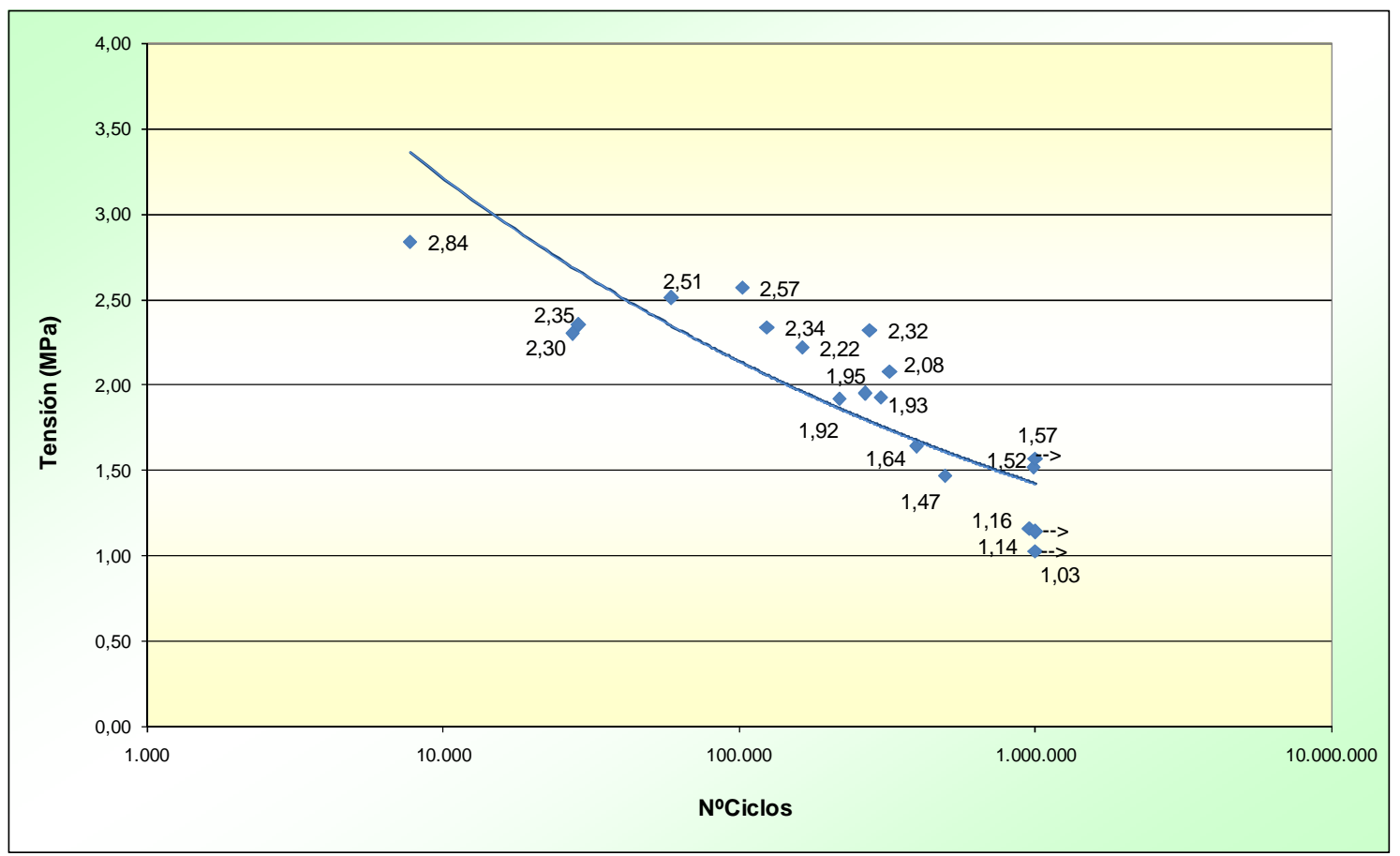

Figura 114. Curva de Wöhler del comportamiento a fatiga de uniones adhesivas con acero recubierto de poliéster epoxi.

Como se puede observar, conforme disminuye la tensión de rotura aumenta el número de ciclos de carga hasta llegar a rotura, como es característico en las curvas $\mathrm{SN}$. El número de ciclos para rotura aumenta considerablemente cuando la tensión máxima desciende por debajo del $50 \%$ de la tensión de rotura a cizalladura.

En la Figura 114 también se puede ver que se ha alcanzado el límite de nivel de tensión debajo del cual la fractura por fatiga no ocurre. El límite de fatiga se localiza aproximadamente en 1,10 $\mathrm{MPa}$.

Es importante destacar el hecho de que este tipo de probetas presenta peores resultados en el tipo de fallo de la unión adhesiva cuando son sometidas a ensayos de fatiga que cuando se someten a ensayos de cizalladura. En estos últimos, se alcanzaba un porcentaje medio de rotura cohesiva del $94,5 \%$, mientras que en los ensayos de fatiga ese porcentaje disminuye un 30,5\%. 


\subsection{Probetas de acero galvanizado y adhesivo silano modificado.}

El sistema de carga introducido durante los ensayos de fatiga de las pobretas de acero galvanizado está comprendido entre el 30\% y $70 \%$ de la tensión máxima obtenida en los ensayos de cizalladura, 1,39 kN. La siguiente tabla resume las cargas aplicadas:

Tabla 31. Perfil de fatiga para probetas de acero galvanizado.

\begin{tabular}{|c|c|c|c|c|}
\hline $\begin{array}{c}\text { \% Fureza } \\
\text { Rotura }\end{array}$ & $\begin{array}{c}\boldsymbol{\sigma m a x} \\
\mathbf{k N}\end{array}$ & $\begin{array}{c}\boldsymbol{\sigma} \mathbf{m i n} \\
\mathbf{k N}\end{array}$ & $\begin{array}{c}\mathbf{A} \\
\mathbf{k N}\end{array}$ & $\begin{array}{c}\mathbf{P i} \\
\mathbf{k N}\end{array}$ \\
\hline \hline $0,7 \mathrm{Fm}$ & 0,97 & 0,10 & 0,44 & 0,53 \\
\hline $0,6 \mathrm{Fm}$ & 0,83 & 0,08 & 0,37 & 0,46 \\
\hline $0,5 \mathrm{Fm}$ & 0,69 & 0,07 & 0,31 & 0,38 \\
\hline $0,4 \mathrm{Fm}$ & 0,55 & 0,06 & 0,25 & 0,30 \\
\hline $0,3 \mathrm{Fm}$ & 0,42 & 0,04 & 0,19 & 0,23 \\
\hline
\end{tabular}

A continuación se muestran los resultados obtenidos en los ensayos de fatiga realizados sobre las probetas de acero galvanizado, y la curva SN correspondiente.

Tabla 32. Resultados de fatiga para probetas de acero galvanizado.

\begin{tabular}{|c|c|c|c|c|c|c|c|c|c|c|}
\hline \multirow{2}{*}{\multicolumn{7}{|c|}{$\begin{array}{ll}\text { ENSAYO: } & \text { Fatiga } \\
\text { UNIÓN: } & \text { Adhesiva-Terostat-MS } 939\end{array}$}} & FR medio & 0,69 & TR medio & 2,03 \\
\hline & & & 39 & & & & $\mathrm{~s}(\mathrm{~N} / \mathrm{mm} 2)$ & 0,20 & $\mathrm{~s}(\mathrm{~N} / \mathrm{mm} 2)$ & 0,58 \\
\hline \multicolumn{7}{|c|}{$\begin{array}{ll}\text { SUPERFICIE: } & \text { Acero Galvanizado } \\
\text { PREP. SUPERFICIAL: } & \text { Limpieza con acetona }\end{array}$} & $\mathbf{A} \%$ & 26,8 & $\mathbf{C} \%$ & 73,3 \\
\hline \multirow[b]{2}{*}{ Probeta } & \multirow[b]{2}{*}{ Ciclos } & \multirow[b]{2}{*}{$\begin{array}{c}\text { \% FR } \\
\text { ensayo } \\
\text { tracción }\end{array}$} & \multirow[b]{2}{*}{$\begin{array}{c}\text { Fuerza } \\
\text { Rotura } \\
k N\end{array}$} & \multirow[b]{2}{*}{$\begin{array}{c}\text { Tensión } \\
\text { Rotura } \\
\text { MPa }\end{array}$} & \multicolumn{2}{|c|}{ Rotura \% } & \multicolumn{4}{|c|}{ Dimensiones de la probeta en $\mathrm{mm}$} \\
\hline & & & & & Adhesiva & Cohesiva & $b$ & $\begin{array}{l}\text { Long. } \\
\text { Solape } \\
\text { I (mm) }\end{array}$ & $\begin{array}{c}\text { Espesor } \\
\text { capa } \\
t(\mathrm{~mm})\end{array}$ & $\begin{array}{c}\text { Espesor } \\
\text { unión adh. } \\
e(\mathrm{~mm})\end{array}$ \\
\hline 1FT & 12.811 & 70 & 0,97 & 3,05 & 5 & 95 & 25,00 & 12,710 & 0,255 & 3,050 \\
\hline $2 \mathrm{FT}$ & 35.276 & 70 & 0,97 & 2,71 & 5 & 95 & 25,00 & 14,295 & 0,225 & 2,985 \\
\hline 3FT & 49.063 & 70 & 0,97 & 2,77 & 7 & 93 & 25,00 & 14,000 & 0,355 & 3,190 \\
\hline $5 \mathrm{FT}$ & 44.176 & 60 & 0,83 & 2,54 & 2 & 98 & 25,00 & 13,090 & 0,150 & 2,980 \\
\hline $15 \mathrm{FT}$ & 235.447 & 60 & 0,83 & 2,37 & 75 & 25 & 25,00 & 13,850 & 0,315 & 3,165 \\
\hline $7 \mathrm{FT}$ & 414.125 & 60 & 0,83 & 2,52 & 50 & 50 & 25,00 & 13,160 & 0,300 & 3,140 \\
\hline $10 \mathrm{FT}$ & 374.912 & 40 & 0,55 & 1,57 & 22 & 78 & 25,00 & 13,695 & 0,200 & 2,990 \\
\hline $18 \mathrm{FT}$ & 687.092 & 40 & 0,55 & 1,68 & 15 & 85 & 25,00 & 12,875 & 0,250 & 3,055 \\
\hline 14FT $x->$ & 1.000 .000 & 40 & 0,55 & 1,71 & - & - & 25,00 & 13,985 & 0,270 & 3,155 \\
\hline 20FT & 901.325 & 30 & 0,42 & 1,31 & 10 & 90 & 25,00 & 12,995 & 0,490 & 3,320 \\
\hline $11 \mathrm{FT} x->$ & 1.000 .000 & 30 & 0,42 & 1,23 & - & - & 25,00 & 15,240 & 0,060 & 2,875 \\
\hline 13FT $x->$ & 1.000 .000 & 30 & 0,42 & 1,18 & - & - & 25,00 & 12,830 & 0,255 & 2,990 \\
\hline
\end{tabular}




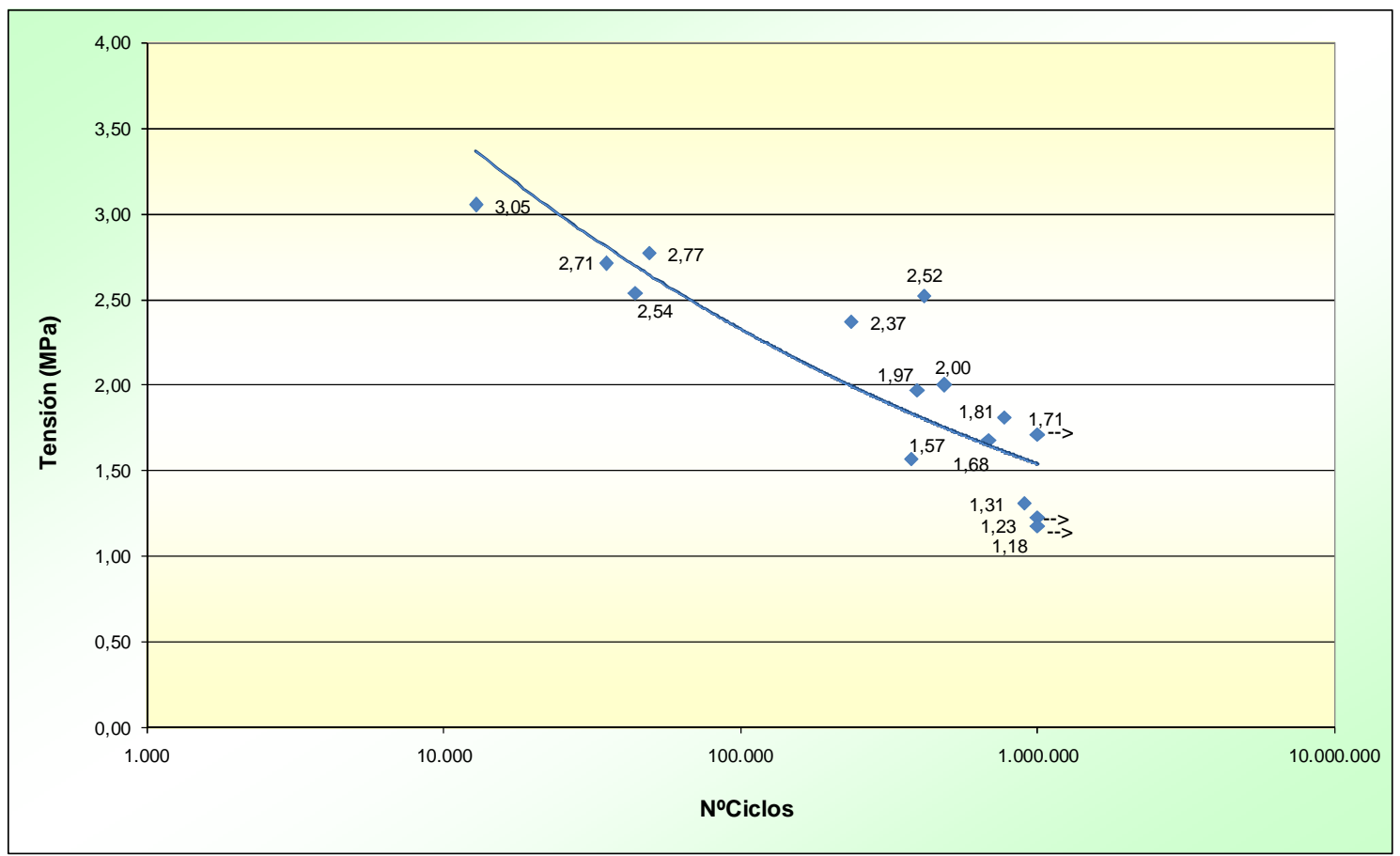

Figura 115. Curva de Wöhler del comportamiento a fatiga de uniones adhesivas con acero galvanizado.

$\mathrm{Al}$ igual que sucedía en las anteriores probetas, se produce un mayor aumento en el número de ciclos de carga cuando la tensión máxima es inferior a la mitad de la tensión de rotura a cizalladura.

En estas uniones también se alcanza el límite de nivel de carga fluctuante que es capaz de soportar el material sin sufrir fractura por fatiga. Ese límite de fatiga se sitúa aproximadamente en 1,20 MPa.

Los resultados obtenidos en el porcentaje de rotura cohesiva sufren un $20,7 \%$ de descenso durante los ensayos de fatiga. Las probetas de acero galvanizado alcanzaban un porcentaje medio del $92,5 \%$ en los ensayos de cizalladura, mientras que en los ensayos de fatiga ese porcentaje se convierte en el $73 \%$. 


\subsection{Resultados comparativos de los ensayos de fatiga.}

En el siguiente diagrama se puede comparar los resultados que se han obtenido con las diferentes probetas de estudio:

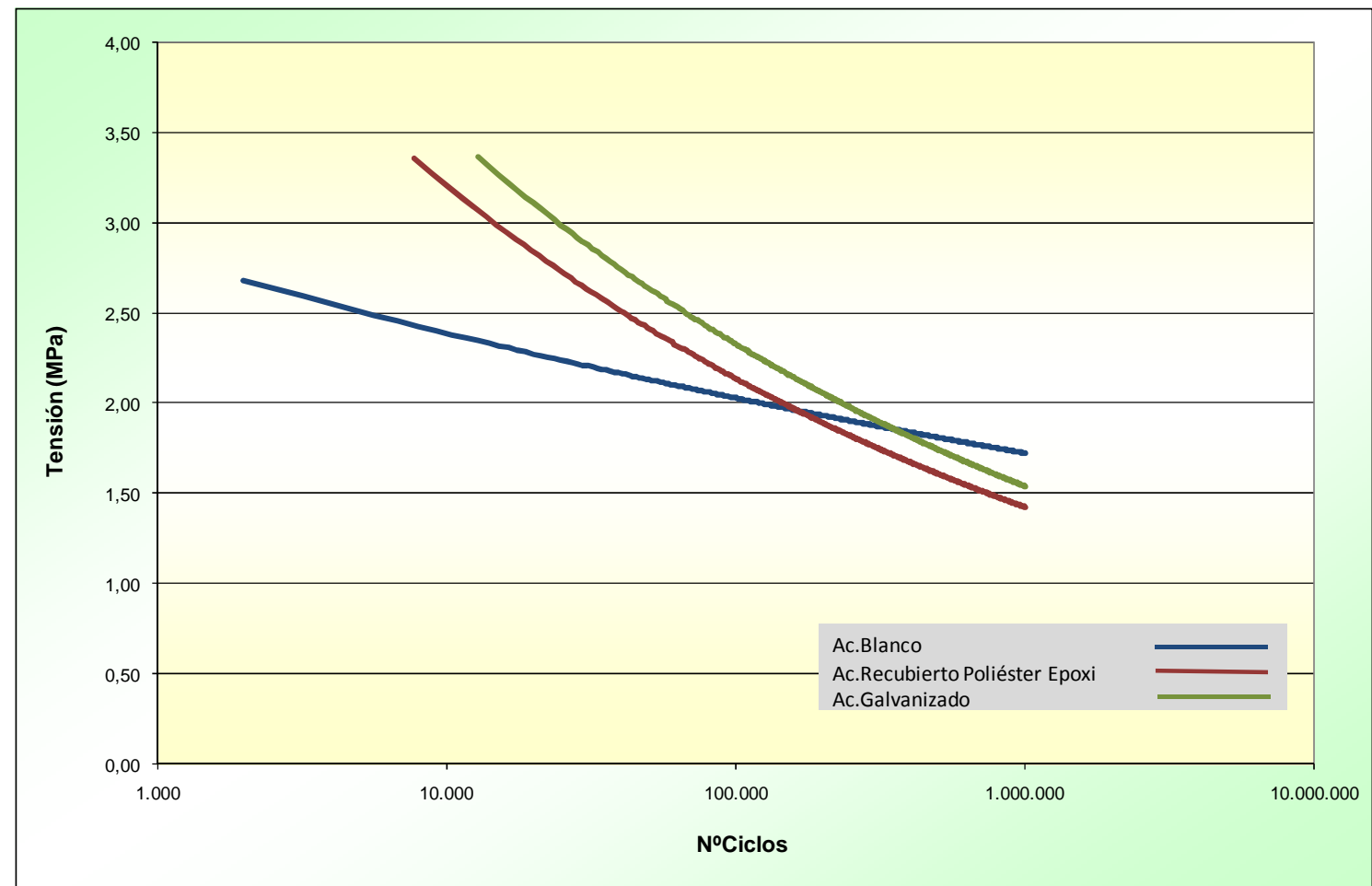

Figura 116. Comparativa entre las Curvas de Wöhler del comportamiento a fatiga.

Los resultados de los ensayos de fatiga con los aceros donde los acabados superficiales han obtenido las mejores propiedades en los ensayos estáticos, las probetas de acero blanco, las probetas de acero recubierto de poliéster epoxi y las probetas de acero galvanizado, presentan, en general, una buena resistencia a fatiga.

En las probetas de acero recubierto en poliéster epoxi y acero galvanizado se aprecia un comportamiento paralelo, pero son las probetas de acero galvanizado las que poseen mejor comportamiento a fatiga y mayor porcentaje de rotura cohesiva.

Las probetas de acero blanco muestran un peor comportamiento a fatiga debido a que presentan un bajo porcentaje de rotura cohesiva. 
Los valores medios del límite de resistencia a la fatiga sin que se haya alcanzado la rotura han sido para tensiones máximas de: 1,50 MPa en el caso de acero blanco, 1,10 MPa para acero recubierto de poliéster epoxi y 1,20 $\mathrm{MPa}$ para acero galvanizado. Estos valores límites representan aproximadamente, el $45 \%$ de la tensión de rotura en los ensayos de cizalladura en el acero blanco, el $28,6 \%$ en el acero con recubrimiento de poliéster epoxi y el 33\% en el acero galvanizada. Como se puede ver, ninguna de las muestras ensayadas presentó rotura por fatiga por debajo del $25 \%$ de su resistencia a cizalladura por tracción.

Los valores medios de porcentaje de rotura cohesiva han sido los siguientes: 60\% para chapas de acero blanco, $66 \%$ para acero recubierto en poliéster epoxi, y $73 \%$ en chas de acero galvanizado.

La disminución del porcentaje de rotura cohesiva en el caso de las probetas de acero recubierto y acero galvanizado con respecto a los valores logrados en las ensayos de cizalladura por tracción, que eran superiores al $90 \%$, revelan que la mayor resistencia a la fatiga parece estar relacionada con su mayor porcentaje de rotura cohesiva. 


\section{ANÁLISIS DE LOS RESULTADOS DEL ENSAYO DE RESISTENCIA RESIDUAL.}

\subsection{Uniones adhesivas con epoxi bicomponente Loctite Hysol 9464.}

Las muestras ensayadas por fatiga que no llegaron a romperse después de $10^{6}$ ciclos de carga han sido ensayadas a cizalla por tracción. Los resultados se muestran en la Tabla 33.

Tabla 33. Resultados ensayos resistencia residual para uniones adhesivas con epoxi bicomponente.

\begin{tabular}{|c|c|c|c|c|c|c|}
\hline ACERO & PROBETA & $\begin{array}{c}\text { Fuerza Rotura } \\
(\mathbf{k N})\end{array}$ & $\begin{array}{c}\text { Tensión Rotura } \\
\text { (MPa) }\end{array}$ & $\begin{array}{c}\text { Rotura } \\
\text { Cohesiva } \\
(\%) \\
\end{array}$ & $\begin{array}{c}\text { Solape } \\
(\mathrm{mm})\end{array}$ & \begin{tabular}{|c}
$\begin{array}{c}\text { Espesor Capa } \\
\text { Adhesiva } \\
(\mathrm{mm})\end{array}$ \\
\end{tabular} \\
\hline \multirow{2}{*}{ Blanco } & $10 \mathrm{FT} x->$ & 4,57 & 13,14 & 0 & 13,910 & 0,440 \\
\hline & $12 \mathrm{FT} x->$ & 4,49 & 12,51 & 0 & 14,360 & 0,100 \\
\hline \multirow{2}{*}{$\begin{array}{c}\text { Recubierto } \\
\text { Poliéster Epoxi }\end{array}$} & $15 F T x->$ & 6,10 & 18,97 & 97 & 12,870 & 0,190 \\
\hline & 19FT x-> & 5,88 & 17,67 & 95 & 13,330 & 0,245 \\
\hline
\end{tabular}

Comparando los resultados logrados en los ensayos de resistencia residual con los valores alcanzados en los ensayos a cizalla por tracción a solape simple (ver Tabla 34), se observa un descenso en la resistencia de unión. Para las probetas de acero blanco el valor fue de 12,8 MPa, y para el acero recubierto en poliéster epoxi fue de 18,3 MPa. Estos resultados corresponden al 94 y $83 \%$, respectivamente, de los valores medios alcanzados en los ensayos a cizalla por tracción a solape simple.

Estos resultados indican que por debajo de cierto valor de tensión el proceso de fatiga ha debilitado poco la unión original a pesar del alto número de ciclos que ha soportado en condiciones de fatiga.

Tabla 34. Resultados ensayos cizalladura tracción vs ensayos resistencia residual.

\begin{tabular}{|c||c|c||c|c|}
\hline \multirow{2}{*}{ ACERO } & \multicolumn{2}{c|}{ Tensión Rotura (MPa) } & \multicolumn{2}{c|}{ Rotura Cohesiva (\%) } \\
\cline { 2 - 5 } & $\begin{array}{c}\text { Cizalla Tracción } \\
\text { Solape Simple }\end{array}$ & $\begin{array}{c}\text { Resistencia } \\
\text { Residual }\end{array}$ & $\begin{array}{c}\text { Cizalla Tracción } \\
\text { Solape Simple }\end{array}$ & $\begin{array}{c}\text { Resistencia } \\
\text { Residual }\end{array}$ \\
\hline \hline Blanco & 13,58 & 12,82 & 1 & 0 \\
\hline Rec.Poliéster Epoxi & 21,95 & 18,32 & 31 & 96 \\
\hline
\end{tabular}




\subsection{Uniones adhesivas con silano modificado Terostat MS 939.}

Las muestras ensayadas por fatiga que no llegaron a romperse después de $10^{6}$ ciclos de carga fueron sometidas a ensayos de resistencia residual. Los resultados se muestran en la Tabla 35.

Tabla 35. Resultados ensayos resistencia residual para uniones adhesivas con silano modificado.

\begin{tabular}{|c|c|c|c|c|c|c|}
\hline ACERO & PROBETA & $\begin{array}{c}\text { Fuerza } \\
\text { Rotura } \\
\text { (kN) } \\
\end{array}$ & $\begin{array}{c}\text { Tensión } \\
\text { Rotura } \\
\text { (MPa) } \\
\end{array}$ & $\begin{array}{c}\text { Rotura } \\
\text { Cohesiva } \\
(\%) \\
\end{array}$ & $\begin{array}{c}\text { Solape } \\
(\mathrm{mm})\end{array}$ & $\begin{array}{c}\begin{array}{c}\text { Espesor Capa } \\
\text { Adhesiva } \\
(\mathrm{mm})\end{array} \\
\end{array}$ \\
\hline \multirow{5}{*}{ Blanco } & $12 \mathrm{FT} x->$ & 1,61 & 4,22 & 93 & 15,250 & 0,330 \\
\hline & 13FT x-> & 1,47 & 4,09 & 88 & 14,370 & 0,310 \\
\hline & $14 \mathrm{FT} x->$ & 0,87 & 2,55 & 78 & 13,650 & 0,065 \\
\hline & $15 F T x->$ & 0,83 & 2,57 & 13 & 12,900 & 0,270 \\
\hline & $16 \mathrm{FT} x->$ & 0,70 & 2,14 & 10 & 13,100 & 0,165 \\
\hline \multirow{3}{*}{$\begin{array}{l}\text { Recubierto } \\
\text { Poliéster } \\
\text { Epoxi }\end{array}$} & $3 \mathrm{FT} x->$ & 1,47 & 3,89 & 98 & 15,105 & 0,155 \\
\hline & $8 \mathrm{FT} x->$ & 1,31 & 3,83 & 100 & 13,650 & 0,145 \\
\hline & $18 \mathrm{FT} \mathrm{X}->$ & 1,41 & 4,25 & 98 & 13,290 & 0,155 \\
\hline \multirow{3}{*}{ Galvanizado } & $11 \mathrm{FT} x->$ & 1,60 & 4,68 & 90 & 13,695 & 0,200 \\
\hline & $13 F T x->$ & 1,36 & 3,83 & 100 & 14,200 & 0,170 \\
\hline & $14 \mathrm{FT} x->$ & 1,47 & 4,59 & 90 & 12,830 & 0,255 \\
\hline
\end{tabular}

Comparando los resultados logrados en los ensayos de resistencia residual con los valores alcanzados en los ensayos a cizalla por tracción a solape simple (ver Tabla 36), se observa un comportamiento casi paralelo en la resistencia de unión. Sólo las probetas de acero galvanizado muestran un ligero aumento en la tensión de rotura.

Estos resultados indican que las muestras no han sufrido un debilitamiento de la unión durante los ensayos de fatiga realizados. El análisis de estas muestras, junto con las muestras rotas ensayadas por fatiga permiten identificar que la rotura por fatiga no se ha producido por un proceso de iniciación y crecimiento de grieta de forma estable. El proceso de fatiga va debilitando la unión hasta que llega un momento que produce su rotura de forma muy rápida.

Tabla 36. Resultados ensayos cizalladura tracción vs ensayos resistencia residual.

\begin{tabular}{|c||c|c||c|c|}
\hline \multirow{2}{*}{ ACERO } & \multicolumn{2}{c||}{ Tensión Rotura (MPa) } & \multicolumn{2}{c|}{ Rotura Cohesiva (\%) } \\
\cline { 2 - 3 } & $\begin{array}{c}\text { Cizalla Tracción } \\
\text { Solape Simple }\end{array}$ & $\begin{array}{c}\text { Resistencia } \\
\text { Residual }\end{array}$ & $\begin{array}{c}\text { Cizalla Tracción } \\
\text { Solape Simple }\end{array}$ & $\begin{array}{c}\text { Resistencia } \\
\text { Residual }\end{array}$ \\
\hline \hline Blanco & 3,34 & 3,11 & 51,97 & 56,40 \\
\hline Rec.Poliéster Epoxi & 3,84 & 3,99 & 94,47 & 98,67 \\
\hline Galvanizado & 3,62 & 4,37 & 92,85 & 93,33 \\
\hline
\end{tabular}




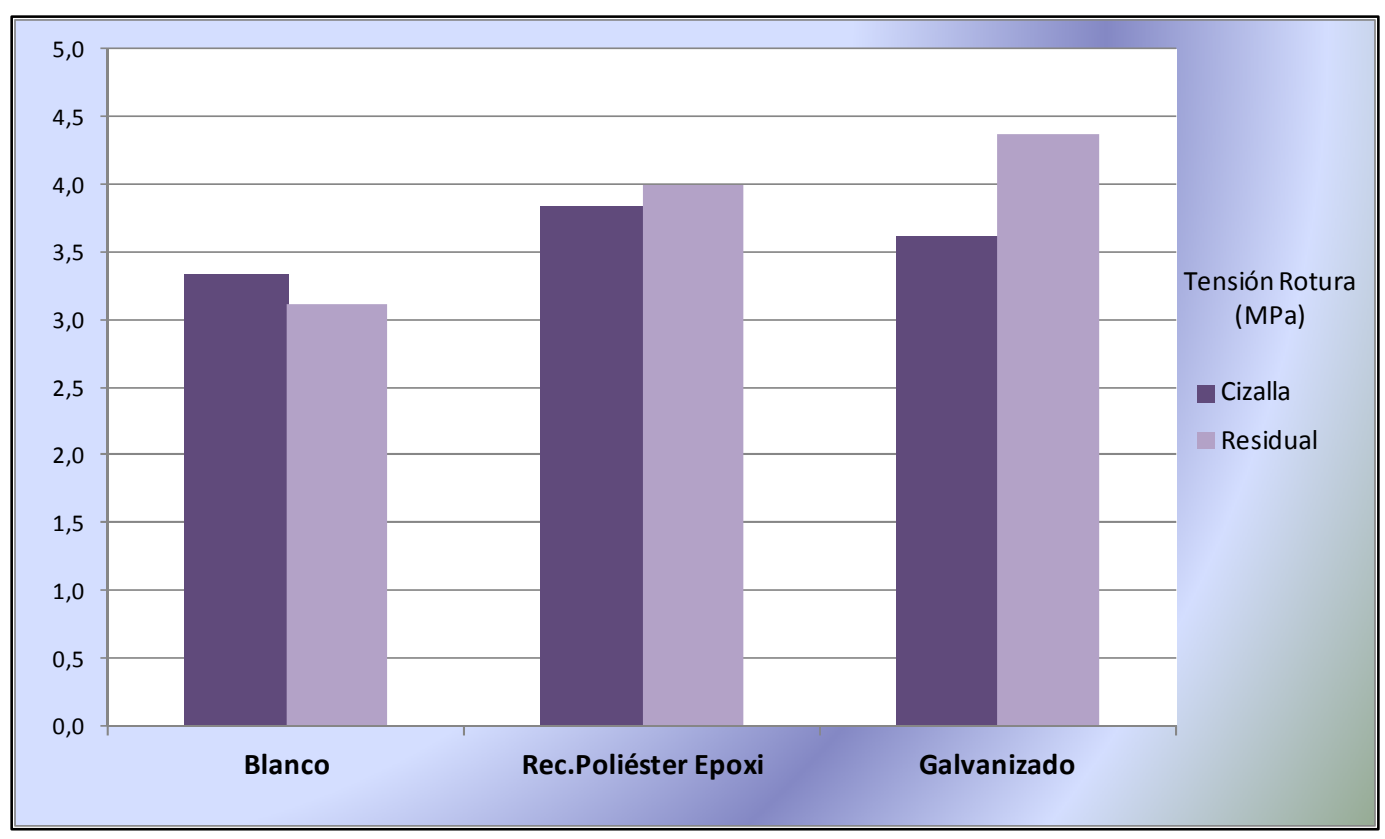

Figura 117. Comparativa de la Tensión de Rotura.

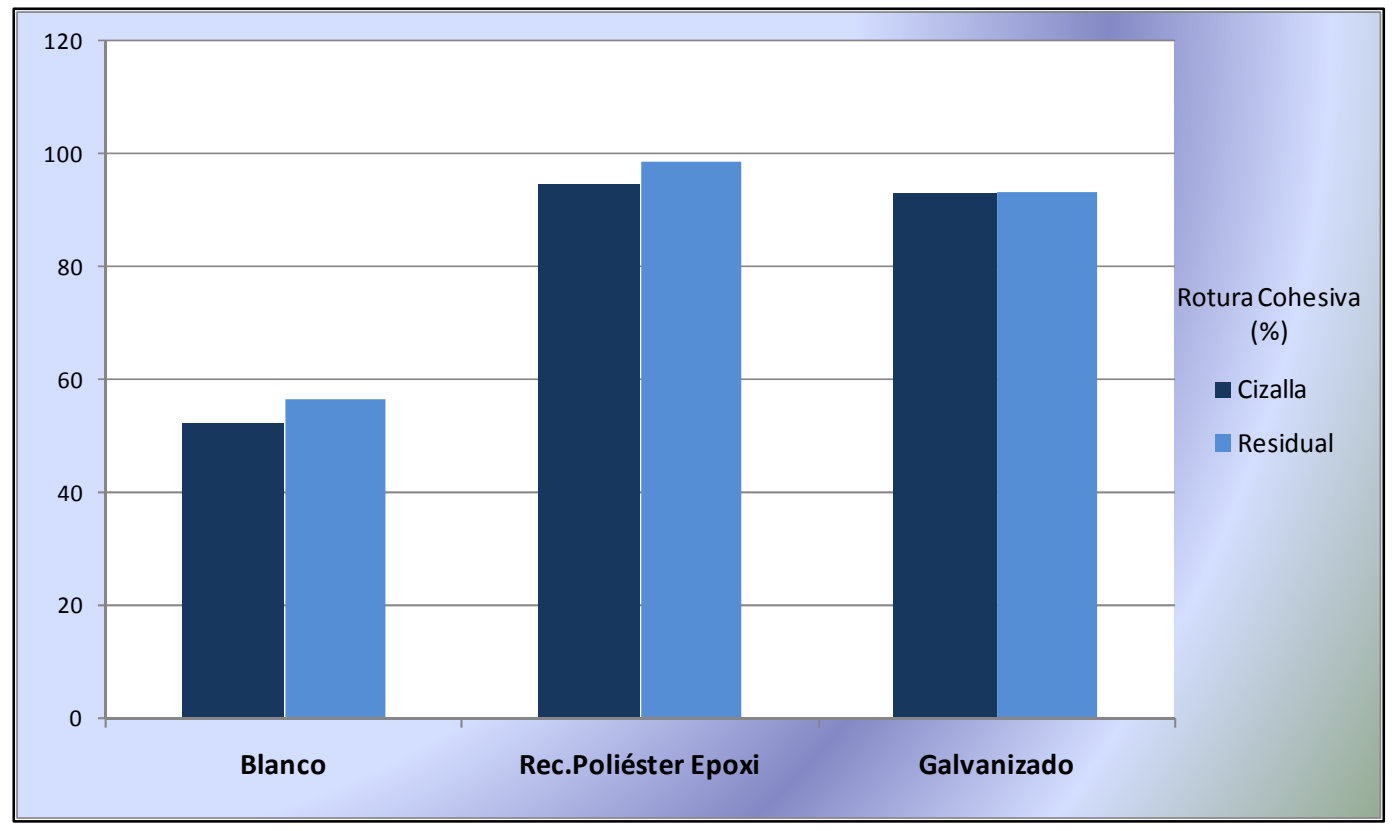

Figura 118. Comparativa del Porcentaje de Rotura Cohesiva. 


\section{CONCLUSIONES.}

\subsection{Conclusiones de la Tesis.}

1. El comportamiento a fatiga de uniones adhesivas presenta variaciones importantes en función tanto del adhesivo como de la naturaleza del sustrato. El desarrollo de esta tesis ha puesto de manifiesto la elevada dependencia que tiene el comportamiento a fatiga de las uniones adhesivas de un gran número de variables y parámetros operacionales. El gran número de muestras ensayadas y estudiadas han permitido identificar y aclarar algunos de los parámetros más críticos y poner de manifiesto las mejores condiciones que pueden utilizarse para intentar optimizar la resistencia de las uniones adhesivas trabajando en condiciones de fatiga.

En esta tesis se han seleccionado dos adhesivos diferentes: un adhesivo epoxi bicomponente en forma de resina más activador, de la marca comercial Loctite Hysol 9464, y un adhesivo/sellador elástico en base a polímero de silano modificado, cuya marca comercial es Terostat MS 939. Los sustratos empleados en las uniones adhesivas han sido: acero acabado en blanco, acero con recubrimiento de pintura poliéster, acero con recubrimiento de pintura poliéster epoxi y acero galvanizado.

La evaluación de la resistencia mecánica y el estudio del comportamiento a fatiga de uniones adhesivas estructurales a solape simple se han llevado a cabo mediante ensayos de cizalladura por tracción y ensayos de cizalladura por fatiga.

2. El comportamiento a fatiga de las uniones adhesivas, tanto con el adhesivo epoxi bicomponente como con adhesivo silano modificado, han presentado un modo de fallo relativamente similar, donde se ha podido comprobar que el proceso de fatiga va debilitando la unión hasta que se produce la rotura de la muestra de forma brusca de naturaleza inestable. No se produce como en otros materiales un proceso de inicialización y crecimiento de grieta de forma estable. El análisis de las probetas rotas ensayadas por fatiga muestra como la acción de cargas cíclicas o de vibraciones fluctuantes producen un daño irreversible en los enlaces más débiles de la unión adhesiva, dicha acción de cargas sometida durante un tiempo prolongado produce un incremento del área de las zonas débiles hasta que la zona dañada es tan amplia que se produce el fallo completo de la unión. La forma de rotura por fatiga de las uniones adhesivas supone pasar de una estructura integral a un componente roto sin que haya posibilidad de detectar la posible existencia del daño acumulado en el material mediante alguna técnica de inspección no destructiva, lo que supone una importante limitación a la hora de poder utilizar uniones adhesivas en elementos estructurales que vayan a trabajar en condiciones de fatiga o vibración en servicio, a no ser que sean reforzadas con algún tipo de unión adicional como uniones mecánicas, etc., que complementen la integridad estructural de la unión.

3. Los ensayos de cizalladura por tracción a solape simple se han utilizado como base de caracterización de los adhesivos y los sustratos utilizados y para, a partir de ellos, planificar los ensayos de fatiga.

Los resultados de los ensayos de cizalladura por tracción a solape simple de uniones con adhesivo epoxi bicomponente Loctite Hysol 9646 muestran que las probetas de acero con recubrimiento de poliéster epoxi han alcanzado los mejores resultados de tensión de rotura y los mayores porcentajes de rotura cohesiva. La tensión de rotura en este tipo de uniones aumenta cuando se alcanzan los valores más bajos de espesor de capa adhesiva y longitud de solape. En las uniones con adhesivo epoxi bicomponente en acero blanco se observa un aumento en el valor 
de la tensión de rotura cuando crece también el porcentaje de rotura cohesiva. La influencia del espesor de capa revela un comportamiento en este tipo de probetas similar al de las probetas de acero recubierto de poliéster epoxi, el valor más bajo de espesor de capa provoca un crecimiento en el valor de la tensión de rotura.

Los resultados de los ensayos de cizalladura por tracción a solape simple de uniones con adhesivo silano modificado Terostat MS 939 revelan que los mejores resultados de resistencia de unión se alcanzan con las probetas de acero recubierto de poliéster epoxi. Los ensayos realizados sobre muestras de acero galvanizado han alcanzado también unos buenos resultados de tensión de rotura, y valores en el porcentaje de rotura cohesiva similares a los obtenidos con las probetas de acero recubierto de poliéster epoxi.

4. Durante la investigación de las propiedades mecánicas de las uniones realizadas con adhesivo silano modificado Terostat MS 939 se ha analizado la influencia que tiene el tiempo de curado. En las uniones adhesivas realizadas con los cuatro tipos de acabados superficiales, se ha demostrado que una vez completado el tiempo de curado especificado por el fabricante, un aumento en ese tiempo no proporciona ninguna modificación en la resistencia de unión.

5. Los ensayos de fatiga realizados sobre muestras a cizalladura a solape simple se han utilizado para la determinación de las curvas de Wöhler de cada adhesivo sobre los diferentes sustratos.

La caracterización de la resistencia a la fatiga en el caso de las uniones adhesivas con epoxi bicomponente Loctite Hysol 9464, se ha llevado a cabo con probetas de acero blanco y probetas de acero con recubrimiento de poliéster epoxi. Los resultados revelan un comportamiento paralelo para ambos materiales, pero son las probetas de acero con recubrimiento de poliéster epoxi las que poseen mejor comportamiento a fatiga. En los ensayos de fatiga de uniones con acero blanco el modo de ruptura ha sido fallo adhesivo, mientras que en las uniones adhesivas con acero recubierto de poliéster epoxi se alcanza un elevado porcentaje de rotura cohesiva, lo que implica un mayor valor en la tensión de rotura.

En los resultados de los ensayos de fatiga se observa un aumento considerable en el número de ciclos para rotura cuando la tensión máxima desciende por debajo del $50 \%$ de la tensión de rotura a cizalladura por tracción, comportamiento característico en las curvas $\mathrm{SN}$ o curvas de Wöhler. Se ha obtenido también el límite de resistencia a fatiga para la tensión máxima sin que se haya producido la rotura, siendo 3,80 $\mathrm{MPa}$ en el caso de acero blanco y 6,60 MPa para recubrimiento de poliéster epoxi. Estos valores y la forma relativamente similar de las curvas SN obtenidas para ambas superficies, indican que las condiciones de fallo en fatiga están directamente relacionadas con la resistencia estática del material.

La caracterización de la resistencia a la fatiga en el caso de las uniones adhesivas con silano modificado Terostat MS 939, se ha llevado a cabo con los aceros donde los acabados superficiales han obtenido las mejores propiedades en los ensayos estáticos: probetas de acero blanco, probetas de acero con recubrimiento de poliéster epoxi y probetas de acero galvanizado. En las probetas de acero recubierto en poliéster epoxi y acero galvanizado se aprecia un comportamiento paralelo, pero son las probetas de acero galvanizado las que poseen mejor comportamiento a fatiga y mayor porcentaje de rotura cohesiva. Aunque el modo de ruptura en las uniones adhesivas con silano modificado ha sido mayoritariamente fallo cohesivo, el acero galvanizado es el acabado superficial que presenta el porcentaje de rotura cohesiva más elevado. 
Para los tres acabados superficiales se han obtenido las curvas de tensión máxima aplicada frente al número de ciclos hasta rotura. Las curvas $\mathrm{SN}$ o curvas de Wöhler alcanzan el valor máximo que es capaz de soportar la unión sin que se haya alcanzado la rotura, siendo en el caso del acero blanco el límite de fatiga de 1,50 MPa, en el caso de acero con recubrimiento de poliéster epoxi de 1,10 MPa y en el caso de acero galvanizado de 1,20 MPa. Estos valores límites de fatiga son superiores al 25\% de la resistencia máxima alcanzada en los ensayos de cizalladura por tracción. Por lo tanto, la utilización de adhesivo silano modificado permite obtener uniones estructurales con buena resistencia a la fatiga, cuando los valores de la carga máxima de fatiga son inferiores a dicho límite de fatiga.

6. Las uniones adhesivas con epoxi bicompoenente Loctite Hysol 9646 ensayadas a fatiga que no llegaron a romper después de $10^{6}$ ciclos de carga fueron ensayadas a cizalla por tracción y mostraron una resistencia residual muy elevada. Para las probetas de acero blanco el valor fue de 12,80 MPa, y para el acero recubierto de poliéster epoxi fue de 18,30 MPa. Estos resultados son muy similares a los valores medios alcanzados en los ensayos a cizalla por tracción a solape simple, e indican que por debajo de cierto valor de tensión el proceso de fatiga ha debilitado poco la unión original a pesar del alto número de ciclos que ha soportado en condiciones de fatiga.

Las uniones adhesivas con silano modificado Terostat MS 939 ensayadas a fatiga que no llegaron a romper después de $10^{6}$ ciclos de carga fueron sometidas a ensayos de resistencia residual. Los resultados logrados fueron 3,11 MPa para las probetas de acero blanco, 3,99 MPa para probetas de acero recubierto de poliéster epoxi y 4,37 MPa para porbetas de acero galvanizado. Comparando estos resultados con los valores alcanzados en los ensayos a cizalla por tracción a solape simple, se observa un comportamiento casi similar, lo que indica que las muestras no han sufrido un debilitamiento de la unión durante los ensayos de fatiga realizados. 


\subsection{Investigaciones Futuras.}

Las propiedades mecánicas de las uniones adhesivas no solo dependen de la naturaleza y propiedades de los adhesivos, hay muchos otros parámetros que influyen directamente en el comportamiento de las uniones adhesivas. Uno de los más importantes es el tratamiento superficial de los sustratos. La elección de una adecuada preparación superficial es fundamental para conseguir una buena resistencia y una larga durabilidad de las uniones adhesivas

El tratamiento superficial elegido en esta tesis ha sido un proceso estándar y sencillo, para no deteriorar ni alterar las características de las superficies tratadas y así poder analizar la influencia del recubrimiento de protección contra la corrosión en el comportamiento a fatiga de uniones adhesivas a solape simple. Esta investigación permite obtener unos resultados de partida con los que poder comparar estudios futuros en los cuales se analizaría la influencia de diferentes tratamientos superficiales con el fin de mejorar la interacción entre el sustrato y el adhesivo en aquellas uniones que han obtenido un fallo mayoritariamente adhesivo.

En esta tesis se ha analizado la durabilidad de las uniones adhesivas por medio de ensayos de cizalladura por fatiga. Otra línea de investigación futura podría ser el estudio de un tratamiento de degradación y envejecimiento acelerado de la unión adhesiva, y analizar de esta forma la influencia de fenómenos de degradación sobre el comportamiento de las uniones adhesivas sometidas a fatiga. 


\section{BIBLIOGRAFÍA}

[1.] Abel, M.L. Adams, A.N.N. Kinoloch, A.J. Shaw, S.J. Watts, J.F. 2006. The effects of surface pretreatment on the cyclic-fatigue characteristics of bonded aluminium-alloy joints. Int. J. Adhes. Adhesives. Vol. 26, pp. 50-61.

[2.] Abdel Wahab, M. M. 2012. Fatigue in Adhesively Bonded Joints: A Review. International Scholarly Research Network. ISRN Materials Science. Vol. 2012, Article ID 746308, 25 pages.

[3.] Admas, R. D. Wake, W.C. 1986. Structural adhesive joints in engineering. Publishers, Londres y Nueva York.

[4.] Alexandre, M. Dubois, P. 2000. Polymer-layered silicate nanocomposites: preparation, properties and uses of a new class of materials. Materials Science and Engineering. Vol. 28, pp. 1-63

[5.] Arán Ais, F. 2003. Tratamientos superficiales. Curso general sobre adhesión. San Sebastián.

[6.] ASM. 1990. Adhesives and sealants. Engineered Materials Handbook. Vol. 3. ASM International.

[7.] Barroso, S. Ibáñez, J. Introducción al conocimiento de los materiales. Cuadernos de la UNED.

[8.] Bermejo, R. Oñoro, J. García Ledesma, R. 2008. Comportamiento a fatiga de uniones a solape simple con adhesivo epoxi de acero y acero prepintado. Revista de Metalurgia. Vol. 44 (4), JulioAgosto, pp. 310-316.

[9.] Bernard, T. Burzer, J. Bergmann, H.W. 2001. Mechanical properties of structures of semifinished products joined to aluminium foams. Journal of Materials Processing Techenology. Vol. 115, pp. 2024.

[10.] Blackman, B.R.K. Hadavinia, H. Kinloch, A.J. Paraschi, M. Williams, J.G. 2003. The calculation of adhesive fracture energies in mode I: revisiting the tapered double cantilever beam (TDCB) test. Engineering Fracture Mechanics, Vol. 70, Iss. 2, pp. 233-248.

[11.] Blackman, B.R.K. Kinloch, A.J. Paraschi, M. 2003. On the mode II loading of adhesive joints. European Structural Integrity Society, Vol. 32, pp. 293-304.

[12.] Blackman, B.R.K. Kinloch, A.J. Rodríguez-Sanchez, F.S. Teo, W.S. Williams, J.G. 2009. The fracture behaviour of structural adhesives under high rates of testing. Engineering Fracture Mechanics, Vol. 76, Iss. 18, pp. 2868-2889.

[13.] Blackman, B.R.K. Kinloch, A.J. Rodríguez-Sanchez, F.S. Teo, W.S. 2012. The fracture behaviour of adhesively-bonded composite joints: Effects of rate of test and mode of loading. International Journal of Solids and Structures, Vol. 49, Iss. 13, pp. 1434-1452.

[14.] Brockmann, W. Ludwig Geiß, P. Klingen, J. Schröder, B. 2009. Adhesive Bonding: Materials, Applications and Technology. WILEY-VCH Verlag GmbH \& Co. KGaA, Weinheim.

[15.] André Meyers, M. Kumr Chawla, K. 2002. Mechanical Behaviour of Materials. NJ. Prentice Hall.

[16.] Clearfield, H.M. Watson, T.J. Mc Namara, D.K. Davis, G.D. 1990. Surface preparation of metals. Adhesives and sealants, ASM International. 
[17.] Conde, A.Durán, A. De Damborenea, J. 2002. Boletín de la Sociedad Española de Cerámica y Vidrio. Vol. 41, núm. 3.

[18.] Cognard, P. 2005. Adhesives and Sealants. Basic Concepts and High Tech Bonding. Ed. Elsevier. Oxford, U.K., pp. 238, 23, 261.

[19.] Chandra, R. Rustgi, R. 1998. Biodegradable polymers. Ed. Elsevier. Vol. 23, pp. 1273-1335.

[20.] Chen, W. 2001. Experimental and numerical study on bending collapse of aluminum foam-filled hat profiles. International Journal of Solids and Structures, Vol. 38, pp. 7919-7944.

[21.] Chiminelli, A. Breto, R. Jiménez, M.A. Lizaranzu, M. Izquierdo, S. 2013. Análisis y simulación de uniones con propiedades variables de adhesivos para la mejora de su comportamiento resistente. Técnicas en adhesión y adhesivos. Vol. 6, pp. 261-270.

[22.] Darwish, S. M. H. Ghanya, A. 2000. Critical assessment of weld-bonded technologies. Journal of Materials Processing Technology. Vol. 105, Iss. 3 , pp. 221-229.

[23.] Dessurealut M. Spelt, J. K. 1997. Observations of fatigue crack initiation and propagation in an epoxy adhesive. Int. J. Adhes. Adhesives. Vol. 17, pp. 183-195.

[24.] Dostal, C.A. 1990. Adhesives and Sealants. Engineered Materials Handbook. Ed. CRC Press, New York.

[25.] Dowling, N.E. 1993. Mechanical Behaviour of Materials. Englewood Cliffs, NJ. Prentice Hall.

[26.] Duncan, B. Abbott, S. Court, R. Roberts, R. Leatherdale, D. 2003. A Review of Adhesive Bonding Assembly Processes and Measurement Methods. Ed. National Physical Laboratory Teddington, Middlesex, UK, pp. 25-35.

[27.] Durán, J. Amo, J.M. Durán, C. Oñoro, J. García-Ledesma, J. 2005. Comportamiento mecánico de uniones estructurales con adhesivo. Influencia de los parámetros operacionales. Rev. Metal. Madrid Vol. Extr., pp. 345-350.

[28.] Durán, J. García-Ledesma, R. Durán, C.M. Amo, J.M. Oñoro, J. 2004. Mecanismos de fractura y comportamiento a fatiga en uniones híbridas adhesivo-mecánicas. Boletín de la Sociedad Española de Cerámica y Vidrio. Vol. 43 (2), pp. 277-281.

[29.] Ebnesajjad, S. 2011. Handbook of Adhesives and Surface Preparation. Ed. Elsevier, Oxford, UK.

[30.] Fernlund, G. Spelt, J.K. 1994. Mixed-mode fracture characterization of adhesive joints. Composite Science and Technology. Vol. 50(4), pp. 441-449

[31.] Fu, M. Mallick, P.K. 2000. Fatigue of hybrid (adhesive/bolted) joints in SRIM composites. Int. J. Adhes. Adhesives. Vol. 21, pp. 145-159.

[32.] Franco, A. Royer-Carfagni, G. 2014. Cohesive debonding of a stiffener from an elastic substrate. Composite Structures. Vol. 111, pp.401-414.

[33.] García-Ledesma, R. Oñoro, J. Amo, J.M. Durán, M.C. Durán, J. 2005. Influencia del espesor de adhesivo de poliuretano en la resistencia de uniones sometidas a cortadura. Rev. Metal. Madrid. Vol. 41, pp.60-65. 
[34.] García-Ledesma, R. Oñoro, J. Amo, J.M. Durán, M.C. Durán, J. 2005. Comportamiento mecánico de uniones estructurales con adhesivo. Influencia de los parámetros operacionales. Rev. Metal. Madrid. Vol. 41, pp. 60-65.

[35.] Georgiou, I. Ivankovic, A. Kinloch, A.J. Tropsa, V. 2003. Rate dependent fracture behaviour of adhesively bonded joints. European Structural Integrity Society, Vol. 32, pp. 317-328.

[36.] Gómez, S. Et al. 2007. A simple mechanical model of a structural hybrid adhesive/riveted single lap joint. International Journal of Adhesion and Adhesives. Vol. 27, pp. 263-267.

[37.] González Martín, J. La pintura como recubrimiento protector. Ed. A. Madrid Vicente.

[38.] Hadavinia, H. Ghasemnejad, H. 2009. Effects of Mode-I and Mode-II interlaminar fracture toughness on the energy absorption of CFRP twill/weave composite box sections. Composite Structures. Vol. 89, Issue 2, pp. 303-314.

[39.] Hadavinia, H. Kawashita, L. Kinloch, A.J. Moore, D.R. Williams, J.G.. 2006. A numerical analysis of the elastic-plastic peel test. Engineering Fracture Mechanics. Vol. 73, Issue 16, pp. $2324-$ 2335 .

[40.] Hadavinia, H. Kinloch, A.J. Little, M.S.G. Taylor, A.C. 2003. The prediction of crack growth in bonded joints under cyclic-fatigue loading I. Experimental studies. Int. J. Adhes. Adhesives. Vol. 23, pp. 449-461.

[41.] Hadavinia, H. Kinloch, A.J. Little, M.S.G. Taylor, A.C. 2003. The prediction of crack growth in bonded joints under cyclic-fatigue loading II. Analytical and finite element studies. Int. J. Adhes. Adhesives. Vol. 23, pp. 463-471.

[42.] Houwink, R. Salomón, G. 1978. Adherencia y adhesivos. Ed. Urmo, Tomo I, Bilbao, pp. 127130.

[43.] Hurme, S. Oinonen, A. Marquis, G. 2011. Fatigue of bonded steel interfaces under cyclic shear loading and static normal stress. Engineering Fracture Mechanics 78, pp. 1644-1656.

[44.] Kinloch, A.J. Little, M.S.G. Watts, J.F. 2000. The role of the interphase in the environmental failure of adhesive joints. Acta Materialia, Vol. 48, Iss. 18-19, pp. 4543-4553.

[45.] Kinloch, A.J. Shaw, S.J. Hunston, D.L.. 1983. Deformation and fracture behaviour of a rubbertoughened epoxy: 2. Failure criteria. Polymer, Vol. 24, Iss. 10, pp. 1355-1363.

[46.] Kinloch, A.J. 2002. The durability of adhesive joints. Adhesion Science and Engineering, Vol. 2, pp 661-698.

[47.] Knox, E.M. Cowling, M.J. 1999. A rapid durability test method for adhesives. Int. J. Adhes. Adhesives. Vol. 20, pp. 201-208.

[48.] Lehman, R.L. 1999. Materials Mechanical Engineering Handbook. Editorial Frank Kreith. Section 12, pp. 34-43.

[49.] Liesa, F. Bilurbina, L. Adhesivos industriales. Editorial Productiva Marcombo S.A.

[50.] Loctite. 1995. Worldwide Desing Handbook. Ed. Loctite, Munich, Alemania, pp. 147-163.

[51.] Loctite. 1998. Worldwide Desing Handbook. Ed. Loctite, $2^{\mathrm{a}}$ edición. 
[52.] Madrid, M. 2002. Tecnología de la Adhesión. Ed. Loctite, Madrid, España, pp. 18-20, 158-168 y 129-139.

[53.] Martín-Martínez, J.M. 1998. Adhesión y uniones adhesivas. Ed. Universidad de Alicante, pp. 31.

[54.] Martín-Martínez, J.M. Orgilés Barceló, A.C.1991. Adhesión y adhesivos de contacto. Ed. Inescop \& Universidad de Alicante.

[55.] Martín-Martínez, J.M. Orgilés Barceló, A.C. 1992. Adhesión. Tecnología y Fundamentos. Ed. Inescop \& Universidad de Alicante.

[56.] Narbón, J.J. Arenas, J.M. del Real, J.C. Arias, M. 2013. Aproximación de van Oss, Chaudhury y Good para la determinación de la energía superficial de un aluminio sometido a diferentes tratamientos superficiales. Técnicas en adhesión y adhesivos. Vol. 6, pp. 95-101.

[57.] Narbón, J.J. Moreno-Díaz, C. Arenas, J.M. del Real, J.C. 2013. Análisis comparativo de los valores de energía superficial obtenidos con la ecuación de Wenzel, con los empíricos obtenidos con valores de rugosidad controladas. Técnicas en adhesión y adhesivos. Vol. 6, pp. 137-145.

[58.] Oñoro, J.2005. Adhesivos-El reto de unir todo con todo. Revista Industria XXI - Vol. 8, pag. inicio: 6, pag. final: 14 .

[59.] Oñoro, J. Portolés, A. García-Ledesma, R. 2007. Estudio de la distribución de tensiones en uniones a solape simple con adhesivos elásticos en función del espesor del adhesivo. Tendencias en adhesión y adhesivos. Ed. Abecedario. Badajoz.

[60.] Oñoro, J. Portolés, A. García-Ledesma, R. 2008. Comportamiento a impacto de estructuras sándwich con núcleo de espuma de aluminio fabricadas con adhesivos. Adhesión en materiales compuestos. Valladolid, pp. 299-304.

[61.] Otero, N. Romero, P. Coto, I. Rodríguez, E. 2013. Modificación de la tensión superficial de piezas plásticas inyectadas por transferencia de microestructuras. Técnicas en adhesión y adhesivos. Vol. 6, pp. 71-81.

[62.] Pan, E. Yang, B. Cai, G. Yuan, F.G. 2001. Stress analyses around holes in composite laminates using boundary element method. Engineering Analysis with Boundary Elements. Vol. 25, pp. 31-40.

[63.] Parker, D. H. Tecnología de los recubrimientos de superficies. Ediciones Urmo.

[64.] Petrie, E.M. 1999. Handbook of Adhesives and Sealants. Ed. McGraw Hill, New York, pp. 26, 61 y 361.

[65.] Pizzi, A. Mittal, K.L. 2003. Handbook of adhesives technology. Marcel Dekker.

[66.] Pocins, A.V. 1997. Adhesion and Adhesives Technology. Ed. Hanser-Gardner, Cincinnati.

[67.] Pocins, A.V. Chaudhury, M. 2002. Preface. Adhesion Science and Engineering, Pages V-VI. Corporate Scientist. 3M Company. St. Paul, MN, USA.

[68.] Pocins, A.V. 2012. Polymer Science: A Comprehensive Reference. 8.12 - Adhesives and Sealants. Vol. 8, pp.. 305-324.

[69.] Pocins, A.V. Hanser. 1997. Adhesion and Adhesives Technology. 
[70.] Real, E. Rodríguez, C. Canteli, A.F. Belzunce, F.J. Aenlle, M.L. 2005. Efecto de la tensión media en el comportamietno a fatiga de barras corrugadas en acero inoxidable dúplex. Anales de Mecánica de la Fractura. Vol. 22, pp. 352-358

[71.] Rodríguez, E. de la Mano, R. Losada, R. 2013. Reparación de acero naval mediante la adhesión de laminados de composite. Técnicas en adhesión y adhesivos. Vol. 6, pp. 55-68.

[72.] Santamaría, F. Jiménez, C. Azpiroz, X. 1993. Estudio de la influencia del espesor del adhesivo en superficie de acero con distintas preparaciones superficiales. INSASMET. Soldadura y Tecnologías de Unión. Año IV, Num. 2, pp. 44-49.

[73.] Sargent, J.P. 2004. Durability studies for aerospace applications using peel and wedge test. Int. J. Adhes. Adhesives. Vol. 25, pp. 247-256.

[74.] Satre, A. 2013. Elasticidad y rigidez en las uniones adhesivas. Factores a tener en cuenta en el diseño y cálculo de uniones adhesivas. Técnicas en adhesión y adhesivos. Vol. 6, pp. 223-228.

[75.] Singh, S. 1992. Fatigue testing of jointed sheet material specimens. Doc. IIS / IIW. III-998-92.

[76.] Sinha Ray, S. Okamoto, M. 2003. Polymer/layered silicate nanocomposites: a review from preparation to processing. Progress in Polymer Science. Vol. 28, pp.1539-1641

[77.] Snogren, R.C.1974. Handbook of surface preparation. Palmerton. New York.

[78.] Skeist, I. Manual de adhesivos. Cía.Editorial Continental S.A.

[79.] Stegemann, T. Hahn, O. Schulte, A. 1998. Advanced joining techniques for modern lightweight steel construction. Rev. Metall-Paris 95, pp. 95-107.

[80.] Underhill, P.R. Duquesnay, D.L. 2006. The dependence of the fatigue life of adhesive joints on surface preparation. Int. J. Adhes. Adhesives. Vol. 26, pp. 62-66.

[81.] Underhill, P.R. Rider, A.N. DuQuesnay, D.L. 2006. The effect of warm water surface treatments on the fatigue life in shear of aluminum joints. Int. J. Adhes. Adhesives. Vol. 26, pp. 199-205.

[82.] Vladimir V. Bolotin. 1999. Mechanics of Fatigue. Nueva York. CRC Press.

[83.] Wegman, R.F. 1989. Surface Preparation Techniques for Adhesive Bonding. Noyes Publications. New Jersey.

[84.] Xu, C. Ramani, K. Kumar, G. 2001. Thermoplasticadhesive bonding of galvanized steel to polypropylene composite and its durability. Int. J. Adhes. Adhesives. Vol. 22, pp. 187-195.

[85.] EU 10169, Productos planos de acero recubiertos en continuo de materiales orgánicos precalentados), 2000.

[86.] UNE-EN 1465:1996, Adhesivos. Determinación de la resistencia a la cizalladura por tracción de juntas pegadas de substratos rígidos, 1996.

[87.] UNE-EN ISO 9664:1996, Adhesivos. Métodos de ensayo para resistencia a la fatiga por esfuerzo de cizalla de adhesivos estructurales, 1996.

[88.] ACESCO. 2000. Manual técnico del acero galvanizado. Acerias de Colombia, S.A. 
[89.] ACELOR. 2006. Productos de acero con recubrimiento metálico.

[90.] AIRBUS DEFECE AND SPACE. 2007. Fatiga y Tolerancia al daño. Métodos de análisis.

[91.] AIRBUS DEFECE AND SPACE. 2011. Fatigue and Damage Tolerance Course.

[92.] AIRBUS DEFECE AND SPACE. 2012. Introducción al diseño de estructuras y sistemas.

[93.] AIRBUS DEFECE AND SPACE. 2015. Introducción a la monitorización de daño, teoría, análisis y ensayos.

[94.] http://www.cidetec.es (18/01/2009).

[95.] http://www.iberisa.com/soporte/fatiga/intro.htm (16/10/2010).

[96.] www.sciencedirect.com (20/02/2015). 